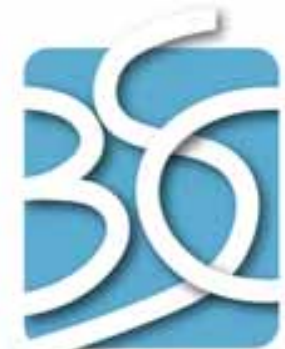

BECHTEL SAIC CONPAN LCC

QA: QA

ANL-MGR-MD-000001 REV 04

June 2006

\title{
Inhalation ExposurMe Input Parameters for the Biosphere Model
}

NOTICE OF OPEN CHANGE DOCUMENTS - THIS DOCUMENT IS IMPACTED BY THE LISTED CHANGE DOCUMENT AND CANNOT BE USED WITHOUT IT.

1) ACN-001, APPROVED 08/03/2006

Prepared for:

U.S. Department of Energy

Office of Civilian Radioactive Waste Management

Office of Repository Development

1551 Hillshire Drive

Las Vegas, Nevada 89134-6321

Prepared by:

Bechtel SAIC Company, LLC

1180 Town Center Drive

Las Vegas, Nevada 89144

Under Contract Number

DE-AC28-01RW12101 


\section{DISCLAIMER}

This report was prepared as an account of work sponsored by an agency of the United States Government. Neither the United States Government nor any agency thereof, nor any of their employees, nor any of their contractors, subcontractors or their employees, makes any warranty, express or implied, or assumes any legal liability or responsibility for the accuracy, completeness, or any third party's use or the results of such use of any information, apparatus, product, or process disclosed, or represents that its use would not infringe privately owned rights. Reference herein to any specific commercial product, process, or service by trade name, trademark, manufacturer, or otherwise, does not necessarily constitute or imply its endorsement, recommendation, or favoring by the United States Government or any agency thereof or its contractors or subcontractors. The views and opinions of authors expressed herein do not necessarily state or reflect those of the United States Government or any agency thereof. 
QA: QA

Inhalation Exposure Input Parameters for the Biosphere Model ANL-MGR-MD-000001 REV 04

June 2006 


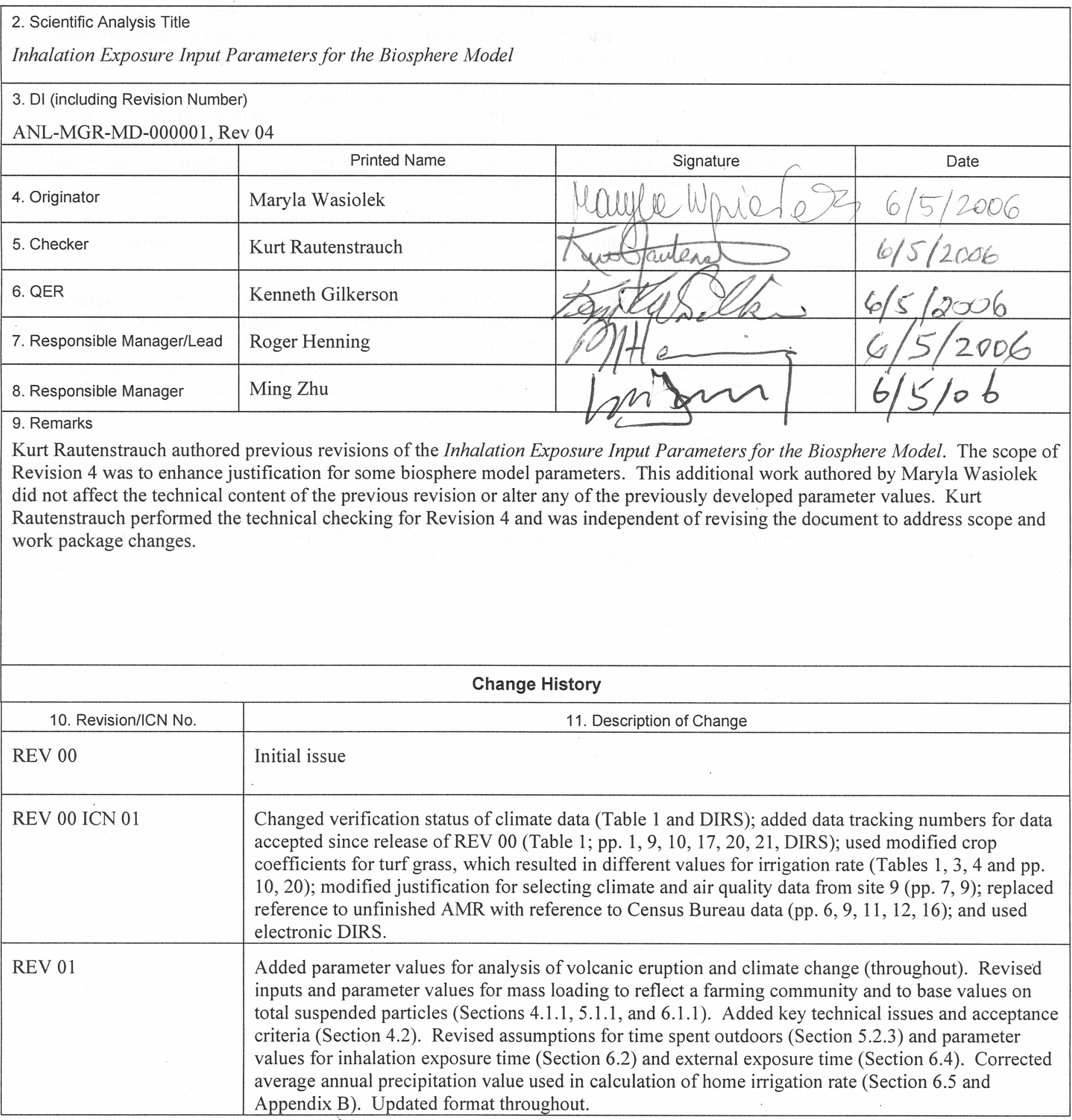




\begin{tabular}{|l|l|}
\hline REV 02 & $\begin{array}{l}\text { Entire report revised. Reanalyzed all mass loading parameter distributions for use in biosphere model } \\
\text { to be used in support of License Application. Added mass loading time function and associated } \\
\text { decrease rate constant parameter. Removed parameters for chronic breathing rate, exposure times, } \\
\text { home irrigation rate, and duration of home irrigation. Changed title }\end{array}$ \\
\hline REV 03 & $\begin{array}{l}\text { Entire scientific analysis revised to modify classification of inputs to comply with current versions of } \\
\text { procedures. Added to Section 4.1.1 qualification for intended use of airborne particle concentration. } \\
\text { Provided additional justification that parameter distributions are consistent with conditions in the } \\
\text { Yucca Mountain region. Updated references to project documents that have been revised. Added } \\
\text { DIRS numbers for all references. Made editorial corrections. }\end{array}$ \\
\hline REV 04 & $\begin{array}{l}\text { Entire scientific analysis was revised to provide additional information clarifying the technical bases } \\
\text { for atmospheric mass loading distributions used in the biosphere model. Editorial corrections were } \\
\text { made and the report was re-formatted. } \\
\text { The revision includes supplementary and corroborating analyses to address the concerns expressed in } \\
\text { the Integrated Issue Resolution Status Report and in the additional information needs for Key } \\
\text { Technical Issue IA 2.11 regarding sensitivity of the mass loading values to the environmental (natural } \\
\text { and anthropogenic) variables. Specific issues that were evaluated include an enhanced analyses of the } \\
\text { influence on mass loading of meteorological conditions, soil morphology, site setting (especially with } \\
\text { respect to human activities), and particle size effects. } \\
\text { The revision also includes the analysis of mass loading data collected in Amargosa Valley. Mass } \\
\text { loading was measured during the activities that disturb surface soil and cause soil resuspension. The } \\
\text { analysis of these data also supports the evaluation of issues documented in the Integrated Issue } \\
\text { Resolution Status Report regarding the mass loading levels in the active and inactive outdoor } \\
\text { environments. Selected biosphere model parameters were modified to incorporate site-specific data } \\
\text { into biosphere model input parameters related to mass loading. }\end{array}$ \\
\hline
\end{tabular}




\section{CONTENTS}

Page

ACRONYMS AND ABBREVIATIONS xiii

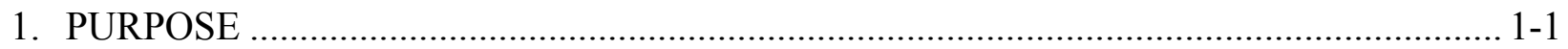

2. QUALITY ASSURANCE ................................................................................ 2-1

3. USE OF SOFTWARE.......................................................................................... $3-1$

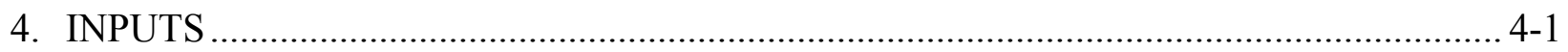

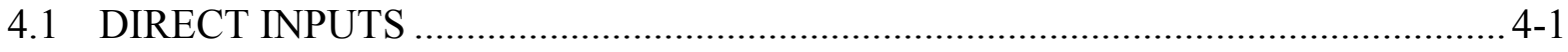

4.1.1 Airborne Particle Concentrations......................................................... 4-1

4.1.2 Total Suspended Particles - United States...................................................... 4-4

4.1.3 Total Suspended Particles - Washington ................................................... 4-5

4.1.4 Suspended Particles - Yucca Mountain...................................................... 4-5

4.1.5 Total Suspended Particulates - Amargosa Valley ........................................ 4-5

4.1.6 Precipitation - United States....................................................................... 4-6

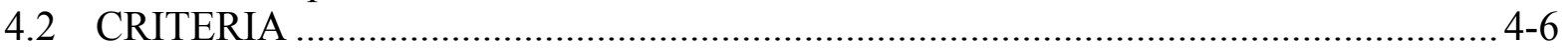

4.3 CODES, STANDARDS, AND REGULATIONS .............................................. 4-8

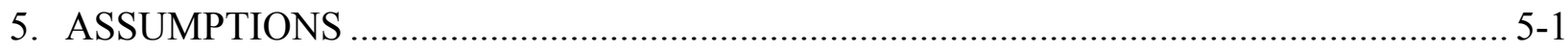

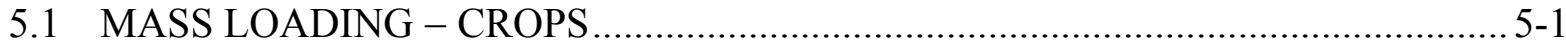

5.2 POSTVOLCANIC INDOOR CONCENTRATIONS.............................................. 5-2

6. SCIENTIFIC ANALYSIS DISCUSSION ............................................................. $6-1$

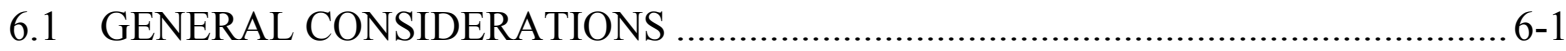

6.1.1 Use of Atmospheric Mass Loading in the Biosphere Model ........................... 6-1

6.1.2 Parameter Development Methods ............................................................ 6-3

6.1.3 Influence of Meteorological Conditions on Mass Loading ............................ 6-5

6.1.3.1 Consideration of Climate in the Development of Mass Loading for the Biosphere Model ............................................... 6-5

6.1.3.2 Dependence of Mass Loading on Precipitation .............................. 6-9

6.1.3.3 Dependence of Mass Loading on Other Local Meteorological Variables ................................................................................. 6-12

6.1.4 Influence of Soil Morphology on Mass Loading ...................................... 6-13

6.1.5 Influence of Site Setting on Mass Loading............................................. 6-17

6.1.6. Particle Size Effects ..................................................................................... 6-19

6.1.7. Evaluation of Dose from Inhaled Radionuclides ........................................ 6-20

6.2 MASS LOADING - NOMINAL CONDITIONS ........................................... 6-23

6.2.1 Active Outdoor Environment................................................................ 6-25

6.2.1.1 Literature Review................................................................. 6-25

6.2.1.2 Mass Loading Measurements in Amargosa Valley - Methods

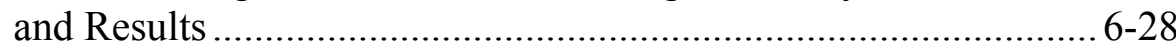

6.2.1.3 Parameter Distribution ......................................................... 6-31

6.2.2 Inactive Outdoor Environment ..................................................... 6-33 


\section{CONTENTS (Continued)}

6.2.2.1 Selection of Data................................................................. 6-34

6.2.2.2 Parameter Distribution .......................................................... 6-37

6.2.3 Active Indoor Environment ................................................................... 6-39

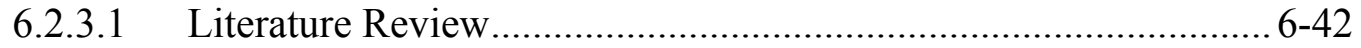

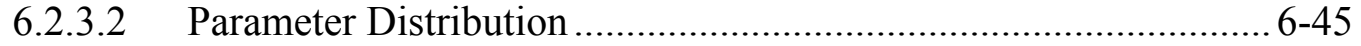

6.2.4 Asleep Indoor Environment ................................................................... 6-47

6.2.4.1 Literature Review............................................................... 6-48

6.2.4.2 Parameter Distribution ............................................................ 6-49

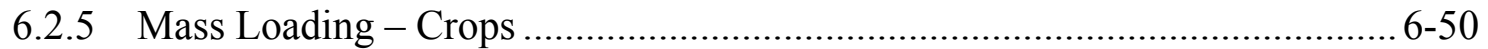

6.3 MASS LOADING - VOLCANIC ASH SCENARIO ........................................... 6-50

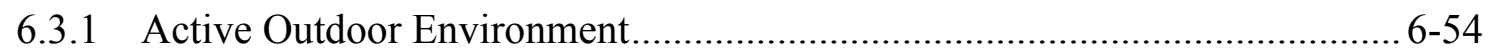

6.3.1.1 Literature Review.................................................................... 6-55

6.3.1.2 Parameter Distribution ............................................................. 6-58

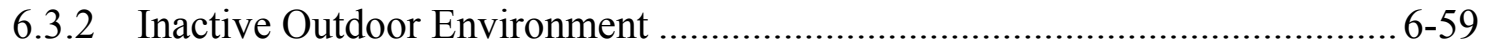

6.3.2.1 Data Analysis .......................................................................... 6-59

6.3.2.2 Literature Review.............................................................. 6-61

6.3.2.3 Parameter Distribution ......................................................... 6-62

6.3.3 Active Indoor Environment .............................................................. 6-63

6.3.3.1 Literature Review................................................................6-63

6.3.3.2 Parameter Development ............................................................. 6-64

6.3.4 Asleep Indoor Environment ............................................................... 6-65

6.3.4.1 Literature Review....................................................................6-65

6.3.4.2 Parameter Development..................................................... 6-66

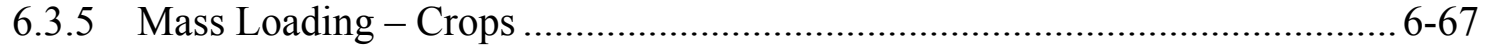

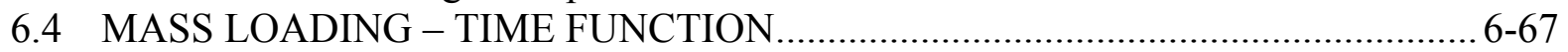

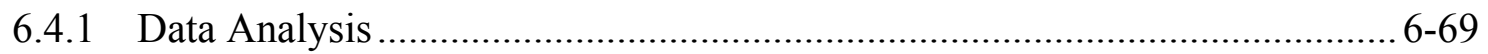

6.4.2 Literature Review.......................................................................... $6-72$

6.4.3 Parameter Development.................................................................. 6-73

6.4.3.1 Particle Size and Other Characteristics of Ash .......................... 6-73

6.4.3.2 Climate .............................................................................. 6-74

6.4.3.3 Ash Deposit Thickness ......................................................... 6-75

6.4.3.4 Incorporation of Uncertainty into Parameter Distribution ............. 6-76

7. CONCLUSIONS ..................................................................................................... $7-1$

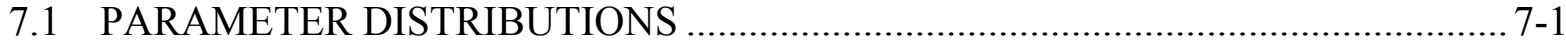

7.2 HOW THE APPLICABLE ACCEPTANCE CRITERIA ARE ADDRESSED .......... 7-2

8. INPUTS AND REFERENCES …....................................................................... 8 8 -

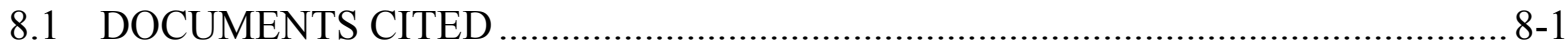

8.2 CODES, STANDARDS, REGULATIONS, AND PROCEDURES ....................... 8-12

8.3 SOURCE DATA, LISTED BY DATA TRACKING NUMBER ........................... $8-12$

8.4 OUTPUT DATA, LISTED BY DATA TRACKING NUMBER ............................. 8-13 


\section{CONTENTS (Continued)}

APPENDIX A-ATMOSPHERIC MASS LOADING SENSITIVITY ANALYSIS A-1

APPENDIX B-TSP CONCENTRATION FOR INACTIVE OUTDOOR ENVIRONMENT AND SOIL TEXTURE DATA

APPENDIX C-LIST AND DESCRIPTION OF FILES USED IN THIS ANALYSIS C-1 
INTERNTIONALLY LEFT BLANK 


\section{FIGURES}

Page

1-1. Documentation Hierarchy for the Environmental Radiation Model for Yucca Mountain, Nevada $1-2$

6-1. Dependence of Annual Average TSP on Annual Average Precipitation in Rural, Agricultural Sites

6-2. Percentages of Sand, Silt and Clay in the Soil Texture Classes ................................. 6-14

6-3. TSP Dependence on Predominant Texture Class of the Upper Soil Layer

6-4. Comparison of TSP Concentrations Versus Precipitation for Rural, Agricultural Sites and Rural, Desert Sites

6-5. Particle Size Distribution Showing Fractions Collected by Size-Selective Sampling Devices

6-6. Frequency Distribution of Ash Thickness from ASHPLUME Realizations with Wind Direction to the South from a Hypothetical Vent

6-7. Comparison of Particulate Concentrations in Air in the Active Outdoor Environment for the Nominal, Including Amargosa Valley, and Postvolcanic Conditions.

6-8. Examples of the Change of Mass Loading from a Hypothetical Initial Concentration of $10 \mathrm{mg} / \mathrm{m}^{3}$ for Seven Values of the Mass Loading Decrease Rate Constant $(\lambda)$.

6-9. TSP Concentrations $\left(\mathrm{mg} / \mathrm{m}^{3}\right)$ at Six Sites in Washington Before and After the Eruption of Mount St. Helens in May-June 1980

B-1. Comparison of Precipitation at the EPA Particulate Matter Monitoring Sites and at the Corresponding Weather Stations

C-1. List of Files Used in the Analysis 


\section{INTENTIONALLY LEFT BLANK}




\section{TABLES}

Page

1-1. Relationship of Parameters and FEPs.................................................................. 1-4

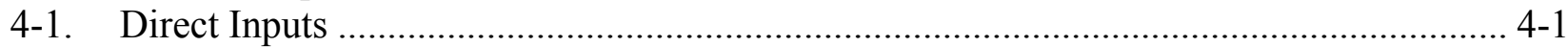

4-2. Sources of Published Measurements of Resuspended Particle Concentrations ................. 4-2

4-3. Requirements Applicable to This Analysis ……........................................................ 4-6

5-1. Correlation Coefficients $(R)$ of Indoor and Personal Versus Outdoor Concentrations of Airborne Particles................................................................................ 5-4

6-1. Average Annual Snowfall (in.), Precipitation (in.), and TSP (mg/ $\left.\mathrm{m}^{3}\right)$ at Rural, Agricultural Sites in the Western United States with Less Than 10, 10 to 20, and More Than 20 in. of Precipitation

6-2. Average Annual Snowfall (in.), Precipitation (in.), and TSP $\left(\mathrm{mg} / \mathrm{m}^{3}\right)$ at Rural, Agricultural Sites in the Western United States with Less Than 10, 10 to 20, and More Than 20 in. of Snowfall.

6-3. Categorization of Soil Separates and Rock Fragments.................................................. 6-14

6-4. Major Types of Soils Occurring in Amargosa Valley …………………........................ 6-15

6-5. Fraction of Clay, Silt, and Sand in Soils by Texture Class............................................ 6-16

6-6. Particulate Concentrations-Nominal Active Outdoor Environment ............................... 6-26

6-7. Mass Loading Measurements for Active Outdoor Environment in Amargosa

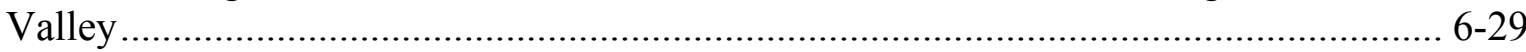

6-8. Average Concentration of TSP at 21 Selected Monitoring Sites..................................... 6-36

6-9. Summary of Mass Loading Measurements for Inactive Outdoor Environment in Amargosa Valley ……………………….................................................................. 6-37

6-10. Particulate Concentrations-Nominal Indoor Active Environment.................................. 6-40

6-11. Particulate Concentrations - Nominal Asleep Indoor Environment ............................... 6-48

6-12. Particulate Concentrations - Postvolcanic Active Outdoor Environment....................... 6-54

6-13. Average Concentrations of TSP $\left(\mathrm{mg} / \mathrm{m}^{3}\right)$ at Six Sites in Washington Before (March 79 to February 80), One Year After (June 80 to May 81), and Two Years After (June 81 to May 82) the May 1980 Eruption of Mount St. Helens .......................... 6-61

7-1. Inhalation Exposure Input Parameters for the Biosphere Model..................................... 7-1

A-1. Mass Loading Sensitivity Analysis - Nominal Conditions ……………….......................

A-2. Mass Loading Sensitivity Analysis - Postvolcanic Conditions..........................................A-3

B-1. Average Concentration of TSP $\left(\mathrm{mg} / \mathrm{m}^{3}\right)$ at Rural, Agricultural Monitoring Sites in the Western United States........................................................................................

B-2. Soil Texture at Rural, Agricultural Monitoring Sites in the Western United States........... B-6 


\section{INTENTIONALLY LEFT BLANK}




\section{ACRONYMS AND ABBREVIATIONS}

AMAD activity median aerodynamic diameter

BDCF biosphere dose conversion factor

CEMP Community Environmental Monitoring Program

EPA U.S. Environmental Protection Agency

ERMYN Environmental Radiation Model for Yucca Mountain, Nevada

FEP feature, event, or process

GSD geometric standard deviation

LDAS Land Data Assimilation Systems

NCDC National Climatic Data Center

NRC

U.S. Nuclear Regulatory Commission

NRCS

USDA Natural Resources Conservation Service

PM particulate matter

$\mathrm{PM}_{2.5} \quad$ particles collected with an upper $50 \%$ cut point of $2.5 \mu \mathrm{m}$ aerodynamic diameter and a specified penetration curve

$\mathrm{PM}_{4} \quad$ particles collected with an upper $50 \%$ cut point of $4 \mu \mathrm{m}$ aerodynamic diameter and a specified penetration curve

$\mathrm{PM}_{10} \quad$ particles collected with an upper $50 \%$ cut point of $10 \mu \mathrm{m}$ aerodynamic diameter and a specified penetration curve

RMEI reasonably maximally exposed individual

SD standard deviation

TSP total suspended particulates

TSPA total system performance assessment

YMRP $\quad$ Yucca Mountain Review Plan, Final Report 


\section{INTENTIONALLY LEFT BLANK}




\section{PURPOSE}

This analysis is one of the technical reports that support the Environmental Radiation Model for Yucca Mountain, Nevada (ERMYN), referred to in this report as the biosphere model. Biosphere Model Report (BSC 2004 [DIRS 169460]) describes in detail the conceptual model as well as the mathematical model and its input parameters. This report documents development of input parameters for the biosphere model that are related to atmospheric mass loading and supports the use of the model to develop biosphere dose conversion factors (BDCFs). The biosphere model is one of a series of process models supporting the total system performance assessment (TSPA) for a Yucca Mountain repository.

Inhalation Exposure Input Parameters for the Biosphere Model is one of five reports that develop input parameters for the biosphere model. A graphical representation of the documentation hierarchy for the biosphere model is presented in Figure 1-1 (based on BSC 2006 [DIRS 176938]). This figure shows the interrelationships among the products (i.e., analysis and model reports) developed for biosphere modeling and how this analysis report contributes to biosphere modeling.

This analysis report defines and justifies values of atmospheric mass loading for the biosphere model. Mass loading is the total mass concentration of resuspended particles (e.g., dust, ash) in a volume of air. Mass loading values are used in the air submodel of the biosphere model to calculate concentrations of radionuclides in air inhaled by a receptor and concentrations in air surrounding crops. Concentrations in air to which the receptor is exposed are then used in the inhalation submodel to calculate the dose contribution to the receptor from inhalation of contaminated airborne particles. Concentrations in air surrounding plants are used in the plant submodel to calculate the concentrations of radionuclides in foodstuffs contributed from uptake by foliar interception. This report is concerned primarily with the physical attributes of airborne particulate matter, such as the airborne concentrations of particles and their sizes. The conditions of receptor exposure (duration of exposure in various microenvironments), breathing rates, and dosimetry of inhaled particulates are discussed in more detail in Characteristics of the Receptor for the Biosphere Model (BSC 2005 [DIRS 172827]).

Two sets of mass loading values are developed in this analysis. The first is representative of nominal, current, and future concentrations of resuspended particles in the Yucca Mountain region. In this report, nominal refers to air-quality conditions in the reference biosphere not measurably affected by a volcanic eruption at Yucca Mountain. As displayed in Figure 1-1, this set of mass loading values is used in the analysis of the biosphere groundwater exposure scenario to calculate the dose caused by inhalation and crop interception of resuspended soil contaminated by irrigation water. These values also are used in the analysis of the biosphere volcanic ash exposure scenario to calculate the dose caused by inhalation and interception of nominal concentrations of resuspended, contaminated ash following a volcanic eruption. The second set of mass loading values is representative of the increase in mass loading expected after a volcanic eruption at Yucca Mountain and is used in the biosphere volcanic ash exposure scenario to calculate the inhalation and ingestion doses following an eruption. The biosphere exposure scenarios are not the same as scenario classes used in the TSPA. 


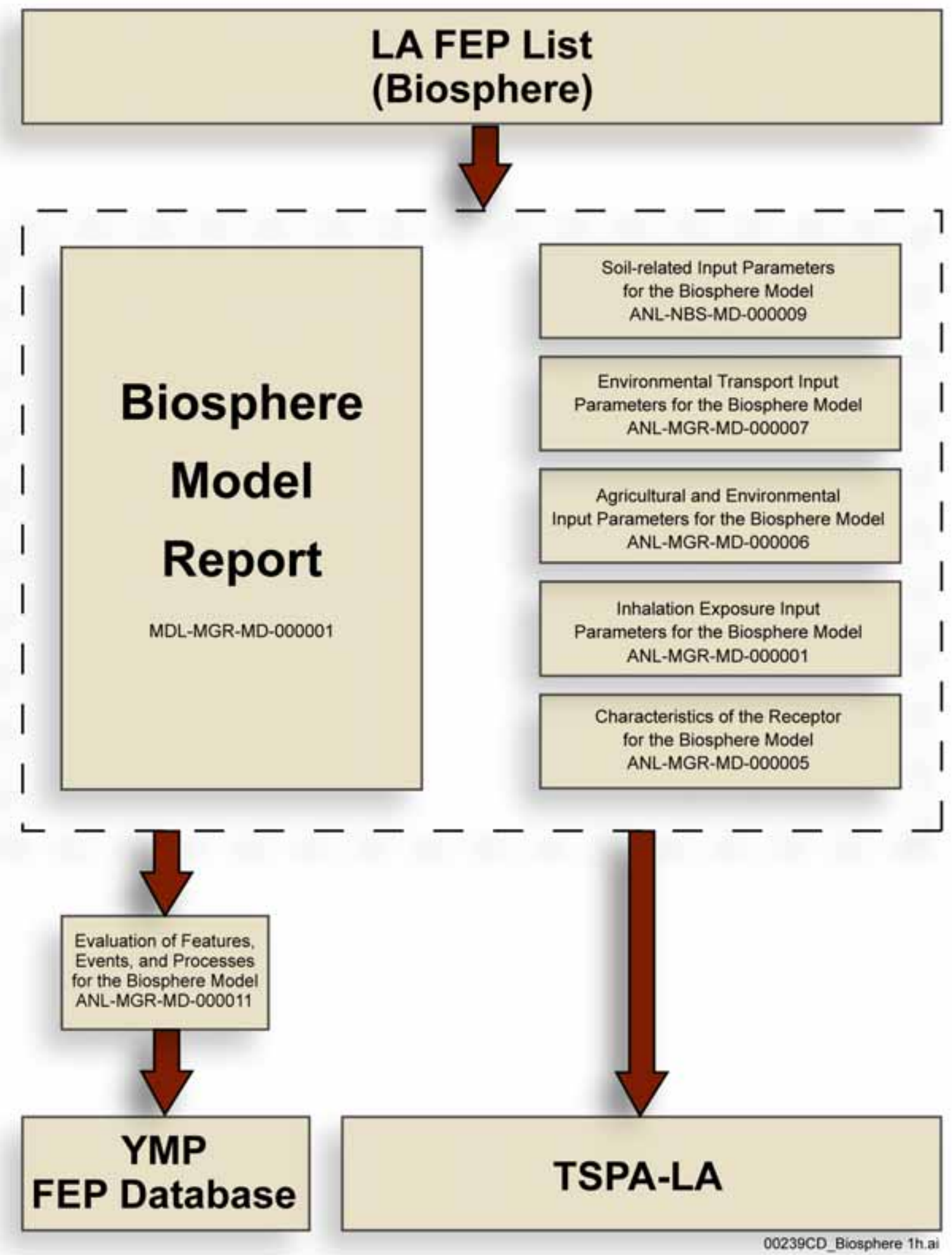

Figure 1-1. Documentation Hierarchy for the Environmental Radiation Model for Yucca Mountain, Nevada 
In addition, the mass loading time function and the parameter mass loading decrease rate constant are developed in this analysis. This function describes how mass loading changes over time following a volcanic eruption. The decrease rate constant defines the rate of change in mass loading following an eruption. The time function and decrease rate constant account for changes in BDCFs caused by a decrease in mass loading through time following an eruption.

To summarize, the following parameters are developed in this report:

- Mass loading-receptor environments, $S_{n}\left(\mathrm{mg} / \mathrm{m}^{3}\right)$ - The average annual mass concentration of suspended particles by receptor environment and exposure scenario.

- Mass loading-crops, $S\left(\mathrm{mg} / \mathrm{m}^{3}\right)$ - The average annual mass concentration of suspended particles in agricultural fields and gardens to which food and forage crops are exposed.

- Mass loading decrease rate constant, $\lambda$ (1/year)_-Proportion of resuspended particles present at the beginning of a year that are not readily resuspendable at the end of the year. This parameter and the associated mass loading time function are applicable only to the volcanic ash exposure scenario.

These parameters support treatment of the features, events, and processes (FEPs) listed in Table 1-1 that are applicable to biosphere modeling (DTN: MO0508SEPFEPLA.002 [DIRS 175064]). See Biosphere Model Report (BSC 2004 [DIRS 169460], Section 6.2) for information on the treatment of FEPs in the biosphere model. Biosphere Model Report (BSC 2004 [DIRS 169460]) uses a previous license application FEPs list (DTN: MO0407SEPFEPLA.000 [DIRS 170760]). However, the names, descriptions, and dispositions of the biosphere-related FEPs are similar in both sets.

This analysis was conducted in accordance with LP-SIII.9Q-BSC, Scientific Analyses, and an approved technical work plan (BSC 2006 [DIRS 176938]). The scope of this revision includes additional evaluations of whether mass loading data for the analogue locations are appropriate for representing the conditions in the Yucca Mountain region. These activities include an evaluation of the effects of various environmental processes and conditions on atmospheric mass loading based on published literature sources and site-specific mass loading data, and modification of some biosphere model parameters to incorporate site-specific data related to mass loading. These activities are conducted in part to address the issues outlined in Integrated Issue Resolution Status Report (NRC 2005 [DIRS 175566], Section 5.1.3.13) and in the additional information need for Key Technical Issue IA 2.11 (Reamer 2004 [DIRS 176773]).

The technical work plan (BSC 2006 [DIRS 176938]) calls for consolidation of some technical reports within the biosphere model documentation suite. The documentation hierarchy illustrated in Figure 1-1 is consistent with that plan. Technical reports shown in this figure that are not scheduled for revision under the current work plan include an earlier version of Figure 1-1 that shows reports that will become incorporated into the revision of Biosphere Model Report (BSC 2004 [DIRS 169460]). 
Table 1-1. Relationship of Parameters and FEPs

\begin{tabular}{|c|c|c|c|c|}
\hline Parameter & FEP Name & $\begin{array}{l}\text { FEP } \\
\text { Number }\end{array}$ & $\begin{array}{l}\text { Biosphere } \\
\text { Submodel }\end{array}$ & $\begin{array}{c}\text { Summary of Disposition in } \\
\text { TSPA }^{\text {T }}\end{array}$ \\
\hline \multirow{6}{*}{$\begin{array}{l}\text { Mass Loading } \\
\text { - Receptor } \\
\text { Environments }\end{array}$} & Ashfall & 1.2.04.07.0A & \multirow{6}{*}{ Air } & \multirow{6}{*}{$\begin{array}{l}\text { The treatment of this parameter } \\
\text { is described in Sections } 6.1 \text { and } \\
6.2 \text { and summarized in } \\
\text { Table } 7-1 .\end{array}$} \\
\hline & Human lifestyle & 2.4.04.01.0A & & \\
\hline & $\begin{array}{l}\text { Wild and natural land and water } \\
\text { use }\end{array}$ & 2.4.08.00.0A & & \\
\hline & $\begin{array}{l}\text { Agricultural land use and } \\
\text { irrigation }\end{array}$ & 2.4.09.01.0B & & \\
\hline & $\begin{array}{l}\text { Urban and industrial land and } \\
\text { water use }\end{array}$ & 2.4.10.00.0A & & \\
\hline & $\begin{array}{l}\text { Atmospheric transport of } \\
\text { contaminants }\end{array}$ & 3.2.10.00.0A & & \\
\hline \multirow{3}{*}{$\begin{array}{l}\text { Mass Loading } \\
- \text { Crops }\end{array}$} & Ashfall & 1.2.04.07.0A & \multirow{3}{*}{ Plant } & \multirow{3}{*}{$\begin{array}{l}\text { The treatment of this parameter } \\
\text { is described in Sections } 6.1 .5 \\
\text { and } 6.2 .5 \text { and summarized in } \\
\text { Table } 7-1 .\end{array}$} \\
\hline & $\begin{array}{l}\text { Agricultural land use and } \\
\text { irrigation }\end{array}$ & 2.4.09.01.0B & & \\
\hline & $\begin{array}{l}\text { Atmospheric transport of } \\
\text { contaminants }\end{array}$ & 3.2.10.00.0A & & \\
\hline \multirow{3}{*}{$\begin{array}{l}\text { Mass Loading } \\
\text { Time Function } \\
\text { and Decrease } \\
\text { Rate Constant }\end{array}$} & Ashfall & 1.2.04.07.0A & \multirow{3}{*}{ N/A } & \multirow{3}{*}{$\begin{array}{l}\text { The treatment of this parameter } \\
\text { is described in Section } 6.3 \text { and } \\
\text { summarized in Table } 7-1 .\end{array}$} \\
\hline & $\begin{array}{l}\text { Soil and sediment transport in } \\
\text { the biosphere }\end{array}$ & 2.3.02.03.0A & & \\
\hline & Inhalation & 3.3.04.02.0A & & \\
\hline
\end{tabular}

Source: DTN: MO0508SEPFEPLA.002 [DIRS 175064].

a The effects of these FEPs are included in the TSPA through the BDCFs. See Biosphere Model Report (BSC 2004 [DIRS 169460], Section 6.2) for a complete description of the inclusion and treatment of FEPs in the biosphere model.

FEP=features, events, and processes; TSPA=total system performance assessment. 


\section{QUALITY ASSURANCE}

Development of this report involves analysis of data to support performance assessment, as described in the technical work plan (BSC 2006 [DIRS 176938]), and is a quality-affecting activity in accordance with LP-2.29Q, Planning for Science Activities. Approved quality assurance procedures identified in Section 4 of the technical work plan have been used to conduct and document the activities described in this report. Electronic data used in this analysis were controlled in accordance with the methods specified in Section 8 of the technical work plan.

The natural barriers and items identified in Q-list (BSC 2005 [DIRS 175539]) are not pertinent to this analysis and a safety category per LS-PRO-0203, Q-List and Classification of Structures, Systems, and Components, is not applicable. 


\section{INTENTIONALLY LEFT BLANK}




\section{USE OF SOFTWARE}

The only software used to manipulate or analyze data were the commercial off-the-shelf products Microsoft Access 97 SR-2, Microsoft Excel 2000 SR-1, and TextPad Version 4.7.3. All methods used within Access, Excel, and TextPad to manipulate or combine data, and associated formulas, inputs, and outputs, are described in the text or tables of this report. The average and standard deviation (SD) functions of Excel were used throughout this analysis to calculate summary statistics and Excel graphics functions were used to create figures. 


\section{INTENTIONALLY LEFT BLANK}




\section{INPUTS}

\subsection{DIRECT INPUTS}

The inputs directly used to develop parameter distributions are described and justified below and summarized in Table 4-1.

Table 4-1. Direct Inputs

\begin{tabular}{|c|c|c|}
\hline Input & Source of Input & Description \\
\hline $\begin{array}{l}\text { Resuspended particle } \\
\text { concentrations and } \\
\text { ratios }\end{array}$ & Peer-reviewed publications listed in Table 4-2 & $\begin{array}{l}\text { External-source measurements of TSP or } \\
\text { other airborne particulate concentrations } \\
\text { taken in the environments considered in } \\
\text { the biosphere model }\end{array}$ \\
\hline $\begin{array}{l}\text { Resuspended particle } \\
\text { concentrations }\end{array}$ & $\begin{array}{l}\text { EPA AirData database } \\
\text { (DTN: MO0210SPATSP01.023 [DIRS 160426]) }\end{array}$ & $\begin{array}{l}\text { Annual average TSP concentrations at } \\
\text { monitoring sites throughout the United } \\
\text { States, 1970-2001 }\end{array}$ \\
\hline $\begin{array}{l}\text { Resuspended particle } \\
\text { concentrations }\end{array}$ & $\begin{array}{l}\text { EPA AirData database } \\
\text { (DTN: MO0008SPATSP00.013 [DIRS 151750]) }\end{array}$ & $\begin{array}{l}\text { 24-hour concentrations of TSP at } \\
\text { monitoring sites in Washington, } \\
\text { 1979-1982 }\end{array}$ \\
\hline $\begin{array}{l}\text { Resuspended particle } \\
\text { concentration ratios }\end{array}$ & $\begin{array}{l}\text { DTN: MO98PSDALOG111.000 [DIRS 119501] } \\
\text { DTN: TM000000000001.039 [DIRS 121386] } \\
\text { DTN: TM000000000001.041[DIRS 121396] } \\
\text { DTN: TM000000000001.042 [DIRS 121405] } \\
\text { DTN: TM000000000001.079 [DIRS 121410] } \\
\text { DTN: TM000000000001.082[DIRS 121416] } \\
\text { DTN: TM000000000001.084 [DIRS 121419] } \\
\text { DTN: TM000000000001.096 [DIRS 121421] } \\
\text { DTN: TM000000000001.097 [DIRS 121426] } \\
\text { DTN: TM000000000001.098 [DIRS 121429] } \\
\text { DTN: TM000000000001.099 [DIRS 121435] } \\
\text { DTN: TM000000000001.105 [DIRS 121440] } \\
\text { DTN: TM000000000001.108 [DIRS 121442] }\end{array}$ & $\begin{array}{l}\text { 24-hour concentrations of TSP and PM10 } \\
\text { at two sites at Yucca Mountain, } \\
\text { 1989-1997. }\end{array}$ \\
\hline Climate & $\begin{array}{l}\text { National Climatic Data Center (NCDC } 1998 \\
\text { [DIRS 135900; DIRS 125325]) }\end{array}$ & $\begin{array}{l}\text { Average annual precipitation and } \\
\text { snowfall, and other measurements of } \\
\text { climate at weather stations in the western } \\
\text { United States through } 1997\end{array}$ \\
\hline $\begin{array}{l}\text { Resuspended particle } \\
\text { concentrations in } \\
\text { Amargosa Valley }\end{array}$ & DTN: MO0603UCCF01JS.001 [DIRS 176759] & $\begin{array}{l}\text { TSP concentrations in milligrams per } \\
\text { cubic meter }\left(\mathrm{mg} / \mathrm{m}^{3}\right) \text { measured during } \\
\text { soil-disturbing activities from } 12 / 15 / 05 \text { to } \\
12 / 16 / 05 \text { in Amargosa Valley }\end{array}$ \\
\hline
\end{tabular}

$E P A=U . S$. Environmental Protection Agency; $\mathrm{PM}_{10}=$ particles with an aerodynamic diameter $\leq 10 \mu \mathrm{m} ; \mathrm{TSP}=$ total suspended particulates.

\subsubsection{Airborne Particle Concentrations}

Measurements of airborne particle concentrations reported within the sources listed in Table 4-2 were used to develop distributions of mass loading. Data from these sources were qualified for use in this analysis. The planning and documentation of qualification process is described 
below. The qualification criteria included the consideration of the extent to which the data demonstrate the properties of interest, factors considered, and basis of the decision to qualify the data.

Table 4-2. Sources of Published Measurements of Resuspended Particle Concentrations

\begin{tabular}{|c|c|}
\hline Source & Source \\
\hline Archer et al. 2002 [DIRS 168488] & Merchant et al. 1982 [DIRS 160102] \\
\hline Baxter et al. 1999 [DIRS 150713] & Molocznik and Zagorski 1998 [DIRS 154281] \\
\hline Brauer et al. 2000 [DIRS 159703] & Molocznik and Zagorski 2000 [DIRS 159587] \\
\hline Brook et al. 1997 [DIRS 160254] & Monn et al. 1997 [DIRS 150888] \\
\hline Buist et al. 1983 [DIRS 159738] & Mozzon et al. 1987 [DIRS 159585] \\
\hline Buist et al. 1986 [DIRS 144632] & Nieuwenhuijsen and Schenker 1998 [DIRS 150854] \\
\hline Buist et al. 1986 [DIRS 160308] & Nieuwenhuijsen et al. 1998 [DIRS 150855] \\
\hline Clausnitzer and Singer 1997 [DIRS 160404] & Nieuwenhuijsen et al. 1999 [DIRS 150711] \\
\hline Clayton et al. 1993 [DIRS 159599] & Pellizzari et al. 1999 [DIRS 159702] \\
\hline Evans et al. 2000 [DIRS 159679] & Quackenboss et al. 1989 [DIRS 159682] \\
\hline Howard-Reed et al. 2000 [DIRS 159680] & Rojas-Bracho et al. 2000 [DIRS 159678] \\
\hline Janssen et al. 1998 [DIRS 159699] & Searl et al. 2002 [DIRS 160104] \\
\hline Kullman et al. 1998 [DIRS 159586] & Thatcher and Layton 1995 [DIRS 159600] \\
\hline Leaderer et al. 1999 [DIRS 160403] & Wheeler et al. 2000 [DIRS 159704] \\
\hline Linn et al. 1999 [DIRS 159602] & Wigzell et al. 2000 [DIRS 159729] \\
\hline Lioy et al. 1990 [DIRS 159655] & Williams et al. 2000 [DIRS 159735] \\
\hline Long et al. 2000 [DIRS 159681] & Yano et al. 1990 [DIRS 160112] \\
\hline Long et al. 2001 [DIRS 159733] & Yocom et al. 1971 [DIRS 159654] \\
\hline
\end{tabular}

The measurements of airborne particle concentrations were taken in settings consistent with the conditions in the active outdoor, active indoor, and asleep indoor environments in Amargosa Valley and used in the biosphere model (the environments are described in Section 6). To ensure that the distributions of mass loading developed from these measurements were consistent with conditions in the Yucca Mountain region, uncertainty about the influence of climate, environment, activity patterns, and other factors were considered, as described in Section 6. Description of these measurements, their use in this analysis, and their applicability to conditions in the Yucca Mountain region, is further described in Sections 5.2, 6.2, 6.3, and 6.4. Applicable mean or other representative values from the publications included in this data set are presented in Tables 6-7, 6-10, 6-11, and 6-12.

To ensure that a comprehensive set of data was included in this analysis, online scientific journal and citation index searches were conducted and reference lists from related reports and publications were reviewed. The resulting data set includes original measurements of resuspended particle concentrations from all publications known to the author of this analysis that met the following requirements. The requirements were selected to ensure that the data are technically defensible and applicable to this analysis. 
- The information was published in a peer-reviewed scientific journal. The location of publication of each data source is listed in Section 8.1.

- The methods used to measure particulate concentrations were sufficiently described to determine whether the methods and equipment used were applicable to this analysis and comparable to other studies.

- Measurements were made in a setting applicable to this analysis (e.g., outdoor settings during dust-disturbing activities, indoor settings with and without activity).

In addition, because mass loading is defined as the concentration of all resuspended particles, most of the sources included in this data set report concentrations of total suspended particulates (TSP) or $\mathrm{PM}_{10}$, i.e., particles collected with an upper $50 \%$ (collection efficiency) cut point of $10 \mu \mathrm{m}$ aerodynamic diameter and a specified penetration curve. For brevity and following the common convention, $\mathrm{PM}_{10}$ is referred to in this report as particles with an aerodynamic diameter less than or equal to $10 \mu \mathrm{m}$, although this term is not entirely accurate because it implies an upper $100 \%$ cut point of $10 \mu \mathrm{m}$. The same convention is also used for other values of cut points (e.g., $\mathrm{PM}_{4}$ or $\mathrm{PM}_{2.5}$ ).

Because of the small number of measurements reported for the active outdoor environment, asleep indoor environment, and postvolcanic environments, sources that report concentrations of smaller particles (e.g., particles with an aerodynamic diameter less than or equal to $4 \mu \mathrm{m}\left(\mathrm{PM}_{4}\right)$ or less than or equal to $\left.2.5 \mu \mathrm{m}\left(\mathrm{PM}_{2.5}\right)\right)$ in those environments also were included. Sources that report concentrations of $\mathrm{PM}_{2.5}$ in the other environments considered in the biosphere model were not included because sufficient measurements of TSP and $\mathrm{PM}_{10}$ were available. Also, sources that report concentrations for environments not considered in the biosphere model were not included.

No requirement was included concerning the accuracy or precision of the data because the mass loading distributions developed in this analysis have a relatively large range and are therefore insensitive to the much smaller levels of error in measurement of airborne particle concentrations. For example, limits of detectability of equipment commonly used to measure mass loading are generally less than $0.01 \mathrm{mg} / \mathrm{m}^{3}$ and sampling precision generally is less than $0.02 \mathrm{mg} / \mathrm{m}^{3}$ (Howard-Reed et al. 2000 [DIRS 159680], p. 1127; Rojas-Brancho et al. 2000 [DIRS 159678], p. 297; Williams et al. 2000 [DIRS 159735], p. 523).

In accordance with LP-SIII.9Q-BSC, the following information was considered to evaluate whether the data were collected using acceptable methodology and to evaluate whether sufficient confidence in the acquisition and development of results is warranted to consider the data suitable for use in this analysis.

- Reliability of Data Sources-Because all data considered here came from peer-reviewed publications, and was thus judged to be appropriate for publication by experts in the associated fields of study, it is concluded that the data sources are reliable for use in this analysis. In addition, the methods used were described in sufficient detail to determine whether the results are applicable to this analysis. Four publications that report resuspended particle concentrations following the eruption of Mount St. Helens 
did not fully describe the methods used to measure and summarize concentrations (Buist et al. 1983 [DIRS 159738]; Buist et al. 1986 [DIRS 144632]; Buist et al. 1986 [DIRS 160308]; Merchant et al. 1982 [DIRS 160102]). However, those methods were fully described in reports published by the National Institute for Occupational Safety and Health (Hewett 1980 [DIRS 168490]; Hewett 1980 [DIRS 168491]; Sanderson 1982 [DIRS 168492]).

- Extent to Which the Data Demonstrate the Properties of Interest-Measurements of resuspended particle concentrations are most applicable to this analysis if they are measurements of personal exposure to TSP taken in the environments considered in the biosphere model under conditions consistent with the conditions in the Yucca Mountain region. As described in Section 6, all measurements considered here were taken in settings that are consistent with the environments considered. In addition, most measurements were of personal exposure to particle concentrations. Measurements of ambient concentrations were not used for the active outdoor environment (Sections 6.2.1 and 6.3.1), and were used for the active indoor environment only if people were active indoors while the measurements were taken (Section 6.2.3 and 6.3.3). Ambient concentrations were included for the asleep indoor environment because they are representative of conditions while people are inactive (Sections 6.2.4 and 6.3.4). Because there were too few measurements of TSP for some environments, such as active indoors, measurements of $\mathrm{PM}_{10}$ and smaller particles also were considered. Because representative ratios of large to small particles specific to each environment were used when considering those concentrations, they are appropriate for use in this analysis. Additional discussion of the applicability of the data to the conditions in the Yucca Mountain region is included in Sections 5.1, 6.2, 6.3, and 6.4.

- Availability of Corroborating Data-Because all applicable data on resuspended particle concentrations were considered in this analysis, there are no corroborating data available. However, all data used were plotted and compared to evaluate the reasonableness of the results of each study and to understand variation and uncertainty of concentrations within each environment (Tables 6-7, 6-10, 6-11, and 6-12). Measurements for each environment are similar, especially for indoor environments (e.g., Table 6-10). These comparisons provide confidence that the data are reliable and do not contain invalid or inconsistent measurements.

Because the data considered here come from peer-reviewed journals, have sufficiently described methods, and were from studies conducted in applicable environments, it is concluded that the data are suitable for the specific application in this analysis. Confidence in the reliability of the data is raised by corroborative comparisons. Thus, the data are considered qualified for the intended use in this analysis.

\subsubsection{Total Suspended Particles - United States}

Annual average concentrations of TSP measured at ambient monitoring stations located in rural, agricultural settings in arid to semi-arid environments in the western United States (DTN: MO0210SPATSP01.023 [DIRS 160426]) were used to determine mass loading in the outdoor inactive environment (Section 6.1.2). The data were obtained from the 
U.S. Environmental Protection Agency (EPA) Office of Air and Radiation AirData database (Ambrose 2002 [DIRS 160080]; Ambrose 2002 [DIRS 160081]). This federal agency is responsible for developing programs, policies, and regulations for controlling air pollution. The AirData database contains measurements of air pollution concentrations collected by federal, state, and local air pollution control agencies to track compliance with emission standards. These data were collected and reported in accordance with EPA requirements for methodology and quality control and therefore were collected using consistent methods that meet federal quality control standards. These data therefore are appropriate for use in this analysis and are considered established fact. See Section 6.2.2 for additional information on the appropriateness of these data for their intended use and the applicability of the data to the conditions in the Yucca Mountain region. Selection of the subset of data used in this analysis is described in Section 6.2.2.1, and those data are displayed in Appendix B and in the Excel file Subset TSP_Rural Agricultural Sites.xls (Appendix C).

\subsubsection{Total Suspended Particles - Washington}

Twenty-four-hour concentrations of TSP during 1979-1982 from air quality monitoring sites in Washington with high ash fall from the eruption of Mount St. Helens (DTN: MO0008SPATSP00.013 [DIRS 151750]) were used in Sections 6.3.2 and 6.4 to predict changes in mass loading following a volcanic eruption. These data were obtained from the EPA AirData database and were collected using consistent methods that meet federal quality control standards. Selection of the subset of data used in this analysis is described in Section 6.2.2.1. See Section 6.3.2 and 6.4 for additional justification on the appropriateness of these data and for caveats about the interpretation of the data for their intended use. Data used in this analysis are displayed in the file TSP Mount St Helens_1979-1982.xls shown in Appendix C and are considered established fact.

\subsubsection{Suspended Particles - Yucca Mountain}

All valid 24-hour concentrations of $\mathrm{PM}_{10}$ and TSP measured concurrently using co-located monitoring equipment at Yucca Mountain during 1989 through 1997 were used in Section 6.1.3.1 to calculate a ratio of TSP to $\mathrm{PM}_{10}$ for the Yucca Mountain region. See Table 4-1 for a list of DTNs containing these data. These data are appropriate because they were collected in areas with soils typical of those in Amargosa Valley (CRWMS M\&O 1999 [DIRS 107736], Figure 1 on pp. 2 and 3) and therefore are consistent with relatively undisturbed conditions of the Yucca Mountain region. In addition, these measurements are comparable to data collected elsewhere in the United States because they were taken in accordance with EPA requirements for methodology and quality control. The data are displayed in the Excel file TSP-to-PM10 Ratios_Yucca Mountain.xls (Appendix C). Deletion of 24 invalid ratios with a TSP:PM 10 ratio of less than or equal to 1 is discussed in Section 6.2.3.1.

\subsubsection{Total Suspended Particulates - Amargosa Valley}

TSP concentrations were measured in Amargosa Valley during soil-disturbing activities (DTN: MO0603UCCF01JS.001 [DIRS 176759]). The data are also shown in Excel file Mass loading Amargosa Valley.xls (Appendix C). Eight activity types were examined that represent common behaviors in a rural setting, such as driving on unpaved and paved roads, walking, 
farming activities and gardening activities (see Section 6.2.1.2 for more detailed description of activities). The measurements were conducted on two consecutive days in December 2005 with a DustScan instrument, which uses light scattering to measure the concentration of particulate matter in ambient air. These data are appropriate to support the development of the mass loading distributions in the biosphere model because the measurements were taken in the Yucca Mountain region and are therefore consistent with present knowledge of the conditions in that region, as required by 10 CFR 63.305(a) [DIRS 173273]. In addition, the measurements were taken during activities typically conducted by residents of Amargosa Valley and are, therefore, consistent with the definition of the reasonably maximally exposed individual (RMEI) in 10 CFR 636.312 [DIRS 173273]. These data were used in Section 6.2.1.2.

\subsubsection{Precipitation - United States}

Measurements of average annual precipitation at weather stations in the western United States obtained from the National Oceanic and Atmospheric Administration, National Climatic Data Center (NCDC) (NCDC 1998 [DIRS 135900]; NCDC 1998 [DIRS 125325]) were used in Section 6.2.2 and Appendix B to aid in selecting analogue air quality monitoring sites representative of arid farming communities. This information also was used throughout Section 6 to describe the climate at weather stations analogous to future conditions predicted for Yucca Mountain. The NCDC is responsible for archiving weather data obtained by the National Weather Service, Military Services, Federal Aviation Administration, Coast Guard, and voluntary cooperative observers. These measurements were collected using the standardized methods and equipment required by the National Climatic Data Center; therefore, they are valid for comparison among sites in the United States and are considered established fact. The data from the NCDC used in this analysis are included in Appendix C in the Excel file Subset TSP_Rural Agricultural Sites.xls.

\subsection{CRITERIA}

The requirements that are applicable to this analysis are listed in Table 4-3 (BSC 2006 [DIRS 176938], Section 3.2). These requirements are for compliance with applicable portions of 10 CFR Part 63 [DIRS 173273]. In addition to the requirements listed in Table 4-3, definitions of terms in 10 CFR 63.2 and description of concepts in 10 CFR 63.102 that are relevant to biosphere modeling are also applicable to this analysis.

Table 4-3. Requirements Applicable to This Analysis

\begin{tabular}{|l|l|}
\hline \multicolumn{1}{|c|}{ Requirement Title } & \multicolumn{1}{c|}{ Related Regulation } \\
\hline Requirements for Performance Assessment & 10 CFR 63.114 [DIRS 173273] \\
\hline Required Characteristics of the Reference Biosphere & 10 CFR 63.305 [DIRS 173273] \\
\hline Required Characteristics of the Reasonably Maximally Exposed Individual & 10 CFR 63.312 [DIRS 173273] \\
\hline
\end{tabular}

Listed below are the acceptance criteria from Yucca Mountain Review Plan, Final Report (YMRP) (NRC 2003 [DIRS 163274]) that are applicable to this analysis. The list is based on meeting the requirements of 10 CFR 63.114, 10 CFR 63.305, and 10 CFR 63.312 [DIRS 173273] that relate in whole or in part to this analysis. See Section 7.2 for a summary of where the criteria are addressed. 
Only the criteria from Section 2.2.1.3.14 (Biosphere Characteristics) of the YMRP (NRC 2003 [DIRS 163274]) apply to this analysis. The modeling of effects of wind erosion on the redistribution of radionuclides in soils, which is partially covered in Section 2.2.1.3.13 (Redistribution of Radionuclides in Soil) of the YMRP, is discussed in other biosphere reports (e.g., BSC 2004 [DIRS 169459], Section 6.4; BSC 2004 [DIRS 169460], Sections 6.4 .1 and 6.5.1). Section 2.2.1.3.11 (Airborne Transport of Radionuclides) of the YMRP is interpreted to apply only to airborne transport of radionuclides to the biosphere following a volcanic eruption. Airborne transport of radionuclides within the biosphere is evaluated in the context of the review criteria in Section 2.2.1.3.14 of the YMRP:

\section{Acceptance Criteria from YMRP Section 2.2.1.3.14: Biosphere Characteristics}

\section{Acceptance Criterion 1: System Description and Model Integration Are Adequate}

(3) Assumptions are consistent between the biosphere characteristics modeling and other abstractions. For example, the U.S. Department of Energy should ensure that the modeling of features, events, and processes, such as climate change, soil types, sorption coefficients, volcanic ash properties, and the physical and chemical properties of radionuclides are consistent with assumption in other total system performance assessment abstractions; and

\section{Acceptance Criterion 2: Data Are Sufficient for Model Justification}

(1) The parameter values used in the license application are adequately justified (e.g., behaviors and characteristics of the residents of the Town of Amargosa Valley, Nevada, characteristics of the reference biosphere, etc.) and consistent with the definition of the reasonably maximally exposed individual in 10 CFR Part 63. Adequate descriptions of how the data were used, interpreted, and appropriately synthesized into the parameters are provided.

(2) Data are sufficient to assess the degree to which features, events, and processes related to biosphere characteristics modeling have been characterized and incorporated in the abstraction. As specified in 10 CFR Part 63, the U.S. Department of Energy should demonstrate that features, events, and processes, which describe the biosphere, are consistent with present knowledge of conditions in the region, surrounding Yucca Mountain. As appropriate, the U.S. Department of Energy sensitivity and uncertainty analyses (including consideration of alternative conceptual models) are adequate for determining additional data needs, and evaluating whether additional data would provide new information that could invalidate prior modeling results and affect the sensitivity of the performance of the system to the parameter value or model.

\section{Acceptance Criterion 3: Data Uncertainty Is Characterized and Propagated Through the Model Abstraction}

(1) Models use parameter values, assumed ranges, probability distributions, and bounding assumptions that are technically defensible, reasonably account for uncertainties and variabilities, do not result in an under-representation of the risk 
estimate, and are consistent with the definition of the reasonably maximally exposed individual in 10 CFR Part 63;

(2) The technical bases for the parameter values and ranges in the abstraction, such as consumption rates, plant and animal uptake factors, mass-loading factors, and biosphere dose conversion factors, are consistent with site characterization data, and are technically defensible;

(3) Process-level models used to determine parameter values for the biosphere characteristics modeling are consistent with site characterization data, laboratory experiments, field measurements, and natural analog research;

(4) Uncertainty is adequately represented in parameter development for conceptual models and process-level models considered in developing the biosphere characteristics modeling, either through sensitivity analyses, conservative limits, or bounding values supported by data, as necessary. Correlations between input values are appropriately established in the total system performance assessment, and the implementation of the abstraction does not inappropriately bias results to a significant degree.

\subsection{CODES, STANDARDS, AND REGULATIONS}

No codes, standards, or regulations other than those identified in Table 4-3 and determined to be applicable were used in this analysis. 


\section{ASSUMPTIONS}

\subsection{MASS LOADING - CROPS}

The distribution of mass loading in fields where crops are growing is assumed to be similar to or higher than that in the inactive outdoor environment, with a minimum value equal to the minimum value of the inactive outdoor environment, and a modal and maximum value twice that of the inactive outdoor environment.

This assumption is used in Sections 6.2.5 and 6.3.5 to develop distributions of mass loading for crops for nominal and postvolcanic conditions.

Dust concentrations during the latter part of the growing season, rather than the entire season, must be considered for development of the mass loading distribution for crops, because dust deposited on the surface of plants quickly falls off, washes off, or is otherwise removed relatively rapidly (Till and Meyer 1983 [DIRS 101895], pp. 5-36 and 5-37; IAEA 2001 [DIRS 158519], p. 64), and because harvested foodstuffs and forage are not present early in the season. Therefore, planting, plowing, weeding, berming, and other soil-disturbing activities that occur early in growing seasons will have little influence on uptake of radionuclides into foodstuffs via dust deposition. Few soil-disturbing activities except harvesting usually occur during the latter part of growing seasons, especially for plants such as alfalfa, wheat, orchard crops, and garden vegetables commonly grown in Amargosa Valley and eastern Washington (the analogue site for consideration of the wettest and coolest future climatic conditions; BSC 2004 [DIRS 170002], Table 6-1). The increase in mass loading during harvesting will occur over a very short period relative to the remainder of the period for which radionuclide concentrations on plant surfaces are considered and much of the dust deposited during harvesting may be removed during field processing of crops. Because fields and gardens are infrequently disturbed and frequently irrigated during the latter part of the growing season, there should be few sources of resuspended particles in the immediate vicinity of plants and mass loading therefore will be influenced most by particle resuspension in the region surrounding the fields and gardens.

The mass loading distribution for the nominal, inactive outdoor environment was developed from measurements of airborne particulate concentrations at stationary monitors in rural, agricultural communities with less than 20 in. of rainfall in the western United States (Section 6.2.2). Those measurements were influenced by resuspended dust from agricultural fields and agricultural activities in the general vicinity of monitoring stations, but not necessarily at the station locations. Therefore, they are consistent with the climatic and rural, agricultural conditions in the Yucca Mountain region and generally match the conditions required to estimate mass loading concentrations for crops. See Section 6.2.2 for additional information on the consistency of these data with conditions in the Yucca Mountain region.

It is possible that mass loading concentrations in some fields are higher than measurements from stationary, community monitors. Crops may be located closer to sources of resuspended particles (e.g., dirt roads, recently plowed fields) than community monitors, and some increase in airborne particle concentrations will occur during harvesting. Also, stationary monitors usually are located about $1.5 \mathrm{~m}$ above the ground surface, and therefore do not measure airborne 
particulate concentrations where most plants grow. Mass loading near the ground surface is expected to be higher than at $1.5 \mathrm{~m}$ because it takes less force (i.e., less wind) to resuspend a particle a short distance off the ground.

To account for uncertainty in these differences between the environment around crops and the locations where community monitors are located, it is assumed that the modal and maximum values of the distribution of mass loading for crops are twice that of the distribution for the inactive outdoor environment. A higher multiplier was not chosen for the following reasons. There are few soil-disturbing activities, other than harvesting, that would occur late in the growing season. In addition, the crops commonly grown in Amargosa Valley, such as alfalfa and other hay, cover much of the soil surface when mature, and are irrigated regularly. The presence of vegetative cover and moist soil reduces soil resuspension. Also, mass loading rapidly returns to background levels after soil-disturbing activities cease (Pinnick et al. 1985 [DIRS 159577], p. 104) and the influence of soil-disturbing activities on mass loading generally is limited to less than $0.75 \mathrm{~km}$ (Chow et al. 1999 [DIRS 145212], p. 652). Thus, for most of the time, there will be few or no soil-disturbing activities or sources of readily resuspendable soil that would cause an increase in mass loading near crops greater than that measured at community monitoring sites.

The minimum value of the distribution of mass loading for crops is assumed to be equal to the minimum value of the inactive outdoor environment, primarily because it is likely that some crops are located in situations very similar to community monitors. Therefore, concentrations measured by those monitors (and used to estimate mass loading in the inactive outdoor environment) will be similar to concentrations for those crops. In addition, some crops such as alfalfa cover almost the entire ground surface; therefore, there would be very little wind erosion in the immediate vicinity of the plants before harvesting.

\subsection{POSTVOLCANIC INDOOR CONCENTRATIONS}

It is assumed that changes in outdoor concentrations of mass loading following a volcanic eruption have a proportional affect on mass loading in indoor environments.

This assumption is used in Section 6.3.3 and 6.3.4 to develop distributions of mass loading in the active indoor and asleep indoor environments for the first year following a volcanic eruption.

This assumption is based on published comparisons of indoor and outdoor concentrations of particulate matter. The studies reviewed were selected as described in Section 4.1.1, and are the same as those described in Section 6.2.3 to evaluate concentrations in the active indoor environments. See Section 6.2.3 for a description of the studies.

Eleven of the 17 studies reviewed in Section 6.2.3 included correlation and some regression coefficients of indoor and outdoor concentrations (Table 5-1). Those coefficients ranged from 0.08 to 0.96 , and most were between 0.25 and 0.75 . Five of seven studies that included statistical tests of correlation coefficients reported that the correlations were significant. Outdoor concentrations were relatively low in the two studies that reported no significant correlation (Leaderer et al. 1999 [DIRS 160403], Table 2; Rojas-Bracho et al. 2000 [DIRS 159678], Table 2). Factors such as amount of smoking, cooking, and personal activity were listed in many 
studies as explanations why correlations between indoor and outdoor concentrations were relatively low.

Seven studies reported the slope of the regression between indoor or personal and outdoor concentrations (Table 5-1). Eight of 10 slopes reported were between 0.39 and 0.55 , indicating that in those studies, an increase in outdoor concentrations resulted in an increase of about half that amount in indoor concentrations. The only study reporting a slope greater than 1 (Quackenboss et al. 1989 [DIRS 159682]) included a substantial number of smokers. It is expected that concentrations inside the homes of smokers would be high relative to outdoor concentrations because smoking generates a large concentration of particles.

In summary, the results of these studies indicate that an increase in outdoor concentrations usually will result in an increase in indoor concentrations, although the magnitude of changes indoors likely will be less than those outdoors, and that other factors, such as the amount of smoking, cooking and other indoor activities also influence the relationship between indoor and outdoor concentrations.

There is some uncertainty in applying the results of these studies to postvolcanic conditions that may occur near Yucca Mountain. It is predicted that modal TSP concentrations in the inactive outdoor environment would double from $0.060 \mathrm{mg} / \mathrm{m}^{3}$ to $0.120 \mathrm{mg} / \mathrm{m}^{3}$ the first year after a volcanic eruption (Section 6.3.2). Few of the studies listed in Table 5-1 were conducted when outdoor concentrations were that high, and none were conducted during a period when concentrations remained high for long. It is possible that a large increase in TSP outdoors, or high concentrations outdoors for most of the year, would result in a larger change in indoor TSP than indicated by the regression slopes listed in Table 5-1. For example, air-filtering systems could become overwhelmed or larger amounts of dust could be tracked indoors, resulting in higher concentrations indoors. It contrast, people may dust and vacuum more often or keep their windows closed to reduce dust concentrations. To account for this uncertainty, and ensure that indoor concentrations following a volcanic eruption are not underestimated, it is assumed that indoor concentrations will increase proportionally to outdoor concentrations. 
Table 5-1. Correlation Coefficients $(R)$ of Indoor and Personal Versus Outdoor Concentrations of Airborne Particles

\begin{tabular}{|c|c|c|c|c|}
\hline Reference & $\boldsymbol{R}$ & $P^{a}$ & Slope $^{b}$ & Comparison $^{c}$ \\
\hline \multirow{4}{*}{$\begin{array}{l}\text { Clayton et al. } 1993 \text { [DIRS 159599], } \\
\text { Table } 3\end{array}$} & 0.35 & - & - & Personal: Ambient $\mathrm{PM}_{10}$, day \\
\hline & 0.62 & - & - & Personal: Ambient $\mathrm{PM}_{10}$, night \\
\hline & 0.46 & - & - & Indoor: Ambient $\mathrm{PM}_{2.5}$, day \\
\hline & 0.65 & - & - & Indoor: Ambient $\mathrm{PM}_{2.5}$, night \\
\hline Lioy et al. 1990 [DIRS 159655], p. 62 & 0.67 & $<0.01$ & 0.50 & Indoor: Ambient $\mathrm{PM}_{10}$ \\
\hline $\begin{array}{l}\text { Quackenboss et al. } 1989 \text { [DIRS } \\
\text { 159682], Figure } 2\end{array}$ & 0.42 & - & 1.14 & $\begin{array}{l}\text { Indoor: Ambient } \mathrm{PM}_{10} \text {, includes } \\
\text { smokers }\end{array}$ \\
\hline \multirow{4}{*}{$\begin{array}{l}\text { Leaderer et al. } 1999 \text { [DIRS 160403], } \\
\text { Table 2, Figure } 2\end{array}$} & 0.29 & $>0.10$ & - & Indoor: Outdoor $\mathrm{PM}_{10}$ \\
\hline & 0.11 & $>0.10$ & - & Indoor: Ambient $\mathrm{PM}_{10}$ \\
\hline & 0.53 & $<0.01$ & 0.43 & Indoor: Outdoor $\mathrm{PM}_{2.5}$ \\
\hline & 0.08 & $>0.10$ & - & Indoor: Ambient $\mathrm{PM}_{2.5}$ \\
\hline \multirow{2}{*}{$\begin{array}{l}\text { Long et al. } 2000 \text { [DIRS 159681], } \\
\text { Figure } 7\end{array}$} & 0.20 & $<0.001$ & - & Indoor: Outdoor $\mathrm{PM}_{2.5-10}$, day \\
\hline & 0.65 & $<0.001$ & - & Indoor: Outdoor $\mathrm{PM}_{2.5-10}$, night \\
\hline \multirow{4}{*}{$\begin{array}{l}\text { Pellizzari et al. } 1999 \text { [DIRS 159702], } \\
\text { Figure } 3\end{array}$} & 0.23 & $<0.01$ & - & Personal: Outdoor $\mathrm{PM}_{2.5}$ \\
\hline & 0.19 & $<0.01$ & - & Personal: Ambient $\mathrm{PM}_{2.5}$ \\
\hline & 0.33 & $<0.01$ & - & Indoor: Outdoor $\mathrm{PM}_{2.5}$ \\
\hline & 0.21 & $<0.01$ & - & Indoor: Ambient $\mathrm{PM}_{2.5}$ \\
\hline \multirow{2}{*}{$\begin{array}{l}\text { Janssen et al. } 1998 \text { [DIRS 159699], } \\
\text { Table } 3\end{array}$} & 0.71 & $<0.01$ & 0.55 & Personal: Ambient $\mathrm{PM}_{10}$ \\
\hline & 0.75 & $<0.01$ & 0.47 & Indoor: Outdoor $\mathrm{PM}_{10}$ \\
\hline \multirow{2}{*}{$\begin{array}{l}\text { Evans et al. } 2000 \text { [DIRS 159679], } \\
\text { Table } 10\end{array}$} & 0.75 & - & - & Indoor: Outdoor $\mathrm{PM}_{10}$ \\
\hline & 0.67 & - & - & Indoor: Ambient $\mathrm{PM}_{10}$ \\
\hline \multirow{2}{*}{$\begin{array}{l}\text { Williams et al. } 2000 \text { [DIRS 159735], } \\
\text { Table } 9\end{array}$} & 0.96 & $<0.001$ & 0.39 & Apartment: Outdoor $\mathrm{PM}_{2.5}$ \\
\hline & 0.96 & $<0.001$ & 0.40 & Apartment: Ambient $\mathrm{PM}_{2.5}$ \\
\hline \multirow{2}{*}{$\begin{array}{l}\text { Linn et al. } 1999 \text { [DIRS 159602], Table } \\
3 \text { and p. } 112\end{array}$} & 0.66 & - & 0.87 & Personal: Outdoor $\mathrm{PM}_{10}$ \\
\hline & 0.54 & - & 0.22 & Indoor: Ambient $\mathrm{PM}_{10}$ \\
\hline $\begin{array}{l}\text { Rojas-Bracho et al. } 2000 \text { [DIRS } \\
\text { 159678], Table } 5\end{array}$ & 0.41 & $>0.05$ & 0.43 & Personal: Ambient $\mathrm{PM}_{10}$ \\
\hline
\end{tabular}

$\mathrm{PM}_{2.5}=$ particles with an aerodynamic diameter $\leq 2.5 \mu \mathrm{m} ; \mathrm{PM}_{10}=$ particles with an aerodynamic diameter $\leq 10 \mu \mathrm{m}$, dash indicates no data reported. 


\section{SCIENTIFIC ANALYSIS DISCUSSION}

This section describes the development of mass loading parameters for the biosphere model. Section 6.1 contains general considerations about how mass loading distributions are used in the biosphere model to calculate radionuclide concentrations in air, the description of methods used to develop mass loading parameters, as well as evaluations of the influence of measurement conditions on the mass loading values. These evaluations provide supporting information to meet the objective of this report and are not used in Sections 6.2 to 6.4 to develop the results (i.e., mass loading parameter distributions) or conclusions of this report. These additional analyses were performed to respond to the concerns expressed in Integrated Issue Resolution Status Report (NRC 2005 [DIRS 175566], Section 5.1.3.13) regarding sensitivity of the mass loading values to the environmental (natural and anthropogenic) variables. Sections 6.2 to 6.4 describe development of the mass loading parameters for the biosphere groundwater scenario (Section 6.2) and the volcanic ash scenario (Section 6.3). Use of the mass loading time function and decrease rate constant, and development of that parameter, is described in Section 6.4.

\subsection{GENERAL CONSIDERATIONS}

\subsubsection{Use of Atmospheric Mass Loading in the Biosphere Model}

Atmospheric mass loading is used in the biosphere model to calculate radionuclide concentration in air in the receptor environments and around crops. Mass loading for the receptor environments is then used in the inhalation submodel to estimate inhalation exposure of the receptor from resuspended contaminated soil. The mass loading for crops is used in the plant uptake submodel to estimate the deposition of resuspended soil on crop surfaces.

To account for variation and uncertainty in the characteristics of the RMEI and concentrations of radionuclides in air throughout the reference biosphere, the biosphere model used a microenvironmental modeling approach to calculate inhalation exposure (this method was also used to calculate external exposure). The total modeled exposure environment (i.e., the reference biosphere) was divided into segments, or environments (described below), that would have different levels of inhalation or external exposure. Radionuclide concentrations in air, time spent in each environment, and intake rates or exposure factors (e.g., breathing rates and shielding factors) were determined for each environment, and total airborne exposure was calculated as the sum of exposure in all environments (BSC 2004 [DIRS 169460], Section 6.4.8). Using this method, estimates of mass loading could be clearly associated with the types of surface-disturbing activities expected at the location of the RMEI, and consideration of the expected duration of those activities could be incorporated into estimates of exposure times (BSC 2005 [DIRS 172827], Section 6.3.2).

Five environments associated with different human activities were considered in the biosphere model. These mutually exclusive environments represented behavioral and environmental combinations under which the RMEI could receive a substantially different rate of exposure via inhalation or external exposure (BSC 2005 [DIRS 172827], Section 6.2). 
1. Active Outdoors - This environment is representative of conditions that occur when a person is outdoors in the contaminated environment conducting dust-generating activities. It encompassed potentially contaminated locations outdoors where the RMEI would conduct activities that would resuspend soil, including dust-generating activities while working (e.g., plowing, excavating, livestock operations), driving on unpaved roads, and performing other outdoor recreational activities (e.g., gardening, landscaping, riding horses, riding motorbikes, and walking on uncompacted soil). Because dust concentrations decrease rapidly after dust-disturbing activities cease (Pinnick et al. 1985 [DIRS 159577], pp. 103 and 104), this category is limited to conditions during and shortly after dust-generating activities.

2. Inactive Outdoors - This environment included outdoor locations within potentially contaminated areas where the RMEI is not conducting soil-disturbing activities. In this environment, the RMEI would spend time outdoors engaged in activities that would not resuspend soil (e.g., sitting, swimming, walking on turf or compacted/covered surfaces, driving on paved roads, barbecuing, and equipment maintenance) in areas where radionuclides may be present. This environment also included time spent commuting within the contaminated area because the major roads in Amargosa Valley are paved.

3. Active Indoors - This environment included locations indoors in areas that may contain radionuclides where the RMEI would spend time active, including working. This environment is representative of conditions indoors within the contaminated area when people are at home or at a place of business, including conditions when they are sedentary or active.

4. Asleep (Inactive) Indoors - This environment included locations where the RMEI would spend time sleeping indoors in areas that may contain radionuclides.

5. Away from Potentially Contaminated Area-This environment encompassed locations that would not contain radionuclides released from the repository, including commuting routes to work as well as work and other locations outside of contaminated areas. No mass loading estimate was required for this environment.

The radionuclide concentrations in air that are used to estimate inhalation doses for the groundwater exposure scenario are calculated in the biosphere model for each of the above environments, except the last one, using the following equation (BSC 2004 [DIRS 169460], Section 6.4.2):

$$
C a_{h, i, n}=f_{\text {enhance }, n} C s_{m, i} S_{n}
$$

where:

$C a_{h, i, n}=$ Activity concentration of radionuclide $i$ in air from soil resuspension for the assessment of human inhalation exposure $(h)$ in environment $n\left(\mathrm{~Bq} / \mathrm{m}^{3}\right)$ 


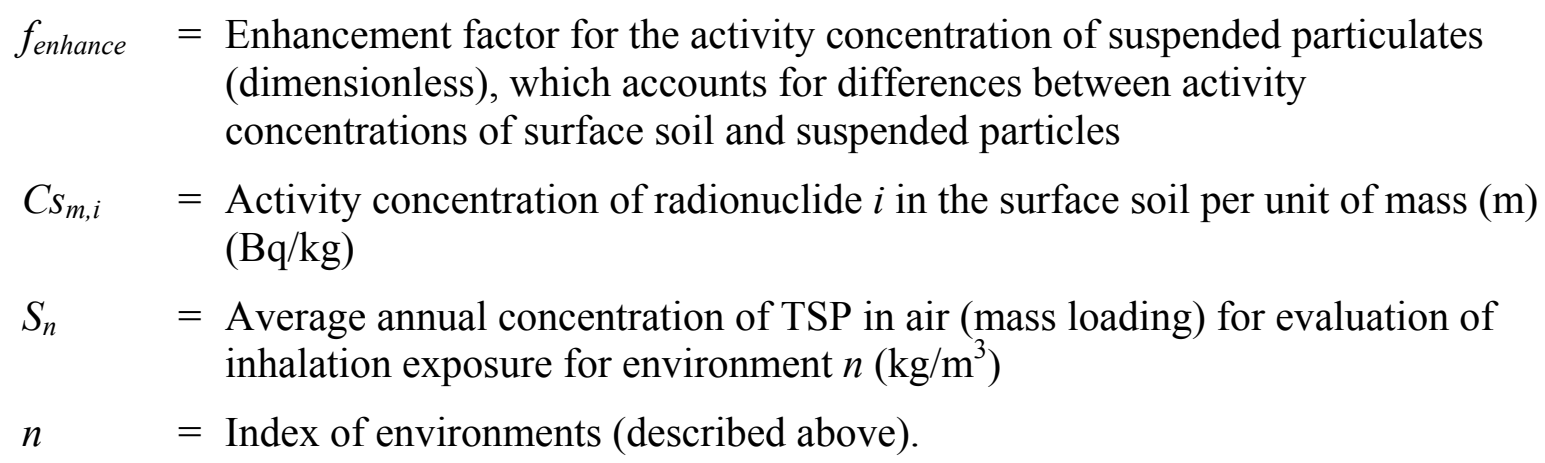

The activity concentration is then combined in the inhalation submodel with environment-specific breathing rate, time spent in each environment by the receptor, and radionuclide-specific dose coefficient to calculate an annual dose from inhalation exposure. Therefore, an increase in mass loading in a given environment results in a proportional increase in the activity concentrations of radionuclides in the air, which results in an increase in the inhalation dose for that environment. The equation used for the volcanic ash scenario is the same except that $S_{n}$ is calculated as a function of time (BSC 2004 [DIRS 169460], Section 6.5.2), as described in Section 6.3.

The equation used to calculate radionuclide concentrations in air from which resuspended particles are intercepted by crops is similar to that used for human inhalation (Equation 6-1), but does not include an enhancement factor and only considers one environment (i.e., immediately around the crops) (BSC 2004 [DIRS 169460], Section 6.4.2). Radionuclide concentrations are combined in the plant submodel of the biosphere model with the deposition velocity of airborne particulates, radionuclide concentrations in soil, crop yield, and other variables to estimate the concentration of radionuclides in the edible portion of crops resulting from foliar interception of particles (BSC 2004 [DIRS 169460], Sections 6.4.2 and 6.5.2). In contrast to receptor environments (for which mass loading following a volcanic eruption is treated as a function of time), radionuclide concentrations in the environment surrounding crops are not treated as a function of time for either exposure scenario.

\subsubsection{Parameter Development Methods}

The rule at 10 CFR 63.311 [DIRS 173273] expresses the dose limit for the individual protection standard as an annual limit and the biosphere model therefore calculates BDCFs as the annual dose to the RMEI per unit concentration of radionuclides in groundwater and volcanic ash. For each realization of the biosphere model, one value of each stochastically sampled parameter is selected and used to calculate a BDCF per radionuclide. These BDCFs are then used in individual TSPA realizations to calculate a predicted annual dose. Therefore, each stochastically sampled value used in the biosphere model must be representative of average annual conditions.

To correctly calculate the annual inhalation dose, distributions of mass loading per environment developed in this analysis must be representative of average annual concentrations of resuspended particles while the RMEI would be in the environment. In this respect, distributions represent an uncertainty in the estimate of the annual average mass loading for the environment 
and do not include infrequent or unusually high or low concentrations, which could occur over short periods because such concentrations are episodic at unpredictable times and amounts.

In general, mass loading distributions were developed based on concentrations of resuspended particles measured in environments in which the relevant conditions were consistent with present knowledge of conditions in the region surrounding Yucca Mountain. Alternatively, mass loading distributions could have been developed using a soil resuspension model (Anspaugh et al. 1975 [DIRS 151548]). However, such models are typically used for early times following deposition of radioactive contaminants on the ground. For longer time frames, a mass-loading approach is usually used, although to evaluate inhalation dose it is preferred to rely on actual measurements of radionuclide concentration in air, if such measurements are available. The mass loading approach was used in this analysis due to the availability of mass loading data for the rural agricultural setting. Resuspension models were examined to select the shape of the mass load decay function for the volcanic eruption parameters. Resuspension models were not used to calculate mass loading values because available models require numerous site- and situation-specific parameter values that are not available and the accuracy of the models is not well understood (Garger et al. 1997 [DIRS 124902]).

Triangular distributions were selected for all parameters in this analysis for the following reasons.

- Although distributions of dust concentrations for single activities or locations generally are lognormal (Morandi et al. 1988 [DIRS 159866], Section 3.2; Nieuwenhuijsen and Schenker 1998 [DIRS 150854], p. 10; Nieuwenhuijsen et al. 1999 [DIRS 150711], p. 37), little information is available about the shape of mass loading distributions that are representative of annual average exposure for a large group of activities such as those typically conducted in the environments used in the biosphere model.

- Distributions for most environments were developed by examining all available, applicable measurements of mass loading taken in an environment. Because the measurements considered for an environment were not all equally applicable to the conditions in the reference biosphere, they could not be used to calculate averages and SDs for lognormal or normal distributions. There was, however, sufficient information to make informed judgments and select central tendencies and bounds for use in defining triangular distributions.

- Uniform distributions were not used because those distributions convey less information than triangular distributions and because the minimum and maximum values of the distributions were selected to be reasonable bounds that have a low probability of occurrence.

- Some distributions were developed based on changes in bounds or the central tendency relative to other environments (e.g., the upper bound of mass loading for crops is twice that for the inactive outdoor environment; see Section 5.1). Moving one bound of a distribution without affecting the central tendency (i.e., mode or average) or other bound is possible for triangular and uniform distributions but is not possible for many other distributions (e.g., lognormal or normal). 
Because dust concentrations for single activities generally are lognormal, geometric mean values of airborne particle concentrations presented in publications are reported in this analysis if available; otherwise, arithmetic mean values are reported.

\subsubsection{Influence of Meteorological Conditions on Mass Loading}

Airborne mass loads for a given location depend on a variety of local-scale meteorological conditions. One variable that may influence mass loading is the amount of precipitation a site receives because the soil moisture content influences the availability of fine-grained material for resuspension, promotes or impedes the vegetative cover development, and also influences other processes occurring at the soil surface, such as particle cementation. An analysis was conducted to investigate the influence of annual precipitation on the mass loading (Section 6.1.3.1). Based on this analysis, it was concluded that, statistically, there was little difference between the annual average mass loading at the sites with less than $10 \mathrm{in}$. precipitation and the sites having 10 to 20 in. precipitation, and that developing separate mass loading distributions for the present-day and the predicted future climate states was not warranted.

A concern was raised by the Nuclear Regulatory Commission (NRC) staff (NRC 2005 [DIRS 175566], Section 5.1.3.13; Reamer 2004 [DIRS 176773]) about using mass loading data from sites with precipitation greater than 5 in. as analogues for present-day conditions (annual precipitation of about 4 to 7 in. (DOE 2005 [DIRS 176996], Section 3.6)). To address this concern an additional analysis was conducted (Section 6.1.3.2) that investigated in more detail, and for a larger data set, the dependence of annual average concentration of TSP measured at rural, agricultural sites in the western United States on the amount of precipitation these sites receive annually.

\subsubsection{Consideration of Climate in the Development of Mass Loading for the Biosphere Model}

A supplementary analysis was conducted using data from the air quality monitoring sites, which were selected and used in Section 6.2.2 to develop the mass loading distribution in the inactive outdoor environment. The objective of this analysis was to determine the effect of precipitation on mass loading for sites with annual precipitation of less than 20 in. and whether separate distributions of mass loading should be used for the present-day and future climatic conditions predicted to occur in the Yucca Mountain region over the next 10,000 years.

Average annual precipitation at Yucca Mountain currently is approximately 4 to 7 in. (data for Site 9, DOE 2005 [DIRS 176996], Section 3.6) and snowfall is rare. It is predicted that the coolest, wettest conditions during the next 10,000 years will be consistent with that currently found in parts of eastern Washington. Analogue weather stations for the coolest, wettest conditions are Spokane (average annual precipitation $=16.2 \mathrm{in}$., average annual snowfall $=42.1$ in.), Rosalia (precipitation $=18.1$ in., snowfall $=24.3$ in.), and St. Johns (precipitation $=17.1$ in., snowfall $=25.8$ in.) $($ BSC 2004 [DIRS 170002], Table 6-1). Climate data are from NCDC reports (NCDC 1998 [DIRS 135900]; NCDC 1998 [DIRS 125325]).

In this analysis, average annual concentrations of TSP measured at rural, agricultural sites in the western United States were compared among sites with different amounts of precipitation and 
snowfall. The data used in this comparison were obtained from the EPA AirData database (DTN: MO0210SPATSP01.023 [DIRS 160426]) and from the NCDC (NCDC 1988 [DIRS 135900; NCDC 1998 [DIRS 125325]) and are listed in Tables B-1 and B-2. See Section 6.2.2 and Appendix B for a description of how the data were obtained and processed. See Table B-1 for a description of each site. Because the sites have comparable land uses and settings, sources of resuspended particulate matter should be similar among sites.

To evaluate the influence of precipitation on concentrations of resuspended particles, the average TSP for sites with less than 10, 10 to 20, and more than $20 \mathrm{in}$. of precipitation per year was calculated (Table 6-1). For this comparison, 25 duplicate sites within a county and 2 sites with conditions that may not be typical for rural agricultural settings were deleted from consideration (see Section 6.2.2). To evaluate the influence of snowfall, the average TSP for sites with less than 10, 10 to 20, and more than 20 in. of snowfall per year was calculated (Table 6-2). To eliminate the influence of high precipitation, the 10 sites listed in Table 6-1 that have more than $20 \mathrm{in}$. of precipitation were not included in this analysis of the effects of snowfall.

Average TSP concentrations differed little between 11 sites with less than $10 \mathrm{in}$. of precipitation (average $=0.055, \mathrm{SD}=0.020$ ) and 21 sites with 10 to $20 \mathrm{in}$. (average $=0.056, \mathrm{SD}=0.023$ ). Ten sites with more than $20 \mathrm{in}$. of precipitation per year had much lower concentrations (average $=0.037, \mathrm{SD}=0.009$ ), also consistent with the conclusions reached in Section 6.1.3.1. There was little difference in TSP concentrations among 14 sites with less than $10 \mathrm{in}$. of snowfall (average $=0.058, \mathrm{SD}=0.020$ ), 7 sites with 10 to 20 in. of snowfall (average $=0.055, \mathrm{SD}=0.019$ ), and 11 sites with more than 20 in. of snowfall (average $=0.053, \mathrm{SD}=0.026$ ).

The conclusion of this analysis is that rural agricultural sites with less than 20 in. of precipitation and less than approximately 45 in. of snowfall have similar concentrations of resuspended particles. Therefore, separate distributions of mass loading are not required for present-day and future climatic states predicted to occur in the Yucca Mountain region during the next 10,000 years. 


\begin{tabular}{|c|c|c|c|c|c|c|c|c|c|c|c|}
\hline \multicolumn{4}{|c|}{$<10$ in. Precipitation } & \multicolumn{4}{|c|}{10 to 20 in. Precipitation } & \multicolumn{4}{|c|}{$>20$ in. Precipitation } \\
\hline $\begin{array}{l}\text { EPA Site ID and } \\
\text { State } \\
\end{array}$ & Snow & Precip & TSP & $\begin{array}{l}\text { EPA Site ID and } \\
\text { State } \\
\end{array}$ & Snow & Precip & TSP & $\begin{array}{l}\text { EPA Site ID and } \\
\text { State } \\
\end{array}$ & Snow & Precip & TSP \\
\hline 06-071-1101, CA & 1.0 & 4.1 & 0.049 & 53-071-1001, WA & 7.7 & 10.1 & 0.066 & 06-111-0005, CA & 0.1 & 21.2 & 0.038 \\
\hline 32-003-1003, NV & 0.4 & 4.1 & 0.061 & 16-053-0001, ID & 23.2 & 10.3 & 0.047 & 53-075-0002, WA & 28.3 & 21.5 & 0.038 \\
\hline 06-027-0002, CA & 8.0 & 5.3 & 0.025 & 35-061-0007, NM & 14.8 & 10.8 & 0.071 & 16-029-0002, ID & 95.0 & 22.1 & 0.038 \\
\hline 06-031-1002, CA & 0.1 & 7.2 & 0.086 & 16-083-1001, ID & 28.2 & 10.8 & 0.045 & 06-089-1002, CA & 50.6 & 27.5 & 0.034 \\
\hline 49-015-0002, UT & 17.8 & 7.7 & 0.030 & 16-011-0001, ID & 22.4 & 11.4 & 0.049 & 06-033-0002, CA & 0.5 & 29.1 & 0.034 \\
\hline 49-027-0002, UT & 25.2 & 7.8 & 0.041 & 16-005-1003, ID & 41.8 & 11.8 & 0.068 & 06-033-0003, CA & 0.5 & 29.1 & 0.019 \\
\hline 32-031-1004, NV & 6.9 & 8.1 & 0.054 & 16-077-0005, ID & 41.8 & 11.8 & 0.118 & 06-061-0001, CA & 1.2 & 35.3 & 0.040 \\
\hline 35-045-0014, NM & 11.5 & 8.1 & 0.044 & 16-001-0001, ID & 20.9 & 11.9 & 0.044 & 06-115-0002, CA & 10.2 & 53.2 & 0.027 \\
\hline & & & & 04-019-0010, AZ & 0.0 & 13.9 & 0.089 & & & & \\
\hline & & & & 06-111-3001, CA & 0.1 & 14.4 & 0.064 & & & & \\
\hline & & & & 06-083-1012, CA & 0.0 & 14.6 & 0.043 & & & & \\
\hline & & & & 35-017-0002, NM & 10.0 & 15.8 & 0.085 & & & & \\
\hline & & & & 16-029-0001, ID & 43.8 & 16.1 & 0.070 & & & & \\
\hline & & & & 06-113-4001, CA & 0.1 & 18.6 & 0.044 & & & & \\
\hline & & & & 04-007-1902, AZ & 2.9 & 19.3 & 0.030 & & & & \\
\hline & & & & & & $N=$ & 21 & & & & \\
\hline & & & & & & Mean $=$ & 0.056 & & & & \\
\hline & & & & & & $S D=$ & 0.023 & & & & \\
\hline
\end{tabular}

Source: DTN: MO0210SPATSP01.023 [DIRS 160426]; NCDC 1998 [DIRS 135900]; NCDC 1998 [DIRS 125325]. See Table B-2 for list of data. 
Table 6-2. Average Annual Snowfall (in.), Precipitation (in.), and TSP $\left(\mathrm{mg} / \mathrm{m}^{3}\right)$ at Rural, Agricultural Sites in the Western United States with Less Than 10, 10 to 20, and More Than 20 in. of Snowfall

\begin{tabular}{|c|c|c|c|c|c|c|c|c|c|c|c|}
\hline \multicolumn{4}{|c|}{$<10$ in. Snowfall } & \multicolumn{4}{|c|}{10 to 20 in. Snowfall } & \multicolumn{4}{|c|}{$>20$ in. Snowfall } \\
\hline $\begin{array}{c}\text { EPA Site ID and } \\
\text { State }\end{array}$ & Snow & Precip & TSP & $\begin{array}{c}\text { EPA Site ID and } \\
\text { State }\end{array}$ & Snow & Precip & TSP & $\begin{array}{c}\text { EPA Site ID and } \\
\text { State }\end{array}$ & Snow & Precip & TSP \\
\hline 06-013-1002, CA & 0.0 & 12.7 & 0.041 & 35-017-0002, NM & 10.0 & 15.8 & 0.085 & 16-001-0001, ID & 20.9 & 11.9 & 0.044 \\
\hline 04-019-0010, AZ & 0.0 & 13.9 & 0.089 & 35-045-0014, NM & 11.5 & 8.1 & 0.044 & 16-011-0001, ID & 22.4 & 11.4 & 0.049 \\
\hline 06-083-1012, CA & 0.0 & 14.6 & 0.043 & 53-077-0003, WA & 11.5 & 7.0 & 0.062 & 16-053-0001, ID & 23.2 & 10.3 & 0.047 \\
\hline $06-031-1002, \mathrm{CA}$ & 0.1 & 7.2 & 0.086 & 35-061-0007, NM & 14.8 & 10.8 & 0.071 & 49-027-0002, UT & 25.2 & 7.8 & 0.041 \\
\hline 06-111-3001, CA & 0.1 & 14.4 & 0.064 & 41-059-1001, OR & 17.1 & 12.2 & 0.040 & 16-083-0003, ID & 28.2 & 10.8 & 0.047 \\
\hline 06-113-4001, CA & 0.1 & 18.6 & 0.044 & 49-015-0002, UT & 17.8 & 7.7 & 0.030 & 16-083-0004, ID & 28.2 & 10.8 & 0.038 \\
\hline 06-019-1002, CA & 0.2 & 6.6 & 0.078 & 53-039-0002, WA & 19.8 & 13.7 & 0.056 & 16-083-1001, ID & 28.2 & 10.8 & 0.045 \\
\hline 32-003-1003, NV & 0.4 & 4.1 & 0.061 & & & $N=$ & 7 & 06-049-1001, CA & 32.6 & 13.1 & 0.017 \\
\hline 06-071-1101, CA & 1.0 & 4.1 & 0.049 & & & Mean $=$ & 0.055 & $16-005-1003$, ID & 41.8 & 11.8 & 0.068 \\
\hline 04-007-1902, AZ & 2.9 & 19.3 & 0.030 & & & $\mathrm{SD}=$ & 0.019 & 16-077-0005, ID & 41.8 & 11.8 & 0.118 \\
\hline 35-013-0004, NM & 4.5 & 9.4 & 0.080 & & & & & 16-029-0001, ID & 43.8 & 16.1 & 0.070 \\
\hline 32-031-1004, NV & 6.9 & 8.1 & 0.054 & & & & & & & $N=$ & 11 \\
\hline 53-071-1001, WA & 7.7 & 10.1 & 0.066 & & & & & & & Mean $=$ & 0.053 \\
\hline \multirow[t]{4}{*}{ 06-027-0002, CA } & 8.0 & 5.3 & 0.025 & & & & & & & $\mathrm{SD}=$ & 0.026 \\
\hline & & & 14 & & & & & & & & \\
\hline & & Mean $=$ & 0.058 & & & & & & & & \\
\hline & & $S D=$ & 0.020 & & & & & & & & \\
\hline
\end{tabular}

Source: DTN: MO0210SPATSP01.023 [DIRS 160426]; NCDC 1998 [DIRS 135900]; NCDC 1998 [DIRS 125325]. See Table B-2 for list of data.

EPA=U.S. Environmental Protection Agency; ID=identification; $N=$ number of sites; $S D=$ standard deviation; $T S P=$ average total suspended particulates concentration. 


\subsubsection{Dependence of Mass Loading on Precipitation}

An additional analysis was conducted, using a larger data set, to examine how precipitation may influence mass loading levels. The analysis investigated the dependence of annual average concentration of TSP measured at rural, agricultural sites in the western United States on the amount of precipitation these sites receive annually. For is analysis, the number of sites was expanded, compared with those considered in Section 6.1.3.1 to cover a greater range of annual average precipitation.

The TSP data used in this comparison were obtained from the EPA AirData database (DTN: MO0210SPATSP01.023 [DIRS 160426]). The database was queried for all rural (location code $=3$ ), agricultural (land use code $=4$ ) sites in the following states in the Western US: Arizona, California, Colorado, Idaho, Nevada, New Mexico, Oregon, Texas, Utah, and Washington. These sites represent conditions with a relatively wide range of precipitation. Annual average particulate concentrations in air for each site were averaged for all years having TSP measurements. The data and accompanying analyses described in this section can be found in the Excel file TSP Data_Ag_Rural_Western States.xls (see Appendix C). The analysis used 97 sites compared with 42 sites used in the previous section. Sixty-nine sites in Montana were initially included in the data set. However, due to the relatively narrow range of precipitation for these sites (87 percent of the sites had annual precipitation in the range from 10.6 to 15.0 in.), they were not included in the further calculations because of their limited contribution to the analysis.

Most TSP data included in the database were collected in the 1970s and 1980s. In 1987 the National Ambient Air Quality Standards for particulate matter were revised to use PM $_{10}$, rather than TSP, as the indicator of air quality with respect to particulate matter. Consequently, in the following years, the emphasis in the particulate matter measurements shifted from TSP to the $\mathrm{PM}_{10}$ and $\mathrm{PM}_{2.5}$ fractions, consistent with the current National Ambient Air Quality Standards (40 CFR 50 [DIRS 173380]) that include primary standards for the $\mathrm{PM}_{2.5}$ (set in 1997) and $\mathrm{PM}_{10}$ fractions, but not for the TSP.

The annual average precipitation data for the TSP measurement locations were obtained from the Spatial Climate Analysis Service (SCAS), Oregon State University (OSU) databases (Oregon State University 2006 [DIRS 176346]), which have been developed through projects funded partly by the US Department of Agriculture (USDA) Natural Resources Conservation Service, USDA Forest Service, National Oceanic and Atmospheric Administration (NOAA) Office of Global Programs, and others. The OSU SCAS web site provides access to the highest-quality spatial climate data sets currently available. These data sets were created using the PRISM climate mapping system. PRISM is unique in that it incorporates a spatial climate knowledge base that accounts for rain shadows, temperature inversions, coastal effects, and more in the climate mapping process (Oregon State University 2006 [DIRS 176346]).

The precipitation data for the geographical coordinates of the EPA air quality stations, included in the AirData database (DTN: MO0210SPATSP01.023 [DIRS 160426]), were extracted from the SCAS databases using an on-line OSU Prism Data Explorer tool (Oregon State University 2006 [DIRS 176346]). The precipitation data were extracted for the years from 1971 to 2000, rather than for the longer times of data availability, to better coincide with the TSP 
measurements period of time. Precipitation data for all stations for years 1971 to 2000 were transferred to an Excel file named Precipitation Ag_Rural_Western 1971-2000.xls (see Appendix C). The averages for individual stations were then used in Excel file TSP Data_Ag_Rural_Western States.xls.

Figure 6-1 shows a plot of the annual average TSP concentrations versus annual average precipitation for all 97 rural agricultural sites in the 11 selected states in the Western United States included in the AirData database, for the subset of these sites with precipitation less than 20 in. (arid and semi-arid sites), and a subset with precipitation less than $10 \mathrm{in}$. (arid sites). All plots include a trendline represented by a second-order polynomial equation. The polynomial expression for the trendline had the greatest R-squared value of the trendline options available in Excel.

Although the data presented in Figure 6-1 show a relatively high scatter, a trend can be observed in the plots. For all rural agricultural sites, encompassing a precipitation range from 4.5 in. to 49.8 in., there is a small decrease of TSP as precipitation increases. This trend may be explained by an increase in soil moisture, which reduces the amount of suspended particulates and by more abundant vegetation providing soil cover and preventing soil resuspension. However, the trend is different for a narrower precipitation range encompassing the semi-arid and arid sites with less than 20 in. of precipitation. For these sites there is no distinct decrease of TSP with precipitation. For sites with 10 in. or less of precipitation, the inverse relationship between the TSP and precipitation can no longer be discerned. Although the data for the arid sites are relatively scarce and scattered, one could even argue that in this range the TSP tends to decrease as precipitation decreases. There are a number of possible reasons, of both natural and mad-made origin, that could explain such a trend.

Wind erodes the Earth's surface by removal of loose, fine-grained particles by the turbulent eddy action of the wind, with coarse material, such as gravels and cobbles, left behind. This process is especially prominent in the arid and semi-arid environment because of the limited protection of the soil surface provided by the scarce vegetation and can result in the depletion of fine particles in some areas and deposition in other areas. In addition, various physical processes in the soil move the fine particles down beneath the pebbles and cobbles, so that the coarser fragments stay on top. Because resuspension affects primarily fine-grained particles, surfaces depleted in fine-grained material are not an important source of TSP, especially if the mechanism of resuspension is entrainment by the wind.

As shown in Figure 6-1, the decrease of TSP with an increase in annual precipitation is not very strong. This is because there are a number of competing processes that can either promote or impede soil resuspension for any amount of annual precipitation. For instance, one effect that may increase the TSP at the wetter sites is the effect of drying of the soil surface, from which the suspended particulates originate. Although, in general, an increase in soil moisture content results in lower airborne mass loads, the soil surface dries more rapidly after rainfall events, relative to the bulk of the deeper soil. 


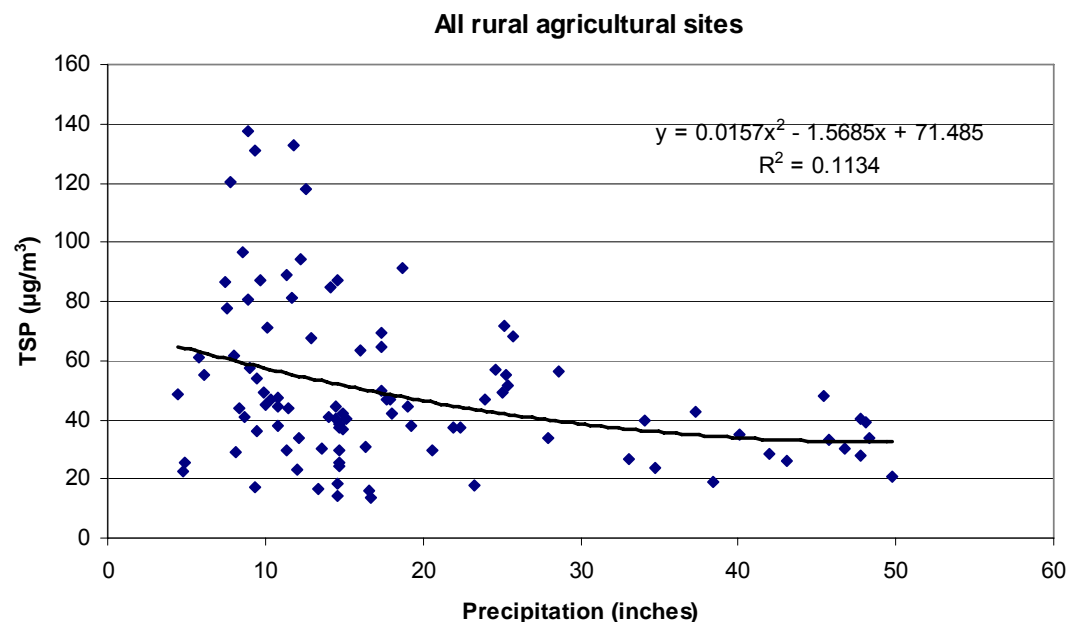

Rural agriculatural sites, precipitation $<20$ inches

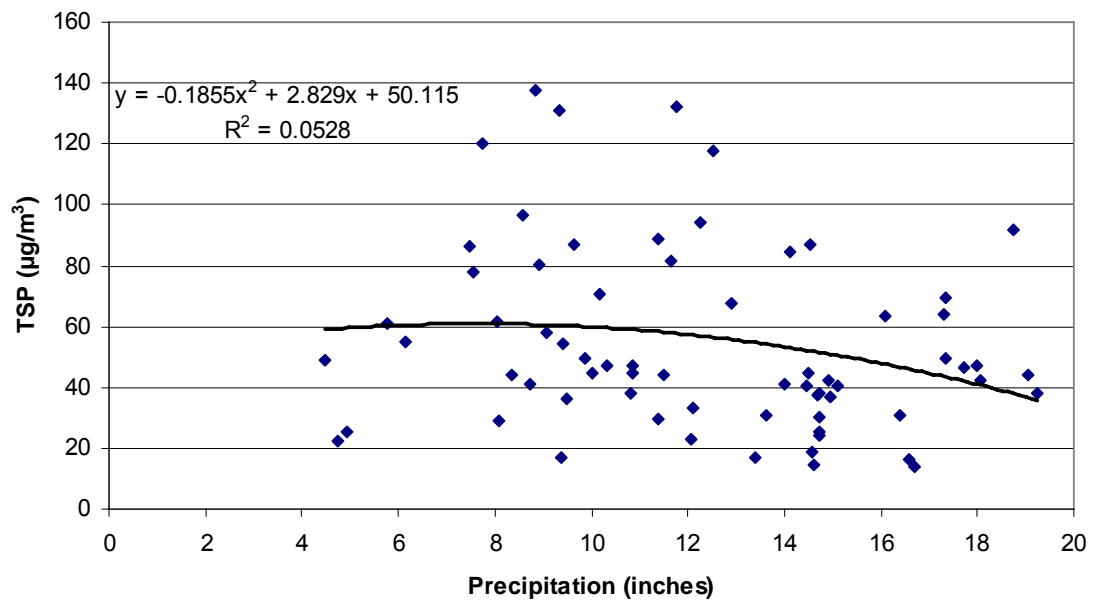

Rural agricultural sites, precipitation $<10$ inches

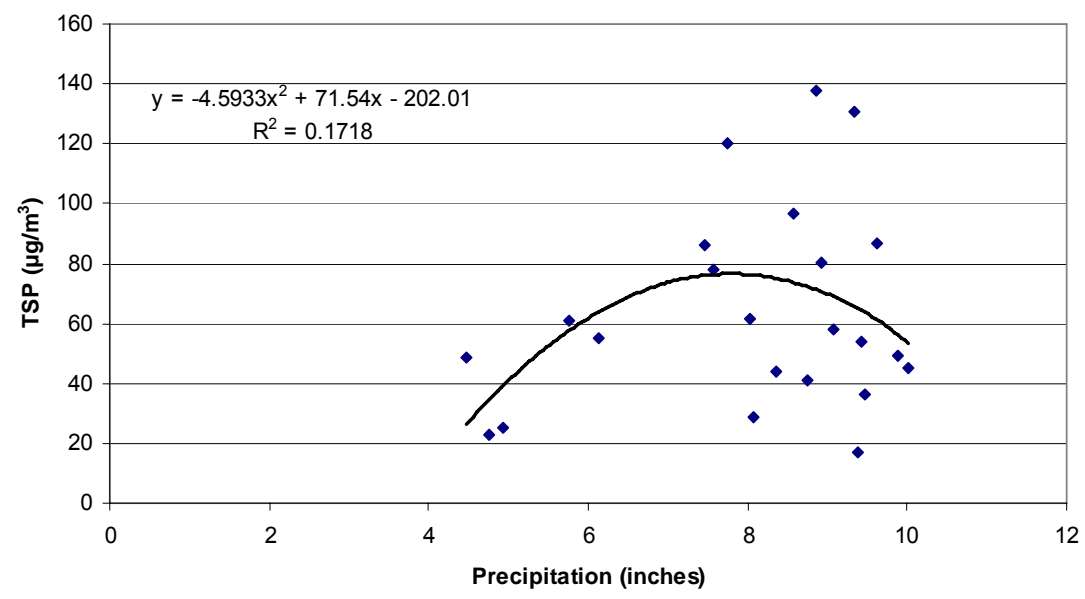

Figure 6-1. Dependence of Annual Average TSP on Annual Average Precipitation in Rural, Agricultural Sites 
Human activities also promote resuspension of particulate matter. The sites included in this analysis were characterized as rural, agricultural. However, the intensity or the scale of agricultural activities is likely to be reduced in the areas that have soils only marginally suitable for farming, such as is the case in Amargosa Valley (CRWMS M\&O 1999 [DIRS 107736], Section 4), and generally in arid climates where availability of water is limited. This may influence the amount of soil resuspended during the agricultural activities that disturb soil surface. Also, if the dust generating activities are conducted on agricultural land, there may be no substantial difference between the dry and wetter climate sites because the soils in the arid climate get irrigated more frequently.

In conclusion, although the analyzed data have a large degree of scatter, they indicate that there is a weak inverse relationship between the TSP and the annual precipitation over a range of precipitation from 5 to $50 \mathrm{in}$. This relationship is not as discernable for arid and semi-arid sites, i.e., for the sites with the annual precipitation of about $20 \mathrm{in.} \mathrm{or} \mathrm{less.} \mathrm{This} \mathrm{more} \mathrm{detailed} \mathrm{analysis}$ confirmed the conclusions of the earlier analysis based on the data from the fewer sites (Section 6.1.3.1) that the TSP at the sites with annual precipitation less than 20 in. does not seem to depend strongly on the amount of precipitation.

\subsubsection{Dependence of Mass Loading on Other Local Meteorological Variables}

The NRC staff also noted that other meteorological variables might have an effect on concentrations of resuspended particulates (Reamer 2004 [DIRS 176773], Enclosure). Local-scale conditions, including wind speed and direction as well as parameters influencing formation of eddies, such as insolation, also play an important role in dust entrainment.

The suspension of soil particles exhibits a threshold with respect to wind velocity; soil particles can become airborne when wind forces exceed soil threshold friction velocities, i.e., the force needed to detach particles from soil surface (Belnap and Gillette 1998 [DIRS 175735], p. 133; Whicker et al. 2002 [DIRS 171050], p. 608). Friction velocities depend on the surface roughness and on local topographic features. Resuspendability of soil particles at a particular location thus depends on wind velocity, particularly on the episodes when the wind velocity exceeds the threshold friction velocity, and on the vegetation or other terrain features that reduce wind velocity near the soil surface and thus increase the threshold friction velocity.

In a study conducted to determine vulnerability of desert soil crusts to wind erosion, it was found that any vehicle or foot traffic over well-developed or previously disturbed crusts drastically decreased the threshold friction velocity, i.e., soil surface resistance to wind erosion in the sandy loam soils tested (Belnap and Gillette 1998 [DIRS 175735], p. 134). The type of soil studied is similar in texture to the soils in Amargosa Valley (see Section 6.1.4). The study demonstrated that soils with well-developed crusts are highly resistant to wind erosion. However, any type of disturbance of the soil surface increased its susceptibility to wind erosion from commonly occurring wind speeds (Belnap and Gillette 1998 [DIRS 175735], p. 140). These findings indicate that the local atmospheric conditions are not always a predictor of soil erosion and thus soil resuspension; soil disturbance is an important factor too.

Local atmospheric conditions such as wind speed can affect turbulent transport and resuspension of soil. However, changes in those conditions will have minimal effect on mass loading values 
used in the biosphere model and on receptor inhalation exposure. The biosphere model uses annual average values of mass loading in the receptor environments to calculate inhalation exposure (Section 6.1.2). Short-term atmospheric conditions, such as episodes of high winds accompanied by increased mass loading, have a small effect on annual averages. In addition, exposure in the active outdoor environment accounts for the majority of inhalation exposure of the RMEI, as indicated in Appendix A and in Biosphere Dose Conversion Factor Importance and Sensitivity Analysis (BSC 2005 [DIRS 173194], Sections 6.2.5.2.1 and 6.3.5.1). In this environment, high mass loading generally persists only as long as the soil is actively disturbed and it quickly decreases when the disturbance ceases (DTN: MO0603UCCF01JS.001 [DIRS 176377]).

Mass loading in the active outdoor environment depends strongly on the type of activities (compare average mass loading among activities listed in Table 6-7), so it is not likely that the effect of atmospheric conditions would be discernable. In the Amargosa Valley setting, the number and size of agricultural and other disturbed sites is small relative to the size of the inhabited area. The majority of agricultural land is planted in alfalfa and other hay, which require infrequent land preparation or other soil disturbances that would resuspend contaminated soil particles (see Section 6.2 for discussion). In addition, the crops provide a ground cover that effectively increases the threshold friction velocity, compared with unvegetated or scarcely vegetated soils, and impedes soil resuspension from agricultural land due to the wind. The undisturbed soils are also resistant to wind-caused resuspension, as was discussed in the study described in the preceding paragraph.

Soil resuspension in the receptor environments will thus depend on human activities that disturb the soil surface. Because the condition of the soil surface plays an important role in this process, soil resuspension in the receptor environments will be dependent on the number and size of agricultural and other disturbed sites in the area. The prevalence of soil-disturbing activities in Amargosa Valley is discussed in Section 6.2.

\subsubsection{Influence of Soil Morphology on Mass Loading}

As discussed in the previous sections, entrainment by wind and overall availability for resuspension of particulates smaller than approximately $100 \mu \mathrm{m}$ from surface deposits depends on many variables, including soil characteristics, such as grain size and mineralogy. Soils containing higher fractions of fine particles, other factors being equal, will have a greater potential for providing resuspendable material.

From the perspective of grain sizes, soils consist of soil separates and rock fragments. Soil separates are mineral particles less than $2.0 \mathrm{~mm}$ in equivalent diameter, ranging between specified size limits (Table 6-3 lists the names and size limits of major categories of soil separates recognized in the United States). Rock fragments are unattached pieces of rock $2 \mathrm{~mm}$ in diameter or larger, also classified depending on their size (Table 6-3). The relative proportions of the various soil separates in a soil, as described by the classes of soil texture, are shown in Figure 6-2. The textural classes may be modified by the addition of suitable adjectives when rock fragments are present in substantial amounts: for example, "stony silt loam." 
Table 6-3. Categorization of Soil Separates and Rock Fragments

\begin{tabular}{|l|l|c|c|}
\hline \multicolumn{1}{|c|}{ Soil Separates } & \multicolumn{2}{c|}{ Rock Fragments } \\
\hline \multicolumn{1}{|c|}{ Size Class } & Particle Diameter $(\mathbf{m m})$ & Size Class & Particle Diameter (mm) \\
\hline Very coarse sand & 2.0 to 1.0 & Pebbles (gravel) & 2 to 75 \\
\hline Coarse sand & 1.0 to 0.5 & Fine & 2 to 5 \\
\hline Medium sand & 0.5 to 0.25 & Medium & 5 to 20 \\
\hline Fine sand & 0.25 to 0.10 & Coarse & 20 to 75 \\
\hline Very fine sand & 0.10 to 0.05 & Stones & 75 to 250 \\
\hline Silt & 0.05 to 0.002 & Boulders & 250 to 600 \\
\hline Clay & Less than 0.002 & More than 600 \\
\hline
\end{tabular}

Source: Soil Survey Manual (USDA 1993 [DIRS 160546], pp. 136 and 143).

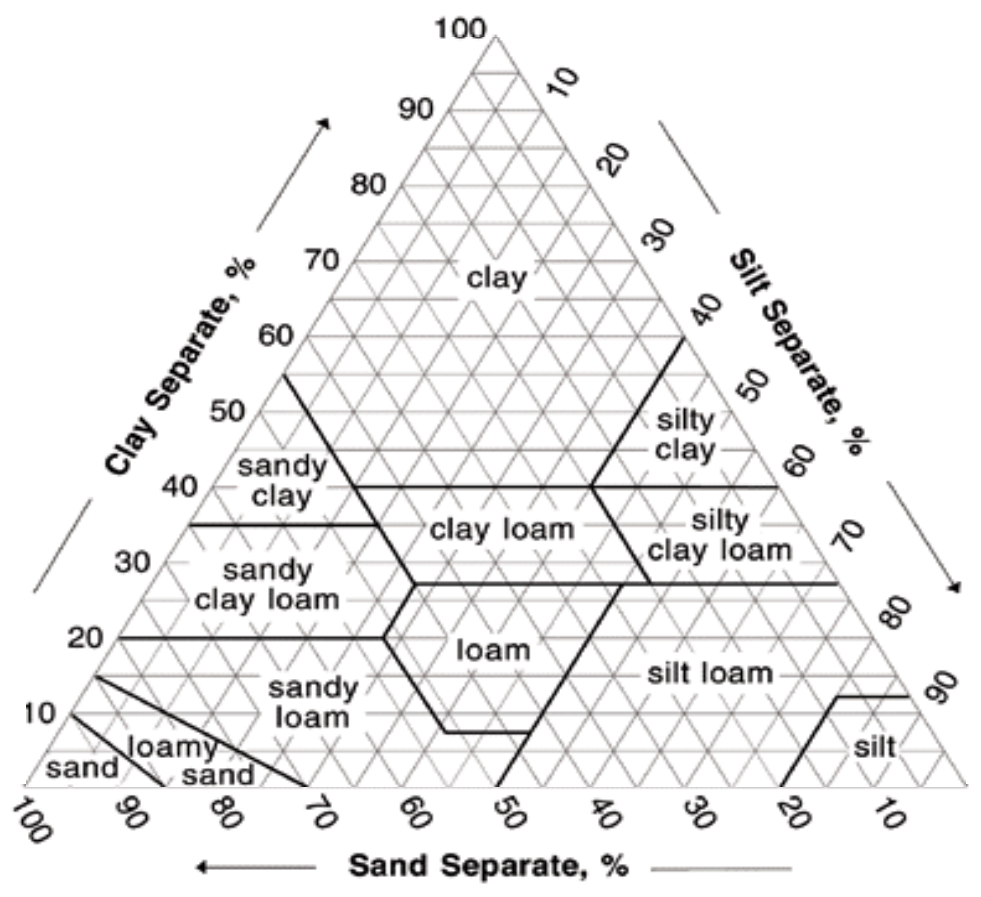

Source: Soil Survey Manual (USDA 1993 [DIRS 160546], p. 138).

Figure 6-2. Percentages of Sand, Silt and Clay in the Soil Texture Classes

The information on soils in Amargosa Valley is available from the USDA Natural Resources Conservation Service (NRCS). For the Amargosa Valley, the NRCS identified several soil series (USDA 2004 [DIRS 173916], Parts I and II). The soils where almost all farming occurs in Amargosa Valley are identified by the following map symbols: 2054, 2070, 2152, 2153, and 2451 (USDA 2004 [DIRS 173916], Part I, Maps 40, 41, 46, and 47). The descriptions of these soils are listed in Table 6-4. The soils in Amargosa Valley generally have a high content of rock fragments, such as gravel and cobble. The most typical soil texture class for the soil fraction (obtained by separating out the coarse fragments) is sandy loam with a relatively large fraction of rock fragments such as pebbles (gravel) and cobbles. 
Table 6-4. Major Types of Soils Occurring in Amargosa Valley

\begin{tabular}{|l|l|}
\hline \multicolumn{1}{|c|}{ Soil Series } & \multicolumn{1}{c|}{ Soil Textural Class } \\
\hline Arizo & Very gravelly sandy loam \\
\hline Corbilt & Very gravelly sandy loam \\
\hline Shamock & Gravelly fine sandy loam \\
\hline Yermo & Very gravelly sandy loam \\
\hline Commski & Very gravelly fine sandy loam \\
\hline Sanwell & Gravelly fine sandy loam \\
\hline
\end{tabular}

Source: USDA 2004 [DIRS 173916], Part II, Volume I, Table 11; soil texture is for the upper soil layer.

To evaluate the effects of soil morphology on TSP concentrations, the prevailing soil type at 42 TSP monitoring stations was determined. The sites included in this evaluation were the rural agricultural sites used in Section 6.2.2 to develop the distribution of mass loading in the inactive outdoor environment (and in Section 6.1.3.1 to evaluate climate). Measurements of TSP at these sites were obtained from the EPA AirData database (DTN: MO0210SPATSP01.023 [DIRS 160426]).

Because the AirData database does not include information on soil types, the dataset on the predominant soil in the top layer $(0$ to $5 \mathrm{~cm}$ ), included in the Land Data Assimilation Systems (LDAS) (LDAS [n.d.] [DIRS 176392]) was used to characterize the type of soils in the vicinity of the particulate matter monitoring stations. The LDAS is developed by several government agencies and academic institutions in support of numerical weather prediction models and is maintained by the National Aeronautics and Space Administration Goddard Space Flight Center. The soils data included in the LDAS sets were derived from the NRCS State Soil Geographic Database and USDA Agricultural Research Service data (LDAS [n.d.] [DIRS 176392]). The files consist of one soil texture value per 1/8th degree grid box (LDAS [n.d.] [DIRS 176392]). The LDAS grid consists of $464 \times 2241 / 8$ th degree gridboxes with the centers of gridboxes extending from -124.9375 to -67.0625 degrees longitude and from 25.0625 to 52.9375 degrees latitude. The gridpoint $(1,1)$ in the soil texture data is located at the upper left of the LDAS grid, i.e., at -124.9375 degrees longitude and 52.9375 degrees latitude. The LDAS soil database was used rather than more detailed NRCS data because of the accessibility of the data from the perspective of this analysis' objectives.

In the LDAS file, soil texture classes are represented by numbers as shown in Table 6-5 (LDAS [n.d.] [DIRS 176392]). In the same table, the approximate ranges of clay, silt, and sand content fractions from Figure 6-2 are shown. Generally, soil texture classes designated by a lower number have a greater content of sand, and a lower content of finer-grained material (silt and clay). 
Table 6-5. Fraction of Clay, Silt, and Sand in Soils by Texture Class

\begin{tabular}{|c|l|c|c|c|}
\hline $\begin{array}{c}\text { Soil Texture Class } \\
\text { Number }\end{array}$ & Soil Texture Class & Clay Content & Silt Content & Sand Content \\
\hline 1 & sand & 0.00 to 0.10 & 0.00 to 0.15 & 0.86 to 1.00 \\
\hline 2 & loamy sand & 0.00 to 0.15 & 0.00 to 0.30 & 0.71 to 0.85 \\
\hline 3 & sandy loam & 0.00 to 0.20 & 0.00 to 0.50 & 0.43 to 0.85 \\
\hline 4 & silt loam & 0.00 to 0.27 & 0.51 to 0.85 & 0.00 to 0.50 \\
\hline 5 & silt & 0.00 to 0.12 & 0.81 to 1.00 & 0.00 to 0.20 \\
\hline 6 & loam & 0.08 to 0.27 & 0.28 to 0.50 & 0.23 to 0.52 \\
\hline 7 & sandy clay loam & 0.21 to 0.35 & 0.00 to 0.27 & 0.46 to 0.80 \\
\hline 8 & silty clay loam & 0.28 to 0.40 & 0.41 to 0.72 & 0.00 to 0.20 \\
\hline 9 & clay loam & 0.28 to 0.40 & 0.16 to 0.52 & 0.21 to 0.45 \\
\hline 10 & sandy clay & 0.36 to 0.55 & 0.00 to 0.20 & 0.46 to 0.65 \\
\hline 11 & silty clay & 0.41 to 0.60 & 0.41 to 0.60 & 0.00 to 0.20 \\
\hline 12 & clay & 0.41 to 1.00 & 0.00 to 0.40 & 0.00 to 0.45 \\
\hline 13 & organic material & N/A & N/A & N/A \\
\hline 14 & water & N/A & N/A & N/A \\
\hline 15 & bedrock & N/A & N/A & N/A \\
\hline 16 & other & N/A \\
\hline
\end{tabular}

Sources: LDAS [n.d.] [DIRS 176392] and USDA 1993 [DIRS 160546], p. 138.

The data on predominant soil type in the upper soil layer (LDAS [n.d.] [DIRS 176392]) were transferred to an Excel file Soil texture.xls (Appendix C). The soil type was then determined for the $1 / 8$ th degree grid cell where each TSP monitoring station was located. The soil texture classes were then transferred to the Excel file with the TSP data (TSP Data_Ag_Rural_Western states.xls). The soil texture data obtained in that manner are shown in Table B-2 in Appendix B. The plot of TSP versus soil texture class is shown in Figure 6-3. The predominant soil type in Amargosa Valley is sandy loam (soil texture class No. 3) with substantial occurrence of rock fragments. As can be seen from Figure 6-3, most of the rural, agricultural TSP measurement locations had soils that contained lower fractions of sand and higher fractions of silt and clay (i.e., higher soil texture class number) than the Amargosa Valley soils.

Figure 6-3 also shows that there may be a weak trend of TSP increasing with the index of the soil texture class (the index is greater for soil containing more silts and clays and less sand). This reflects a greater potential for resuspension of fine-grained soil and longer airborne residence time of finer soil separates, compared with coarser separates, due to differences in their settling velocities. It has to be kept in mind that TSP is not only influenced by the soil type and proportion of soil separates but also by a number of other variables, such as precipitation, as discussed in the previous section, and that some of those variables may be correlated. For example, the availability of fine particles in soil does not necessarily result in their higher concentrations in air. Particle cements, such as salts or sheath material extruded by cyanobacteria, or the presence of vegetation cover may impede the resuspension (Middleton 2000 [DIRS 175894], pp. 415-416; Belnap and Gillette 1998 [DIRS 175735], p. 134). However, from Figure 6-3 it can be concluded that from the perspective of soil morphology, using the TSP data from rural, agricultural sites in the Western U.S. does not underestimate the TSP levels in Amargosa Valley. This is because the concentration of TSP for 
sandy loam soils, the prevailing texture class for soils in Amargosa Valley, is not higher than the TSP for other soil texture classes.

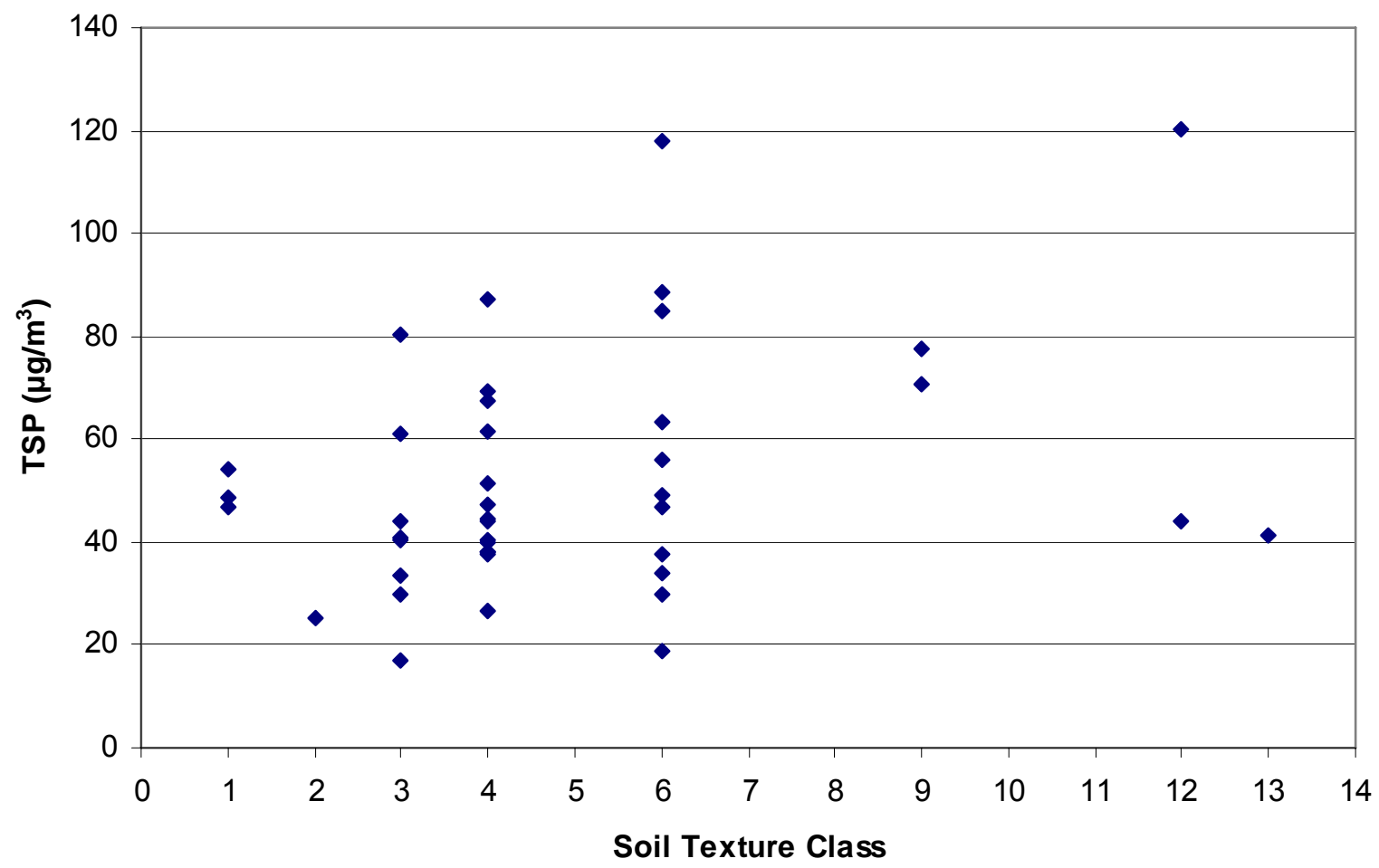

Figure 6-3. TSP Dependence on Predominant Texture Class of the Upper Soil Layer

\subsubsection{Influence of Site Setting on Mass Loading}

Site setting may influence the level of airborne mass loading. The sites used in this analysis are predominantly located in rural, agricultural settings in the Western U.S. Although the location (i.e., rural versus urban or suburban) and land use (i.e., agricultural versus residential or commercial) for those sites are analogous to that of Amargosa Valley, there are many parameters that may be different among the sites. The influence on airborne particulate matter of meteorological conditions and soil morphology was evaluated in the preceding sections of this analysis. Some of the conclusions of these evaluations included a finding that the effect of precipitation was not pronounced. It has been suggested that sparsely vegetated terrain in the Yucca Mountain area would have higher airborne mass loads than analogue sites with more abundant vegetation, because the wetter, more vegetated conditions are more capable of stabilizing or depleting the abundance of resuspendable particles relative to the arid, sparsely vegetated conditions at the receptor location (Reamer 2004 [DIRS 176773], Enclosure). However, the analysis indicated that sites with annual precipitation below $20 \mathrm{in}$. are good analogues, with respect to the TSP levels, of the conditions at the location of the receptor.

TSP concentrations depend not only on the climate and soil conditions but also on human activities, particularly those activities that disturb the soil surface and cause resuspension of soil particles. To evaluate this phenomenon, TSP concentrations at rural, agricultural 
sites in the Western U.S. were compared with TSP concentration at rural, desert sites (not classified as having agricultural activities) taken from the same AirData database (DTN: MO0210SPATSP01.023 [DIRS 160426]). Figure 6-4 shows the results of this comparison (TSP Data_Ag_Rural_Western states.xls).

The annual precipitation at the sites characterized as rural, desert was less than 14 in. and most sites had precipitation below $10 \mathrm{in}$. The TSP concentrations at the desert sites generally were lower than TSP concentrations at the rural agricultural sites for the same precipitation levels (Figure 6-4). This indicates that agricultural activities contribute to TSP concentrations and that desert sites have a relatively low TSP in the absence of the soil-disturbing activities. Because the receptor location is expected to have characteristics of inhabited rural, agricultural areas, TSP data from rural desert sites were not used to develop mass loading for the biosphere model.

Only a small part of the Amargosa Valley area is used for agricultural purposes. In this respect, some of the analogue locations with more extensive agriculture are likely to have higher average TSP concentrations. In addition, portions of the Yucca Mountain area have a soil surface particularly resistant to soil resuspension because of the presence of an undisturbed desert pavement, which is characterized by a wind-resistant surface. It needs to be noted that a portion of Amargosa Valley is covered by Fortymile Wash alluvial fan, parts of which can be considered a favorable dust-producing surface (Middleton 2000 [DIRS 175894], p. 416). However, the surface area of the alluvial fan is a small fraction of the Amargosa Valley area, and parts of the fan have developed a desert pavement surface, which limits its influence on the TSP levels.

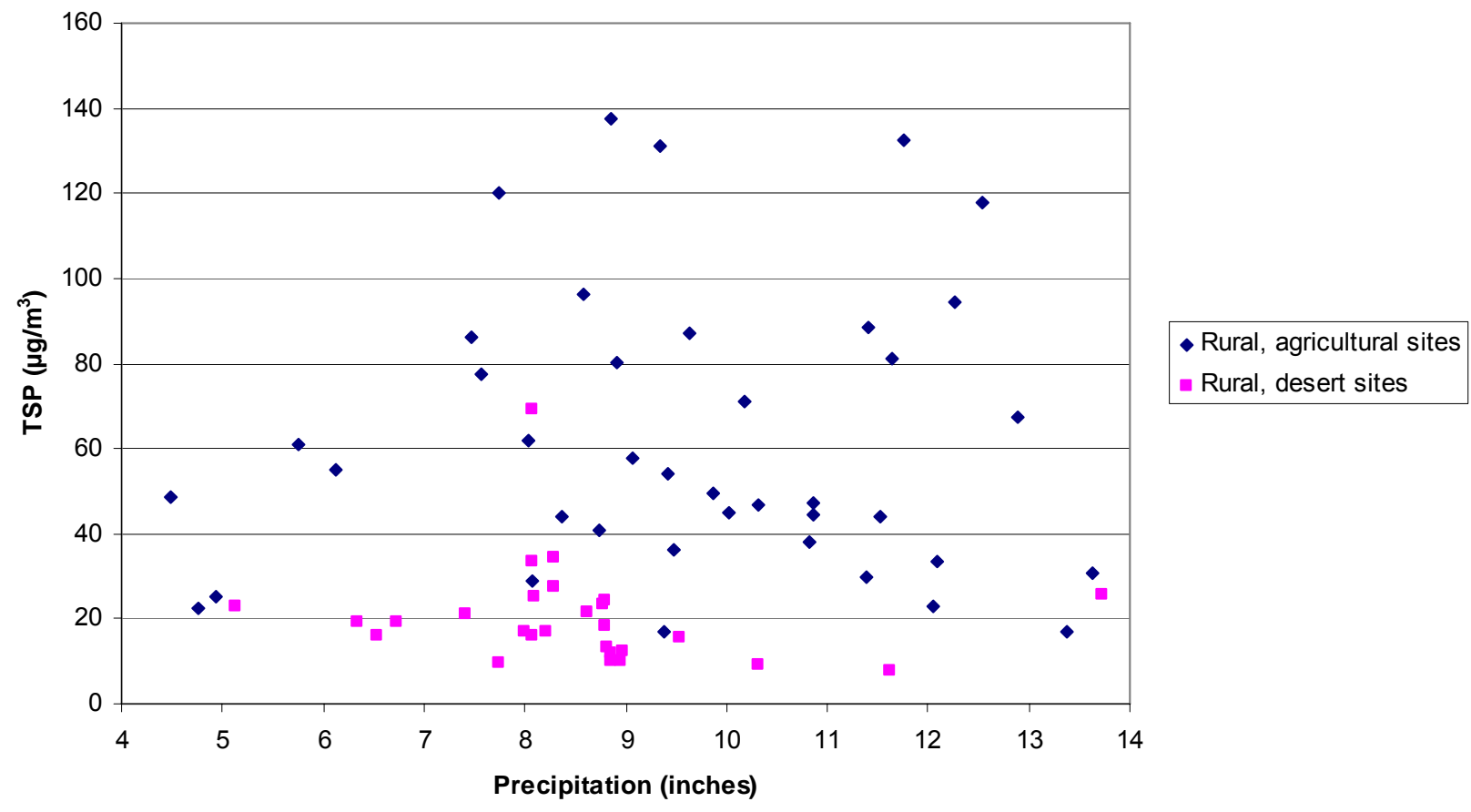

Figure 6-4. Comparison of TSP Concentrations Versus Precipitation for Rural, Agricultural Sites and Rural, Desert Sites 


\subsubsection{Particle Size Effects}

The distribution of airborne particles with respect to size is an important physical parameter governing particle behavior (EPA 2004 [DIRS 175978], Section 2.1.2.2). Measurements of particle size distributions indicate that most of the particles are quite small, below $0.1 \mu \mathrm{m}$, whereas most of the particle volume (and therefore most of the mass) is found in particles greater than $0.1 \mu \mathrm{m}$ (EPA 2004 [DIRS 175978], Figure 2-1). There are several classifications of particles with respect to their size. Particles of interest to this analysis originating from native soils are found primarily in the coarse particle size fraction. The coarse mode refers to particles formed by the mechanical breakdown of minerals, crustal material, and organic debris. The particle size distribution of the coarse particle size fraction typically has the mode between 5 and $30 \mu \mathrm{m}$ diameter. Fine particles originating from soil resuspension processes may appear in the particle size range usually associated with the so-called accumulation mode (EPA 2004 [DIRS 175978], Section 2.1.2.2).

Another set of definitions of particle size fractions arises from considerations of size-selective sampling. Size-selective sampling refers to the collection of particles below or within a specified aerodynamic size range. Size fractions are usually specified by the 50\% cut point size: e.g., $\mathrm{PM}_{2.5}$ refers to particles collected by a sampling device that collects $50 \%$ of $2.5 \mu \mathrm{m}$ particles and rejects $50 \%$ of $2.5 \mu \mathrm{m}$ particles (EPA 2004 [DIRS 175978], Section 2.1.2.2). The $2.5 \mu \mathrm{m}$ cut point is generally used for the separation of fine and coarse particles. Although the $\mathrm{PM}_{2.5}$ Sample will contain most of the fine particles, it may also collect a small fraction of the coarse particles, especially in dry areas or during dry conditions, such as is the case in the Yucca Mountain region. In areas where winds cause high concentrations of windblown soil, there is evidence that a significant amount of coarse-mode particulate matter may be found below $2.5 \mu \mathrm{m}$ (EPA 2004 [DIRS 175978], Section 2.1.2.2).

An idealized particle size distribution with the normally observed division of ambient aerosols into fine and coarse particles and the size fractions collected by the size-selective samplers is shown in Figure 6-5.

Particle size influences the suspension times of particles in the air. Coarse particles can settle rapidly from the atmosphere within minutes or hours and normally travel only short distances. However, when mixed high into the atmosphere, as in dust storms, the smaller-sized, coarse-mode particles may be suspended longer and travel greater distances. Accumulation-mode particles are kept in suspension by normal air motions and have a lower deposition velocity than coarse-mode particles; they can be transported thousands of kilometers and remain in the atmosphere for a number of days. Dry deposition rates are expressed in terms of a deposition velocity that varies with particle size, reaching a minimum between aerodynamic diameters of 0.1 and $1.0 \mu \mathrm{m}$ (EPA 2004 [DIRS 175978], Section 2.3.1). Size dependent settling times of resuspended particles influence mass loading, especially in the active outdoor environment. In this environment soil gets resuspended by mechanically disturbing soil surface. However, the temporal and spatial extent of elevated mass loading is limited. 


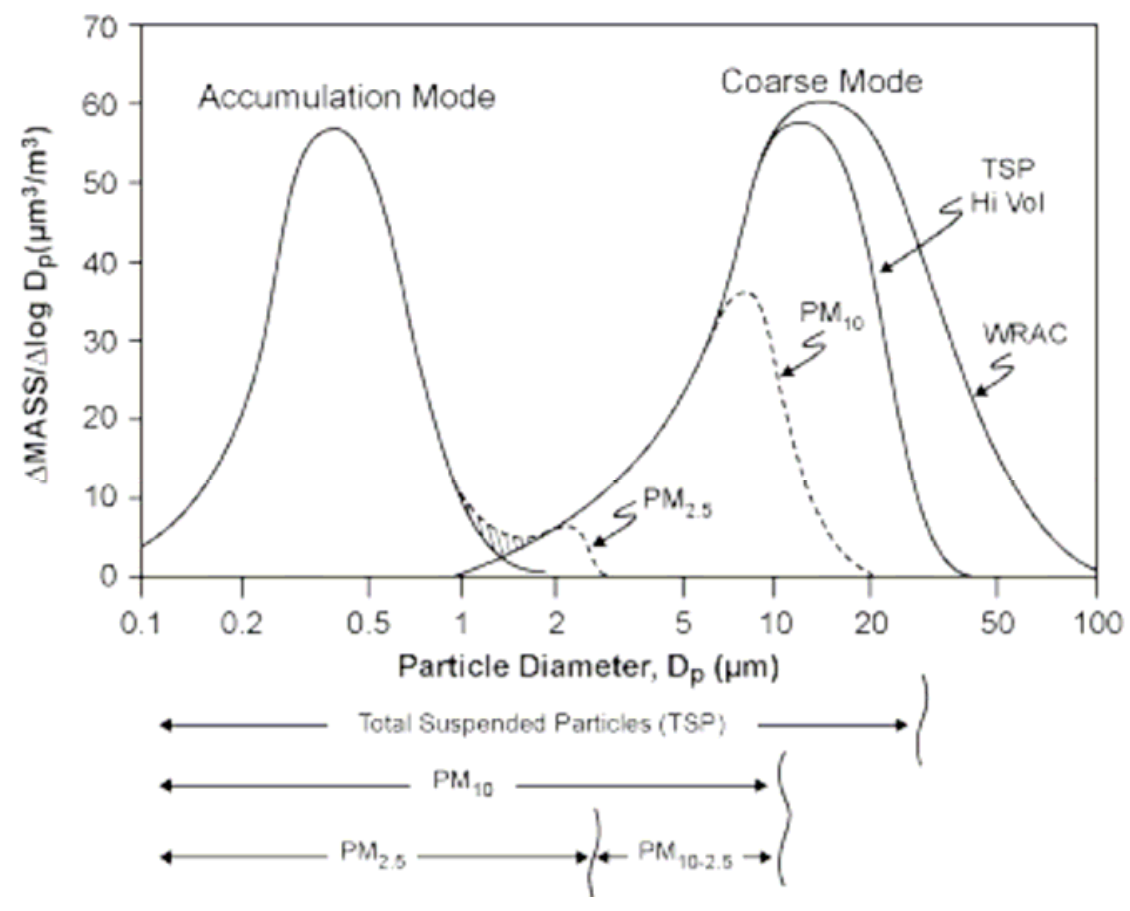

Source: EPA 2004 [DIRS 175978], Figure 2-8.

NOTE: $\quad \Delta M A S S / \Delta \log D_{p}=$ mass concentration of airborne particles per $\mathrm{m}^{3}$ of air having diameters (in $\mu \mathrm{m}$ ) in the size range from log $D_{p}$ to $\log \left(D_{p}+\Delta D_{p}\right) ;$ WRAC=wide range aerosol classifier which collects the entire coarse mode; Hi Vol=high volume sampler.

Figure 6-5. Particle Size Distribution Showing Fractions Collected by Size-Selective Sampling Devices

From a health effects point of view, size fractions are defined in terms of their entrance into various compartments of the respiratory system. This convention classifies particles into inhalable, thoracic, and respirable particles according to their upper size cuts. Inhalable particles enter the respiratory tract, beginning with the head (extrathoracic) airways. Thoracic particles travel past the larynx and reach the lung airways and the gas-exchange regions of the lung. Respirable particles are a subset of thoracic particles that are more likely to reach the gas-exchange region of the lung (EPA 2004 [DIRS 175978], Section 2.1.2.2).

Particle size distribution is an important characteristic of airborne radioactive aerosols because it influences deposition of radionuclides in the respiratory tract and, consequently, the inhalation dose. This aspect of the analysis is discussed in the following section.

\subsubsection{Evaluation of Dose from Inhaled Radionuclides}

The dose from inhaled particles is governed by a number of factors. These include radionuclide concentration in air, exposure duration, respiratory tract anatomy, breathing parameters, and particle properties (e.g., particle size; radioactivity distribution on airborne particles of various sizes; and chemical form of radionuclides, which influences hygroscopicity of inhaled particles and solubility in airway fluids and cellular components). This report is concerned only with the physical attributes of airborne particulate matter, such as the airborne concentrations of particles and their sizes. The conditions of receptor exposure (duration of exposure in various 
microenvironments), breathing characteristics of the receptor, and dosimetry of inhaled particulates are discussed in more detail in the Characteristics of the Receptor for the Biosphere Model (BSC 2005 [DIRS 172827]). This section provides a brief description of how the physical characteristics of airborne particulates may influence the inhalation dose.

Not all airborne particles can enter the respiratory tract. Ambient air often contains particles whose diameters are too large to be inhaled. The term "inhalability" is used to denote the overall spectrum of particle sizes that are potentially capable of entering the respiratory tract. Inhalability is defined as the ratio of the number concentration of particles of a certain aerodynamic diameter that are inspired through the nose or mouth to the number concentration of the same diameter particle present in ambient air (ICRP 1994 [DIRS 153705], Section D.2). The inhalability of particles with aerodynamic diameter greater than about $40 \mu \mathrm{m}$ is about 0.5 (ICRP 1994 [DIRS 153705], Figure D.2) and particles with aerodynamic diameter greater than $100 \mu \mathrm{m}$ have a low probability of entering the mouth or nose in still air (EPA 2004 [DIRS 175978], Section 6.2.2). (Aerodynamic diameter of is the diameter of a unit density sphere that would have same terminal settling velocity as the real particle.)

Once radioactive particles enter the respiratory tract, they can deliver a dose to various regions and target tissues. Dose to a target tissue depends on the initial deposition and subsequent retention of particles within the respiratory tract. Once particles have deposited onto the surfaces of the respiratory tract, they are subsequently subjected to either absorptive or nonabsorptive particulate removal processes, which may result in their removal or translocation from airway surfaces, as well as their removal from the respiratory tract itself. Clearance of deposited particles depends upon the initial site of deposition as well as upon the physical and chemical properties of the particles, all of which affect specific translocation pathways. Retained particle burdens are determined by the dynamic relationship between deposition and clearance rates (EPA 2004 [DIRS 175978], Section 6.1).

Deposition of radioactive aerosols in the respiratory tract is particle size-dependent and, consequently, so is dose. As discussed in Section 6.1.6, environmental aerosols consisting of resuspended soil particles are polydisperse, i.e., the constituent particles within an aerosol have a range of sizes (EPA 2004 [DIRS 175978], Section 6.1.1). The coarse mode, where the particles resuspended by mechanical processes from surface soil are found, consists primarily of particles greater than about $1 \mu \mathrm{m}$ (Figure 6-5). For particles with aerodynamic diameter greater than $1 \mu \mathrm{m}$, deposition in the respiratory tract is governed by impaction and sedimentation, and it increases with increasing aerodynamic diameter. For diameters greater than $10 \mu \mathrm{m}$, almost all inhaled particles are deposited. However, it needs to be kept in mind that, as noted previously, inhalability of particles in that size range decreases as their size increases. As the particle size decreases from $0.5 \mu \mathrm{m}$, diffusional deposition becomes dominant. Decreasing particle diameter below $0.1 \mu \mathrm{m}$ leads to an increase in total deposition. Total deposition in the respiratory tract is lowest for particle diameters in the range of 0.2 to $1.0 \mu \mathrm{m}$, where neither sedimentation, impaction, or diffusion deposition are very effective (EPA 2004 [DIRS 175978], Section 6.2.2.1). This pattern of aerosol deposition in the respiratory tract with respect to particle size is also reflected in the distribution of inhalation dose coefficients as a function of particle size (BSC 2005 [DIRS 172827], Figure 6-18). Inhalation dose coefficients are used to convert inhaled activity to dose. 
The inhalation dose calculations in the biosphere model utilize concentrations of suspended particulates in air (mass loading), the parameters developed in this analysis. The distributions of mass loading, as described in Sections 6.2 and 6.3 of this report, are based on measured values of particulate concentrations in air expressed in terms of TSP (in some instances converted from the $\mathrm{PM}_{10}$ measurements) because the majority of the relevant published data are presented in that format. Such an approach involves a number of approximations, the most important of which is how well the analogue values represent site-specific conditions. This issue is addressed in part in the preceding sections and is revisited throughout Sections 6.2 to 6.4. The other questions that need to be addressed are how well does a single value of mass loading, TSP in this case, represent the mass distribution over the range of particles sizes present in resuspended soil for the purpose of dose assessment, and what are the other possible biases between the true and estimated dose.

Ideally, inhalation dose would be calculated using the actual particle size-dependent distribution of radionuclide concentration in air coupled with the particle size-dependent distribution of inhalation dose coefficients, and by taking into consideration conditions of the receptor's exposure. In practice, numerous biases may be present. For example, sampling of ambient aerosols is always particle size-dependent and also depends on a particular sampling technique used. As a result, the measured and true aerosol concentrations in air may differ. Dose coefficients typically used in radiological assessments are not expressed as particle size-dependent functions, but rather as single values for an assumed distribution of activity over particle sizes (usually lognormal) with a given activity median aerodynamic diameter (AMAD) and a geometric standard deviation.

A study was conducted to evaluate the impact on the inhalation exposure of the uncertainty associated with the particle size distribution of the ambient aerosols (Degrange and Witschger 2005 [DIRS 176119]). The conclusion reached was that to minimize the impact of an unknown particle size distribution on estimates of inhalation exposure, an inhalable sampler should be chosen (Degrange and Witschger 2005 [DIRS 176119], p. 406). An inhalable sampler collects particles with the size spectrum corresponding to that of particles that a person can inhale, i.e., all particles that enter the respiratory tract. In this respect, TSP is an appropriate parameter for evaluating inhalation exposure in a situation when a specific size distribution of ambient aerosols is not known (Degrange and Witschger 2005 [DIRS 176119], p. 406). For evaluation of inhalation dose, the sampler should be chosen according to the absorption rate (into blood) of the compound considered, to follow as closely as possible dependency of the dose coefficients for this compound on the AMAD. For compounds with a slow and moderate absorption rate, a thoracic sampler should be chosen; for fast absorption rate compounds an inhalable sampler should be chosen (Degrange and Witschger 2005 [DIRS 176119], p. 406). The estimate of the dose may also be biased due to the fact that the particle size distribution of the ambient aerosols is not known. The sampler that minimizes such a bias is the sampler for which the dependency on AMAD of the sampling efficiency follows as closely as possible the dependency on AMAD of the inhalation dose coefficients for the compound under consideration (Degrange and Witschger 2005 [DIRS 176119], p. 397).

Because of the uncertainty in the chemical form of inhaled or ingested material, a conservative assumption was made in the biosphere model regarding the absorption rates for the radionuclides of interest, such that the dose coefficients selected for the use in the model were the highest. For 
the actinides considered in the biosphere model, whose dose contributions are dominated by the inhalation pathway, the absorption rates for the compounds that result in the highest inhalation dose coefficient are predominantly either fast or slow (discussion of the absorption parameters used in the respiratory tract model and the related nomenclature can be found in ICRP 1994 [DIRS 153705], Section 7.3). For radionuclides with a fast absorption rate, measurements of TSP are a good approximation for dose estimates because they are comparable with the inhalable sampling. For radionuclides with slow absorption rates, measurements of TSP will generally overestimate the inhalation dose for the particulates in the coarse mode.

Degrange and Witschger (2005 [DIRS 176119]) also recommend that in the absence of precise information on the particle size characteristics of the ambient aerosols, the following default values for the distribution should be chosen: AMAD of $5 \mu \mathrm{m}$ and geometric standard deviation of 2.5. The biosphere model uses AMAD of $1 \mu \mathrm{m}$, which in the case of radionuclides (compounds) with the slow absorption rate results in an overestimate of the inhalation dose; for the radionuclides (compounds) with the fast absorption rate, using 1- $\mu \mathrm{m}$ AMAD dose coefficients may underestimate the dose, but typically by about 20 percent or less, which is small relative to inherent uncertainties in the values of dose coefficients (BSC 2005 [DIRS 172827], Section 6.5.3.1). More detailed discussion of dose coefficients used in the biosphere model and particle size dependence of inhalation dose coefficients can be found in Characteristics of the Receptor for the Biosphere Model (BSC 2005 [DIRS 172827]).

\subsection{MASS LOADING - NOMINAL CONDITIONS}

This section describes the development of mass loading distributions within the five environments (four receptor environments and the environment around crops) for nominal conditions, i.e., air quality conditions in the reference biosphere not measurably influenced by a volcanic eruption at Yucca Mountain. These values are intended for use in the groundwater exposure scenario. They also are intended for use in the volcanic ash exposure scenario for calculation of BDCFs representative of the period after mass loading concentrations have returned to pre-eruption conditions. See Section 6.3 for a description of that scenario.

For the groundwater exposure scenario, the reference biosphere represents a rural community with conditions consistent with the Yucca Mountain region and a population with a living style representative of the people residing in the Town of Amargosa Valley (based on requirements in 10 CFR 63.305 and 10 CFR 63.312 [DIRS 173273]). The only common potential sources of contaminated, resuspended soil particles for this scenario would be agricultural fields, gardens, and landscapes irrigated with contaminated well water.

For the volcanic ash exposure scenario during nominal conditions, the sources of contaminated resuspended particles would be ash/waste particles initially deposited during the eruption, ash/waste particles washed into the valley from Fortymile Wash, and ash/waste particles blown into the valley. By definition of the mass loading time function, the tephra deposit will have been stabilized by the time nominal conditions occur (see Section 6.3). Thus, resuspension on undisturbed sites will be similar to that before the eruption, and the main source of resuspended particles will be agricultural fields and other disturbed sites. 
The number and size of agricultural and other disturbed sites in Amargosa Valley is small relative to the size of the inhabited area. The inhabited portion of Amargosa Valley extends south and west of Highway 373 from the Lathrop Wells Junction of Highway 95 to the California border. Most people in Amargosa Valley live in the southern portion of the valley in a triangular area approximately $17 \times 17 \times 24 \mathrm{~km}$ (about $150 \mathrm{~km}^{2}$ ) in size (BSC 2003 [DIRS 168723], Figure 1). This area, known as the farming triangle, is also where most agriculture in the valley occurs (CRWMS M\&O 1999 [DIRS 107736], pp. 1 to 3). The U.S. Census Bureau estimated that only 26 of 449 employed Amargosa Valley residents 16 years old or older worked in agriculture (Bureau of the Census 2002 [DIRS 159728], Table P49). During 1998, there were about $8.9 \mathrm{~km}^{2}$ (2,199 acres) of commercial agriculture in Amargosa Valley, $8.4 \mathrm{~km}^{2}(2,072$ acres $)$ of which were planted at the time agricultural acreage was measured. About 87 percent of all acreage was planted in alfalfa and other hay (92 percent of planted acreage) and about 6 percent was orchards or vineyards (YMP 1999 [DIRS 158212], Table 10). During 1999, there were $8.2 \mathrm{~km}^{2}$ (2,015 acres), $7.3 \mathrm{~km}^{2}$ (1,798 acres) of which were planted at the time of the survey. Eighty-three percent was planted in alfalfa and other hay (93 percent of planted acreage) and 6 percent was orchards or vineyards (YMP 1999 [DIRS 158212], Table 11). In spring 2004, about 85 percent of the agricultural acreage identified in the valley in 1998 was re-surveyed (Rasmuson 2004 [DIRS 169506]). About $8 \mathrm{~km}^{2}$ $(2,000$ acres $)$ were planted for commercial agriculture; over 95 percent of that was planted in alfalfa and other hay. An additional approximately $4 \mathrm{~km}^{2}$ (1,000 acres) had recently been planted in pine trees (Rasmuson 2004 [DIRS 169506]). Thus, only a small portion of the valley (about eight percent of the farming triangle and a much smaller portion of the entire inhabited valley) is planted in agriculture, and most of that is planted in hay, orchards, tree farms, and vineyards. Those crops require infrequent land preparation or other soil disturbances that would resuspend contaminated soil particles. There also is one large dairy near the south end of the agricultural region in Amargosa Valley that had about 5,000 cows (YMP 1999 [DIRS 158212], Tables 8 and 9; Rasmuson 2004 [DIRS 169506]). About 46 percent of 195 Amargosa Valley households surveyed during 1997 had a garden (DOE 1997 [DIRS 100332], Tables 2.4.2 and 3.5.1). In summary, Amargosa Valley has a small agricultural industry and most fields are planted in crops that require infrequent soil disturbances. Within the valley, large disturbed sites occupy only a small portion of the landscape, although small sites (e.g., gardens) may be found near about 50 percent of residences.

Resuspended particle concentrations measured at stationary monitoring sites in northern Amargosa Valley and elsewhere in the Yucca Mountain region are very low. Average annual concentrations of TSP at Yucca Mountain monitoring site 1, which was near the Yucca Mountain Exploratory Studies Facility and surrounded by numerous unpaved roads and other disturbed sites, had annual average concentrations of TSP ranging from 0.022 to $0.027 \mathrm{mg} / \mathrm{m}^{3}$ during 1992 to 1997 (CRWMS M\&O 1999 [DIRS 102877], Table 2-3), the years when most construction was occurring at Yucca Mountain. Average concentrations of $\mathrm{PM}_{10}$ there ranged from 0.009 to $0.012 \mathrm{mg} / \mathrm{m}^{3}$. Average annual concentrations of $\mathrm{PM}_{10}$ at a monitoring site in northern Amargosa Valley (Yucca Mountain monitoring site 9 at the southern boundary of the Nevada Test Site) ranged from 0.007 to $0.010 \mathrm{mg} / \mathrm{m}^{3}$ during 1993 through 1997 (TSP was not measured at that site). Maximum 24-hour concentrations of $\mathrm{PM}_{10}$ per year at that site ranged from 0.015 to $0.057 \mathrm{mg} / \mathrm{m}^{3}$. Concentrations in the farming and residential community farther south in Amargosa Valley probably are higher. However, concentrations there would not be substantially greater because the only large sources of resuspended particles in that area are 
about 3,000 acres of agricultural fields, most of which have perennial crops such as alfalfa that cover the ground surface and require infrequent soil-disturbing activities.

\subsubsection{Active Outdoor Environment}

Applicable literature (see Section 4.1.1) was reviewed to determine the range of average concentrations of particles resuspended while soil-disturbing activities were being conducted. The relevant factors considered in evaluating whether the conditions under which those studies were conducted were consistent with the present conditions in the Yucca Mountain region included the types of activities conducted, aridity, and soil texture. A review of the pertinent literature is presented in Section 6.2.1.1. In addition, measurements of particulate concentration in air in the active outdoor environment were conducted in Amargosa Valley. These measurements are discussed in Section 6.2.1.2. Section 6.2.1.3 describes parameter development.

\subsubsection{Literature Review}

Applicable studies are presented below, with the most applicable results presented first. Studies were considered most applicable if they (1) reported particulate concentrations resulting from behaviors that are consistent with those conducted outdoors in Amargosa Valley while soil is being disturbed, (2) were conducted in arid to semi-arid environments, and (3) measured and reported concentrations of TSP. Only measurements of personal exposure were considered applicable for analysis of this environment. Unless otherwise stated, personal exposure was measured by placing the inlet device of a dust sampler near the head of the person performing the activity (e.g., on a shirt collar); thus, measurements of personal exposure are representative of the concentration of resuspended particles inhaled by a person while conducting an activity. A summary of this review is in Table 6-6.

Nieuwenhuijsen et al. (1999 [DIRS 150711]) recorded 142 measurements of personal exposure to TSP during farming activities at 10 farms near Davis and Sacramento, California, over 15 months. Cultivated soils in that area generally are silty clay loams to clays and loams, and annual rainfall ranges from 16 to 24 in. (Andrews 1972 [DIRS 170526]). The mean TSP concentrations of 23 farming activities ranged from 0.30 (scraping cattle stalls) to $45.14 \mathrm{mg} / \mathrm{m}^{3}$ (machine harvesting of nut trees from an open tractor cab); the average was $4.14 \mathrm{mg} / \mathrm{m}^{3}$ (Nieuwenhuijsen et al. 1999 [DIRS 150711], Table 2). The dustiest activity would be conducted infrequently in Amargosa Valley, in part because nut orchards occur on less than 5 percent of fields in Amargosa Valley (YMP 1999 [DIRS 158212], Tables 10 and 11) and because harvesting only occurs for a short time each year. Only three other activities (machine harvesting vegetables from an open cab, $7.93 \mathrm{mg} / \mathrm{m}^{3}$; scraping poultry houses, $6.67 \mathrm{mg} / \mathrm{m}^{3}$; mowing weeds from an open cab, $5.11 \mathrm{mg} / \mathrm{m}^{3}$ ) had geometric mean values greater than $5 \mathrm{mg} / \mathrm{m}^{3}$. The average of all activities excluding nut harvesting was $2.19 \mathrm{mg} / \mathrm{m}^{3}$. 
Table 6-6. Particulate Concentrations-Nominal Active Outdoor Environment

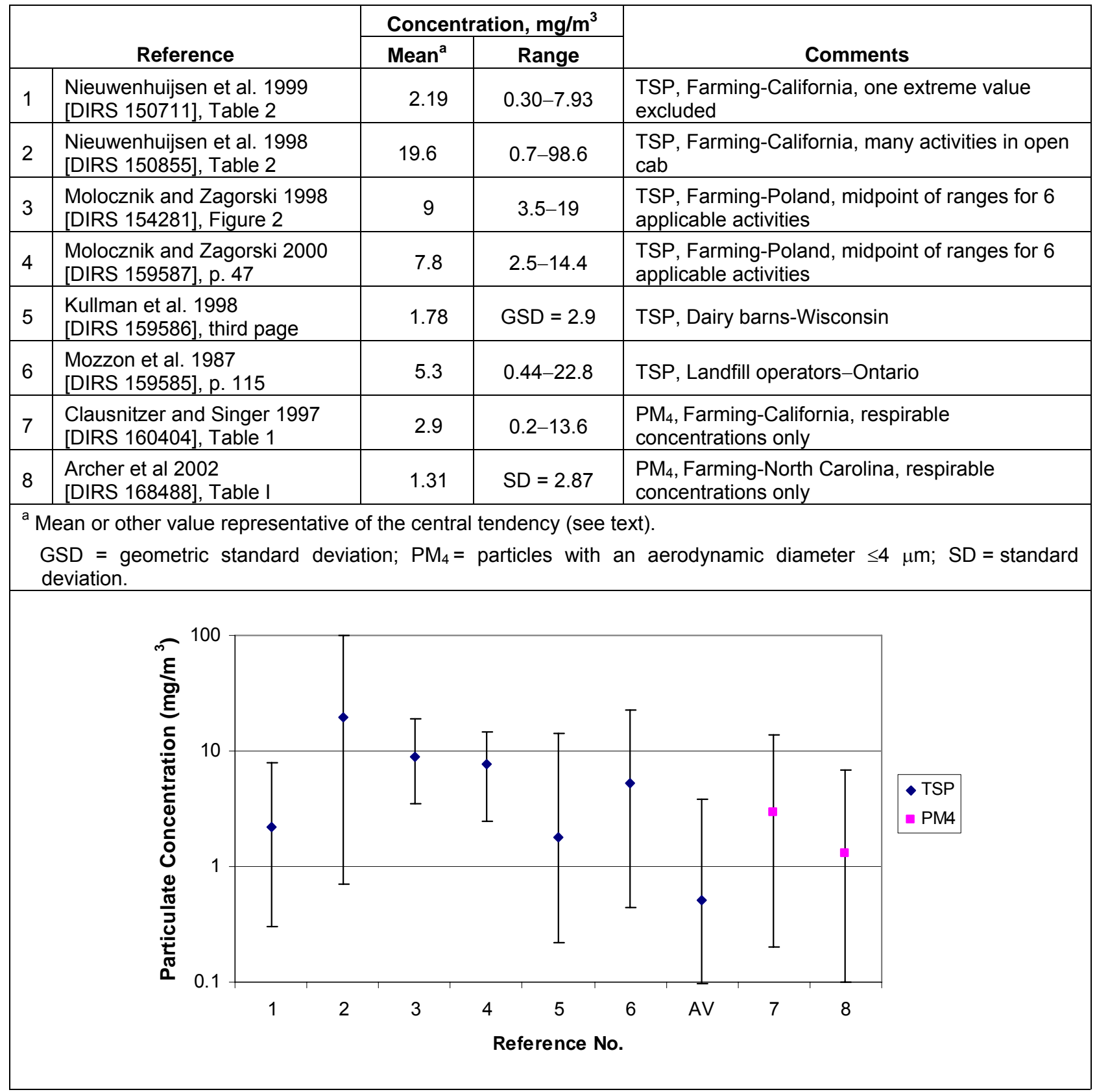

NOTE: In the graph above, symbols represent mean values and vertical bars represent ranges of measured values. If SD or GSD is given in place of the range to describe variation in the measured values, the ranges are presented as the $95 \%$ confidence interval. The graph was produced in the Excel file Mass loading graphs.xIs (Appendix C).

Nieuwenhuijsen et al. (1998 [DIRS 150855]) measured higher levels of personal exposure to TSP during a smaller-scale study of farming operations at three experimental farms near Davis, California, during April through November. The soils in this region have a loam to silty loam texture and no rainfall occurred during the study (Nieuwenhuijsen and Schenker 1998 [DIRS 150854], p. 10). The mean TSP concentrations of 18 farming activities ranged from 0.7 (milking) to $98.6 \mathrm{mg} / \mathrm{m}^{3}$ (disking from an open cab); the average was $19.6 \mathrm{mg} / \mathrm{m}^{3}$ 
(Nieuwenhuijsen et al. 1998 [DIRS 150855], Table 2). Ten activities had geometric mean values greater than $10 \mathrm{mg} / \mathrm{m}^{3}$; all except cattle feeding and nut harvesting were field preparation or similar activities conducted from an open tractor cab. Concentrations measured during this study may be higher than those reported in the Sacramento study (Nieuwenhuijsen et al. 1999 [DIRS 150711]), because the Davis study was conducted only during the dry season and because 10 of the 18 activities were conducted in an open cab. Nieuwenhuijsen and Schenker (1998 [DIRS 150854], p. 11) reanalyzed data from the Davis study and concluded that the presence of an enclosed cab had a very large influence on exposure levels (e.g., exposure during disking was 50 times lower when conducted from an enclosed cab). Molocznik and Zagorski (1998 [DIRS 154281]) measured personal exposure to TSP during seven activities conducted by tractor drivers on large farms and by farmers on small, private farms in Poland. Figure 2 of the Molocznik and Zagorski report presents the results as the minimum and maximum average concentrations for seven types of activities (concentrations per activity are reported here as approximated whole numbers because the chart does not present more precise results). The activity with the highest concentrations, 2 to $58 \mathrm{mg} / \mathrm{m}^{3}$ (indoor occupations, including threshing of wheat indoors), does not apply to this analysis, because indoor threshing of wheat probably is not conducted in Amargosa Valley and because that activity would not result in exposure to a substantial amount of contaminated soil (i.e., only that remaining on the plant surface). The activity with the second highest concentrations was plant harvesting, ranging from about 3 to $35 \mathrm{mg} / \mathrm{m}^{3}$. The activity with the lowest concentrations was plant protection, ranging from about 2 to $5 \mathrm{mg} / \mathrm{m}^{3}$. The average of the midpoints of the six applicable values was about $9 \mathrm{mg} / \mathrm{m}^{3}$, with a range of 3.5 to $19 \mathrm{mg} / \mathrm{m}^{3}$. Activity budgets per farmer were also recorded and used to calculate average annual exposure to TSP per eight hours of work, which ranged from 5.3 to $10.8 \mathrm{mg} / \mathrm{m}^{3}$ for 10 tractor drivers and from 3.6 to $10.7 \mathrm{mg} / \mathrm{m}^{3}$ for 7 private farmers.

In a similar study of 10 females working on private farms in Poland, average personal exposure to TSP during six applicable activities (excluding household occupations) ranged from 1.3 to $23.6 \mathrm{mg} / \mathrm{m}^{3}$. The average of the six midpoints was $7.8 \mathrm{mg} / \mathrm{m}^{3}$ (range 2.5 to 14.4 ). Average personal exposure while working ranged from 3.5 to $9.3 \mathrm{mg} / \mathrm{m}^{3}$ (Molocznik and Zagorski 2000 [DIRS 159587], p. 47 and 48).

Personal exposure to TSP during routine work in 85 dairy barns in Wisconsin averaged $1.78 \mathrm{mg} / \mathrm{m}^{3}$ (geometric SD = 2.9). Area concentrations within barns averaged $0.74 \mathrm{mg} / \mathrm{m}^{3}$ (geometric SD = 3.05) (Kullman et al. 1998 [DIRS 159586], third page).

Personal exposure to TSP of bulldozer operators and other workers at three landfills in Ontario averaged $5.3 \mathrm{mg} / \mathrm{m}^{3}$ and ranged from 0.44 to $22.8 \mathrm{mg} / \mathrm{m}^{3}$. Only one measurement was greater than $10 \mathrm{mg} / \mathrm{m}^{3}$ (Mozzon et al. 1987 [DIRS 159585], p. 115).

Clausnitzer and Singer (1997 [DIRS 160404]) measured exposure to $\mathrm{PM}_{4}$ during farming activities conducted in Davis, California. Sampler inlets were placed directly on farm implements; therefore, dust concentrations may have been higher than those experienced by equipment operators if the inlets were located closer to the source of dust than operators or if operators were within enclosed cabs. The texture of the surface soil was clay loam. Average (arithmetic) concentrations of respirable dust during 29 farming activities ranged from 0.2 to $13.6 \mathrm{mg} / \mathrm{m}^{3}$. The average of those 29 activities was $2.9 \mathrm{mg} / \mathrm{m}^{3}$. Eighteen of the activities had average concentrations of equal to or less than $2 \mathrm{mg} / \mathrm{m}^{3}$. Only one activity (land 
planing, $13.6 \mathrm{mg} / \mathrm{m}^{3}$ ) had an average concentration more than $10 \mathrm{mg} / \mathrm{m}^{3}$, and four others had concentrations greater than $5 \mathrm{mg} / \mathrm{m}^{3}$ (Clausnitzer and Singer 1997 [DIRS 160404], Table 1).

Archer et al. (2002 [DIRS 168488], Table I) measured personal exposure to $\mathrm{PM}_{4}$ during farming activities in North Carolina. The soils there had a loamy sand to sandy loam texture (Archer et al. 2002 [DIRS 168488], p. 754). The arithmetic mean concentration of 37 measurements was $1.31 \mathrm{mg} / \mathrm{m}^{3}(\mathrm{SD}=2.87)$. The only activity having an average concentration of more than $1.3 \mathrm{mg} / \mathrm{m}^{3}$ was planting of sweet potatoes (average $=7.62$ ). The average of all activities except planting of sweet potatoes was $0.32 \mathrm{mg} / \mathrm{m}^{3}$.

\subsubsection{Mass Loading Measurements in Amargosa Valley - Methods and Results}

Measurements of atmospheric mass loading in the active outdoors environment were performed in Amargosa Valley for various agricultural, domestic, and recreational activities. The measurements were taken by the Desert Research Institute staff during a two-day campaign in the late fall of 2005 (DTN: MO0603UCCF01JS.001 [DIRS 176759]).

Methods - The mass loading readings were taken using the DustScan Scout Model 3020 Aerosol Monitor. DustScan Scout is a battery-operated, compact handheld survey tool that can be used to assess particulate matter concentrations in indoor and outdoor environments. The DustScan Scout unit is a light scattering device that provides real-time particulate measurements. The monitor can be operated either in its TSP (inhalable, total suspended particulates) mode without a foam insert, or with a defined collection efficiency at $50 \%$ collection efficiency cut points of $10 \mu \mathrm{m}$ (thoracic, $\mathrm{PM}_{10}$ ), $4.5 \mu \mathrm{m}$ (respirable) and $2.5 \mu \mathrm{m}$ (fine, $\mathrm{PM}_{2.5}$ ). The instrument has a very large dynamic range, with the ability to assess PM concentrations in clean ambient settings as well as heavily loaded environments. The system makes use of near-forward light scattering to assess the concentration of particulate matter in ambient air. It is an advanced nephelometer with auto zeroing and continuous optics purging. The light source is a safetyinterlocked laser that operates at a wavelength of $670 \mathrm{~nm}$. The scattered light caused by the presence of particles is received by a sensor, forming the basis of the monitor's computations.

To measure concentrations of airborne particulates in Amargosa Valley in the active outdoors environments the monitor was operated in the TSP mode and was placed as close as possible to a person involved in soil-disturbing activities, for example by being held on a shoulder during activities involving walking, or positioned by a driver. The hourly averaged wind speed at the time of measurements was between 4.3 and $6.0 \mathrm{mph}$ on the first day of the campaign and about $2.1 \mathrm{mph}$ on the second day, although there were periods of no detectable wind while the measurements were taken (CEMP 2006 [DIRS 176393], CEMP 2006 [DIRS 176776]). The most recent precipitation prior to the time of measurement occurred over a month before (CEMP 2006 [DIRS 176777]; CEMP 2006 [DIRS 176779]; CEMP 2006 [DIRS 176780]). Since the measurements took place in the late autumn, the fields adjacent to the farm where most of the measurements were taken had not been irrigated for over two months so the soil likely was drier than it would be during the growing season.

The local meteorological conditions at the time of mass loading measurements were obtained from the Community Environmental Monitoring Program (CEMP) system. The CEMP is a network of monitoring stations located in communities surrounding the Nevada Test Site that 
monitor the airborne environment for manmade radioactivity that could result from Nevada Test Site activities. The CEMP network includes a station in Amargosa Valley.

Table 6-7 contains a summary of mass lading measurements for various activities that cause soil resuspension (DTN: MO0603UCCF01JS.001 [DIRS 176759]). The activities include driving on dirt roads, doing farm work, gardening and recreating. Table 6-7 shows the mean TSP concentration for the activity as well and the minimum and maximum instantaneous values measured while the activity was conducted. The results shown in Table 6-7 are different from those shown in Table 6-6, where the ranges of the mean mass loading values for different activities are presented, rather than the ranges of instantaneous values.

Table 6-7. Mass Loading Measurements for Active Outdoor Environment in Amargosa Valley

\begin{tabular}{|c|c|c|c|c|c|}
\hline \multicolumn{3}{|r|}{ Activity } & \multicolumn{3}{|c|}{$\operatorname{TSP}\left(\mathrm{mg} / \mathrm{m}^{3}\right)$} \\
\hline & Description & Details & Mean & Minimum & Maximum \\
\hline 1 & \multirow{5}{*}{$\begin{array}{l}\text { Driving on } \\
\text { unpaved } \\
\text { road }\end{array}$} & $20 \mathrm{mph} 20 \mathrm{ft}$ behind another vehicle, windows down (open) & 3.261 & 0 & 7.048 \\
\hline 2 & & $20 \mathrm{mph} 60 \mathrm{ft}$ behind another vehicle, windows down (open) & 0.598 & 0.121 & 1.741 \\
\hline 3 & & $\begin{array}{l}20 \mathrm{mph} 20 \mathrm{ft} \text { behind another vehicle, windows up (closed), } \\
\text { but vents open }\end{array}$ & 1.586 & 0.907 & 2.273 \\
\hline 4 & & $\begin{array}{l}20 \mathrm{mph} 60 \mathrm{ft} \text { behind another vehicle, windows up (closed), } \\
\text { but vents open }\end{array}$ & 0.681 & 0.025 & 2.406 \\
\hline 5 & & Single vehicle, windows open & 0.082 & 0 & 0.327 \\
\hline 6 & \multirow{7}{*}{$\begin{array}{l}\text { Farm } \\
\text { activities }\end{array}$} & Walking near moving tractor & 0.011 & 0 & 0.049 \\
\hline 7 & & Working around animals & 0.125 & 0.001 & 0.822 \\
\hline 8 & & Moving large animals (cattle) & 0.202 & 0.001 & 2.441 \\
\hline 9 & & Tractor operator while moving hay bales (open cab) & 0.672 & 0.097 & 1.679 \\
\hline 10 & & Pitchforking hay to animals & 0.047 & 0.001 & 0.315 \\
\hline 11 & & Tractor operator while working in orchard & 0.461 & 0.001 & 5.17 \\
\hline 12 & & Splitting wood & 0.136 & 0 & 1.377 \\
\hline 13 & \multirow{2}{*}{$\begin{array}{l}\text { Driving an } \\
\text { all-terrain } \\
\text { vehicle }\end{array}$} & $\begin{array}{l}\text { On unimproved dirt road (a cut in the local ground) at } \\
\text { relatively low speed }\end{array}$ & 1.284 & 0.001 & 19.28 \\
\hline 14 & & On improved dirt road at higher speeds (up to $35 \mathrm{mph}$ ) & 0.230 & 0.013 & 1.594 \\
\hline 15 & Dairy & Fenceline, cows moving, some vehicles & 0.059 & 0.001 & 0.423 \\
\hline 16 & \multirow[t]{4}{*}{ Home } & Hand tool gardening & 0.022 & 0 & 0.066 \\
\hline 17 & & Rototilling small garden plot & 0.964 & 0 & 6.849 \\
\hline 18 & & Walking dog & 0.083 & 0 & 0.578 \\
\hline 19 & & Walking dog; dog digging for gopher & 0.281 & 0 & 7.636 \\
\hline 20 & \multirow{3}{*}{$\begin{array}{l}\text { Walking on } \\
\text { disturbed } \\
\text { surface }\end{array}$} & Dirt road (disturbed surface) with periodic cars driving by & 0.079 & 0 & 0.75 \\
\hline 21 & & $\begin{array}{l}\text { Dirt road (disturbed surface) with periodic cars driving by } \\
\text { (simulated heavy traffic not typical for Amargosa Valley) }\end{array}$ & 0.486 & 0 & 3.851 \\
\hline 22 & & Dirt road (disturbed surface) with no cars nearby & 0 & 0 & 0 \\
\hline
\end{tabular}


Table 6-7. Mass Loading Measurements for Active Outdoor Environment in Amargosa Valley (Continued)

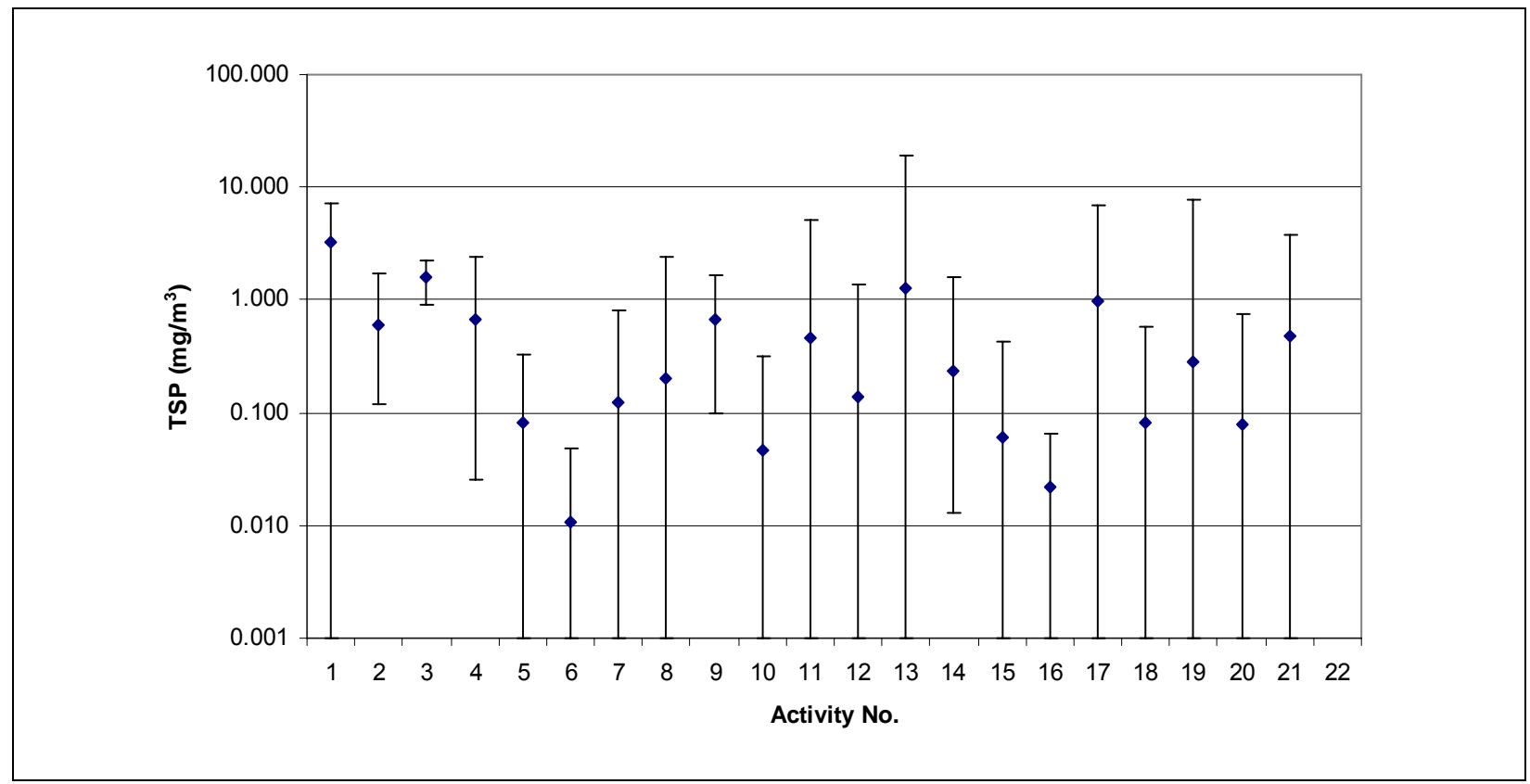

Source: DTN: MO0603UCCF01JS.001 [DIRS 176759].

NOTE: In the graph above, diamonds represent the means and vertical bars represent ranges of instantaneous measured values. The graph was produced in the Excel file Mass loading Amargosa Valley.xls (Appendix C).

The average TSP for all activities that disturbed soil surface was $0.52 \mathrm{mg} / \mathrm{m}^{3}$; the minimum average TSP for a soil-disturbing activity was $0 \mathrm{mg} / \mathrm{m}^{3}$; and the maximum average value measured was $3.3 \mathrm{mg} / \mathrm{m}^{3}$ (Excel file Mass loading Amargosa Valley.xls in Appendix C).

The instantaneous maxima were higher, up to almost $20 \mathrm{mg} / \mathrm{m}^{3}$ but the instantaneous measurements also included many low values, both of which influence the mean. The average of instantaneous maximum values for all soil-disturbing activities in Amargosa Valley was $3.0 \mathrm{mg} / \mathrm{m}^{3}$.

The results of instantaneous measurement show that even during the soil-disturbing activities there are periods of time when the particulate concentrations in air are near zero. This is consistent with the relatively fast decrease of elevated mass loading after the soil-disturbing activity has temporarily ceased, which is described below. The highest instantaneous value occurred while driving an all-terrain vehicle (ATV) on an unimproved farm road at relatively low speed, especially while the vehicle was slowed down (e.g., to turn) and the dust cloud generated by the ATV "caught up" with the driver. The only instance when walking was accompanied by a relatively high mass loading involved walking on dirt road with simulated heavy vehicular traffic. In this scripted scenario, the frequency of cars driving by a pedestrian carrying the TSP measuring instrument exceeded by far what would be typically expected in Amargosa Valley. Walking alone, in the absence of mechanical disturbance of the soil, did not generate elevated TSP concentrations (Tables 6-7 and 6-9). 
The duration of the peak TSP concentrations, when they were caused by transient events, such as a car driving by on a dirt road or large animals running by, was usually less than a minute and localized in extent because of fast settling of the resuspended soil (Excel file Mass loading Amargosa Valley.xls in Appendix C). Sustained activities, such as driving a tractor, could also cause periodical short-term increase in TSP concentrations measured by the driver, especially when driving into the resuspended dust cloud while maneuvering the tractor.

Overall, the average TSP concentrations measured in Amargosa Valley during soil-disturbing activities were lower than those recorded during farming activities conducted in a similar setting, e.g., those measured in southern California (Table 6-6). Most activities did not generate average TSP concentrations greater than $1 \mathrm{mg} / \mathrm{m}^{3}$, while all measurements in southern California (listed in Table 6-6) recorded average TSP greater than $1 \mathrm{mg} / \mathrm{m}^{3}$. Possible reasons for this difference include different soil textures and different types of agricultural activities that were conducted while the measurements were taken.

\subsubsection{Parameter Distribution}

The distribution of mass loading recommended for use in the biosphere model must be representative of the average annual concentration that would be experienced by the RMEI within this environment (see Sections 6.1.1 and 6.1.2). Therefore, extremely high or low values associated with activities that are conducted infrequently would be outside of the range of the distribution of the annual average concentration.

Based on the results of Nieuwenhuijsen et al. (1999 [DIRS 150711]), which constitute the bulk of the available experimental results at analogue locations over extended periods of time, and the results from Amargosa Valley, a triangular distribution with a mode of $3 \mathrm{mg} / \mathrm{m}^{3}$, minimum of $1 \mathrm{mg} / \mathrm{m}^{3}$, and maximum of $10 \mathrm{mg} / \mathrm{m}^{3}$ is selected. The mode of $3 \mathrm{mg} / \mathrm{m}^{3}$ corresponds to the average maximum mass loading measured in Amargosa Valley during soil-disturbing activities, as shown in the previous section. This value is about $1 \mathrm{mg} / \mathrm{m}^{3}$ higher than the average of activities monitored by Nieuwenhuijsen et al. (1999 [DIRS 150711], Table 2). It is also higher than most of the average TSP measurements in Amargosa Valley but lower than the average or midpoint of some of the other studies (Tables 6-6 and 6-7). The activities monitored in Amargosa Valley did not include field preparation or harvesting, which in other studies involved relatively high TSP concentration (although riding an open-cab tractor was included among the Amargosa Valley activities). The activities included in the Amargosa Valley measurements were, however, more typical of those that would likely be conducted at a small farm or at a residence of an individual not involved in farming full-time, which is representative of the majority of the Amargosa Valley population (BSC 2005 [DIRS 172827], Section 6.3.1). The minimum value was selected to bound possible minimum concentrations in this environment in the Yucca Mountain region, where there are few outdoor workers and where many soil-disturbing activities likely do not involve the use of farm implements or other mechanical devices. The selected minimum value was still higher than the average TSP measured for many soil-disturbing activities in Amargosa Valley (Table 6-7). The upper bound was selected to bound uncertainty in the consistency of precipitation, soil texture, and other conditions at the analogue study sites with the conditions in the Yucca Mountain region. 
Numerous factors, including the type of activity or operation, use of an enclosed tractor cab, relative humidity and other climatic factors, and soil texture have been identified that influence the concentrations of resuspended particles during farming activities (Clausnitzer and Singer 1997 [DIRS 160404]; Niewenhuijsen et al. 1998 [DIRS 150855]; Nieuwenhuijsen and Schenker 1998 [DIRS 150854]; Archer et al. 2002 [DIRS 168488]). Based on these studies, the important factors identified that are relevant to evaluating uncertainty in the use of the analogue measurements and the consistency of the selected distributions of mass loading with the conditions in the Yucca Mountain region are the types of activities conducted during the studies and the climate and soil texture at the study sites. The TSP values measured in Amargosa Valley were lower than those measured by Nieuwenhuijsen et al. (1999 [DIRS 150711]) at 10 farms near Davis and Sacramento, California. One reason for the difference could be that cultivated soils in that area generally are silty clay loams to clays and loams (Andrews 1972 [DIRS 170526]) while soils in Amargosa Valley are generally sandy loams, i.e., have a higher fraction of coarser soil separates.

Dust concentrations were measured during a wide variety of farming activities. Activities with the highest dust concentrations generally were soil preparation, planting, and other activities that required direct disturbance of the soil and that were conducted from an open tractor cab or other farm implement. Activities that were conducted in an enclosed cab or did not involve intensive soil disturbance had much lower dust concentrations. Typical dust-generating activities conducted by people while working outdoors in Amargosa Valley include field preparation, harvesting, and other activities required to grow field crops; livestock feeding and management; and excavating. Because most crops grown in Amargosa Valley are perennials such as alfalfa and fruit and nut trees, disking, plowing, and other soil-disturbing activities that generate very high concentrations of dust are conducted infrequently. People in Amargosa Valley would also generate dust while gardening, landscaping, walking on loose soil, or participating in other recreational activities outdoors. Gardening using hand tools, home landscaping, and similar activities would generate less dust than the soil-disturbing agricultural activities included in the studies reviewed above, because large mechanical equipment usually is not used. This was confirmed by the TSP concentration measurements in Amargosa Valley (Table 6-7).

It is estimated that local outdoor workers comprise 5.5 percent of the Amargosa Valley population and spend 3.1 hours per day in the active outdoor environment. The remainder of the population is estimated to spend 0.3 hours active outdoors (BSC 2005 [DIRS 172827], Sections 6.3.1 and 6.3.2). Thus, about 62 percent of the time spent outdoors by this population is spent by people not employed in farming or other local, outdoor occupations $([0.945 \times 0.3$ hours $] /[0.945 \times 0.3$ hours $+0.055 \times 3.1$ hours $])$. Because soil-disturbing activities are conducted infrequently on agricultural fields in Amargosa Valley, and because much of the time spent in this environment by the population is during recreational and other non-occupational activities, the average concentration in this environment in the Yucca Mountain region will be lower than that reported in the studies summarized in Table 6-6. The lower bound of the distribution was selected as a reasonable minimum estimate of conditions in the Yucca Mountain region for the population. This value is similar to the lower concentrations measured during farming and other activities in the reviewed studies. However, it is lower than that measured while conducting most soil-disturbing activities in Amargosa Valley. 
Soil moisture, relative humidity, wind speed, and other climate-related factors may affect mass loading concentrations during soil-disturbing activities. The influence of these and other factors on average particulate concentrations in air was discussed in Sections 6.1.3 to 6.1.5 but the conclusions are likely to remain valid for the conditions involving disturbance of surface soil. Two of the analogue studies (Nieuwenhuijsen et al. 1998 [DIRS 150855]; Nieuwenhuijsen et al. 1999 [DIRS 150711]) were conducted in a semi-arid environment, but the other studies were conducted in more mesic regions. The lower precipitation and relative humidity (and possibly other differences such as wind speed) could result in higher concentrations of resuspended particles than those measured in some of the studies reviewed. However, soil moisture during the growing and harvesting season likely was similar among studies because soil moisture must be maintained within the tolerance limits of crops. An upper bound of $10 \mathrm{mg} / \mathrm{m}^{3}$ was selected to account for uncertainty in differences in climate between the studies reviewed and the conditions in the Yucca Mountain region. This bound includes average concentrations from all Amargosa Valley measurements, all but one activity measured by Nieuwenhuijsen et al. (1999 [DIRS 150711]), and all average measurements made in the other studies except those from cultivating, plowing, disking, or similar activities conducted from an open cab. A higher bound was not selected because the types of activities that would result in concentrations greater than $10 \mathrm{mg} / \mathrm{m}^{3}$ would be conducted infrequently by the population in the Yucca Mountain region and therefore a higher value would not be representative of average annual conditions in the region.

The proportion of resuspendable material in soil (i.e., soil texture) may also influence mass loading during soil-disturbing activities. Soils in northern Amargosa Valley are sandy to sandy loams and have a low proportion of readily resuspendable material in the surface layer. For example, the surface layer of the Shamock gravelly fine sandy loam soil type found along Fortymile Wash north of Highway 95 has a soil texture of more than 80 percent sand and 3 to 8 percent clay, with 50 to 70 percent coarse fragments larger than $2 \mathrm{~mm}$ (CRWMS M\&O 1999 [DIRS 107736], Table 2 and Appendix B). The four studies reviewed above for which soil texture could be determined were conducted on soils having a similar or higher proportion of smaller particles (i.e., clay and silt) than those in northern Amargosa Valley. Thus, the measurements from those studies should bound uncertainty in the influence of soil texture on mass loading (also see discussion on the influence of soil texture on average mass loading in Section 6.1.4).

The selected distribution of mass loading for the active outdoor environment ranges over an order of magnitude. This distribution was selected to bound uncertainty about the influence of relevant conditions in the studies reviewed to the current conditions in the Yucca Mountain region. Therefore, this distribution is consistent with the applicable current conditions in the Yucca Mountain region. This consistency supports a conclusion that the FEPs associated with this parameter (Table 1-1) are also consistent with the present knowledge of the conditions in the region surrounding the Yucca Mountain site, as required by 10 CFR 63.305(a) [DIRS 173273].

\subsubsection{Inactive Outdoor Environment}

Averages of TSP concentrations measured over 24-hour periods at stationary, outdoor sites in arid to semi-arid, rural, agricultural settings in the western United States were used to develop a distribution of mass loading for the inactive outdoor environment. These data were selected 
because measurements taken at stationary, outdoor sites are consistent with the conditions that would be experienced by a person in the rural, agricultural setting of the Yucca Mountain region who is outdoors and not conducting activities that resuspend dust.

Average concentrations calculated from measurements taken over 24-hour periods are appropriate for use in this analysis because they are representative of average conditions within an environment. Measurements taken over shorter periods would have greater variation because they would include short-term peaks in concentrations of resuspended particles. Including those short-term peaks in the distribution of mass loading would be invalid because they are not representative of average annual concentrations. As described in Section 6.1.2, distributions representative of average annual conditions are required in the biosphere model to calculate an annual dose to the RMEI for evaluation of compliance with the annual dose limit specified in 10 CFR 63.311 [DIRS 173273].

\subsubsection{Selection of Data}

A database of average annual concentrations of TSP for the United States and territories for 1970 through 2001 was obtained from the AirData database managed by the EPA Office of Air and Radiation (DTN: MO0210SPATSP01.023 [DIRS 160426]; see Section 4.1.2). All correspondence and data files associated with this set of data are located in the Records Information System and can be accessed via the link on the Automatic Technical Data Information Form for this DTN in the Technical Data Management System. The data were obtained via e-mail, rather than from the EPA AirData internet database, because that internet database does not provide access to TSP data.

Two datasets received from the EPA were used in this analysis:

1. KR450TSP.TXT, obtained from the EPA on September 6, 2002 (Ambrose 2002 [DIRS 160080]). This dataset contains 76,220 records. Each record includes an annual average concentration of TSP at a monitoring site.

2. KR380.NATION.TXT, obtained from the EPA on September 17, 2002 (Ambrose 2002 [DIRS 160081]). This dataset contains 11,763 records. Each record contains site description information (e.g., address, setting, years active) for TSP monitoring sites.

Information from these two datasets were imported into an Access database (24h TSP Database.mdb, see Appendix C) and parsed according to the report manual (AQ1.WPD) provided by the EPA (Ambrose 2002 [DIRS 160080]). The two files were then merged by station number to create a database labeled COMBINEDTSP that contains all the TSP data (from KR450TSP.TXT) for each station as well as the site description data (from KR380.NATION.TXT).

The following was done to select data from sites having conditions that are consistent with the current conditions in the Yucca Mountain region. The database COMBINEDTSP was queried to obtain all records having a land use classification of agricultural (EPA code $=4$ ), and a location setting of rural (EPA code $=3$ ) for the following eight states: Arizona, California, Idaho, Nevada, New Mexico, Oregon, Utah, Washington. These states were selected to ensure that a large sample of analogue sites with a climate consistent with present-day and predicted future conditions for Yucca Mountain would be selected. The rural, agricultural location and land use 
classifications were selected to match the setting, land use, and range of surface disturbing conditions in Amargosa Valley. That query resulted in a list of 486 valid annual measurements. Fifty-nine of those measurements from sites located west of the Cascade Range in Oregon were eliminated from further consideration because the climate in that region is not consistent with Yucca Mountain conditions. An additional 32 duplicate annual averages (included by EPA to present annual averages with and without unusually high 24-hour measurements) were deleted; the lower of the values for a year were deleted. The remaining 395 records for 68 sites are listed in the file Subset TSP_Rural Agricultural Sites.xls (Appendix C).

To identify which sites have an arid or semi-arid climate, representative data on average annual precipitation and snowfall were obtained for the 68 sites from NCDC reports (NCDC 1998 [DIRS 135900]; NCDC 1998 [DIRS 125325]) (Table B-2). Information for each site was then examined to select those that are appropriate analogue sites for Amargosa Valley. Sites were deleted or selected for the following reasons.

- Two sites (35-006-0007 and 35-061-0007) were combined because they were in the same location but had different New Mexico county codes, resulting in a total of 67 sites.

- Ten sites were deleted because average annual precipitation exceeded 20 in. (Table B-2). The average TSP concentration of those sites was $0.036 \mathrm{mg} / \mathrm{m}^{3}(\mathrm{SD}=0.009)$. An additional 11 sites were deleted because average annual snowfall exceeded $20 \mathrm{in}$. (arithmetic mean concentration $\left.=0.053 \mathrm{mg} / \mathrm{m}^{3}, \mathrm{SD}=0.026\right)($ Table B-2). This was done to ensure that only sites with a climate that is consistent with present-day and potential future conditions at Yucca Mountain were included. Arid sites generally are considered to have less than about 10 in. of precipitation per year (Brady and Weil 1999 [DIRS 160019], p. 830) and the future climate for the next 10,000 years is predicted to have a maximum precipitation of 16 to 18 in. per year (BSC 2004 [DIRS 170002], Section 6.6.2; NCDC 1998 [DIRS 125325]). The results of this analysis show little sensitivity to these cutoff values. The average TSP concentration for the 20 sites with less than $10 \mathrm{in}$. of precipitation (mean $=0.060 \mathrm{mg} / \mathrm{m}^{3}, \mathrm{SD}=0.036$ ) was similar to that for 57 sites with less than 20 in. (mean $=0.056 \mathrm{mg} / \mathrm{m}^{3}, \mathrm{SD}=0.029$ ), and to all 67 sites (mean $=0.053 \mathrm{mg} / \mathrm{m}^{3}, \mathrm{SD}=0.028$ ). Likewise, the average concentration for the 42 sites with less than $10 \mathrm{in}$. of snowfall (mean $=0.056 \mathrm{mg} / \mathrm{m}^{3}, \mathrm{SD}=0.031$ ) was similar to that for 52 sites with less than 20 in. (mean $=0.054 \mathrm{mg} / \mathrm{m}^{3}, \mathrm{SD}=0.030$ ) and to all 67 sites (mean $=0.053 \mathrm{mg} / \mathrm{m}^{3}, \mathrm{SD}=0.028$ ). (Also, see discussion in Section 6.1.3.1.)

- Based on the site description information in the file KRNATIONRPT.WPD (Ambrose 2002 [DIRS 160081]), one site (04-019-0009) was deleted because it was near an electrical power plant, and a second (04-013-0008) was deleted because it had abnormal readings "due to substantial updraft." These two sites had average TSP concentrations of 0.081 and $0.131 \mathrm{mg} / \mathrm{m}^{3}$, respectively.

- Twenty-three sites were deleted because there was more than one monitoring site within a county (Table B-2). The average concentration at those sites was $0.051 \mathrm{mg} / \mathrm{m}^{3}$ $(\mathrm{SD}=0.035)$. For counties with more than one monitoring station, the site with the greatest number of years of data was selected. If sites within a county had the same 
number of years of data, the site with the highest average TSP was chosen (because a higher TSP will result in a higher predicted inhalation dose, see Equation 6-1).

The remaining 21 sites had an average TSP concentration of $0.057 \mathrm{mg} / \mathrm{m}^{3}$ (SD $\left.=0.019\right)$ (Table 6-8). The minimum and maximum annual average concentrations were 0.025 and $0.089 \mathrm{mg} / \mathrm{m}^{3}$, respectively.

Table 6-8. Average Concentration of TSP at 21 Selected Monitoring Sites

\begin{tabular}{|c|c|c|c|c|c|}
\hline EPA Site ID ${ }^{a}$ & State & City & County & $\operatorname{TSP}\left(\mathrm{mg} / \mathrm{m}^{3}\right)$ & N Years \\
\hline 04-007-1902 & Arizona & Miami & Gila & 0.030 & 8 \\
\hline 04-019-0010 & Arizona & Tucson & Pima & 0.089 & 2 \\
\hline 06-013-1002 & California & Bethel Island & Contra Costa & 0.041 & 6 \\
\hline 06-019-1002 & California & Five Points & Fresno & 0.078 & 13 \\
\hline 06-027-0002 & California & Bishop & Inyo & 0.025 & 8 \\
\hline 06-031-1002 & California & Kettleman City & Kings & 0.086 & 9 \\
\hline 06-071-1101 & California & Twentynine Palms & San Bernardino & 0.049 & 11 \\
\hline 06-083-1011 & California & Jalama & Santa Barbara & 0.045 & 7 \\
\hline 06-111-3001 & California & El Rio & Ventura & 0.064 & 13 \\
\hline 06-113-4001 & California & Dunnigan & Yolo & 0.044 & 13 \\
\hline $32-003-1003$ & Nevada & Moapa & Clark & 0.061 & 1 \\
\hline $32-031-1004$ & Nevada & Sparks & Washoe & 0.054 & 12 \\
\hline $35-013-0004$ & New Mexico & Sunland Park & Dona Ana & 0.080 & 17 \\
\hline $35-017-0002$ & New Mexico & Hurley & Grant & 0.085 & 3 \\
\hline $35-045-0014$ & New Mexico & Kirtland & San Juan & 0.044 & 14 \\
\hline 35-061-0007 & New Mexico & Bluewater & Cibola/Valencia & 0.071 & 6 \\
\hline 41-059-1001 & Oregon & Pendleton & Umatilla & 0.040 & 5 \\
\hline 49-015-0002 & Utah & Huntington & Emery & 0.030 & 4 \\
\hline 53-039-0002 & Washington & Bingen & Klickitat & 0.056 & 4 \\
\hline $53-071-1001$ & Washington & Wallula Junction & Walla Walla & 0.066 & 9 \\
\hline \multirow[t]{3}{*}{$53-077-0003$} & Washington & Sunnyside & Yakima & 0.062 & 10 \\
\hline & & & Average $=$ & 0.057 & \\
\hline & & & $S D=$ & 0.019 & \\
\hline
\end{tabular}

Source: DTN: MO0210SPATSP01.023 [DIRS 160426]. Note that site ID numbers are not presented with leading zeros or dashes in the database.

a See Appendix $B$ for additional descriptions of these sites and annual average measurements.

Average TSP=average of annual average concentrations; $S D=$ standard deviation.

Airborne mass loads for inactive outdoor environment are used in the biosphere model to calculate the inhalation exposure while the RMEI is outdoors not involved in soil-disturbing activities (Section 6.1.1). Such a categorization implies primarily daytime occupancy of this environment. However, the TSP measurements at the EPA sites were derived from 24-hour average values. Temporal variability in ambient particulate matter concentrations was discussed in Air Quality Criteria for Particulate Matter (EPA 2004 [DIRS 175978], Section 3.2). Seasonal and diurnal (circadian) variability was observed in the particulate matter concentrations. Diurnal variability arises from interactions between variations in emissions (soil-disturbing activities 
usually take place at daytime) and the vertical extent and intensity of turbulent mixing in the atmospheric boundary layer near the soil surface.

Generally, there is a distinct pattern in the particulate matter concentrations with maxima occurring during the day. However, there is also substantial day-to-day variability in the diurnal profile of PM measured at the same location (EPA 2004 [DIRS 175978], Section 3.2.2), which tends to attenuate the peaks in the annually averaged diurnal PM profile (EPA 2004 [DIRS 175978], Figure 3-17).

The measurements of TSP concentrations in Amargosa Valley, described in Section 6.2.1.2, included a few activities (walking and driving on paved road) that in the biosphere model are associated with the inactive outdoors environment. The summary of these measurements is shown in Table 6-9.

Table 6-9. Summary of Mass Loading Measurements for Inactive Outdoor Environment in Amargosa Valley

\begin{tabular}{|c|l|l|c|c|c|}
\hline \multicolumn{2}{|c|}{ Activity } & \multicolumn{3}{c|}{ TSP $\left(\mathbf{m g} / \mathbf{m}^{3}\right)$} \\
\hline & \multicolumn{1}{|c|}{ Description } & \multicolumn{1}{c|}{ Details } & Average & Minimum & Maximum \\
\hline 1 & $\begin{array}{l}\text { Driving on paved } \\
\text { road }\end{array}$ & $\begin{array}{l}60 \mathrm{mph}, 30 \text { to } 40 \mathrm{ft} \text { behind another vehicle, } \\
\text { windows open }\end{array}$ & 0.032 & 0 & 0.073 \\
\cline { 3 - 6 } & $\begin{array}{l}\text { 60 mph, 30 to 40 ft behind another vehicle, } \\
\text { windows closed, but vents open }\end{array}$ & 0.013 & 0 & 0.025 \\
\hline 3 & Walking & Dry grassy surface undisturbed & 0 & 0 & 0 \\
\cline { 3 - 6 } & Dirt undisturbed desert surface & 0.003 & 0.003 & 0.003 \\
\hline
\end{tabular}

Source: DTN: MO0603UCCF01JS.001 [DIRS 176759].

The TSP concentrations associated with driving on paved roads and walking are consistent with the average TSP concentration at 21 selected monitoring sites shown in Table 6-8.

\subsubsection{Parameter Distribution}

The TSP concentrations in Table 6-8 do not appear to be symmetrically distributed because there are more values near the high end of the distribution ( 5 values from 0.078 to $0.089 \mathrm{mg} / \mathrm{m}^{3}$ ) than at the low end ( 3 values from 0.025 to $0.036 \mathrm{mg} / \mathrm{m}^{3}$ ). Therefore, a triangular distribution is selected for the nominal inactive outdoor environment with a mode of $0.060 \mathrm{mg} / \mathrm{m}^{3}$, minimum of $0.025 \mathrm{mg} / \mathrm{m}^{3}$, and maximum of $0.100 \mathrm{mg} / \mathrm{m}^{3}$. The mode and maximum are slightly higher than the average and maximum in Table 6-2 to account for the cluster of high values. This distribution encompasses most annual average values from rural agricultural sites in the entire set of EPA data. Of 426 annual average concentrations reported for rural agricultural sites in eight western states (range $=0.012$ to $0.173 \mathrm{mg} / \mathrm{m}^{3}$ ), only 18 were less than $0.025 \mathrm{mg} / \mathrm{m}^{3}$ and 17 were greater than $0.100 \mathrm{mg} / \mathrm{m}^{3}$; thus, the distribution encompasses or is greater than all but about 4 percent of the measurements from all rural, agricultural sites. (Also, see discussion in Section 6.1 .5 of the influence of site setting on mass loading.)

The modal value is much higher than concentrations measured at relatively undisturbed, non-agricultural sites at Yucca Mountain (minimum and maximum annual TSP concentrations equal 0.019 and $0.030 \mathrm{mg} / \mathrm{m}^{3}$, respectively) (CRWMS M\&O 1999 [DIRS 102877], Table 2-3). 
This confirms that the measurements selected are influenced to some extent by dust-disturbing activities, such as those encountered in agricultural settings or by some other sources of resuspended particles.

The important factors considered to evaluate uncertainty in the use of measurements from the stationary monitoring sites to predict the conditions in the Yucca Mountain region are the types and level of soil-disturbing activities, climate, vegetation, soil, and the applicability of the averaged TSP concentrations to the inactive outdoors environment.

The measurements considered in this analysis were taken in rural, agricultural settings. This setting matches the land use conditions and level of soil-disturbing activities in the occupied portion of the Yucca Mountain region (i.e., Amargosa Valley). Because the Yucca Mountain region has no unique sources of resuspended particles, and because the common sources of readily resuspendable particles there (gardens and cultivated land) would be common in rural agricultural monitoring settings elsewhere, the types and levels of soil-disturbing activities at the monitoring sites considered in this analysis are consistent with the conditions in the occupied portions of the Yucca Mountain region.

Precipitation and presence of vegetation may affect the resuspendability of soil particles. The difference in average ambient mass loading over the range of precipitation predicted to occur at Yucca Mountain over the next 10,000 years (Section 6.1.3) is insignificant, and, as described above, the results of this analysis are insensitive to the precipitation limits used to select data for this analysis. As a further example, the four sites listed in Appendix B, which have less than or equal to 6 in. of precipitation (i.e., consistent with present-day precipitation in northern Amargosa Valley), have an average ambient concentration of $0.053 \mathrm{mg} / \mathrm{m}^{3}$ ( $\mathrm{SD}=0.022$, range $=0.025$ to 0.078). The sites are Twentynine Palms, Moapa, Bishop, and Five Points; precipitation is listed in Table B-2. This is similar to the distribution of the values listed in Table 6-2 for all selected sites with less than $20 \mathrm{in}$. of precipitation. Those four sites also have sparse desert vegetation consistent with that in the Yucca Mountain region. Thus, precipitation and native vegetation at the analogue sites are sufficiently consistent with the conditions in the Yucca Mountain region and using one distribution for all climate states will not underestimate mass loading for the present-day climate.

Soil characteristics at the air-quality monitoring sites may affect mass loading but were not considered in the selection of data for use in this analysis for the following reason: Soils in northern Amargosa Valley are sandy to sandy loams and have a low proportion of readily resuspendable material in the surface layer and a well-developed, indurated layer of pebbles and cobble on the surface of most undisturbed areas. For example, the surface layer of the Shamock gravelly fine sandy loam soil type found along Fortymile Wash north of Highway 95 has a soil texture of more than 80 percent sand and 3 to 8 percent clay. Those soils also have 50 to 70 percent coarse fragments larger than 2 mm (CRWMS M\&O 1999 [DIRS 107736], Table 2 and Appendix B). Soils with a loam, silty loam, and other textures commonly found in farming areas have a higher percentage of readily resuspendable material than those found in northern Amargosa Valley (Brady and Weil 1999 [DIRS 160019], Figure 4.8). Thus, measurements of mass loading taken at monitoring sites on other soils bound the soil conditions in the Yucca Mountain region. (Also, see discussion of influence of soil morphology on mass loading in Section 6.1.4.) 
Other factors such as average annual wind speed, topography, and diurnal patterns of wind speed, that could have an influence mass loading in the inactive outdoor environment were not considered, because calculations of the amount of dust inhaled in the biosphere model are not sensitive to changes in mass loading in the inactive outdoor environment (Appendix A). This is because the RMEI spends on average only about 1.5 hours in the inactive outdoor environment (BSC 2005 [DIRS 173194], Figures 6.2-40 and 6.3-18) and the TSP concentration in the active outdoor environment is much greater thus accounting for the majority of the inhalation exposure to particulate matter. For example, tripling the average mass loading in this environment from 0.06 to $0.18 \mathrm{mg} / \mathrm{m}^{3}$ would increase the predicted amount of dust inhaled by about 5 percent (calculated using the methods described in Appendix A). This would have a similar effect on the calculation of BDCFs and predicted dose for those radionuclides for which inhalation is the dominant pathway $\left({ }^{237} \mathrm{~Np},{ }^{239} \mathrm{Pu}\right.$ ) (BSC 2005 [DIRS 172814], Tables 6.2-19 and 6.2-20) because of the linear equations used in those calculations (BSC 2004 [DIRS 169460], Sections 6.4.10 and 6.5.8). It would have a smaller effect on the BDCFs and predicted dose of radionuclides for which inhalation is not a dominant pathway (e.g., ${ }^{99} \mathrm{Tc},{ }^{129} \mathrm{I}$ ) (BSC 2005 [DIRS 172814], Tables 6.2-19 and 6.2-20). Thus, differences in conditions between the monitoring sites and the Yucca Mountain region not considered here would not affect the results of the biosphere model or result in underestimation of risk in the TSPA calculations. This conclusion was confirmed by the additional sensitivity studies included in Biosphere Dose Conversion Factor Importance and Sensitivity Analysis (BSC 2005 [DIRS 173194], Sections 6.2.5.2.1 and 6.3.5.1).

Because the most important conditions under which the analogue measurements were taken are consistent with the current conditions in the Yucca Mountain region, and because the biosphere model is not sensitive to changes that may result from other conditions not considered here, the distribution of mass loading in the inactive outdoor environment is consistent with the applicable conditions in the Yucca Mountain region. This consistency supports a conclusion that the FEPs associated with this parameter (Table 1-1) are also consistent with the present knowledge of the conditions in the region surrounding the Yucca Mountain site, as required by 10 CFR 63.305(a) [DIRS 173273].

\subsubsection{Active Indoor Environment}

A review of applicable literature (see Section 4.1.1) was conducted to identify average concentrations of resuspended particles measured indoors while people were present and awake. The results are summarized in Table 6-10. The relevant factors considered in evaluating whether the conditions under which those studies were taken are consistent with the present conditions in the Yucca Mountain region included the types of activities conducted, the types of dwellings or buildings within which the studies were conducted, and the ambient outdoor particle concentrations while the studies were being conducted.

Studies were considered applicable to the conditions in the active indoor environment in the Yucca Mountain region if measurements of ambient indoor particulate concentrations were taken while people were home and active or if personal particulate concentration (i.e., inlet of the monitoring device was located on a person) was measured while people were indoors and active. Because there are few public buildings in Amargosa Valley, and because about 40 percent of the population there does not work (Bureau of the Census 2002 [DIRS 159728], Table P43), measurements taken in homes were considered more applicable than those taken in public 
buildings. Because concentrations of TSP were measured in only three of the studies reviewed, studies that measured $\mathrm{PM}_{10}$ were also included.

Table 6-10. Particulate Concentrations-Nominal Indoor Active Environment

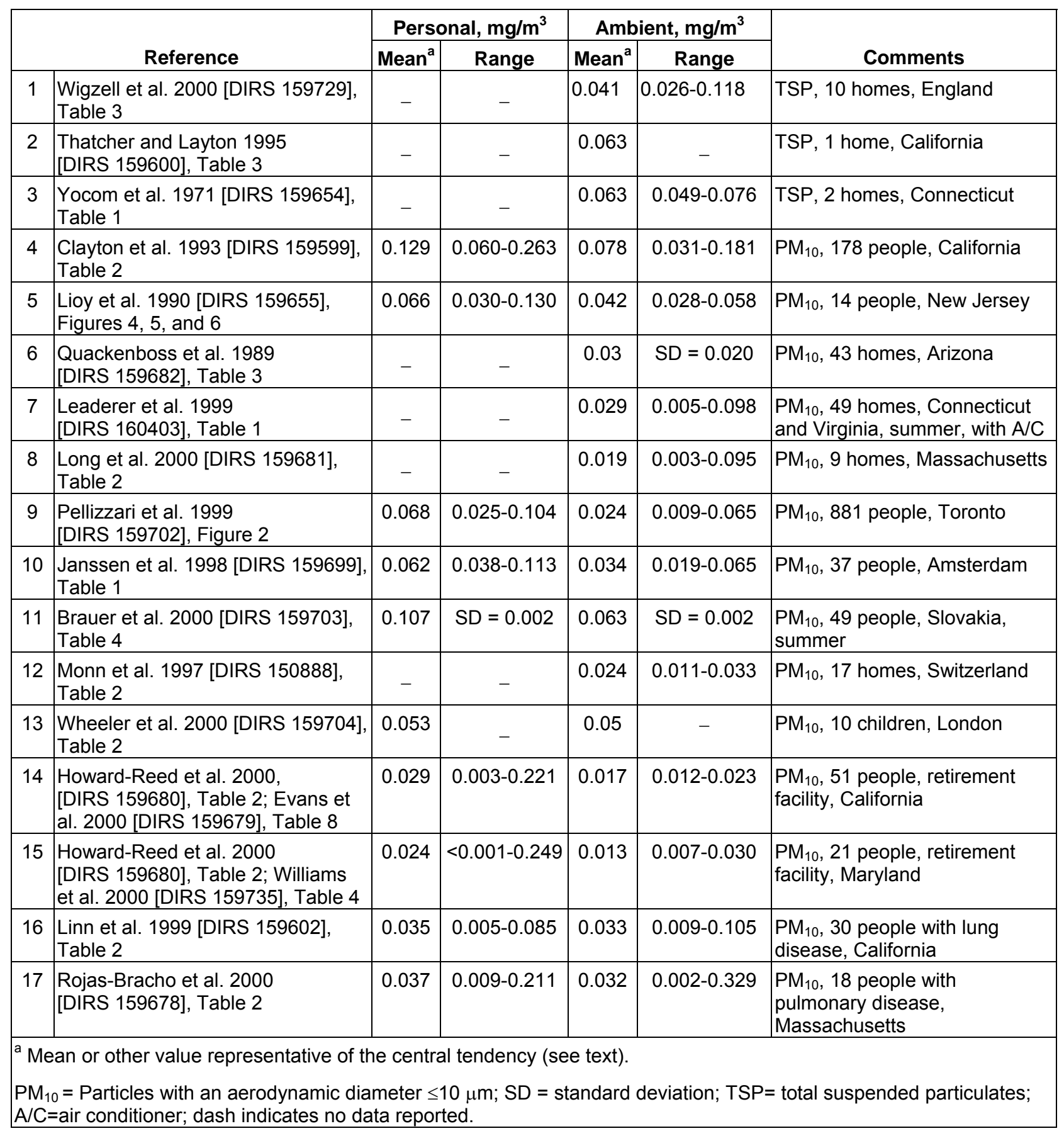


Table 6-10. Particulate Concentrations-Nominal Indoor Active Environment (Continued)

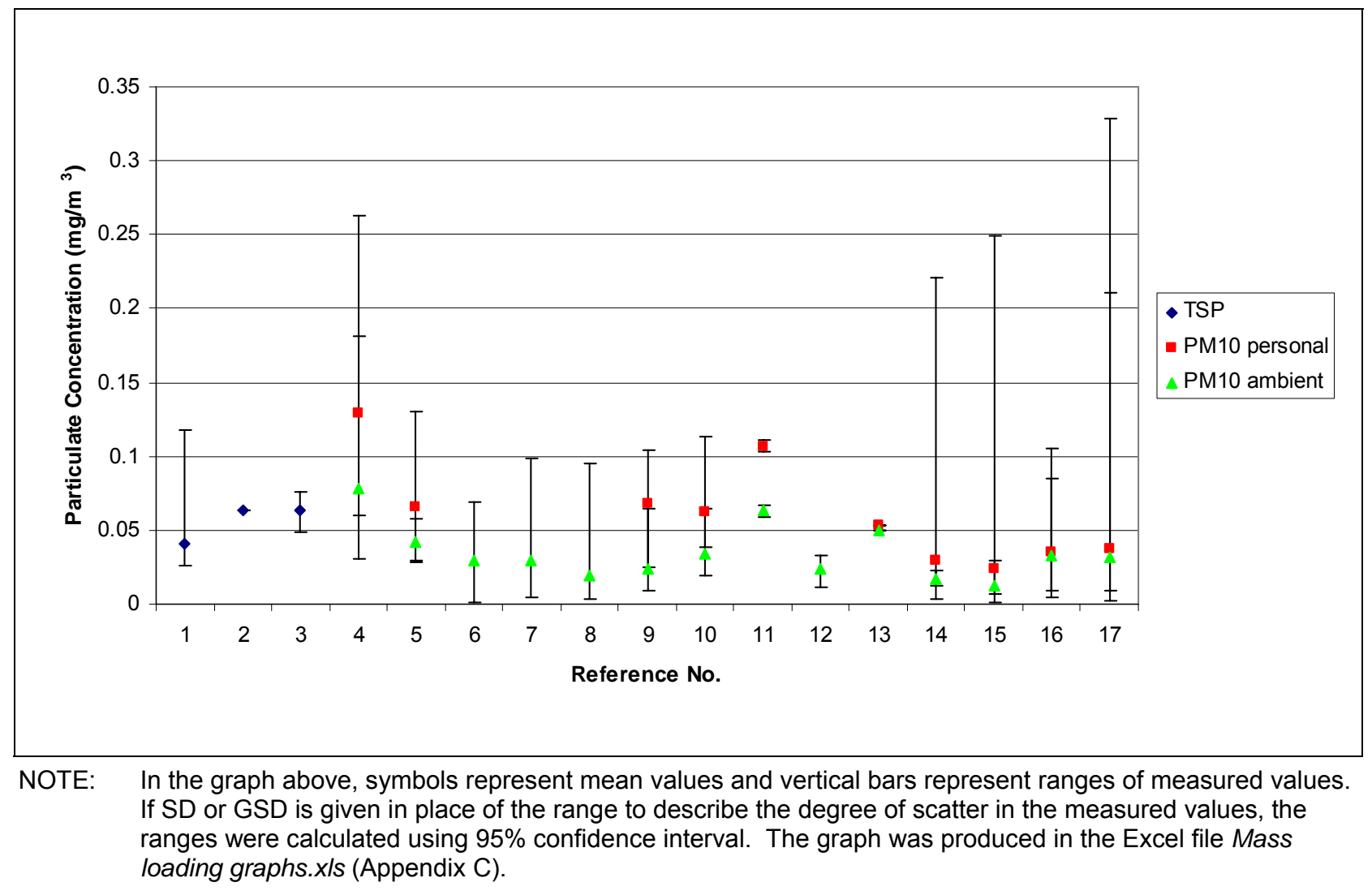

For use in this analysis, $\mathrm{PM}_{10}$ concentrations must be converted to TSP, so applicable measurements of the ratio of TSP to $\mathrm{PM}_{10}$ also were reviewed.

For many of the following studies, both personal and ambient indoor concentrations (i.e., measured using a stationary monitor placed in a central location in the house) were reported. Measurements of personal particulate concentrations are most applicable to this environment if the people monitored spent their time indoors conducting a variety of typical activities. Measurements of personal concentration during indoor dust-generating activities (e.g., during housework and cooking) are useful for understanding maximum indoor concentrations, but are not representative of average concentrations while indoors. Ambient measurements are most applicable if they were taken while people were present and active. Outdoor concentrations measured at regional monitoring sites were also reported in most studies and are included here to compare levels of dustiness outdoors during the studies to those in the Yucca Mountain region (see Section 6.2.2).

The only source of indoor contaminated particulates for the biosphere model is soil or ash that is tracked or blown indoors. Other sources of indoor, airborne particles may have contributed substantially to mass load concentrations in some studies. For example, smoking resulted in a 37 percent increase in average daytime $\mathrm{PM}_{10}$ concentrations in homes in Riverside, California (Clayton et al. 1993 [DIRS 159599], Table 6), and concentrations in homes in Tucson with smokers were more than twice as high as those without (Quackenboss et al. 1989 [DIRS 159682], Table 3). Cooking, use of household cleaning products, and other activities also 
generate resuspended particles that would not be contaminated in the scenarios considered in this analysis (e.g., Long et al. 2000 [DIRS 159681], pp. 1242 to 1245). Therefore, the most applicable studies are those that omitted homes with smokers or that present data separately for homes with and without smokers.

\subsubsection{Literature Review}

Indoor and Personal Exposure Concentrations -Wigzell et al. (2000 [DIRS 159729]) measured TSP and $\mathrm{PM}_{2.5}$ concentrations over 48-hour periods in the kitchens and living rooms of 10 homes in Oxford, England. Sampling devices in the living rooms were on only when residents were home. The average TSP concentration in living rooms was $0.041 \mathrm{mg} / \mathrm{m}^{3}$ (range $=0.026$ to 0.118 ). The average in nine homes where smoking did not occur was $0.036 \mathrm{mg} / \mathrm{m}^{3}$. Outdoor $\mathrm{PM}_{10}$ concentrations averaged $0.019 \mathrm{mg} / \mathrm{m}^{3}$ (Wigzell et al. 2000 [DIRS 159729], Table 3).

Thatcher and Layton (1995 [DIRS 159600]) measured TSP and $\mathrm{PM}_{10}$ concentrations in one home in California during normal and staged activities. The TSP concentration while five residents (two adults and three children) were present "performing normal activities" was $0.063 \mathrm{mg} / \mathrm{m}^{3}$. Outdoor $\mathrm{PM}_{10}$ concentrations at that time were $0.014 \mathrm{mg} / \mathrm{m}^{3}$. In one experiment, TSP concentrations after vigorous cleaning was about $0.2 \mathrm{mg} / \mathrm{m}^{3}$, and decreased to about 0.05 within 60 minutes. Walking into a room that previously had no activity caused concentrations of particles with an average aerodynamic diameter equal to or more than $5 \mu \mathrm{m}$ to more than double. Cleaning caused an 11.4-times increase in the concentration of particles 5 to $10 \mu \mathrm{m}$ and a 29.5-times increase in the concentration of particles equal to or greater than $10 \mu \mathrm{m}$ (Thatcher and Layton 1995 [DIRS 159600], Table 3, Figures 3 and 7).

Yocom et al. (1971 [DIRS 159654]) measured TSP concentrations in two homes, two office buildings, and two public buildings over three seasons in Hartford, Connecticut. The average daytime concentration in the homes was $0.063 \mathrm{mg} / \mathrm{m}^{3}$ (range $=0.049$ to 0.076 ). Average daytime concentrations in office and public buildings were $0.073 \mathrm{mg} / \mathrm{m}^{3}$ (range $=0.057$ to 0.087 ) and $0.046 \mathrm{mg} / \mathrm{m}^{3}$ (range $=0.036$ to 0.060 ), respectively. Outdoor concentrations in the area averaged $0.089 \mathrm{mg} / \mathrm{m}^{3}$ (Yocom et al. 1971 [DIRS 159654], Table 1).

Clayton et al. (1993 [DIRS 159599]) summarized the results of a study conducted by the EPA to estimate population levels of exposure to particulates in Riverside, California. Indoor, outdoor, and personal exposure concentrations of $\mathrm{PM}_{10}$ were measured for a probability-based sample of 178 nonsmokers 10 years old or older. Daytime personal exposure averaged $0.129 \mathrm{mg} / \mathrm{m}^{3}$ (10th and 90th percentiles $=0.060$ and 0.263, respectively) (Clayton et al. 1993 [DIRS 159599], Table 2). Nighttime personal exposure averaged $0.068 \mathrm{mg} / \mathrm{m}^{3}$ (10th to 90 th percentiles $=0.037$ to 0.135$)$. The people monitored spent an average of about 50 percent of their daytime hours out of their house; therefore, measurements of personal exposure may not be as applicable to this analysis as indoor measurements. Daytime and nighttime concentrations measured at a stationary indoor monitor averaged $0.078 \mathrm{mg} / \mathrm{m}^{3}(0.031$ to 0.181$)$ and $0.053 \mathrm{mg} / \mathrm{m}^{3}(0.025$ to 0.117$)$, respectively. Average indoor concentrations were 37 percent higher in homes on days when housework occurred $\left(0.091 \mathrm{mg} / \mathrm{m}^{3}\right.$ compared to $0.057 \mathrm{mg} / \mathrm{m}^{3}$ on days with no housework). The average indoor concentration $\left(0.078 \mathrm{mg} / \mathrm{m}^{3}\right)$ is between those values and therefore appears to be a reasonable estimate of homes with and without substantial dust-generating activities. 
$\mathrm{PM}_{10}$ concentrations at outdoor, regional monitoring sites averaged $0.079 \mathrm{mg} / \mathrm{m}^{3}$ (Clayton et al. 1993 [DIRS 159599], Table 2).

Personal exposure to $\mathrm{PM}_{10}$ for 14 people in Phillipsburg, New Jersey, averaged $0.066 \mathrm{mg} / \mathrm{m}^{3}$ (range approximately 0.030 to $0.130 \mathrm{mg} / \mathrm{m}^{3}$ ). Most personal exposure concentrations were between 0.040 and 0.080 . Concentrations inside fourteen homes averaged $0.042 \mathrm{mg} / \mathrm{m}^{3}$ (range approximately 0.028 to $0.058 \mathrm{mg} / \mathrm{m}^{3}$ ). Outdoor concentrations averaged $0.048 \mathrm{mg} / \mathrm{m}^{3}$. There were no smokers living in the homes and all measurements lasted 24 hours (Lioy et al. 1990 [DIRS 159655], Figures 4, 5, and 6).

$\mathrm{PM}_{10}$ concentrations in 43 homes in Tucson, Arizona, without smokers averaged $0.030 \mathrm{mg} / \mathrm{m}^{3}$ ( $\mathrm{SD}=0.020,24$-hour measurements). Homes with evaporative coolers had lower concentrations (average $=0.021$ ) than those without (average $=0.038$ ). Homes with smokers had much higher concentrations (average $=0.075$ ) (Quackenboss et al. 1989 [DIRS 159682], Table 3). Outdoor concentrations were not reported.

$\mathrm{PM}_{10}$ concentrations during summer in 49 homes in Connecticut and Virginia with air conditioning was $0.029 \mathrm{mg} / \mathrm{m}^{3}$ (range $=0.005$ to $0.098,24$-hour measurements). Concentrations in eight homes without air conditioning averaged $0.033 \mathrm{mg} / \mathrm{m}^{3}$ (range $=0.018$ to 0.60 ). Concentrations during winter in 84 homes without kerosene heaters averaged $0.026 \mathrm{mg} / \mathrm{m}^{3}$ (range $=0.003$ to 0.182 ). Concentrations outside of homes averaged 0.028 and $0.024 \mathrm{mg} / \mathrm{m}^{3}$ during summer and winter, respectively (Leaderer et al. 1999 [DIRS 160403], Tables 1 and 4).

Concentrations of $\mathrm{PM}_{10}$ in nine homes without smokers in Boston, Massachusetts, averaged $0.019 \mathrm{mg} / \mathrm{m}^{3}$ (range $=0.003$ to $0.095,24$-hour measurements). Peak concentrations during dusting and vigorous walking were 0.105 and $0.041 \mathrm{mg} / \mathrm{m}^{3}$, respectively. Outdoor $\mathrm{PM}_{10}$ concentrations averaged $0.013 \mathrm{mg} / \mathrm{m}^{3}$, lower than other studies reviewed here (Long et al. 2000 [DIRS 159681], Tables 2 and 3).

Personal exposure to $\mathrm{PM}_{10}$ in a stratified sample of the population in Toronto, Canada, averaged $0.068 \mathrm{mg} / \mathrm{m}^{3}$ (10th and 90th percentiles approximately 0.025 and $0.104,24$-hour measurements). Indoor concentrations averaged $0.024 \mathrm{mg} / \mathrm{m}^{3}$ (10th and 90th percentiles approximately 0.009 and 0.065). Outdoor concentrations averaged $0.024 \mathrm{mg} / \mathrm{m}^{3}$ (Pellizzari et al. 1999 [DIRS 159702], Figure 2).

Personal exposure to $\mathrm{PM}_{10}$ for 37 nonsmokers (50 to 70 years old) in Amsterdam, Netherlands, averaged $0.062 \mathrm{mg} / \mathrm{m}^{3}$ (range $=0.038$ to 0.113 ). Indoor exposure averaged $0.034 \mathrm{mg} / \mathrm{m}^{3}$ (range $=0.019$ to 0.065 ) and outdoor concentrations averaged $0.042 \mathrm{mg} / \mathrm{m}^{3}$. On the days they were monitored, subjects spent an average of 1.3 hours outdoors and 20.5 hours at home; therefore, personal exposure concentrations reported here likely are a good measure of concentrations in the active indoor environment of this sample (Janssen et al. 1998 [DIRS 159699], Table 1).

Brauer et al. (2000 [DIRS 159703], Table 4) measured personal exposure and $\mathrm{PM}_{10}$ concentrations in homes of 18 office workers, 15 high school students, and 16 industrial workers in Slovakia. Personal exposure (24-hour) during summer and winter averaged $0.107 \mathrm{mg} / \mathrm{m}^{3}$ (geometric $\mathrm{SD}=1.7$ ) and $0.105 \mathrm{mg} / \mathrm{m}^{3}$ (geometric $\mathrm{SD}=1.7$ ), respectively. Twenty-four hour 
average concentrations in homes during summer and winter were 0.063 (geometric SD $=2.0$ ) and $0.060 \mathrm{mg} / \mathrm{m}^{3}$ (geometric $\mathrm{SD}=1.6$ ), respectively. Outdoor $\mathrm{PM}_{10}$ concentrations averaged 0.033 and $0.040 \mathrm{mg} / \mathrm{m}^{3}$ during summer and winter. Participants of this study spent an average of 71 percent of their time at home (Brauer et al. 2000 [DIRS 159703], Table 1).

$\mathrm{PM}_{10}$ concentrations in 17 homes in Switzerland averaged $0.024 \mathrm{mg} / \mathrm{m}^{3}$ (range 0.011 to 0.033 ). Homes where substantial activity occurred (home groups A and C) had average concentrations of $0.029 \mathrm{mg} / \mathrm{m}^{3}$. Outdoor concentrations averaged $0.022 \mathrm{mg} / \mathrm{m}^{3}$ (Monn et al. 1997 [DIRS 150888], Table 2).

Personal exposure to $\mathrm{PM}_{10}$ for 10 children in London, England, during daytime averaged $0.053 \mathrm{mg} / \mathrm{m}^{3}$ (no range presented). Concentrations in homes while children were present averaged 0.050; smokers were present in some homes. Average concentrations in gardens, classrooms, and at a regional outdoor monitoring site were $0.022,0.079$, and $0.024 \mathrm{mg} / \mathrm{m}^{3}$, respectively (Wheeler et al. 2000 [DIRS 159704], Table 2).

The lifestyles, physical conditions, and similarity between personal and indoor concentrations indicate that the subjects of the following studies were sedentary and therefore did not resuspend substantial concentrations of particles. These results therefore are applicable only for identifying a lower bound of the average mass loading concentration for the Amargosa Valley population.

Personal exposure to $\mathrm{PM}_{10}$ was measured in retirement facilities in Fresno, California, and Baltimore, Maryland. Average exposure while awake at home indoors was 0.029 (range $=0.003$ to 0.221 ) and $0.024 \mathrm{mg} / \mathrm{m}^{3}$ (range $=<0.001$ to 0.249 ) in Fresno and Baltimore, respectively (Howard-Reed et al. 2000 [DIRS 159680], Table 2). Concentrations in apartments at the Fresno facility averaged $0.017 \mathrm{mg} / \mathrm{m}^{3}$ (range $=0.012$ to 0.023 ), and outdoor ambient concentrations there averaged $0.021 \mathrm{mg} / \mathrm{m}^{3}$ (Evans et al. 2000 [DIRS 159679], Table 8). Concentrations in apartments in Baltimore averaged $0.013 \mathrm{mg} / \mathrm{m}^{3}$ (range $=0.007$ to 0.030 ) and outdoor concentrations averaged $0.028 \mathrm{mg} / \mathrm{m}^{3}$ (Williams et al. 2000 [DIRS 159735], Table 4).

Personal exposure to $\mathrm{PM}_{10}$ for 30 people in Los Angeles, California, with severe lung disease averaged $0.035 \mathrm{mg} / \mathrm{m}^{3}$ (range $=0.005$ to 0.085 ). Concentrations in their homes averaged $0.033 \mathrm{mg} / \mathrm{m}^{3}$ (range $=0.009$ to 0.105 ). Outdoor concentrations averaged $0.033 \mathrm{mg} / \mathrm{m}^{3}$ (Linn et al. 1999 [DIRS 159602], Tables 1 and 2).

Personal exposure to $\mathrm{PM}_{10}$ for 18 people in Boston, Massachusetts, with chronic obstructive pulmonary disease averaged $0.037 \mathrm{mg} / \mathrm{m}^{3}$ (range $=0.009$ to 0.211 , winter and summer, daytime measurements). Concentrations in their homes averaged $0.032 \mathrm{mg} / \mathrm{m}^{3}$ (range $=0.002$ to 0.329 , 24-hour measurements). Outdoor concentrations averaged $0.022 \mathrm{mg} / \mathrm{m}^{3}$ (Rojas-Bracho et al. 2000 [DIRS 159678], Table 2).

TSP: $\mathbf{P M}_{10}$ Ratios-The following are summaries of applicable measurements of the ratio of TSP to $\mathrm{PM}_{10}$ and TSP to $\mathrm{PM}_{2.5}$. The ratios measured by Brook et al. (1997 [DIRS 160254]) and at Yucca Mountain (DTNs: MO98PSDALOG111.000 [DIRS 119501], TM000000000001.039 [DIRS 121386], TM000000000001.041 [DIRS 121396], TM000000000001.042 [DIRS 121405], TM000000000001.079 [DIRS 121410], TM000000000001.082 [DIRS 121416], TM000000000001.084 [DIRS 121419], TM000000000001.096 [DIRS 121421], 
TM000000000001.097 [DIRS 121426], TM000000000001.098 [DIRS 121429], TM000000000001.099 [DIRS 121435], TM000000000001.105 [DIRS 121440], TM000000000001.108 [DIRS 121442]; see Excel file TSP-to-PM10 Ratios_Yucca Mountain.xls, Appendix C) were derived from stationary outdoor monitors and are not as applicable as ratios from the other studies, which were based on indoor measurements. However, results of the latter studies are useful for corroborating the other results.

Thatcher and Layton (1995 [DIRS 159600], Table 3 and Figure 3) measured a TSP:PM 10 ratio of 2.7:1 during normal indoor activities, 3.2:1 immediately after vigorous cleaning, and 1.6:1 one hour after cleaning had ended.

The ratio of TSP:PM $\mathrm{PM}_{10}$ in homes following the eruption of Mount St. Helens was 3:1 (Buist et al. 1986 [DIRS 144632], Table 2).

The average ratio of TSP to $\mathrm{PM}_{2.5}$ measured in nine homes in England was 2.7:1 (Wigzell et al. 2000 [DIRS 159729], Table 3, comparison of arithmetic mean of concentrations in living rooms). The TSP:PM $\mathrm{PM}_{10}$ ratio would have been lower because the concentration of fragments from 2.5 to $10 \mu \mathrm{m}$ would be included in the denominator of the ratio.

Average TSP to $\mathrm{PM}_{10}$ ratios for 19 locations in Canada was 1.8 to 2.0:1. Tenth and 90th percentiles were $3.3: 1$ and 1:1. These measurements were taken at stationary outdoor monitors (Brook et al. 1997 [DIRS 160254], Table 3).

The ratio of TSP to $\mathrm{PM}_{10}$ outdoors at Yucca Mountain averaged about 2.5. This value is based on 1,276 simultaneously collected measurements of TSP and PM $_{10}$ taken during 1989 through 1997. These data and the associated DTNs are displayed in Excel file TSP-to-PMIO Ratios_Yucca Mountain.xls (Appendix C). Twenty-four ratios of less or equal to 1.0 (i.e., $\mathrm{PM}_{10}$ concentrations the same as or higher than TSP, which is very unlikely or not possible) were omitted from consideration. Six of these ratios had $\mathrm{PM}_{10}$ values of zero and 15 others had very low values of TSP and $\mathrm{PM}_{10}\left(<10 \mu \mathrm{g} / \mathrm{m}^{3}\right)$ or very small differences between TSP and $\mathrm{PM}_{10}$ $\left(\leq 2 \mu \mathrm{g} / \mathrm{m}^{3}\right)$. Thus, most of these incorrect ratios likely were the result of normal measurement error for the equipment used. The average TSP:PM 10 ratio for the remaining 1,276 measurements was 2.49:1 $(\mathrm{SD}=1.03)$. The median value was 2.22 and the ratios ranged from 1.0 to 12.57. The data were skewed toward small values; 84 percent of ratios were less than 4.0 and 94.3 percent were less than 5.0.

\subsubsection{Parameter Distribution}

Average personal exposure to $\mathrm{PM}_{10}$ in the studies reviewed ranged from 0.024 to $0.129 \mathrm{mg} / \mathrm{m}^{3}$. Average indoor concentrations of TSP and $\mathrm{PM}_{10}$ while people were active ranged from 0.041 to $0.063 \mathrm{mg} / \mathrm{m}^{3}$ and from 0.013 to $0.078 \mathrm{mg} / \mathrm{m}^{3}$, respectively (Table 6-10). As discussed below, it is reasonable to conclude that these ranges include the average annual conditions in the Yucca Mountain region because the studies were conducted over a variety of applicable conditions, including some with relatively high outdoor concentrations (Clayton et al. 1993 [DIRS 159599]; Lioy et al. 1990 [DIRS 159655]), and because results did not vary much among studies. 
A triangular distribution with a mode of $0.100 \mathrm{mg} / \mathrm{m}^{3}$, minimum of $0.060 \mathrm{mg} / \mathrm{m}^{3}$, and maximum of $0.175 \mathrm{mg} / \mathrm{m}^{3}$ is selected for the active indoor environment. The minimum value is based on the three studies that measured TSP indoors (references 1,2, and 3 in Table 6-3). The upper bound is based on a high $\mathrm{PM}_{10}$ concentration of $0.070 \mathrm{mg} / \mathrm{m}^{3}$ and a TSP:PM 10 ratio of 2.5:1. The $\mathrm{PM}_{10}$ concentration of $0.070 \mathrm{mg} / \mathrm{m}^{3}$ is similar to the maximum of the average indoor concentrations measured in the studies reviewed (Table 6-10) and higher than all but two of the average personal exposure concentrations measured. It was selected to bound uncertainty in conditions such as types of dwellings that may differ between the analogue studies and the conditions in the Yucca Mountain region. The subjects of the two studies that had higher average levels of personal exposure (Clayton et al. 1993 [DIRS 159599]; Brauer et al. 2000 [DIRS 159703]) spent a substantial amount of time away from their homes and therefore may have been exposed to excess sources of particulates or to particulates that would not be contaminated in the biosphere analysis scenarios (e.g., car exhaust, industrial pollutants). The TSP:PM $\mathrm{PM}_{10}$ ratio is based on the range of $1.6: 1$ to $3: 1$ measured indoors in three studies, and confirmed by outdoor ratios. The modal value selected is less than the midpoint between the minimum and maximum, because all three applicable measurements of TSP are at the minimum end of the distribution. This indicates that the true average for the Amargosa Valley population likely is closer to the minimum than the maximum value. As shown in Appendix A, a change in the average mass loading from the modal to the maximum values of this distribution would increase the predicted amount of dust inhaled by the receptor by about 24 percent. This change is small relative to the approximately order-of-magnitude variation in BDCFs calculated by the biosphere model (BSC 2005 [DIRS 172814], Section 6.2.3; BSC 2005 [DIRS 172812], Section 6.2.3).

The important factors relevant to evaluating uncertainty in the use of the analogue measurements and the consistency of the selected distribution of mass loading to the conditions in the Yucca Mountain region are the types of indoor activities, types of dwellings, and outdoor ambient concentrations. Outdoor ambient concentrations would be influenced by outdoor conditions such as precipitation, vegetation, sources of outdoor particles, and types of outdoor activities; therefore, those outdoor conditions are not discussed separately.

The types of activities that were conducted during the studies reviewed are typical of those expected to occur in dwellings in the Yucca Mountain region (e.g., walking, cleaning, cooking, sitting). Because there are no unique industries, occupations, or other conditions in the Yucca Mountain region (see the introduction to Section 6.1 and BSC 2004 [DIRS 172827], Section 6.3), there is no reason to expect that people in the region would conduct indoor activities that differ substantially from people elsewhere or result in higher concentrations of resuspended particles. Conditions during some of the studies that measured the lowest concentrations (e.g., Linn et al. 1999 [DIRS 159602]) may not be representative of average annual conditions in the Yucca Mountain region, because the subjects had medical conditions that would cause them to be less active than other people. The studies with the highest concentrations of $\mathrm{PM}_{10}$ included measurements of subjects that spent a substantial amount of time away from their homes (Clayton et al. 1993 [DIRS 159599]; Brauer et al. 2000 [DIRS 159703]). The results of those studies were considered less applicable in the selection of the distribution of mass loading for this environment. Some of the studies took place while subjects were conducting activities that cause high concentrations of resuspended particles that would not be contaminated with radionuclides by the use of groundwater, such as smoking and 
cooking. Measurements from those studies would be higher than concentrations of contaminated, resuspended particles applicable to this analysis.

The reviewed studies were conducted in a variety of dwellings and concentrations varied little among the studies. However, no measurements were reported to have been taken in mobile homes, the type of dwelling lived in by most people in Amargosa Valley (Bureau of the Census 2002 [DIRS 159728], Tables H30 and H31). It is possible that more resuspended dust from outdoors would be transferred into mobile homes than into dwellings constructed of brick or other building materials. The upper bound for this distribution is similar to or greater than all applicable measurements of indoor and personal exposure concentrations and was selected to account for this source of uncertainty. A higher value was not selected because no higher applicable average measurement was reported, indoor concentrations varied little among different types of dwellings, and because a small increase in this value would have little effect on the predicted amount of dust inhaled by the receptor (Appendix A).

Changes in outdoor concentrations of resuspended particles have been shown to influence indoor concentrations (see the studies listed in Table 5-1). Thus, differences in outdoor concentrations resulting from differences in the outdoor sources of resuspended particles, precipitation, vegetation, and other factors could affect the applicability of the studies reviewed. Average outdoor concentrations of $\mathrm{PM}_{10}$ at regional monitoring sites ranged from 0.013 to 0.079 in those studies. That range is similar to the range of concentrations in rural, agricultural sites in arid to semi-arid settings (Table 6-2) and similar to or higher than that measured in the Yucca Mountain region (see the introduction to Section 6.1 and CRWMS M\&O 1999 [DIRS 102877], Table 2-3). Because almost all analogue studies were conducted in areas having higher outdoor concentrations than those expected for a rural, agricultural setting in the Yucca Mountain region, the distribution for this environment, which was based on the results of those studies, bounds conditions in the region.

Because most relevant conditions under which the analogue measurements were taken are consistent with the current conditions in the Yucca Mountain region, and because the range of the distribution was selected to bound uncertainty in other relevant conditions that may have differed (e.g., type of dwelling), the distribution of mass loading in the active indoor environment is consistent with the applicable current conditions in the Yucca Mountain region. This consistency supports a conclusion that the FEPs associated with this parameter (Table 1-1) are also consistent with the present knowledge of the conditions in the region surrounding the Yucca Mountain site, as required by 10 CFR 63.305(a) [DIRS 173273].

\subsubsection{Asleep Indoor Environment}

A review of applicable literature (see Section 4.1.1) was conducted to determine the range of average concentrations of resuspended particles measured while people were asleep indoors. The results are summarized in Table 6-11. Studies were considered most applicable if concentrations were measured while people were sleeping. Studies were also considered applicable if indoor concentrations were measured while subjects were inactive or absent. Because most applicable studies measured concentrations of $\mathrm{PM}_{10}$, a review of applicable $\mathrm{TSP}: \mathrm{PM}_{10}$ ratios also was conducted. 


\subsubsection{Literature Review}

Thatcher and Layton (1995 [DIRS 159600], Figure 3) reported a TSP concentration of about $0.055 \mathrm{mg} / \mathrm{m}^{3}$ in a home in California one hour after all resuspension activities were stopped. The TSP:PM 10 ratio at that time was about 1.6:1. This measurement is analogous to one hour after people became inactive or went to bed.

Table 6-11. Particulate Concentrations - Nominal Asleep Indoor Environment

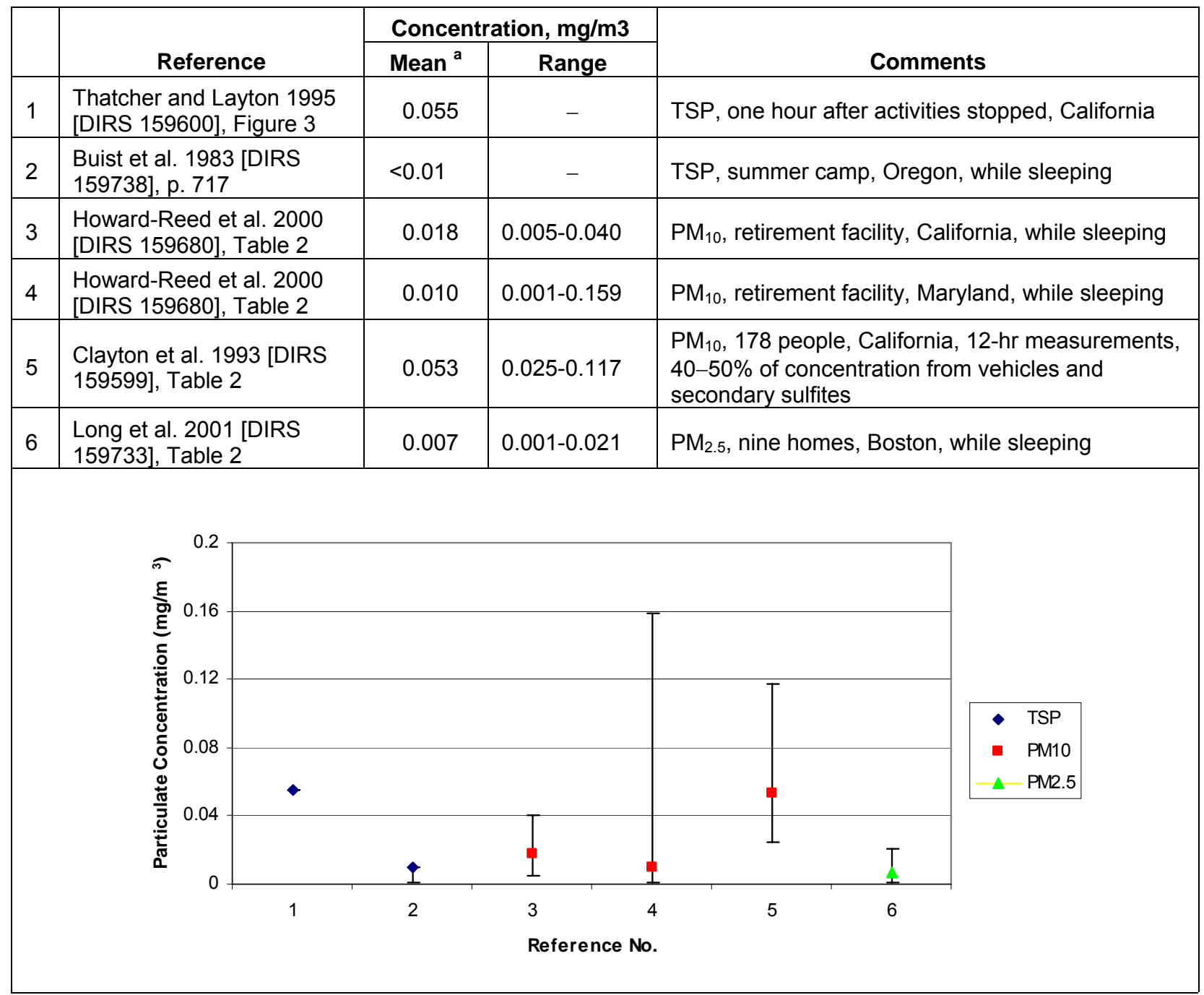

a Mean or other value representative of the central tendency (see text).

$\mathrm{PM}_{10}=$ particles with an aerodynamic diameter $\leq 10 \mu \mathrm{m} ; \mathrm{PM}_{2.5}=$ particles with an aerodynamic diameter $\leq 2.5 \mu \mathrm{m} ;$ TSP = total suspended particulates; dash indicates no data reported.

NOTE: In the graph above, symbols represent mean values and vertical bars represent ranges of measured values. If SD or GSD is given in place of the range to describe the degree of scatter in the measured values, the ranges were calculated using $95 \%$ confidence interval. The graph was produced in the Excel file Mass loading graphs.xIs (Appendix C). 
Buist et al. (1983 [DIRS 159738]) measured personal TSP exposure concentrations of children ages 8 to 13 who were attending a summer camp in Oregon shortly after $1.2 \mathrm{~cm}$ of ash had fallen from the eruption of Mount St. Helens. The methods used for that study are more fully described by Hewett (1980 [DIRS 168491]). Nighttime TSP concentrations were at or below the $0.01-\mathrm{mg} / \mathrm{m}^{3}$ limit of detection of sampling equipment (Buist et al. 1983 [DIRS 159738], p. 717). Although the results of this study are most applicable to analysis of the volcanic ash scenario, they are listed here to demonstrate that dust concentrations in the asleep indoor environment can be very low even when conditions outdoors are very dusty.

$\mathrm{PM}_{10}$ concentrations in retirement apartments in Fresno, California, and Baltimore, Maryland, while residents were asleep averaged $0.018 \mathrm{mg} / \mathrm{m}^{3}$ (range $=0.005$ to 0.040 ) and $0.010 \mathrm{mg} / \mathrm{m}^{3}$ (range $=0.001$ to 0.159) (Howard-Reed et al. 2000 [DIRS 159680], Table 2). Concentrations varied little while residents were asleep (Howard-Reed et al. 2000 [DIRS 159680], Figures 1 and 2).

Indoor concentrations of $\mathrm{PM}_{10}$ at night $(7: 00 \mathrm{pm}$ to 7:00 am) in homes of 178 people monitored in Riverside, California, averaged $0.053 \mathrm{mg} / \mathrm{m}^{3}$ (10th and 90th percentiles $=0.025$ and 0.117 ) (Clayton et al. 1993 [DIRS 159599], Table 2). These measurements are overestimates of concentrations of soil particles experienced while subjects were sleeping for two reasons. First, the measurement period includes times when people where active during the evening and early morning. Second, a portion of the mass loading concentration consists of particles that would not be contaminated in the groundwater or volcanic ash scenarios. Yakovleva et al. (1999 [DIRS 159730], Figure 7) examined the source contributions in this study and concluded that about 40 to 50 percent of particulate concentrations at night were from motor vehicles and secondary sulfates.

Long et al. (2001 [DIRS 159733]) measured $\mathrm{PM}_{2.5}$ concentrations and volume of $\mathrm{PM}_{2.5}$ and $\mathrm{PM}_{10}$ particles in nine homes of nonsmokers in Boston at night while people were asleep and/or inactive. The average $\mathrm{PM}_{2.5}$ concentration was $0.007 \mathrm{mg} / \mathrm{m}^{3}$ ( 5 th and 95 th percentiles $=<0.001$ to 0.021 ). Less than 10 percent of the $\mathrm{PM}_{10}$ particle volume consisted of particles 2.5 to $10 \mu \mathrm{m}$ in diameter (Long et al. 2001 [DIRS 159733], Table 2). Because few of the resuspended particles were larger than $2.5 \mu \mathrm{m}$, concentrations measured during this study are comparable to $\mathrm{PM}_{10}$ concentrations reported in other studies.

\subsubsection{Parameter Distribution}

A triangular distribution with a mode of $0.030 \mathrm{mg} / \mathrm{m}^{3}$, minimum of $0.010 \mathrm{mg} / \mathrm{m}^{3}$, and maximum of $0.050 \mathrm{mg} / \mathrm{m}^{3}$ is selected for the asleep indoor environment. The minimum and maximum are based on the two measurements of TSP concentrations reported (Table 6-11). All but one applicable measurement of $\mathrm{PM}_{10}$ and $\mathrm{PM}_{2.5}$ (Table 6-11), if multiplied by a TSP:PM 10 ratio of 1.6:1 (Thatcher and Layton 1995 [DIRS 159600], Figure 3), are within this range. As discussed above, the average value of $0.053 \mathrm{mg} / \mathrm{m}^{3}$ measured by Clayton et al. (1993 [DIRS 159599]) is an overestimate of applicable concentrations by a factor of at least two because it includes secondary sulfates and particles generated by motor vehicles (Yakovleva et al. 1999 [DIRS 159730]). Thus, this distribution encompasses the range of variation and uncertainty in measurements of mass loads in the asleep indoor environment. 
As shown in Appendix A, estimates of the amount of dust inhaled are insensitive to changes in dust concentrations in the asleep indoor environment. Because of the insensitivity of the biosphere model to changes in this distribution, and because there is very little variation in mass loading indoors while people are asleep, the only factor considered in evaluating whether the conditions in the studies reviewed were consistent with the conditions in the Yucca Mountain region was the type or level of human activity. All studies were conducted when people were asleep or inactive and it is therefore concluded that the distribution developed based on those studies is consistent with the applicable current conditions in the Yucca Mountain region. This consistency supports a conclusion that the FEPs associated with this parameter (Table 1-1) are also consistent with the present knowledge of the conditions in the region surrounding the Yucca Mountain site, as required by 10 CFR 63.305(a) [DIRS 173273].

\subsubsection{Mass Loading - Crops}

As described and justified in Section 5.1, it is assumed that the distribution of mass loading in fields and gardens where crops are growing is similar to or higher than that in the inactive outdoor environment, with a minimum value equal to the minimum value of the inactive outdoor environment, and a modal and maximum value twice that of the inactive outdoor environment. That assumption is based on the crops grown and farming practices in Amargosa Valley and therefore is consistent with the current conditions in the Yucca Mountain region.

The distribution of mass loading in the inactive outdoor environment is triangular with a mode of $0.060 \mathrm{mg} / \mathrm{m}^{3}$, and a range of 0.025 to $0.100 \mathrm{mg} / \mathrm{m}^{3}$. Based on the above assumption, the distribution of mass loading for crops is predicted to have a mode of $0.120 \mathrm{mg} / \mathrm{m}^{3}$, and a range of 0.025 to $0.200 \mathrm{mg} / \mathrm{m}^{3}$.

\subsection{MASS LOADING - VOLCANIC ASH SCENARIO}

This section describes the development of mass loading distributions within the five environments (four receptor environments and the environment around crops) for the volcanic ash exposure scenario. The representative biosphere for this scenario is the same as for the groundwater scenario: a rural community in an arid to semi-arid environment with conditions consistent with those in the Yucca Mountain region and a population with living styles representative of the residents of the Town of Amargosa Valley today (based on requirements in 10 CFR Part 63 [DIRS 173273], Sections 305 and 312; also, see Section 4.3). However, the source of radionuclides differs. For the volcanic ash scenario, the source of radionuclides is contaminated ash from a volcanic eruption at Yucca Mountain. Ash could be deposited at the location of the receptor during the eruption (original deposition) or be transported there from other deposition sites by fluvial and aeolian processes (fluvial and aeolian remobilization).

The amount of ash deposited at the receptor site can be evaluated by analyzing the results of the ASHPLUME model, which predicts atmospheric dispersal and deposition of tephra from a potential volcanic eruption for a stylized deposition scenario. Ash depths $18 \mathrm{~km}$ downwind from Yucca Mountain were predicted to range from 0.07 to $55 \mathrm{~cm}$. This range was estimated based on areal ash density results from 100 realizations of the ASHPLUME model at a point $18 \mathrm{~km}$ south from a hypothetical vent along the midline of a tephra sheet (BSC 2005 [DIRS 174067], Table 6-4). Wind direction was held fixed for those realizations so that the mid-line of the plume 
would be the same in each realization. The areal ash density, given in units of $\mathrm{g} / \mathrm{cm}^{2}$, is numerically equal to ash thickness in $\mathrm{cm}$ when ash settled density of $1 \mathrm{~g} / \mathrm{cm}^{3}$ is used (BSC 2005 [DIRS 174067], Table 6-5 notes). The results of those runs are shown in Figure 6-6. About 35 percent of predicted depths were less than $1 \mathrm{~cm}, 75$ percent were less than $5 \mathrm{~cm}$, and 90 percent were less than $15 \mathrm{~cm}$ (BSC 2005 [DIRS 174067], Table 6-4). Under normal, variable wind conditions, ash depths at the location of the RMEI (18 km south of Yucca Mountain) would be much lower because the wind at Yucca Mountain blows to the south infrequently (BSC 2005 [DIRS 174067], Figure 8-1).

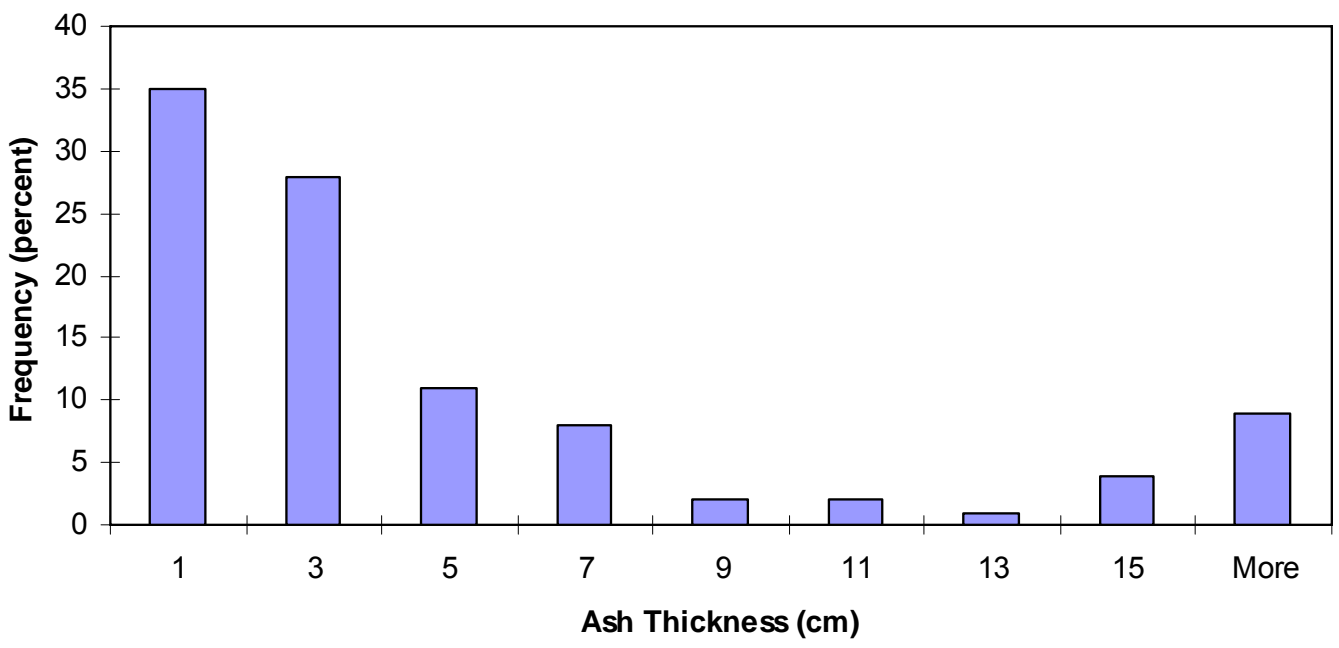

Source: BSC 2005 [DIRS 174067], Table 6-4; graph was constructed in Excel file Ash thickness histogram.xls (Appendix C).

Figure 6-6. Frequency Distribution of Ash Thickness from ASHPLUME Realizations with Wind Direction to the South from a Hypothetical Vent

Observations at volcanic sites (e.g., see Section 6.3.1 and 6.3.2) indicate that tephra is more readily suspended than the soil upon which it was deposited, which would result in higher mass loading concentrations than experienced under nominal conditions (i.e., prior to the eruption). Through time the ash would erode, become mixed into the soil, become buried, or otherwise become stabilized. That erosion or stabilization would result in a decrease in mass loading, with concentrations eventually returning to conditions similar to those considered in the groundwater scenario (i.e., nominal concentrations). Because of this change in mass loading through time, dose resulting from a volcanic eruption must be calculated as a function of time, as described in the following equation (BSC 2004 [DIRS 169460], Section 6.5.8):

$$
D_{\text {all }, i}\left(d_{a}, t\right)=D_{\text {ext,ing,Rn,i}}+D_{\text {inh, }, i} g\left(d_{a}\right) f(t)+D_{\text {inh, }, i} g\left(d_{a}\right)
$$

where:

$D_{\text {all, }}\left(d_{a}, t\right)=$ All-pathway annual dose from internal and external exposure to radionuclide $i$ for an ash thickness $d_{a}$ at time $t$ following a volcanic eruption (Sv/yr) 
$D_{\text {ext,ing, Rn,i }}=$ Annual dose from external exposure, inhalation of radon decay products, and ingestion of radionuclide $i$ following a volcanic eruption ( $\mathrm{Sv} / \mathrm{yr}$ )

$D_{i n h, p, i}=$ Annual dose from inhalation exposure to radionuclide $i$ resulting from exposure to nominal $(p)$ mass loading following a volcanic eruption ( $\mathrm{Sv} / \mathrm{yr})$

$D_{i n h, v, i} \quad=$ Annual dose from inhalation exposure to radionuclide $i$ resulting from exposure to elevated, postvolcanic $(v)$ mass loading in addition to nominal concentrations (Sv/yr)

$d_{a} \quad=$ Thickness of the contaminated ash/soil layer $(\mathrm{m})$

$g\left(d_{a}\right) \quad=\quad$ Function of ash thickness, representing the fraction of total activity that is available for resuspension

$t \quad=$ Time $(\mathrm{yr})$

$f(t)=$ Decay function describing reduction of mass loading with time.

Three components of the BDCFs are required by this model, as shown in Equation 6-3 (BSC 2004 [DIRS 169460], Section 6.5.8).

$$
B D C F_{i}\left(d_{a}, t\right)=B D C F_{e x t, i n g, R n, i}+\left(B D C F_{i n h, v, i} f(t)+B D C F_{i n h, p, i}\right) g\left(d_{a}\right)
$$

These BDCF components are used to calculate the all-pathway annual dose for a radionuclide $i$ as follows:

$$
\begin{aligned}
& D_{a l l, i}\left(d_{a}, t\right)=B D C F_{i}\left(d_{a} t\right) \times C s_{i}(t)= \\
& B D C F_{\text {ext,ing }, R n, i} \times C s_{i}(t)+\left(B D C F_{i n h, v, i} f(t)+B D C F_{i n h, p, i}\right) g\left(d_{a}\right) \times C s_{i}(t)
\end{aligned}
$$

where:

$$
\begin{array}{ll}
B D C F_{i}\left(d_{a}, t\right)= & \begin{array}{l}
\text { BDCF of radionuclide } i \text { for an ash deposition depth } d_{a} \text { at time } t \text { following } \\
\text { a volcanic eruption }\left(\mathrm{Sv} / \mathrm{yr} \text { per } \mathrm{Bq} / \mathrm{m}^{2}\right)
\end{array} \\
B D C F_{\text {ext,ing,Rn,i }}= & \begin{array}{l}
\text { BDCF of radionuclide } i \text { for external exposure, radon inhalation, and } \\
\text { ingestion following a volcanic eruption }\left(\mathrm{Sv} / \mathrm{yr} \text { per } \mathrm{Bq} / \mathrm{m}^{2}\right)
\end{array} \\
B D C F_{\text {inh, }, i}= & \text { BDCF of radionuclide } i \text { for inhalation of resuspended particles at } \\
& \text { nominal mass loading following a volcanic eruption }\left(\mathrm{Sv} / \mathrm{yr} \text { per } \mathrm{Bq} / \mathrm{m}^{2}\right) \\
B D C F_{\text {inh }, v, i}= & \text { BDCF of radionuclide } i \text { for inhalation of resuspended particles at } \\
& \text { concentrations in addition to nominal mass loading following a volcanic } \\
& \text { eruption (Sv/yr per } \left.\mathrm{Bq} / \mathrm{m}^{2}\right) \\
= & \begin{array}{l}
\text { Time dependent activity concentration of radionuclide } i \text { in volcanic ash } \\
\text { deposited on the ground }\left(\mathrm{Bq} / \mathrm{m}^{2}\right) .
\end{array}
\end{array}
$$

The component $B D C F_{\text {ext,ing,Rn,i }}$ accounts for the consequences of all exposure pathways except inhalation of particulate matter. This component of BDCFs is not a function of time or ash depth. The parameter mass loading for crops is not treated as a function of time in the volcanic 
ash scenario because it is used in the calculation of the ingestion dose. Therefore, the equation in the biosphere model for the volcanic ash scenario that uses mass loading for crops is the same as that described in Section 6.1.1.

The component $B D C F_{i n h, p, i}$ accounts for the consequences of inhalation of resuspended particles at concentrations to be expected at some time following a volcanic eruption when mass loading has stabilized. Because concentrations of resuspended particles at that time will be influenced by the same factors considered when developing distributions for nominal conditions, the mass loading distributions for receptor environments developed in Section 6.2 are intended for use in calculating $B D C F_{i n h, p, i}$. This BDCF component is a function of ash depth, because the dose contribution may change as ash depth decreases, but is not a function of time.

The component $B D C F_{i n h, v, i}$ accounts for the additional dose contribution resulting from inhalation of elevated concentrations of resuspended contaminants following a volcanic eruption. This component contributes to the total dose (i.e., is greater than zero) only for the period starting in the year when the volcanic eruption ended (i.e., time $=t_{0}$, which starts after the initial ash fall has ceased) and ending when the ash blanket has eroded or stabilized and airborne concentrations are equal to predisturbance, nominal conditions.

Concentrations of resuspended particles decrease following a volcanic eruption, and therefore the total mass loading in receptor environments following a volcanic eruption must be calculated as a function of time, as shown in the following equation (BSC 2004 [DIRS 169460], Section 6.5.2):

$$
S_{n}(t)=S_{n}+S_{v, n} f(t)
$$

where:

$$
\begin{aligned}
& S_{n}(t)= \begin{array}{l}
\text { Total average annual mass loading in receptor environment } n \text { at time } t \\
\text { following a volcanic eruption }\left(\mathrm{mg} / \mathrm{m}^{3}\right)
\end{array} \\
& S_{n}= \begin{array}{l}
\text { Nominal average annual mass loading in receptor environment } n\left(\mathrm{mg} / \mathrm{m}^{3}\right) \\
S_{v, n}=
\end{array} \\
& \begin{array}{l}
\text { Elevated, postvolcanic }(v) \text { average annual mass loading in receptor } \\
\text { environment } \left.n \text { (i.e., in addition to or greater than } S_{v, n}\right) \text { during the first year (i.e., } \\
\\
t=0) \text { following a volcanic eruption }\left(\mathrm{mg} / \mathrm{m}^{3}\right)
\end{array} \\
& f(t)=\begin{array}{l}
\text { Mass loading time function, which describes the rate of change in mass loading } \\
\text { after a volcanic eruption. }
\end{array}
\end{aligned}
$$

$S_{n}$ is used in the calculation of the BDCF component $B D C F_{i n h, p, i}$ and $S_{v, n}$ is used in the calculation of the BDCF component $B D C F_{i n h, v, i}$. The distributions of elevated mass loading concentrations, $S_{v, n}$ are developed in the remainder of this section. Because $S_{v, n}$ is combined with $S_{n}$ to calculate the total mass loading in receptor environments following a volcanic eruption, $\mathrm{S}_{v, n}$ represents only the additional concentrations of resuspended ash/dust in excess of nominal conditions during the first year following an eruption at Yucca Mountain. Because mass loading for crops is not treated as a function of time, that parameter distribution is representative of the entire concentration of resuspended particles following a volcanic eruption. The mass loading time function is developed in Section 6.4. 


\subsubsection{Active Outdoor Environment}

A review of applicable literature (see Section 4.1.1) was conducted to identify the magnitude of change in mass loading following the deposition of ash the first year following a volcanic eruption. Studies were considered applicable if personal exposure to TSP or $\mathrm{PM}_{10}$ were measured during dust-disturbing activities, or ambient TSP concentrations were measured during dust-disturbing activities, in areas having a relatively recent tephra deposit (i.e., less than about 5 years old). Summary values for each study reviewed are presented in Table 6-12.

Table 6-12. Particulate Concentrations - Postvolcanic Active Outdoor Environment

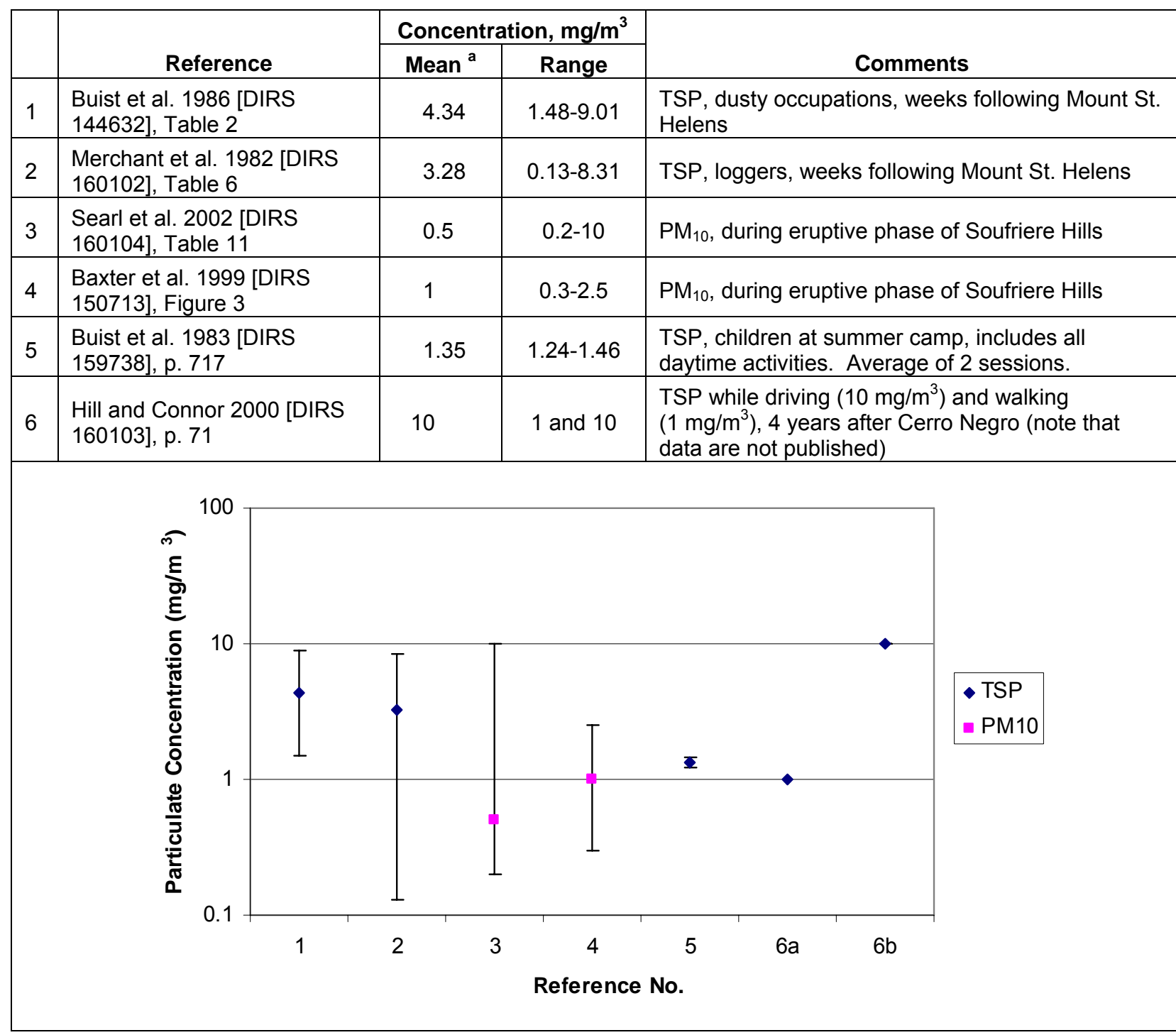

a Mean or other value representative of the central tendency (see text).

$\mathrm{PM}_{10}=$ particles with an aerodynamic diameter $\leq 10 \mu \mathrm{m} ; \mathrm{TSP}=$ total suspended particulates.

NOTE: In the graph above, symbols represent mean values and vertical bars represent ranges of measured values. The graph was produced in Excel file Mass loading graphs.xIs (Appendix C). 
The mean values and ranges of particulate concentrations in air measured in the outdoor active environment after a volcanic eruption are not substantially different from the analogous concentrations for the nominal conditions. To illustrate this, the particulate concentrations measured in the outdoor active environment shown in Tables 6-6 and 6-12 for the nominal and postvolcanic conditions, respectively, are redrawn in Figure 6-7 as side-by-side graphs using the same scale.

\subsubsection{Literature Review}

Buist et al. (1986 [DIRS 144632], Table 2) report personal exposure to TSP for numerous occupations during the weeks following the eruption of Mount St. Helens. The methods used for that study are described by Hewett (1980 [DIRS 168490]). Many of the people monitored were involved in cleanup and removal of ash. Average concentrations were $2.65 \mathrm{mg} / \mathrm{m}^{3}$ (range $=0.64$ to 6.46) for hand-shoveling and sweeping, $5.50 \mathrm{mg} / \mathrm{m}^{3}$ (range $=0.60$ to 23.1 ) for sweeper-truck and broom-truck drivers, $5.96 \mathrm{mg} / \mathrm{m}^{3}$ (range $=0.01$ to 31.9 ) for grader operators, $1.48 \mathrm{mg} / \mathrm{m}^{3}$ ( 0.23 to 6.14 ) for water-truck drivers, $9.01 \mathrm{mg} / \mathrm{m}^{3}$ (range $=0.73$ to 25.5 ) for rubbish workers, $1.42 \mathrm{mg} / \mathrm{m}^{3}$ (range $=0.79$ to 3.20 ) for agricultural workers, and $0.57 \mathrm{mg} / \mathrm{m}^{3}$ (range $=0.04$ to 4.17 ) for law enforcement personnel. The average of all occupational averages except law enforcement (excluded because law enforcement personnel may not have been conducting activities that resuspend ash) is $4.34 \mathrm{mg} / \mathrm{m}^{3}$.

Merchant et al. (1982 [DIRS 160102], Table 6) compared personal exposure to TSP between loggers working in an area in Washington covered by ash from Mount St. Helens and loggers working in Oregon where there was no ash. See study by Sanderson (1982 [DIRS 168492]) for a description of the methods and location of the study sites. Average TSP concentrations (and geometric SD) for Washington were $5.97 \mathrm{mg} / \mathrm{m}^{3}$ (2.95) for cutters, $8.31 \mathrm{mg} / \mathrm{m}^{3}$ (5.50) for choker setters, 0.49 for one truck driver, $0.13 \mathrm{mg} / \mathrm{m}^{3}$ (3.84) for yarder and loader operators, and $1.52 \mathrm{mg} / \mathrm{m}^{3}$ (5.24) for landing men. The average of these five occupations was $3.28 \mathrm{mg} / \mathrm{m}^{3}$. Average concentrations for cutters in Washington were about twice those of cutters in Oregon (average $=2.81 \mathrm{mg} / \mathrm{m}^{3}, \mathrm{SD}=1.46$ ), but concentrations for yarder and loader operators (average $=0.17 \mathrm{mg} / \mathrm{m}^{3}, \mathrm{SD}=1.04$ ) were similar.

Searl et al. (2002 [DIRS 160104]) measured ambient concentrations and personal exposure to $\mathrm{PM}_{4}$ and $\mathrm{PM}_{10}$ on the island of Montserrat in the British West Indies during 1996-2000. The Soufriere Hills volcano erupted periodically during much of this study, and was most active during 1996 through mid-1998. Measurements were taken throughout the island, including on the southern portion, where the tephra deposit was from about $5 \mathrm{~cm}$ to more than $30 \mathrm{~cm}$ thick (these areas were evacuated during 1996-1997 in part because of concerns about high concentrations of airborne particles), and to the north, where the ash was less than $1 \mathrm{~cm}$ to about $5 \mathrm{~cm}$ thick. Average personal exposure to $\mathrm{PM}_{4}$ during 1997 was $0.825 \mathrm{mg} / \mathrm{m}^{3}$ (range $=0.817-0.833$ ) for gardeners, more than $20 \mathrm{mg} / \mathrm{m}^{3}$ (range $=0.077$ to 71 ) for road workers, and $0.442 \mathrm{mg} / \mathrm{m}^{3}$ for a housekeeper (Searl et al. 2002 [DIRS 160104], Table 7). Concentrations of $\mathrm{PM}_{10}$ associated with mowing grass and sweeping inside were of the order of 10 to $20 \mathrm{mg} / \mathrm{m}^{3}$. 
Active Outdoors - Nominal

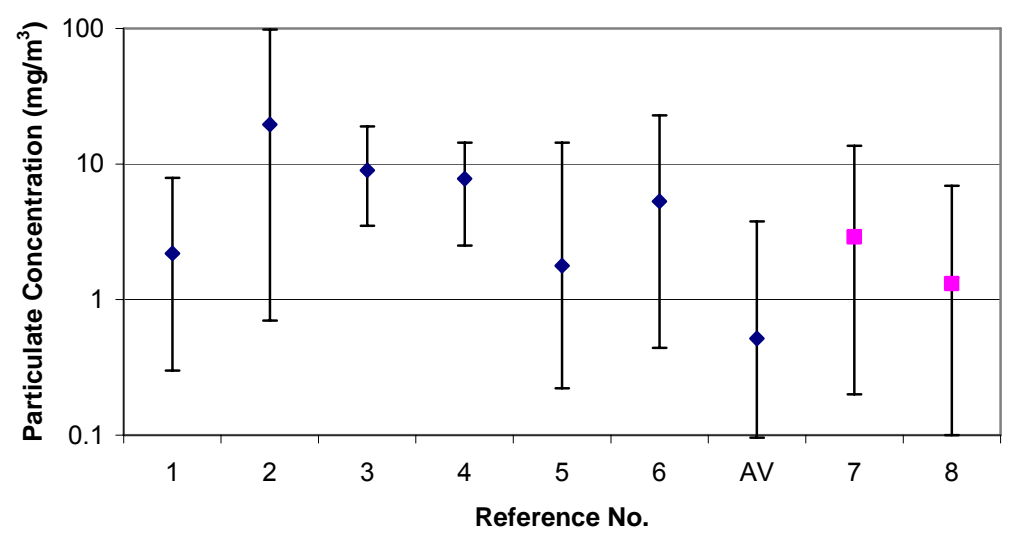

Active Outdoors - Postvolcanic

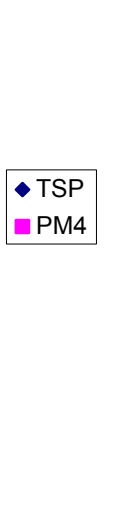

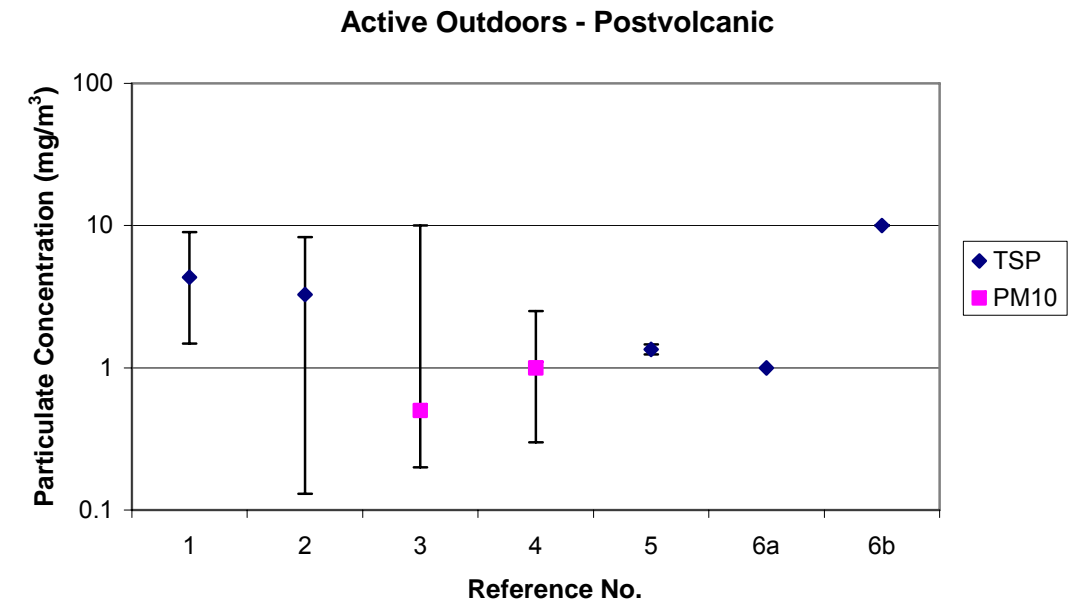

i NOTE: Reference numbers correspond to the references in Tables 6-6 and 6-12; AV = Amargosa Valley.

Figure 6-7. Comparison of Particulate Concentrations in Air in the Active Outdoor Environment for the Nominal, Including Amargosa Valley, and Postvolcanic Conditions 
During 2000, personal exposure by those groups was considerably lower: $0.134 \mathrm{mg} / \mathrm{m}^{3}$ (range $=0.007$ to 0.444 ) for gardeners and $0.050 \mathrm{mg} / \mathrm{m}^{3}$ (range $=0.012$ to 0.105 ) for housekeepers (Searl et al. 2002 [DIRS 160104], Table 8). Personal exposure to $\mathrm{PM}_{10}$ by children at school during 2000 was estimated to be $0.144 \mathrm{mg} / \mathrm{m}^{3}$ while playing outdoors, 0.098 to $0.155 \mathrm{mg} / \mathrm{m}^{3}$ while indoors, and $0.272 \mathrm{mg} / \mathrm{m}^{3}$ while sweeping (Searl et al. 2002 [DIRS 160104], Table 9). To model population exposure, the authors estimated average personal exposure to $\mathrm{PM}_{10}$ during various activities and for four levels of ash (Searl et al. 2002 [DIRS 160104], Table 11). The low ash and raised ash concentrations appear to be most appropriate for this analysis, because alert and very high levels occurred during less than five percent of days on the northern and middle (i.e., Salem) portions of the island (Searl et al. 2002 [DIRS 160104], Table 6). The very high and alert concentrations appear to correspond to days when the Soufriere Hills volcano was erupting and the wind was blowing ash toward a community. Estimated concentrations of $\mathrm{PM}_{10}$ during dusty work were 0.2 to $0.5 \mathrm{mg} / \mathrm{m}^{3}$ for low and raised ash conditions, and 5 to $10 \mathrm{mg} / \mathrm{m}^{3}$ for very high and alert concentrations. Estimated concentrations for outdoor play were 0.1 to $0.5 \mathrm{mg} / \mathrm{m}^{3}$ for low and raised ash conditions, and 5 to $10 \mathrm{mg} / \mathrm{m}^{3}$ for very high and alert conditions. Estimates for "active outside" were 0.05 to $0.2 \mathrm{mg} / \mathrm{m}^{3}$ and 1 to $3 \mathrm{mg} / \mathrm{m}^{3}$ for low to raised and very high to alert levels, respectively. A summary value of $0.5 \mathrm{mg} / \mathrm{m}^{3}$, based on the estimate for dusty work during raised ash conditions, and a range of 0.2 to $10 \mathrm{mg} / \mathrm{m}^{3}$ (also based on dusty work) is presented in Table $6-5$ for this study. Assuming a TSP:PM 10 ratio of about 10:1 (e.g., Nieuwenhuijsen et al. 1998 [DIRS 150855], Table 2), an approximate TSP concentration for dusty work during this study is about $5 \mathrm{mg} / \mathrm{m}^{3}$.

Baxter et al. (1999 [DIRS 150713], Figure 3) reported concentrations of $\mathrm{PM}_{10}$ at two outdoor settings during an eruptive phase of the Soufriere Hills volcano. Peak concentrations during human activity were about 0.5 to $1.5 \mathrm{mg} / \mathrm{m}^{3}$ outside at a primary school and 0.3 to 2.5 at a resort. A summary value of $1 \mathrm{mg} / \mathrm{m}^{3}$ is presented in Table 6-5; this value is the approximate midpoint between low and high peak concentrations.

Buist et al. (1983 [DIRS 159738]) measured personal exposure to TSP during the summer of 1980 among children ages 8 to 13 at a summer camp where about $1.2 \mathrm{~cm}$ of ash had fallen after the June 12 eruption of Mount St. Helens. The methods used for that study are described by Hewett (1980 [DIRS 168491]). Daytime personal exposure averaged $1.24 \mathrm{mg} / \mathrm{m}^{3}$ and $1.46 \mathrm{mg} / \mathrm{m}^{3}$ during two sessions (Buist et al. 1983 [DIRS 159738], p. 717). No information was presented on the percentage of time the children were active; therefore, these values may underestimate exposure in the active outdoor environment.

The following information, which is not listed as an input in Section 4.1.1 (because it has not yet been published in a peer-reviewed journal), is included here to corroborate results of the other studies. Concentrations of TSP were measured in 1999 above the tephra deposit from the 1995 eruption of the basaltic volcano Cerro Negro in Nicaragua. Concentrations during light activity such as walking were on the order of $1 \mathrm{mg} / \mathrm{m}^{3}$, and concentrations while driving over the tephra deposits in an open truck were on the order of $10 \mathrm{mg} / \mathrm{m}^{3}$ (Hill and Connor 2000 [DIRS 160103], p. 71). 


\subsubsection{Parameter Distribution}

The types of activities monitored during the studies reviewed in this section include activities known to or expected to occur in the Yucca Mountain region, including removal of ash by hand and with machinery, agricultural work, gardening, and outdoor play. The measurements of personal exposure during those activities on tephra deposits (Table 6-12) are similar to measurements taken under nominal conditions in areas without tephra (Table 6-6), except that most maximum postvolcanic measurements are lower than those from nominal conditions; the comparison of particulate concentrations in air for the nominal and postvolcanic conditions is shown in Figure 6-6. For example, TSP concentrations for agricultural workers after the eruption of Mount St. Helens (average $=1.42 \mathrm{mg} / \mathrm{m}^{3}$, Buist et al. 1986 [DIRS 144632], Table 2) generally were lower than those reported by Nieuwenhuijsen et al. (1998 [DIRS 150855], Table 2), although the distribution of all activities reported by Buist et al. is not substantially different from that of Nieuwenhuijsen et al. In the only study where a comparison was made of personal exposure during the same type of activities in areas with and without ash, average respirable and total dust concentrations were about twice as high or less for various groups of loggers in areas with and without ash (Merchant et al. 1982 [DIRS 160102], Table 6). Measurements of mass loading over disturbed tephra deposits may be similar to those over other soil because most soils contain a reservoir of particles that are readily suspended when disturbed.

The maximum postvolcanic concentrations in Table 6-12 probably are lower than those reported for nominal conditions (Table 6-6) because few measurements have been taken on tephra deposits for the types of activities expected to occur in the Yucca Mountain region that would create very large concentrations of mass loading, such as farming (although see Buist et al. 1986 [DIRS 144632], Table 2). As noted in Section 6.3 (Equation 6-5), the biosphere model parameter of postvolcanic mass loading represents an increase of particulate concentration in air after a volcanic eruption above the level that existed before an eruption, i.e., the nominal mass loading. This parameter is added to the nominal mass loading for the appropriate environment, in the case of the active outdoors environment, to the triangular distribution with a minimum of $1 \mathrm{mg} / \mathrm{m}^{3}$, a mode of $3 \mathrm{mg} / \mathrm{m}^{3}$, and a maximum of $10 \mathrm{mg} / \mathrm{m}^{3}$. The literature data indicate that the atmospheric mass loading accompanying soil-disturbing activities depends to a larger degree on the types of activities than on the presence of volcanic ash on the ground and that no substantial differences were observed in the range and average atmospheric mass loading between the nominal and postvolcanic conditions. Therefore, based strictly on the literature data, it would appear that the distribution of mass loading for the active outdoor environment under nominal conditions sufficiently represents postvolcanic atmospheric mass loading in the active outdoor environment. The ensuing value of the volcanic mass loading (term $S_{v, n}$ in Equation 6-5) for this environment would then be equal to zero. However, there are additional considerations and sources of uncertainty that need to be taken into account when developing this parameter.

No studies were conducted in areas as arid as the current conditions at Yucca Mountain. The climate in the region where some measurements were taken following the eruption of Mount St. Helens is predicted to be consistent with that likely to occur at Yucca Mountain over much of the next 10,000 years. The other measurements were taken in more mesic areas where fine particles may be more rapidly removed from the ground surface by precipitation. However, because most studies reviewed were conducted shortly after eruptions occurred, there likely was insufficient time for resuspendable particles to be eroded from the tephra deposit. Also, none of the values 
presented above except those of Hill and Connor (2000 [DIRS 160103]) are from basaltic tephra deposits like those predicted to occur at Yucca Mountain (see Section 6.3.3 for a discussion of this uncertainty). Therefore, there is some uncertainty about the consistency of the study conditions to the conditions in the Yucca Mountain region.

Because measurements for nominal and postvolcanic conditions are very similar, a lower bound of a distribution of mass loading in the postvolcanic, active outdoor environment of $1 \mathrm{mg} / \mathrm{m}^{3}$ is selected, the same as that for nominal conditions. To account for the uncertainty in the physical conditions affecting mass loading between the analogue locations and the receptor location, a mode of $6 \mathrm{mg} / \mathrm{m}^{3}$ and maximum upper bound of $15 \mathrm{mg} / \mathrm{m}^{3}$ are selected. The mode is 100 percent greater and the maximum mass loading for the postvolcanic outdoor active environment is 50 percent greater than the values selected for nominal conditions. This distribution sufficiently represents the range of the measured values shown in Table 6-12 and Figure 6-6.

For use in Equation 6.2-3, mass loading distributions for the first year following a volcanic eruption, $S_{v, n}$ must be presented as the expected average annual increase in concentrations of resuspended particles that is greater than nominal concentrations. Thus, the recommended distribution of mass loading for $S_{v}$ in the active outdoor environment is triangular, with a mode of $3 \mathrm{mg} / \mathrm{m}^{3}$, minimum of $0 \mathrm{mg} / \mathrm{m}^{3}$ (i.e., equal to the minimum mass loading predicted for nominal conditions), and maximum of $5 \mathrm{mg} / \mathrm{m}^{3}$. Because some relevant conditions under which the analogue measurements were taken are consistent with the conditions in the Yucca Mountain region, and because the range of the distribution was selected to bound uncertainty in other relevant conditions that may have differed, this distribution of mass loading is consistent with the applicable current and predicted future conditions in the Yucca Mountain region. This consistency supports a conclusion that the FEPs associated with this parameter (Table 1-1) are also consistent with the present knowledge of the conditions in the region surrounding the Yucca Mountain site, as required by 10 CFR 63.305(a) [DIRS 173273].

\subsubsection{Inactive Outdoor Environment}

Measurements of TSP before and after the eruption of Mount St. Helens were analyzed to evaluate changes in the inactive outdoor environment before and after a volcanic eruption. A literature review also was conducted to confirm the results of data analysis.

\subsubsection{Data Analysis}

A dataset containing 24-hour concentrations of TSP measured in the state of Washington during 1979 through 1992 was obtained from the EPA Office of Air Quality and Standards (DTN: MO0008SPATSP00.013 [DIRS 151750]). The dataset was sorted by date and concentration, and values for May 18 to July 31, 1980, (the 10-week period during which the four largest eruptions occurred) (Sarna-Wojcicki et al. 1982 [DIRS 160227], Figure 350) were examined to identify monitoring sites where large increases in TSP were measured following the eruption of Mount St. Helens. Thirteen sites in six cities were identified that had at least one 24-hour concentration greater than $0.4 \mathrm{mg} / \mathrm{m}^{3}$. A value of $0.4 \mathrm{mg} / \mathrm{m}^{3}$ was chosen as representative of a large increase because it is substantially higher than most other concentrations in this dataset. The thickness of the tephra deposit at these cities ranged from about $0.5 \mathrm{~mm}$ to about $10 \mathrm{~mm}$ (Sarna-Wojcicki et al. 1982 [DIRS 160227], Figures 336, 344, 345, and 346). 
Clarkston had about $0.5 \mathrm{~mm}$ deposited on May 18, and Richland had 0.5 to $1 \mathrm{~mm}$ deposited on that date. Longview had 1 to $2 \mathrm{~mm}$ deposited on May 25 and less than $1 \mathrm{~mm}$ on June 12 . Vancouver had more than $1 \mathrm{~mm}$ deposited on May 25 and 4 to $5 \mathrm{~mm}$ deposited on June 12 . Spokane had 2.5 to $5 \mathrm{~mm}$ deposited on May 18, and Yakima had 5 to $10 \mathrm{~mm}$ on that date (Sarna-Wojcicki et al. 1982 [DIRS 160227], Figures 336, 344, and 345).

For this analysis, one site was selected from each city. For all cities except Vancouver, data from the monitoring site with the highest reading during May 18 to July 31, 1980, were selected. Data from the Vancouver site with the second highest reading were selected, because data from May 28 through September 5, 1980, were missing for the site with the highest concentration. The only monitoring station in Clarkston was established in September 1979. Measurements from the six sites are listed in the file TSP Mount St Helens_1979-1982.xls in Appendix C.

Distance to Mount St. Helens was not considered in the selection of sites. Instead, sites were selected that had high TSP concentrations and an initial thickness of ash similar to that expected at the location of the RMEI (Section 6.3).

Average concentrations for the six sites were calculated for the 12-month periods March 1979 to February 1980, June 1980 to May 1981, and June 1981 to May 1982 (Table 6-13). The first period ends before initial volcanic activity in March 1980, and the second period starts about 2 weeks after the major eruption on May 18. These three periods represent average annual TSP concentrations the year before and the two years following the major eruption.

Changes in concentrations the year following the eruption appear to have been influenced by ash thickness (Table 6-13). Average annual concentrations and SDs at the two sites with less than $1 \mathrm{~mm}$ of ash (Clarkston and Richland) were lower or only slightly higher than concentrations the year before the eruption. Concentrations at the other four sites were about 40 to 90 percent higher, and variation was about two to three times higher the year following the eruption. Average concentrations and SDs the second year after the eruption were very similar to those before the eruption at all sites (Table 6-13).

Based on this analysis, it was concluded that, in areas having less than 1 to $10 \mathrm{~mm}$ of ash from the eruption of Mount St. Helens, average concentrations of TSP were no more than two times higher the year following the eruption, but returned to pre-eruption levels the following year. 
Table 6-13. Average Concentrations of TSP $\left(\mathrm{mg} / \mathrm{m}^{3}\right)$ at Six Sites in Washington Before (March 79 to February 80), One Year After (June 80 to May 81), and Two Years After (June 81 to May 82) the May 1980 Eruption of Mount St. Helens

\begin{tabular}{|c|c|c|c|c|c|}
\hline \multicolumn{2}{|c|}{ Site (EPA site \#) and Ash Depth ${ }^{a, b}$} & \multirow[b]{2}{*}{$\begin{array}{l}\text { Standard } \\
\text { Deviation }\end{array}$} & \multirow[b]{2}{*}{ Minimum } & \multirow[b]{2}{*}{ Maximum } & \multirow[b]{2}{*}{$\begin{array}{c}\text { Number of } \\
\text { 24-hour } \\
\text { Observations }\end{array}$} \\
\hline Dates & Mean & & & & \\
\hline \multicolumn{6}{|c|}{ Clarkston (53-003-0003) $0.5 \mathrm{~mm}$ ash } \\
\hline Mar 79 to Feb 80 & 0.091 & 0.044 & 0.023 & 0.221 & 49 \\
\hline Jun 80 to May 81 & 0.107 & 0.058 & 0.048 & 0.388 & 76 \\
\hline Jun 81 to May 82 & 0.084 & 0.029 & 0.051 & 0.168 & 54 \\
\hline \multicolumn{6}{|c|}{ Richland (53-005-1001) 0.5 to $1.0 \mathrm{~mm}$ ash } \\
\hline Mar 79 to Feb 80 & 0.069 & 0.057 & 0.005 & 0.333 & 60 \\
\hline Jun 80 to May 81 & 0.063 & 0.040 & 0.009 & 0.181 & 60 \\
\hline Jun 81 to May 82 & 0.050 & 0.028 & 0.011 & 0.111 & 59 \\
\hline \multicolumn{6}{|c|}{ Longview (53-015-0008) 1 to $3 \mathrm{~mm}$ ash } \\
\hline Mar 79 to Feb 80 & 0.054 & 0.041 & 0.008 & 0.222 & 57 \\
\hline Jun 80 to May 81 & 0.097 & 0.141 & 0.021 & 0.986 & 56 \\
\hline Jun 81 to May 82 & 0.054 & 0.030 & 0.018 & 0.161 & 56 \\
\hline \multicolumn{6}{|c|}{ Spokane (53-063-0016) 2.5 to $5 \mathrm{~mm}$ ash } \\
\hline Mar 79 to Feb 80 & 0.165 & 0.093 & 0.028 & 0.375 & 57 \\
\hline Jun 80 to May 81 & 0.226 & 0.155 & 0.024 & 0.743 & 59 \\
\hline Jun 81 to May 82 & 0.168 & 0.131 & 0.029 & 0.846 & 55 \\
\hline \multicolumn{6}{|c|}{ Vancouver (53-011-0006) 4 to $5 \mathrm{~mm}$ ash } \\
\hline Mar 79 to Feb 80 & 0.050 & 0.030 & 0.005 & 0.158 & 61 \\
\hline Jun 80 to May 81 & 0.076 & 0.075 & 0.014 & 0.474 & 61 \\
\hline Jun 81 to May 82 & 0.055 & 0.029 & 0.014 & 0.124 & 61 \\
\hline \multicolumn{6}{|c|}{ Yakima $(53-077-1006) 5$ to $10 \mathrm{~mm}$ ash } \\
\hline Mar 79 to Feb 80 & 0.060 & 0.041 & 0.011 & 0.259 & 59 \\
\hline Jun 80 to May 81 & 0.116 & 0.089 & 0.014 & 0.426 & 60 \\
\hline Jun 81 to May 82 & 0.061 & 0.046 & 0.012 & 0.339 & 61 \\
\hline
\end{tabular}

Source: DTN: MO0008SPATSP00.013 [DIRS 151750].

a See file TSP Mount St Helens_1979-1982.xls in Appendix C for the daily concentrations upon which these values were based.

b Initial ash depth, from Sarna-Wojcicki et al. (1982 [DIRS 160227], Figures 336, 344, 345, and 346).

\subsubsection{Literature Review}

Information about concentrations of resuspended particles during and after eruptions of two additional volcanoes was reviewed to evaluate whether the analysis of data collected following the eruption of Mount St. Helens produced reasonable conclusions.

Gordian et al. (1996 [DIRS 160111]) examined the association between $\mathrm{PM}_{10}$ levels and daily outpatient visits in Anchorage, Alaska, after about $3 \mathrm{~mm}$ of ash were deposited from the August 1992 eruption of Mount Spurr (McGimsey et al. 2001 [DIRS 160386], p. 4). During the three months before the eruption, $\mathrm{PM}_{10}$ concentrations in Anchorage ranged from about 0.010 to $0.080 \mathrm{mg} / \mathrm{m}^{3}$ (Gordian et al. 1996 [DIRS 160111], Figure 1). The peak 1-hour concentration 
during the eruption was $3 \mathrm{mg} / \mathrm{m}^{3}$ and the 24-hour average concentration the day after the eruption was $0.565 \mathrm{mg} / \mathrm{m}^{3}$ (Gordian et al. 1996 [DIRS 160111], p. 290). Concentrations returned to pre-eruption levels after about three months, although there were occasional peaks of 0.1 to $0.2 \mathrm{mg} / \mathrm{m}^{3}$ for about 9 months. By May 1993, $\mathrm{PM}_{10}$ concentrations had returned to pre-eruption levels. Gordian et al. (1996 [DIRS 160111], p. 293) concluded that $\mathrm{PM}_{10}$ concentrations in Anchorage were influenced by the volcano August 18 through December 31, 1992. Average $\mathrm{PM}_{10}$ concentrations during that period were about $0.70 \mathrm{mg} / \mathrm{m}^{3}$, less than twice the average concentration of $0.40 \mathrm{mg} / \mathrm{m}^{3}$ during periods not influenced by the eruption (May 1 , 1992, through August 17, 1992, and January 1, 1993, through March 1, 1994).

Yano et al. (1990 [DIRS 160112]) compared TSP concentrations in the city of Kanoya, Japan, with those of Tahiro. Kanoya is $25 \mathrm{~km}$ from Mount Sakurajima and in the region that experiences the highest exposure to ash from that volcano, which "erupts hundreds of times each year" (Yano et al. 1990 [DIRS 160112], p. 368). Tashiro is $50 \mathrm{~km}$ from the volcano and outside of the affected area, and is similar to Kanoya in size and industrial development. Monthly average TSP concentrations, calculated as the sum of suspended particulate matter and respirable particulates in Table 1 of Yano et al. (1990 [DIRS 160112]), during summer 1995 were about twice as high in Kayona $\left(0.030 \mathrm{mg} / \mathrm{m}^{3}\right)$ than in Tashiro $\left(0.013 \mathrm{mg} / \mathrm{m}^{3}\right)$. Winter concentrations were about three times greater in Kayona $\left(0.596 \mathrm{mg} / \mathrm{m}^{3}\right)$ compared to Tashiro $\left(0.196 \mathrm{mg} / \mathrm{m}^{3}\right)$.

\subsubsection{Parameter Distribution}

Average ambient outdoor concentrations of TSP no more than doubled the year following the 1980 eruption of Mount St. Helens, and returned to pre-eruption levels the second year. This information is consistent with most climatic conditions and the thickness of the tephra deposit predicted for the area south of Yucca Mountain. Four of the six cities included in this analysis are in eastern Washington and have a climate consistent with that predicted for Yucca Mountain for much of the next 10,000 years (BSC 2004 [DIRS 170002], Section 6.6.2) (Clarkston: average annual precipitation $=16.5$ in., average annual snowfall $=15.1$ in.; Richland: precipitation $=$ 7.0 in., snowfall $=10.2$ in.; Spokane: precipitation $=16.2$ in., snowfall $=42.14$ in.; and Yakima: precipitation $=8.25$ in., snowfall $=23.4$ in.; NCDC 1998 [DIRS 125325]). Therefore, the influence of precipitation and vegetation on consolidation and removal of ash at those sites following Mount St. Helens likely would be similar to that after an eruption at Yucca Mountain. Also, ash thickness at the four sites examined (1 $\mathrm{mm}$ to $10 \mathrm{~mm}$ ) was comparable or higher than predicted ash depths from the original deposit $18 \mathrm{~km}$ south of Yucca Mountain under normal, variable wind conditions (see discussion in Section 6.3). Information from two other volcanoes confirms that the average annual ambient concentrations of TSP are about twice as high the year following an eruption compared to pre-eruption levels or to similar areas without ash. Therefore, a distribution with a mode of $0.120 \mathrm{mg} / \mathrm{m}^{3}$ and a lower bound of $0.050 \mathrm{mg} / \mathrm{m}^{3}$ are selected for the postvolcanic, inactive outdoor environment, twice that selected for nominal conditions.

None of the data analyzed or studies reviewed above were from areas that had tephra deposits as thick as the maximum predicted for $18 \mathrm{~km}$ downwind of Yucca Mountain (BSC 2005 [DIRS 174067], Table 6-4). Because the thickness of the initial tephra blanket may influence mass loading the year following deposition, there is some uncertainty about the upper end of the distribution for the inactive outdoor environment. Also, none of the measurements were taken in areas as arid as the current conditions at Yucca Mountain. The increase in precipitation and 
vegetative cover in eastern Washington may have resulted in lower mass loading in those regions soon after the eruption. In addition, there is uncertainty about the influence of redistribution of ash from aeolian and fluvial processes on mass loading. For example, if heavy rains occur soon after an eruption, additional ash particles may be carried through Fortymile Wash into the region south of Yucca Mountain, causing a temporary increase in mass loading within and near that wash (see Section 6.4 for additional information). To account for this uncertainty, a maximum value of $0.300 \mathrm{mg} / \mathrm{m}^{3}$ is selected, three times the maximum selected for nominal conditions. A higher value is not selected, because an original tephra deposit of more than $1 \mathrm{~cm}$ (the maximum thickness for which analogue data are available) would be an uncommon event south of Yucca Mountain in the area to be considered as the location of the receptor (BSC 2005 [DIRS 174067], Table 6-4) and because the influence of fluvial transport of ash on mass loading likely will be temporary and restricted to the vicinity of Fortymile Wash.

The distribution to be used in the biosphere model, which represents the increase in mass loading in the inactive outdoor environment the first year following a volcanic eruption at Yucca Mountain, is triangular with a mode of 0.060 , minimum of 0.025 , and maximum of $0.200 \mathrm{mg} / \mathrm{m}^{3}$. Because some relevant conditions under which the analogue measurements were taken are consistent with the conditions in the Yucca Mountain region, and because the range of the distribution was selected to bound uncertainty in other relevant conditions that may have differed, this distribution of mass loading is consistent with the applicable current and predicted future conditions in the Yucca Mountain region. This consistency supports a conclusion that the FEPs associated with this parameter (Table 1-1) are also consistent with the present knowledge of the conditions in the region surrounding the Yucca Mountain site, as required by 10 CFR 63.305(a) [DIRS 173273].

A sensitivity analysis, analogous to that described in Section 6.2.2.2 for the nominal conditions, was conducted to determine the degree of change in the inhaled mass of suspended particulates in response to the changes in contributing parameters, including mass loading in the inactive outdoor environment. It was concluded (Appendix A) that the conditions in the inactive outdoor environment have an insignificant effect on the total mass of inhaled particulate matter. Even when the mass loading in the inactive outdoor environment was kept at a maximum value, i.e., three times the maximum value for the nominal conditions, the resulting increase in the mass of inhaled material was only about 4 percent (Table A-2).

\subsubsection{Active Indoor Environment}

Applicable literature (see Section 4.1.1) was reviewed to evaluate mass loading concentrations indoors following volcanic eruptions. Because few such measurements have been taken, an assumption (Section 5.2) was developed and is used with the results of the literature review to develop a distribution for the active indoor environment.

\subsubsection{Literature Review}

Buist et al. (1986 [DIRS 144632], Table 2) reported concentrations of TSP measured indoors in the weeks following the eruption of Mount St. Helens by the National Institute of Occupational Safety and Health. Average TSP concentrations were $0.09 \mathrm{mg} / \mathrm{m}^{3}$ in homes (range $=0.03$ to $0.20 \mathrm{mg} / \mathrm{m}^{3}$ ), $0.30 \mathrm{mg} / \mathrm{m}^{3}$ in schools (range $=0.20$ to $0.50 \mathrm{mg} / \mathrm{m}^{3}$ ), and $0.30 \mathrm{mg} / \mathrm{m}^{3}$ in 
commercial establishments (range $=0.1$ to $0.44 \mathrm{mg} / \mathrm{m}^{3}$ ). Buist et al. (1986 [DIRS 144632], p. 41) concluded that "Generally, there were very low levels of airborne respirable dust in homes and other buildings and, for the most part, it is likely that the general population received a very low exposure."

Searl et al. (2002 [DIRS 160104]) measured $\mathrm{PM}_{4}$ and $\mathrm{PM}_{10}$ concentrations during 1996-2000 in areas where ash was being or had been deposited by the Soufriere Hills volcano. Personal exposure concentrations of $\mathrm{PM}_{4}$ were $0.050 \mathrm{mg} / \mathrm{m}^{3}$ for housekeepers (range $=0.012$ to $0.105 \mathrm{mg} / \mathrm{m}^{3}$ ), $0.105 \mathrm{mg} / \mathrm{m}^{3}$ for shop workers (range $=0.083$ to $0.126 \mathrm{mg} / \mathrm{m}^{3}$ ), $0.012 \mathrm{mg} / \mathrm{m}^{3}$ for one housewife, and $0.039 \mathrm{mg} / \mathrm{m}^{3}$ for one office worker (Searl et al. 2002 [DIRS 160104], Table 8). To model population exposure, the authors estimated average personal exposure to $\mathrm{PM}_{10}$ during various activities and for four levels of ash concentrations: alert, very high, raised, and low (Searl et al. 2002 [DIRS 160104], Table 11). The low ash and raised ash concentrations are the most consistent with the predicted conditions in the Yucca Mountain region because alert and very high concentrations occurred during less than five percent of days on the portions of the island where ash thickness was less than $5 \mathrm{~cm}$ (Searl et al. 2002 [DIRS 160104], Table 6). The very high and alert concentrations appear to correspond to days when the Soufriere Hills volcano was erupting and the winds were blowing ash toward a community. Including such values in the distribution of mass loading is inconsistent with the use of this parameter in the biosphere model, where the biosphere model distribution represents annual average values. Estimated concentrations of $\mathrm{PM}_{10}$ while active indoors were 0.05 to $0.15 \mathrm{mg} / \mathrm{m}^{3}$ for low and raised ash concentrations, and 0.5 to $2.0 \mathrm{mg} / \mathrm{m}^{3}$ for very high and alert concentrations. If the ratio of TSP to $\mathrm{PM}_{10}$ in this environment is approximately 2.5:1 (see Section 6.2.3), then corresponding TSP ratios for the low and raised ash conditions would be 0.125 and $0.375 \mathrm{mg} / \mathrm{m}^{3}$.

\subsubsection{Parameter Development}

Because an insufficient number of measurements of mass loading in the active indoor environment following a volcanic eruption have been reported, an assumption was developed (Section 5.2) that predicts that changes in the active indoor environment will be proportional to changes predicted for the inactive outdoor environment. The distribution selected for the active indoor environment under nominal conditions is triangular with a mode of $0.100 \mathrm{mg} / \mathrm{m}^{3}$ and a range of 0.060 to $0.175 \mathrm{mg} / \mathrm{m}^{3}$. Based on measurements of TSP the year following the eruption of Mount St. Helens, and a review of literature from Mount St. Helens, Mount Spurr, and Montserrat, it was predicted that outdoor mass loading would double the first year after an eruption at Yucca Mountain (Section 6.2.2). Thus, the predicted distribution of TSP for the active indoor environment the first year following a volcanic eruption at Yucca Mountain has a mode of $0.200 \mathrm{mg} / \mathrm{m}^{3}$ and a range of 0.120 to $0.350 \mathrm{mg} / \mathrm{m}^{3}$.

For the inactive outdoor environment, the maximum value in the distribution was three times higher than that predicted for nominal conditions. The maximum for the active indoor environment was doubled for the following reasons. As explained in Section 5.2, the rate at which indoor concentrations are assumed to increase relative to outdoor concentrations is about twice that measured in most studies, and was selected to account for uncertainty in the relationship between indoor and outdoor concentrations during very dusty conditions. Increasing that ratio further is unreasonable because such an increase would be greater than any applicable measured value. Also, it is unlikely that people would allow their homes to be extremely dusty 
for a long period following an eruption. In contrast to outdoor dust concentrations, which cannot be controlled easily, indoor concentrations can be decreased easily by dusting, vacuuming, changing air filters, and keeping windows and doors shut.

Predicted and measured concentrations of TSP indoors during and immediately following the eruptions of Mount St. Helens and Soufriere Hills ranged from about $0.09 \mathrm{mg} / \mathrm{m}^{3}$ to $0.375 \mathrm{mg} / \mathrm{m}^{3}$, respectively. These values are similar to the minimum and maximum values of the predicted range for the indoor active environment, and this range and the assumption upon which it was based therefore appear to be reasonable.

The distribution to be used in the biosphere model, which represents the increase in mass loading in the active indoor environment the first year following a volcanic eruption at Yucca Mountain, is triangular with a mode of 0.100 , minimum of 0.060 , and maximum of $0.175 \mathrm{mg} / \mathrm{m}^{3}$. Because the range of the distribution, and the assumption upon which it was based, was selected to bound uncertainty in relevant conditions in the Yucca Mountain region, this distribution of mass loading is consistent with the applicable current and predicted future conditions in the Yucca Mountain region. This consistency supports a conclusion that the FEPs associated with this parameter (Table 1-1) are also consistent with the present knowledge of the conditions in the region surrounding the Yucca Mountain site, as required by 10 CFR 63.305(a) [DIRS 173273].

\subsubsection{Asleep Indoor Environment}

Applicable literature (see Section 4.1.1) was reviewed to evaluate mass loading concentrations in the asleep indoor environment following volcanic eruptions. Because few such measurements have been taken, an assumption (Section 5.2) was developed and is used with the results of the literature review to develop a distribution for this environment.

\subsubsection{Literature Review}

Buist et al. (1983 [DIRS 159738]) measured personal TSP exposure concentrations of children ages 8 to 13 who were attending a summer camp in Oregon shortly after $1.2 \mathrm{~cm}$ of ash had fallen from the eruption of Mount St. Helens. The methods used for that study are fully described by Hewett (1980 [DIRS 168491]). Nighttime TSP concentrations were at or below the $0.01-\mathrm{mg} / \mathrm{m}^{3}$ limit of detection of sampling equipment (Buist et al. 1983 [DIRS 159738], p. 717).

Searl et al. (2002 [DIRS 160104]) measured $\mathrm{PM}_{4}$ and $\mathrm{PM}_{10}$ concentrations during 1996-2000 in areas where ash was being or had been deposited by the Soufriere Hills volcano. To model population exposure, the authors estimated average personal exposure to $\mathrm{PM}_{10}$ during various activities and for four levels of ash concentrations (Searl et al. 2002 [DIRS 160104], Table 11). The low ash and raised ash concentrations are the most consistent with the predicted conditions in the Yucca Mountain region because alert and very high concentrations occurred during less than five percent of days on the portions of the island where ash thickness was less than $5 \mathrm{~cm}$ (Searl et al. 2002 [DIRS 160104], Table 6). The very high and alert concentrations appear to correspond to days when the Soufriere Hills volcano was erupting and the winds were blowing ash toward a community. As noted in Section 6.3.3.1, such values represent temporary conditions and are inconsistent with the annual exposure timeframe used in the biosphere model. Estimated concentrations of $\mathrm{PM}_{10}$ while inactive were 0.03 to $0.1 \mathrm{mg} / \mathrm{m}^{3}$ for low and raised ash 
conditions, and 0.3 to $1.0 \mathrm{mg} / \mathrm{m}^{3}$ for very high and alert concentrations. If the ratio of TSP to $\mathrm{PM}_{10}$ in this environment were 1.6:1 (from Thatcher and Layton 1995 [DIRS 159600], Figure 3; see Section 6.1.4), then corresponding TSP ratios for the low and raised ash conditions would be about 0.048 and $0.160 \mathrm{mg} / \mathrm{m}^{3}$.

\subsubsection{Parameter Development}

Because an insufficient number of measurements of mass loading in the active indoor environment following a volcanic eruption have been reported, an assumption was developed (Section 5.2) that predicts that changes in mass loading indoors following a volcanic eruption will be proportional to changes predicted for the inactive outdoor environment. The distribution selected for the asleep indoor environment under nominal conditions is triangular with a mode of $0.030 \mathrm{mg} / \mathrm{m}^{3}$ and a range of 0.010 to $0.050 \mathrm{mg} / \mathrm{m}^{3}$. Based on measurements of TSP the year following the eruption of Mount St. Helens, and a review of literature from Mount St. Helens, Mount Spurr, and Montserrat, it was predicted that outdoor mass loading in the Yucca Mountain region would double the first year after an eruption at Yucca Mountain (Section 6.2.2). Thus, the predicted distribution of TSP for the asleep indoor environment the first year following a volcanic eruption at Yucca Mountain has a mode of $0.060 \mathrm{mg} / \mathrm{m}^{3}$ and a range of 0.020 to $0.100 \mathrm{mg} / \mathrm{m}^{3}$.

For the inactive outdoor environment, the maximum value in the distribution was three times higher than that predicted for nominal conditions. The maximum for the asleep indoor environment was doubled for the following reasons. As explained in Section 5.2, the rate at which indoor concentrations increase relative to outdoor concentrations is about twice that measured in most studies, and was selected to account for uncertainty in the relationship between indoor and outdoor concentrations during very dusty conditions. Increasing that ratio further is unreasonable because such an increase would be greater than any applicable measured value. Also, it is unlikely that people would allow their homes to be three times as dusty for a long period following an eruption. In contrast to outdoor dust concentrations, which cannot be controlled easily, indoor concentrations can be decreased easily by dusting, vacuuming, changing air filters, and keeping windows and doors shut.

Predicted and measured concentrations of TSP indoors during and immediately following the eruptions of Mount St. Helens and Soufriere Hills ranged from less than $0.010 \mathrm{mg} / \mathrm{m}^{3}$ to about $0.160 \mathrm{mg} / \mathrm{m}^{3}$. The high value is the predicted value of Searl et al. (2002 [DIRS 160104]) for raised ash conditions while inactive, and is higher than the predicted maximum for the asleep indoor environment. The value from Searl et al. is based on sleeping and sedentary activities while awake, such as watching television (Searl et al. 2002 [DIRS 160104], Table 10) and is 20 times higher than the maximum values measured by Buist et al. (1983 [DIRS 159738]). Because it includes concentrations while people are awake, it likely is an overestimate of concentrations while asleep. Thus, the predicted range for the asleep indoor environment, and the assumption upon which it was based, appear to be reasonable.

The distribution to be used in the biosphere model, which represents the increase in mass loading in the asleep indoor environment the first year following a volcanic eruption at Yucca Mountain, is triangular with a mode of 0.030 , minimum of 0.010 , and maximum of $0.050 \mathrm{mg} / \mathrm{m}^{3}$. Because the range of the distribution, and the assumption upon which it was based, was selected to bound 
uncertainty in relevant conditions in the Yucca Mountain region, this distribution of mass loading is consistent with the applicable current and predicted future conditions in the Yucca Mountain region. This consistency supports a conclusion that the FEPs associated with this parameter (Table 1-1) are also consistent with the present knowledge of the conditions in the region surrounding the Yucca Mountain site, as required by 10 CFR 63.305(a) [DIRS 173273].

\subsubsection{Mass Loading - Crops}

No measurements have been taken of mass loading near crops, so it is assumed that the distribution of mass loading in fields where crops are growing is similar to or higher than that in the inactive outdoor environment, with a minimum value equal to the minimum value of the inactive outdoor environment, and a modal and maximum value twice that of the inactive outdoor environment. See Section 5.1 for justification of this assumption. As described in the introduction to Section 6.3, mass loading for crops is not treated as a function of time in the biosphere model. Therefore, this distribution of mass loading must be representative of the total concentration of resuspended particles following a volcanic eruption (versus the increase the first year following an eruption, as is done for mass loading distributions for human environments).

The distribution of mass loading in the inactive outdoor environment the first year following a volcanic eruption is predicted to have a mode of $0.120 \mathrm{mg} / \mathrm{m}^{3}$, and a range of 0.050 to $0.300 \mathrm{mg} / \mathrm{m}^{3}$. Based on the above assumption, the distribution of mass loading for crops is triangular with a mode of $0.240 \mathrm{mg} / \mathrm{m}^{3}$, and a range of 0.050 to $0.600 \mathrm{mg} / \mathrm{m}^{3}$.

\subsection{MASS LOADING - TIME FUNCTION}

The mass loading time function account for changes in inhalation exposure of the RMEI caused by a decrease in mass loading through time following a volcanic eruption, as shown in Equation 6-5.

Ash from a volcanic eruption initially would be more readily suspendable than the soil upon which it was deposited, and mass loading therefore would be higher than it was prior to the eruption (i.e., under nominal conditions defined in Section 6.2). Through time the tephra deposit, whether originally deposited at the location of the receptor during eruption or redistributed from other deposition sites by fluvial and aeolian processes, would erode; become mixed into the soil; buried; removed from homes, yards, and other living areas; or otherwise become stabilized. That erosion, removal, and stabilization would result in a decrease in mass loading, with concentrations eventually returning to nominal conditions. Because of this change in mass loading through time, annual dose resulting from a volcanic eruption must be calculated in the TSPA model as a function of time (Section 6.3).

If mass loading decreases exponentially through time, the mass loading time function in Equation 6-5 is expressed as:

$$
S_{v, n} f(t)=S_{v, n} e^{-\lambda t}
$$


where:

$$
\begin{aligned}
& \lambda=\text { Mass loading decrease rate constant }(1 / \mathrm{yr}) \\
& t=\text { Time (years); } 0 \leq t \leq 1 \text { is the first year after a volcanic eruption. }
\end{aligned}
$$

The other variables in this equation are defined for Equation 6-5.

An exponential decrease in mass loading following a volcanic eruption is selected for Equation 6-6 based on commonly used equations for predicting the change in concentrations of resuspended particles and radionuclides through time. Dahneke (1975 [DIRS 151756], p. 194) developed a generalized exponential equation for particle resuspension of $\mathrm{N}_{\mathrm{t}}=\mathrm{N}_{0} \mathrm{e}^{-\lambda t}$, where $\mathrm{N}_{\mathrm{t}}=$ concentration at time $\mathrm{t}, \mathrm{N}_{0}=$ initial concentration, $\lambda=$ resuspension factor or decrease rate constant (i.e., an estimate of how quickly the decay occurs), and $t=$ time. Similar exponential decay equations have been used to calculate resuspension in dose assessment models (Till and Meyer 1983 [DIRS 101895], pp. 5-32 through 5-33; IAEA 1982 [DIRS 103768], p. 20; IAEA 1992 [DIRS 103772], Figure 1 on p. 13; Napier et al. 1988 [DIRS 100953], p. 4.64).

Inverse or inverse power functions have also been used to predict concentrations of resuspended radionuclides (IAEA 1992 [DIRS 103772], Figure 1 on p. 13; Garger et al. 1997 [DIRS 124902], p. 1651). Garger et al. (1997 [DIRS 124902], Figure 3 on p. 1654) evaluated how eight equations (six exponential, one inverse power, and one combination) predicted temporal changes in radionuclide concentrations following the accident at the Chernobyl nuclear power plant. Equation with an inverse power function generally predicted concentrations more accurately than the exponential equations in that mesic environment (Garger et al. 1997 [DIRS 124902], p. 1655) because the exponential equations overestimated concentrations (i.e., did not calculate a rapid enough decay). However, an inverse power decay function is less conservative than an exponential function because it predicts a more rapid decrease in concentrations.

The mass loading decrease rate constant controls the rate at which the mass loading concentration would decrease over time. Figure 6-8 is a plot of the decrease in mass loading per year for seven arbitrarily selected values of $\lambda$.

The average annual concentration for a period of years $T I\left(S_{x, T I}^{-}\right)$and an initial concentration $S_{v, n}$ can be calculated using the following equation, which was developed by integrating Equation 6-6 between the times of zero and the time interval $T I$ and dividing this by the time interval. This equation is used only within this analysis to compare average concentrations among selected decrease rate constants; it is not used in the biosphere model report.

$$
S_{\bar{x}, T I}=\frac{\int d S_{n}}{\int d t}=\frac{S_{v, n}}{t} \times \frac{1}{\lambda} \times\left(1-e^{-\lambda t}\right)
$$

Concentrations of TSP measured before and after eruptions of Mount St. Helens were analyzed to predict the mass loading decrease rate constant for a volcanic eruption at Yucca Mountain. Literature from that and other volcanoes were reviewed to corroborate the rate at which mass loading returns to pre-eruptive conditions. 


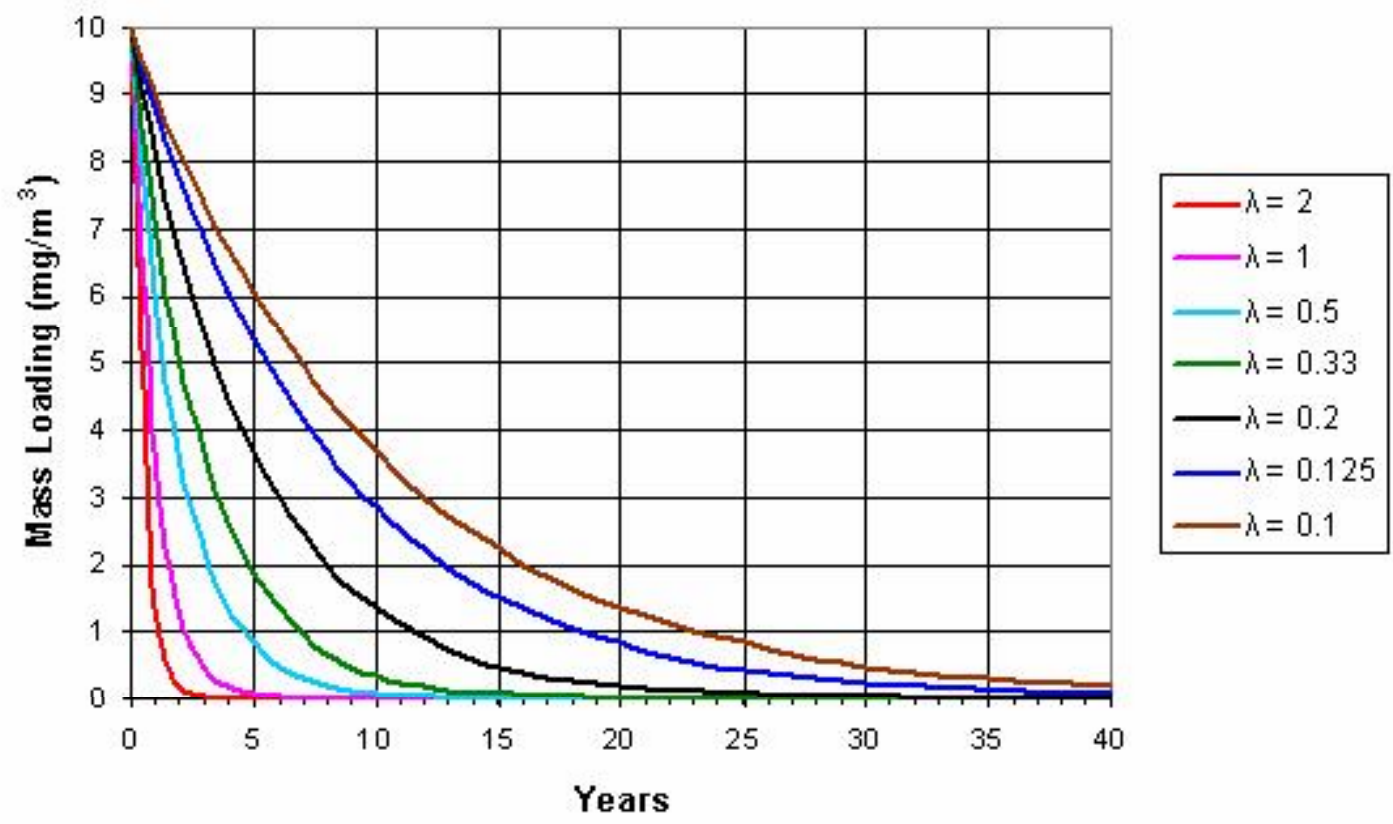

Figure 6-8. Examples of the Change of Mass Loading from a Hypothetical Initial Concentration of $10 \mathrm{mg} / \mathrm{m}^{3}$ for Seven Values of the Mass Loading Decrease Rate Constant $(\lambda)$

\subsubsection{Data Analysis}

Mount St. Helens TSP Data - TSP measurements for 1979-1982 from six sites in Washington that had about 0.5 to $10 \mathrm{~mm}$ of ash were plotted to evaluate the rate at which ash stabilized after the eruption of Mount St. Helens. The dataset (DTN: MO0008SPATSP00.013 [DIRS 151750]) and methods used to select the six sites are described in Section 6.3.2.1.

TSP concentrations at the sites are plotted in Figure 6-9. This figure displays five-measurement running averages, which were calculated to smooth changes over short periods. These averages were calculated as the average of the concentration for a date and the four previous measurements (see Excel file TSP Mount St Helens_1979-1982.xls in Appendix C). Concentrations returned to pre-eruption levels at Clarkston, Longview, and Vancouver within about three months, and within about six to eight months at Spokane and Yakima. Average annual concentrations two years after the eruption were equal to pre-eruption concentrations at all sites (Table 6-13). The corresponding $\lambda$ for this rate of decrease is at least 2.0 per year or greater (Figure 6-8).

The eruption of Mount St. Helens did not have a large effect on TSP concentrations in Richland. The graph (Figure 6-9) shows a seasonal pattern in TSP concentrations, with maxima occurring in the summer. The difference between TSP concentrations in 1979 and 1980 is not substantial except for a peak of short duration coinciding in time with the eruption. 

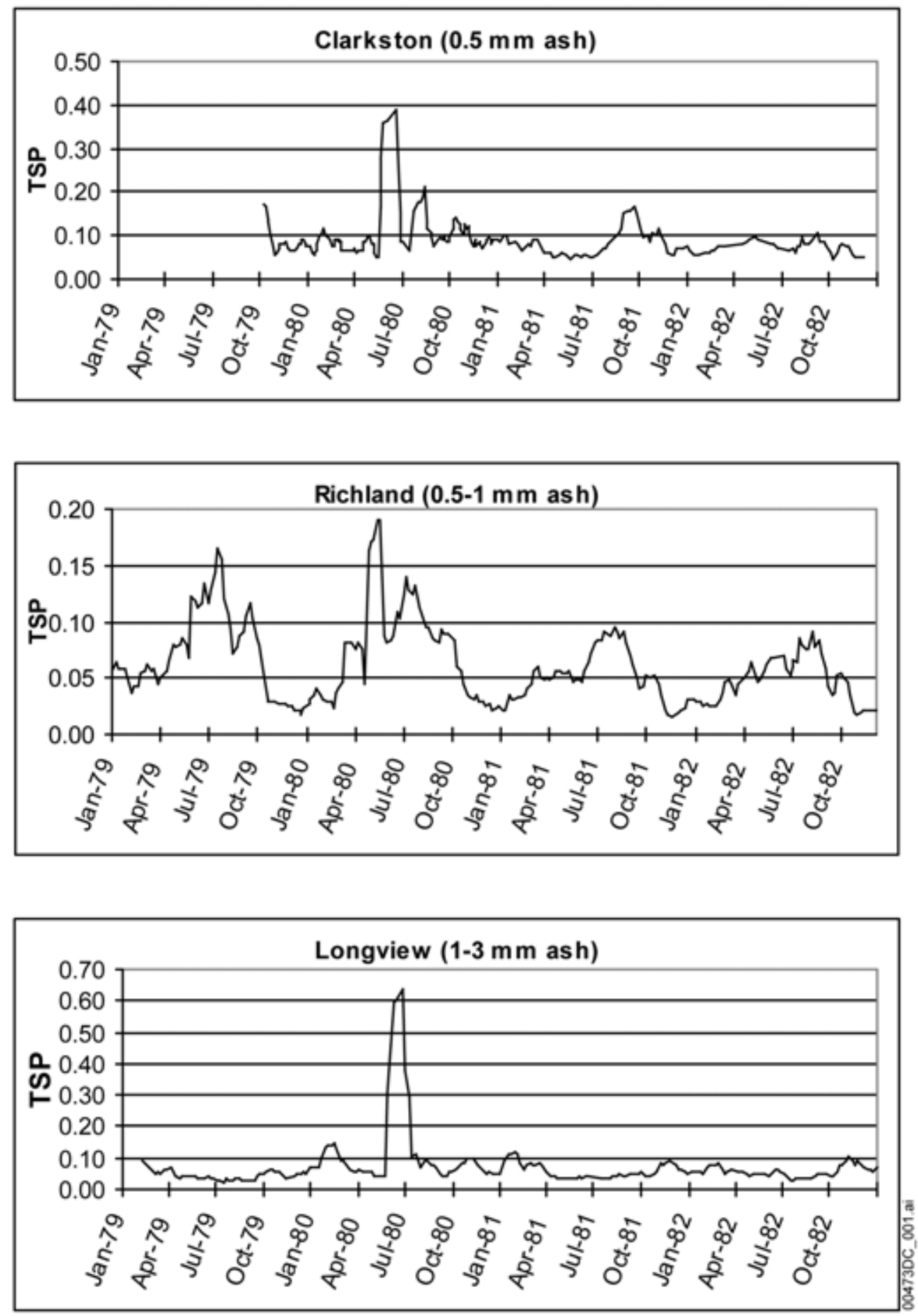

DTN: MO0008SPATSP00.013 [DIRS 151750].

NOTE: TSP is presented as the running average of 5 consecutive measurements (see file TSP Mount St Helens_1979-1982.xIs in Appendix C).

Figure 6-9. TSP Concentrations $\left(\mathrm{mg} / \mathrm{m}^{3}\right)$ at Six Sites in Washington Before and After the Eruption of Mount St. Helens in May-June 1980 

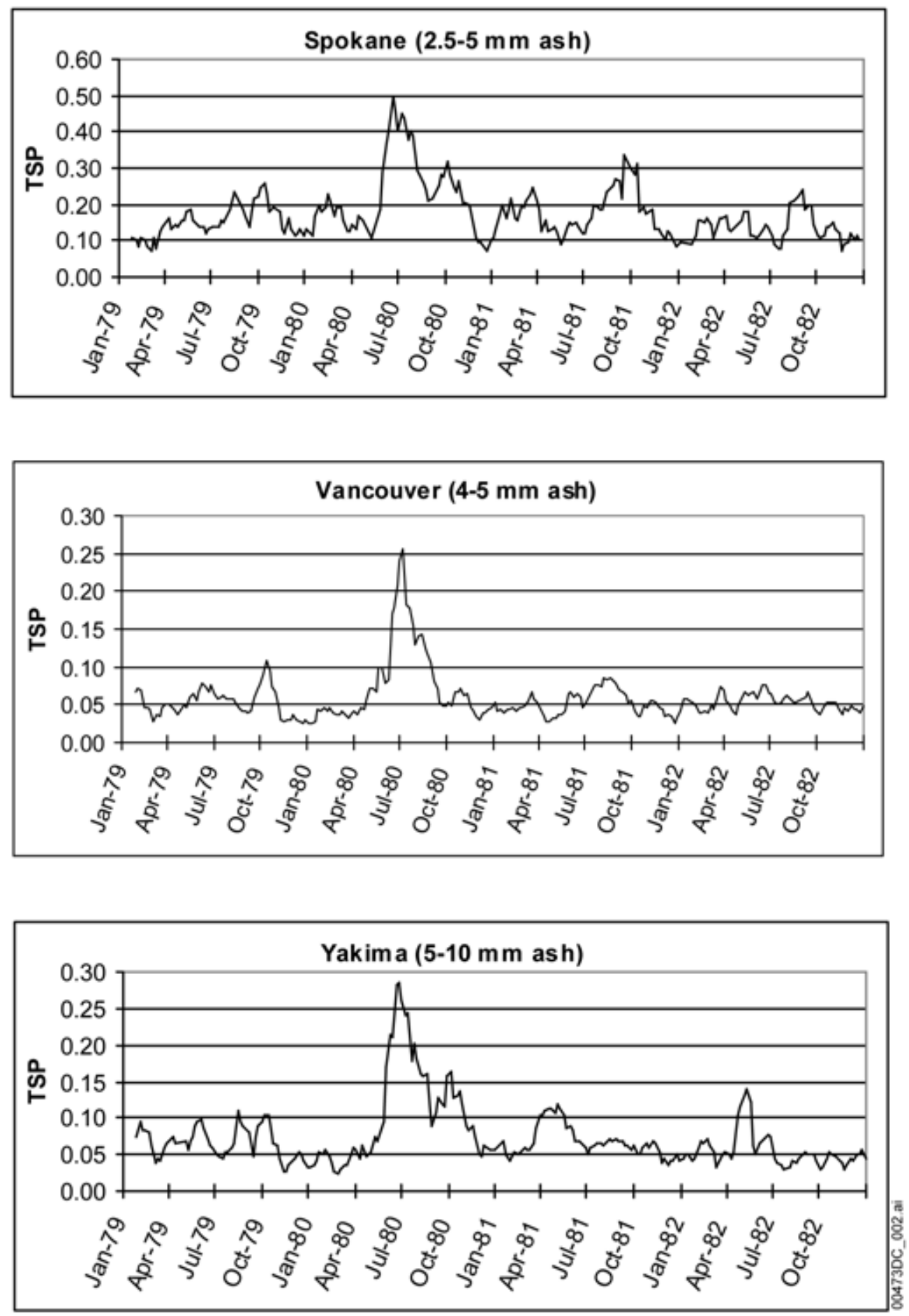

NOTE: $\quad$ TSP is presented as the running average of 5 consecutive measurements (see file TSP Mount St Helens_1979-1982.xls in Appendix C).

Figure 6-9. TSP Concentrations $\left(\mathrm{mg} / \mathrm{m}^{3}\right)$ at Six Sites in Washington Before and After the Eruption of Mount St. Helens in May-June 1980 (Continued) 


\subsubsection{Literature Review}

Buist et al. (1986 [DIRS 160308], p. 70) report changes in personal-exposure concentrations of respirable dust for loggers working in areas having substantial deposits of ash from Mount St. Helens. Sanderson (1982 [DIRS 168492]) gives a complete description of the methods and location of the study sites. Dust concentrations for cutting crews were $0.900 \mathrm{mg} / \mathrm{m}^{3}$ in June 1980 (one month or less after the major eruption of Mount St. Helens) and $0.270 \mathrm{mg} / \mathrm{m}^{3}$ in September 1980. This is a 70 percent decrease in mass loading over four months (maximum of 122 days), or 0.57 percent per day $(0.7 / 122$ days $\times 100)$, which is approximately equal to a $\lambda$ of 2.1 per year $(0.57$ percent per day $\times 365$ days $)$.

Buist et al. (1986 [DIRS 144632], p. 41) summarize results of monitoring of personal exposure to dust and ash for many other occupations and settings following the eruption of Mount St. Helens. Although they do not present specific data on how concentrations changed through time, they state that high occupational exposures were "largely restricted to the summer months" (i.e., 3 to 4 months following the eruption), and that "environmental exposures were also modest except in the path of the plume for the few days immediately following the May 18, 1980 eruption." They also state that "[i]n exposed areas, rain and weathering have tended to create a crust that has helped to reduce the aerosolization of the ash, and on farmed land, the ash has gradually become worked into the topsoil."

Gordian et al. (1996 [DIRS 160111]) present a plot of $\mathrm{PM}_{10}$ concentrations in Anchorage, Alaska, before and after about $3 \mathrm{~mm}$ of ash were deposited from the August 1992 eruption of Mount Spurr (McGimsey et al. 2001 [DIRS 160386], p. 4). During the three months prior to the eruption, $\mathrm{PM}_{10}$ concentrations in Anchorage ranged from about 0.010 to $0.080 \mathrm{mg} / \mathrm{m}^{3}$ (Gordian et al. 1996 [DIRS 160111], Figure 1). The peak one-hour concentration during the eruption was $3 \mathrm{mg} / \mathrm{m}^{3}$ and the 24-hour average concentration the day after the eruption was $0.565 \mathrm{mg} / \mathrm{m}^{3}$ (Gordian et al. 1996 [DIRS 160111], p. 290). Concentrations returned to pre-eruption levels after about three months, although there were occasional peaks of 0.1 to $0.2 \mathrm{mg} / \mathrm{m}^{3}$ for about nine months. By May 1993, $\mathrm{PM}_{10}$ concentrations had returned to pre-eruption levels. The corresponding $\lambda$ for this rate of decrease is at least 2.0 per year (Figure 6-7).

Yano et al. (1990 [DIRS 160112], p. 373) stated that although concentrations as high as $2 \mathrm{mg} / \mathrm{m}^{3}$ have been measured in high-exposure areas after the eruption of Mount Sakurijima (Japan), "these high levels of suspended particulate matter seldom last long, and they usually decrease rapidly to approximately $0.1 \mathrm{mg} / \mathrm{m}^{3}$."

In summary, the mass loading decrease rate constant for six sites in Washington following the eruption of Mount St. Helens, and in Anchorage following the eruption of Mount Spurr, was about 2.0 per year (see Figure 6-7). The average concentration of particulate matter in air for a decrease rate constant of 2 per year and a hypothetical $S_{v}$ of $10 \mathrm{mg} / \mathrm{m}^{3}$ is $0.5 \mathrm{mg} / \mathrm{m}^{3}$ over 10 years and $0.25 \mathrm{mg} / \mathrm{m}^{3}$ over 20 years (using Equation 6-7). This rate of decrease in mass loading following eruptions is corroborated by other reports of conditions following Mount St. Helens and from monitoring following the eruptions of Mount Spurr and Mount Sakurijima. 


\subsubsection{Parameter Development}

The conditions under which the data from Mount St. Helens were collected are generally consistent those for the area south of Yucca Mountain. There are, however, some differences between the conditions under which data from Mount St. Helens were measured and those expected at Yucca Mountain. These differences may be important sources of uncertainty in the use of information from Mount St. Helens and other volcanoes to develop a distribution of the mass load decay rate constant.

First, the size, resuspendability, or other characteristics of ash from non-basaltic volcanoes such as Mount St. Helens and other volcanoes may differ from that of the type of basaltic volcano predicted for Yucca Mountain. Second, climatic conditions at Mount St. Helens are wetter and cooler than current conditions at Yucca Mountain. Third, no data are available on the rate of change in mass loading following an initial deposit of more than $1 \mathrm{~cm}$. Also, all locations where changes in mass loading through time were measured after volcanic eruptions were outside of the volcanoes' watersheds; therefore, the only important source of ash was the initial, airborne deposit. Amargosa Valley is within the watershed of Yucca Mountain and ash initially deposited upstream of Amargosa Valley may be washed and blown into and through that valley.

\subsubsection{Particle Size and Other Characteristics of Ash}

If ash particles from non-basaltic volcanoes used as analogues in this analyses (Mount St. Helens, and to a lesser extent Soufriere Hills, Mount Spurr, and Mount Sakurijima) are larger than those from a basaltic volcano of the type predicted at Yucca Mountain, then predicted concentrations of resuspended ash developed from those analogues may underestimate mass loading following an eruption at Yucca Mountain and overestimate the rate at which concentrations decrease through time. All of the following measurements of particle size distributions are presented as percent mass. Hill and Connor (2000 [DIRS 160103], p. 71) report that ash $21 \mathrm{~km}$ from the vent of the basaltic Cerro Negro volcano had about two percent of particles by weight less than $10 \mu \mathrm{m}, 10$ percent less than $60 \mu \mathrm{m}$, and 50 percent less than $200 \mu \mathrm{m}$. They report that other fall deposits from larger basaltic cinder cone eruptions (Paricutin, Tolbachik, Sunset Crater) may contain two to five percent weight of particles less than $10 \mu \mathrm{m}$ at $20 \mathrm{~km}$. Hill and Connor (2000 [DIRS 160103], p. 71) also state that basaltic volcanoes may produce unusually fine-grained deposits (greater than 40 percent of particle weight less than $60 \mu \mathrm{m}$ ) late in an eruption during subsurface brecciation events.

About 90 percent of ash from Mount St. Helens by particle count, although only 10 percent or less by mass, was less than $10 \mu \mathrm{m}$ (Craighead et al. 1983 [DIRS 160338], p. 6; Buist et al. 1986 [DIRS 144632], p. 40). Particle size distribution depends on the proximity to a volcano - the distribution tends to shift towards smaller particle sizes with an increase in distance. Ash at two sites 30 to $35 \mathrm{~km}$ east of Anchorage from the August 1992 eruption of Mount Spurr had about 30 to 35 percent of particles equal to or less than $63 \mu \mathrm{m}, 8$ to 15 percent less than $15 \mu \mathrm{m}$, and 5 to 10 percent equal to or less than $7.5 \mu \mathrm{m}$ (McGimsey et al. 2001 [DIRS 160386], Figure 12; particle sizes are midpoints of values from bar charts). However, ash collected at a site about $25 \mathrm{~km}$ west of Anchorage (closer to Mount Spurr) had few or no particles equal to or less than $63 \mu \mathrm{m}$. Ash from Soufriere Hills had 13 to 20 percent weight of particles equal to or less than $10 \mu \mathrm{m}$ and 60 to 70 percent weight of particles 10 to $125 \mu \mathrm{m}$ (Baxter et al. 1999 
[DIRS 150713], p. 1142). Thus, ash from the volcanoes used as analogues in this analysis appears to have had higher concentrations of fine particles than that from basaltic volcanoes. This is in part due to the distances from a volcano of the sites where the measurements used as analogues in this analysis were collected, which were typically greater than $20-\mathrm{km}$ distance cited in comparisons for the basaltic volcanoes in the study by Hill and Connor (2000 [DIRS 160103], p. 71). As noted before, at distances farther away the fraction of fine particles is greater than the location closer to a volcano. Another reason is the type of volcano. For instance, Baxter (in McKague 1998 [DIRS 151841], Enclosure 3 - Item 17) stated, "[f]or exposure estimates, the $\left[\mathrm{PM}_{10}\right]$ results obtained from Mount St. Helens and Monsterrat will almost certainly need to be reduced by a factor to allow for the coarser material emitted at Cerro Negro." Thus, ash particles from the analogue volcanoes used in this analysis generally were similar in size or smaller than those from basaltic volcanoes. However, the amount of fine ash deposited at a site can be quite variable, depending on wind direction and speed, distance from the volcano, and possibly other factors (Sarna-Wojcicki et al. 1982 [DIRS 160227], pp. 585-588; McGimsey et al. 2001 [DIRS 160386], Figure 12). In addition, other characteristics of the ash and environment, such as grain adhesion and the presence of an indurated surface layer, may affect the concentrations of resuspended ash particles.

The other characteristics of ash at the analogue sites considered in this analysis, and their effects on measurements of resuspended particles considered here, are unknown. For example, measurements of mass loading taken over the tephra deposit from the eruption of basaltic Cerro Negro (Hill and Conner 2000 [DIRS 160103], p. 71) are higher than analogous measurements taken following the eruption of the silicic Mount St. Helens (Buist et al. 1986 [DIRS 144632], Table 2; Merchant et al. 1982 [DIRS 160102], Table 6) (see Section 6.2.1). To account for uncertainty about the influence of differences in the characteristics of ash from analogue measurements considered here and the potential conditions in the reference biosphere following an eruption, the modal and lower bounds of the distribution of the decay rate constant described below are smaller (i.e., have a slower decay rate) than the value of about 2 measured after eruptions of Mount St. Helens and Mount Spurr.

\subsubsection{Climate}

The conditions under which the data from Mount St. Helens were collected are consistent with the coolest, wettest climatic conditions predicted for the area south of Yucca Mountain. The climate at the four cities in eastern Washington examined (Clarkston: average annual precipitation $=16.5$ in., average annual snowfall $=15.1$ in.; Richland: precipitation $=7.0 \mathrm{in}$., snowfall $=10.2$ in.; Spokane: precipitation $=16.2$ in., snowfall $=42.1$ in.; Yakima: precipitation $=8.3$ in., snowfall $=23.4$ in.; NCDC 1998 [DIRS 125325]) is predicted to be consistent with that at Yucca Mountain for much of the next 10,000 years (BSC 2004 [DIRS 170002], Section 6.6.2). Therefore, the influence of precipitation and vegetation on consolidation and removal of ash at those sites following Mount St. Helens likely will be consistent with that after an eruption at Yucca Mountain.

The present-day, arid climate at Yucca Mountain is predicted to continue for less than 1,000 years (BSC 2004 [DIRS 170002], Table 6-1). The rate of change in mass loading measured in eastern Washington under wetter and cooler conditions may not apply to current conditions. However, concentrations of airborne particulates currently do not differ much among arid, rural 
sites with less than 20 in. of precipitation and less than about 45 in. of snowfall (Section 6.1.3.1); therefore, changes in mass loading through time likely would not differ greatly between presentday and future climates predicted for Yucca Mountain (Section 6.1.3). To ensure that uncertainty in the effects of current, arid conditions are not underestimated, the lower bound of the distribution of the decay rate constant below is smaller than the value measured at analogue sites.

\subsubsection{Ash Deposit Thickness}

The analogue data from Mount St. Helens used in this analysis are from ash deposits of $10 \mathrm{~mm}$ or less. An ash deposit greater than $10 \mathrm{~mm}$ is unlikely in the area south of Yucca Mountain at the receptor location (see BSC 2005 [DIRS 174067], Table 6-4, and discussion in Section 6.2); however, there is a possibility that the thickness of material redistributed by fluvial and aeolian transport to the location of the receptor may exceed $10 \mathrm{~mm}$. The influence of such a deposit on the mass loading time function must be included. Because there is much more uncertainty in the decay rate constant for ash deposits equal to or more than $10 \mathrm{~mm}$, separate distributions of this parameter are developed below for deposits less than 10 and equal to or greater than $10 \mathrm{~mm}$ deep.

The effects of aeolian and fluvial redistribution of ash into northern Amargosa Valley must be included in the model. Large quantities of ash from an eruption at Yucca Mountain may be deposited in the Fortymile Wash watershed. During and after very heavy precipitation events, some of the ash in that watershed would be washed downstream and deposited in Amargosa Valley. Such events may bring fine-grained particulates, originally deposited upstream, into the receptor location. Before surface processes stabilize this material, it can contribute to mass loading levels, especially in the Fortymile Wash alluvial fan. During that fluvial transport, some of the fuel and ash may be broken down into smaller particles and diluted by mixing with uncontaminated upstream sediments. If the quantity of resuspendable fuel and ash at or near the location of the receptor is greater than the quantity of resuspendable soil now washed through that area, dust concentrations would increase temporarily after deposition.

The ash redistribution model treats the areas where the original deposition occurred separately from the distributary channels that carry redistributed ash (BSC 2005 [DIRS 174067], Section 6.6). The selection of the mass loading decrease rate constants in the TSPA model will, accordingly, depend on the thickness of the original ash and the thickness of redistributed material (ash mixed with the sediments). Subsequently, even for the circumstances when the original deposit is less than $10 \mathrm{~mm}$ or there is no original deposit at all at the receptor location, the mass loading decrease function for the redistributed ash can potentially be that for deposits greater than $10 \mathrm{~mm}$ in depth.

The Fortymile Wash watershed starts approximately 25 miles north of Yucca Mountain, and continues southward along the eastern edge of Yucca Mountain before entering Amargosa Valley. The wash terminates at the Amargosa River in western Amargosa Valley. It drains the southern part of Pahute Mesa, western Jackass Flats, and the eastern slopes of Fortymile Wash. Just south of the southern boundary of the Nevada Test Site (i.e., about $20 \mathrm{~km}$ south of Yucca Mountain), the Fortymile Wash channel changes from a moderately confined channel to several distributary channels that are poorly defined (Tanko and Glancy 2001 [DIRS 159895], Figure 1). 
Fortymile Wash flows into Amargosa Valley infrequently and flows into the Amargosa River have been documented only three times since 1969. During the two floods (1995 and 1998) that have been well studied, unusually severe or long-lasting rains combined with melting of the snowpack in the northern part of the watershed resulted in flows throughout all or most of the major tributaries of Fortymile Wash and the Amargosa River (Beck and Glancy 1995 [DIRS 160389]; Tanko and Glancy 2001 [DIRS 159895]). Thus, any sediment from one portion of the watershed was mixed with and buried within sediment from throughout the watershed.

There is little evidence of flooding over the bank in the washes in Amargosa Valley (BSC 2004 [DIRS 169980], Section 6.3.4.2.5); therefore, most sediment transported into Amargosa Valley would be restricted primarily to the bottoms and sides of the channels of Fortymile Wash. Although Fortymile Wash consists of a series of diffuse channels in Amargosa Valley, the surface area of the channels is small relative to the entire valley. Tephra blankets deposited throughout entire regions following other volcanic eruptions resulted in increases in resuspended particles for only months (e.g., Figure 6-8). Therefore, it is reasonable to expect that ash redistributed during flooding restricted to the channels of Fortymile Wash and well-mixed with other sediment would affect mass loading for a much shorter period of time, likely days to at most weeks.

\subsubsection{Incorporation of Uncertainty into Parameter Distribution}

To account for uncertainty in how long mass loading would remain high after such flooding, how much higher than background levels it would be, changes in particle size distributions over time, and how frequently Fortymile Wash would flood in the future, the selected modal and minimum values of the mass loading decrease rate constant are much lower than those measured following other volcanic eruptions.

For ash thickness of less than $10 \mathrm{~mm}$, a triangular distribution of the mass load decrease rate constant with a mode of 0.33 per year, maximum of 2.0 per year, and minimum of 0.2 per year is selected.

- The maximum value of 2.0 per year is approximately equal to the rate measured at community monitoring sites following the eruption of Mount St. Helens (Figure 6-7). It is also similar to the change in personal exposure to resuspended particles during logging after Mount St. Helens erupted (Buist et al 1986 [DIRS 160308]), and to the decrease in mass loading following the eruptions of Mount Spurr and Mount Sakurijima (Gordian et al 1996 [DIRS 160111]; Yano et al. 1990 [DIRS 160112]). A rate of 2.0 year $^{-1}$ would result in a decrease in mass loading to 5 percent of the maximum concentrations in about 2 years and an average annual concentration over 10 years of about $0.5 \mathrm{mg} / \mathrm{m}^{3}$ for a hypothetical $S_{v}$ of $10 \mathrm{mg} / \mathrm{m}^{3}$ (from Equation 6-7).

- The modal rate of 0.33 per year would result in a decrease of about 96 percent over 10 years (Figure 6-7) and an average annual concentration over 10 years of $2.9 \mathrm{mg} / \mathrm{m}^{3}$ for a hypothetical $S_{v}$ of $10 \mathrm{mg} / \mathrm{m}^{3}$ (from Equation 6-7). This corresponds to a rate that takes at least 10 times longer to approach pre-eruption levels, and an average annual concentration over 10 years about 6 times greater than for a $\lambda$ of 2 per year $\left(0.5 \mathrm{mg} / \mathrm{m}^{3}\right)$, the approximate decrease rate constant following the eruptions at Mount St. Helens and 
other volcanoes for which data are available. This modal rate was selected to account for uncertainty in the effects of differences such as precipitation, vegetation, ash characteristics, and ash redistribution, between those sites and the reference biosphere.

- The minimum rate of 0.2 per year would result in a decrease of about 86 percent in 10 years and an average annual concentration over 10 years of $4.3 \mathrm{mg} / \mathrm{m}^{3}$ for a hypothetical $S_{v}$ of $10 \mathrm{mg} / \mathrm{m}^{3}$, more than eight times greater than that for a $\lambda$ of 2 per year. For this rate it would take about 15 to 16 years for mass loading to decrease to 5 percent of initial concentrations. Because this rate is much slower than those measured over tephra deposits of similar depth to those expected at the reference biosphere, it reasonably bounds uncertainty in the effects of differences in conditions between analogue sites and the reference biosphere.

For ash thickness of $10 \mathrm{~mm}$ or greater, a triangular distribution of the mass load decrease rate constant with a mode of 0.2 per year, maximum of 1.0 per year, and minimum of 0.125 per year is selected. These lower (i.e., slower) rates were selected to account for the additional uncertainty in the effects of an initial tephra deposit greater than those measured at analogue sites.

- The maximum value of this distribution is slightly larger than the decay rate constant of about 2.0 per year measured after other eruptions, and was selected because some predicted ash depths covered by this distribution are only slightly greater than the $10 \mathrm{~mm}$ maximum ash thickness for analogue data from Mount St. Helens. This rate would result in a decrease in mass loading to 5 percent of the maximum concentrations in 5 to 6 years and an average annual concentration over 10 years of about $1.0 \mathrm{mg} / \mathrm{m}^{3}$ for a hypothetical $S_{v}$ of $10 \mathrm{mg} / \mathrm{m}^{3}$ (from Equation 6-7).

- The modal rate of 0.2 per year would result in a decrease of about 86 percent in 10 years and 98 percent in 20 years (Figure 6-7). The average annual concentration over 10 years for a $\lambda$ of 0.2 per year and a hypothetical $S_{v}$ of $10 \mathrm{mg} / \mathrm{m}^{3}$ would be $4.3 \mathrm{mg} / \mathrm{m}^{3}$ (from Equation 6-7), more than eight times greater than for a $\lambda$ of 2.0 per year.

- The minimum decay rate constant of 0.125 per year would result in a decrease of 71 percent over 10 years, 92 percent decrease over 20 years, and 98 percent decrease over 30 years. It would take about 24 years for mass loading to decrease to 5 percent of the initial concentration. The average annual concentrations for a $\lambda$ of 0.125 per year and a hypothetical $S_{v}$ of $10 \mathrm{mg} / \mathrm{m}^{3}$ would be 5.7 and $3.7 \mathrm{mg} / \mathrm{m}^{3}$ over 10 and 20 years, respectively. This is more than an order of magnitude higher than for a $\lambda$ of 2.0 per year; therefore, this rate reasonably bounds uncertainty in the effects of differences in conditions between analogue sites and the reference biosphere, including the effects of an initial tephra deposit deeper than $1 \mathrm{~cm}$. 
As noted before, the ash redistribution model considers the interchannel divides separately from the distributary channels that carry redistributed ash (BSC 2005 [DIRS 174067], Section 6.6). These areas can have a different thickness of ash or ash mixed with soil, and thus different mass loading decay rate constants. To account for this, it is recommended that the mass loading decrease rate is that for the greater of the contaminated material thickness in the distributary channels and interchannel divides. 


\section{CONCLUSIONS}

\subsection{PARAMETER DISTRIBUTIONS}

This analysis report documents the selection of distributions for mass loading and the mass loading decrease function for use in the biosphere model. This information is summarized in Table 7-1 and contained in the product output DTN: MO0605SPAINEXI.003. The only limitation on the use of these distributions and the function is that they are intended for the present-day and predicted future climatic conditions for the Yucca Mountain reference biosphere during the next 10,000 years. They must be used with caution for other, more mesic and colder conditions. Uncertainties in the inputs and assumptions related to use of analogue data, climate change, thickness of the initial tephra deposit, and redistribution of tephra by aeolian and fluvial transport are described in Section 6.

This analysis does not provide direct input to TSPA. The product output of this analysis is an input to the Biosphere Model Report, whose product output is intended for use in the TSPA model (see Figure 1-1).

Table 7-1. Inhalation Exposure Input Parameters for the Biosphere Model

\begin{tabular}{|c|c|c|c|c|}
\hline $\begin{array}{c}\text { Parameter } \\
\text { Environment or Condition }\end{array}$ & $\begin{array}{c}\text { Type of } \\
\text { Distribution }\end{array}$ & Mode & Minimum & Maximum \\
\hline \multicolumn{5}{|l|}{ Mass Loading - Nominal Conditions } \\
\hline Active Outdoors $\left(\mathrm{mg} / \mathrm{m}^{3}\right)$ & Triangular & 3.000 & 1.000 & 10.000 \\
\hline Inactive Outdoors $\left(\mathrm{mg} / \mathrm{m}^{3}\right)$ & Triangular & 0.060 & 0.025 & 0.100 \\
\hline Active Indoors $\left(\mathrm{mg} / \mathrm{m}^{3}\right)$ & Triangular & 0.100 & 0.060 & 0.175 \\
\hline Asleep Indoors $\left(\mathrm{mg} / \mathrm{m}^{3}\right)$ & Triangular & 0.030 & 0.010 & 0.050 \\
\hline Crops $\left(\mathrm{mg} / \mathrm{m}^{3}\right)$ & Triangular & 0.120 & 0.025 & 0.200 \\
\hline \multicolumn{5}{|l|}{ Mass Loading - Post-Volcanic Conditions ${ }^{a}$} \\
\hline Active Outdoors $\left(\mathrm{mg} / \mathrm{m}^{3}\right)$ & Triangular & 3.000 & 0.000 & 5.000 \\
\hline Inactive Outdoors $\left(\mathrm{mg} / \mathrm{m}^{3}\right)$ & Triangular & 0.060 & 0.025 & 0.200 \\
\hline Active Indoors $\left(\mathrm{mg} / \mathrm{m}^{3}\right)$ & Triangular & 0.100 & 0.060 & 0.175 \\
\hline Asleep Indoors $\left(\mathrm{mg} / \mathrm{m}^{3}\right)$ & Triangular & 0.030 & 0.010 & 0.050 \\
\hline Crops $\left(\mathrm{mg} / \mathrm{m}^{3}\right)^{\mathrm{b}}$ & Triangular & 0.240 & 0.050 & 0.600 \\
\hline \multicolumn{5}{|c|}{ Mass Loading Decrease Rate Constant $(\lambda)$ to Be Used in Equation $S_{0} e^{-\lambda t} \mathrm{c}$} \\
\hline For ash depth $<10 \mathrm{~mm}$ (1/year) & Triangular & 0.33 & 0.2 & 2.0 \\
\hline For ash depths $\geq 10 \mathrm{~mm}$ (1/year) & Triangular & 0.20 & 0.125 & 1.0 \\
\hline
\end{tabular}

Output DTN: MO0605SPAINEXI.003.

a Distributions for postvolcanic conditions for human environments represent the predicted change in mass loading the first year following a volcanic eruption. These values must be added to predicted values for nominal conditions to determine the total predicted mass loading for postvolcanic conditions.

b The distribution for crops for postvolcanic conditions represents the total mass loading the first year following an eruption and should not be added to predicted values for nominal conditions.

${ }^{c}$ It is recommended that the mass loading decrease rate constant is that for the greater of the contaminated material thickness in the distributary channels and interchannel divides. 


\subsection{HOW THE APPLICABLE ACCEPTANCE CRITERIA ARE ADDRESSED}

The following information describes how this analysis report addresses the acceptance criteria in the YMRP (NRC 2003 [DIRS 163274], Section 2.2.1.3.14). Only those acceptance criteria that are applicable to this report (see Section 4.2) are discussed.

This analysis report is one of 10 reports (Figure 1-1) that support biosphere modeling and describe how the acceptance criteria have been addressed by the biosphere model. A consideration of all 10 reports is required to understand how all applicable acceptance criteria are satisfied by the biosphere model.

\section{Acceptance Criterion $1 \quad$ System Description and Model Integration Are Adequate.}

Subcriterion (3) - This analysis considers information and assumptions about climate change, ash depth, and ash redistribution that are developed or also considered in other TSPA modeling abstractions. The analysis of the effects of climate change on mass loading is described in Section 6.1.3 and is based on the three climate states modeled in other TSPA abstractions (present-day, monsoon, and glacial transition) (BSC 2003 [DIRS 166296], p. 79). The analogue weather stations representative of the future climatic conditions considered in Sections 4.1 .5 and 6.1.3, and elsewhere in this report are identified in Future Climate Analysis (BSC 2004 [DIRS 170002], Table 6-1). The distribution of ash depth considered in Sections 6.3 and 6.4 was developed in the TSPA model abstraction that describes atmospheric dispersal of ash (BSC 2005 [DIRS 174067], Section 6.5). Information and assumptions about the redistribution of ash that were considered in the evaluation of uncertainty in the mass loading decrease rate constant (Section 6.4.3) are consistent with those considered in the development of the ash redistribution conceptual model (BSC 2004 [DIRS 169980], Section 6.3.4; BSC 2005 [DIRS 174067], Section 6.6).

\section{Acceptance Criterion 2 Data Are Sufficient for Model Justification.}

Subcriterion (1)-The justification for the parameter distributions developed in this report, and the consistency of those distributions with the conditions in the Yucca Mountain region, are described in Section 6, with additional justification for assumptions in Section 5. The data identified in Sections 4.1 were used, interpreted, and appropriately synthesized into the parameter distributions as described in Section 6.

Subcriterion (2) - The sufficiency of data used to develop parameter distributions is described in Sections 4.1 and 6. Demonstration that the parameter distributions are consistent with present knowledge of the conditions in the Yucca Mountain region is in Section 6. The relationship between the parameters developed in this report and the FEPs included in biosphere characteristics modeling is shown in Table 1-1. Because the FEPs comprise several parameters, the determination that the parameters discussed in this report are consistent with present knowledge of conditions in the region surrounding Yucca Mountain supports a determination that the corresponding FEPs also are consistent with present knowledge of conditions in that region. However, a final determination of whether a FEP is consistent with present knowledge of conditions in the region surrounding Yucca Mountain can be made only after all of the parameters which contribute to that FEP have been evaluated for consistency with present 
knowledge of conditions in the region surrounding Yucca Mountain. Sensitivity and uncertainty analyses are addressed in the Biosphere Model Report shown in Figure 1-1.

\section{Acceptance Criterion 3 Data Uncertainty Is Characterized and Propagated Through the} Model Abstraction

Subcriterion (1) - The technical defensibility of assumptions used in this analysis is included in Section 5. The technical defensibility of the probability distribution developed for each parameter is described in Section 6. The identification of uncertainties and variabilities, and how those uncertainties and variabilities were accounted for in the development of parameter bounds that do not under-represent risk, is also described in Section 6.

Subcriterion (2)-The technical defensibility of the technical bases for the parameter distributions is described in Section 6. The consistency of the data and mass loading parameter distributions with site characterization data and the climate and level of disturbance expected to be found at the location of the RMEI during the compliance time period is described in Sections 4.1 and 6.

Subcriterion (3)-No process-level models were used to determine parameter values in this analysis. The consistency of the parameter distributions with site characterization data, laboratory experiments, field measurements, and natural analogue research is described in Section 6.

Subcriterion (4)-The bounding values of the parameter distributions developed in this analysis were selected to adequately represent uncertainty and are supported by data, as described in Sections 5 and 6. No correlations among biosphere model input parameters are identified in this analysis. 


\section{INTENTIONALLY LEFT BLANK}




\section{INPUTS AND REFERENCES}

\subsection{DOCUMENTS CITED}

Ambrose, V. 2002. "Re: AQS System AMP450 + AMP 380 ASCII Text \& Report 160080 Files." E-mail from V. Ambrose (EPA) to K. Rautenstrauch, September 6, 2002, with attachment ACC: MOL.20020923.0190; MOL.20020923.0196.

Ambrose, V. 2002. "Re: Site/Monitor Information." E-mail from V. Ambrose 160081 (EPA) to T. Wirth, September 17, 2002, with attachment.

ACC: MOL.20020923.0191; MOL.20020923.0196.

Andrews, W.F. 1972. "Soil Survey of Yolo County, California." Woodland, 170526 California: U.S. Department of Agriculture, Natural Resources Conservation Service. Accessed July 12, 2004. ACC: MOL.20040712.0180.

URL: http://www.ca.nrcs.usda.gov/mlra02/yolo.html

Anspaugh, L.R.; Shinn, J.H.; Phelps, P.L.; and Kennedy, N.C. 1975.

"Resuspension and Redistribution of Plutonium in Soils." Health Physics, 29, (4), 571-582. New York, New York: Pergamon Press. TIC: 248619.

Archer, J.D.; Cooper, G.S.; Reist, P.C.; Storm, J.F.; and Nylander-French, L.A. 168488 2002. "Exposure to Respirable Crystalline Silica in Eastern North Carolina Farm Workers." AIHA Journal, 63, (6), 750-755. Fairfax, Virginia: American Industrial Hygiene Association. TIC: 255625.

Baxter, P.J.; Bonadonna, C.; Dupree, R.; Hards, V.L.; Kohn, S.C.; Murphy, M.D.; 150713 Nichols, A.; Nicholson, R.A.; Norton, G.; Searl, A.; Sparks, R.S.J.; and Vickers, B.P. 1999. "Cristobalite in Volcanic Ash of the Soufriere Hills Volcano, Montserrat, British West Indies." Science, 283, 1142-1145. Washington, D.C.: American Association for the Advancement of Science. TIC: 248128.

Beck, D.A. and Glancy, P.A. 1995. Overview of Runoff of March 11, 1995, in Fortymile Wash and Amargosa River, Southern Nevada. Fact Sheet FS-210-95. Las Vegas, Nevada: U.S. Geological Survey. ACC: MOL.20010524.0189.

Belnap, J. and Gillette, D.A. 1998. "Vulnerability of Desert Biological Soil Crusts to Wind Erosion: The Influences of Crust Development, Soil Texture, and Disturbance." Journal of Arid Environments, 39, 133-142. New York, New York: Academic Press. TIC: 255020.

Brady, N.C. and Weil, R.R. 1999. The Nature and Properties of Soils. 12th 160019 Edition. Upper Saddle River, New Jersey: Prentice-Hall. TIC: 242178. 
Brauer, M.; Hrubá, F.; Mihalíková, E.; Fabiánová, E.; Miskovic, P.; Plziková, A.;

Lendacka, M.; Vandenberg, J.; and Cullen, A. 2000. "Personal Exposure to

Particles in Banská Bystrica, Slovakia." Journal of Exposure Analysis and

Environmental Epidemiology, 10, 478-487. Princeton, New Jersey: Princeton

Scientific Publishing. TIC: 251299.

Brook, J.R.; Dann, T.F.; and Burnett, R.T. 1997. "Relationship Among TSP, PM 10 , 160254

$\mathrm{PM}_{2.5}$, and Inorganic Constituents of Atmospheric Particulate Matter at Multiple Canadian Locations." Journal of the Air \& Waste Management Association, 47, (1), 2-19. Pittsburgh, Pennsylvania: Air \& Waste Management Association.

TIC: 243189.

BSC (Bechtel SAIC Company) 2003. Total System Performance Assessment-

166296 License Application Methods and Approach. TDR-WIS-PA-000006 REV 00 ICN 01. Las Vegas, Nevada: Bechtel SAIC Company. ACC: DOC.20031215.0001.

BSC 2003. Yucca Mountain Project Summary of Socioeconomic Data Analyses Conducted in Support of the Radiological Monitoring Program, During FY 2003. TDR-MGR-EV-000040 REV 00. Las Vegas, Nevada: Bechtel SAIC Company. ACC: DOC.20031203.0003.

BSC 2004. Biosphere Model Report. MDL-MGR-MD-000001 REV 01. 169460 Las Vegas, Nevada: Bechtel SAIC Company. ACC: DOC.20041108.0005.

BSC 2004. Characterize Eruptive Processes at Yucca Mountain, Nevada. 169980 ANL-MGR-GS-000002 REV 02. Las Vegas, Nevada: Bechtel SAIC Company. ACC: DOC.20041004.0006; DOC.20050718.0005.

BSC 2004. Future Climate Analysis. ANL-NBS-GS-000008, Rev. 01. Las Vegas, 170002 Nevada: Bechtel SAIC Company. ACC: DOC.20040908.0005.

BSC 2004. Soil-Related Input Parameters for the Biosphere Model.

ANL-NBS-MD-000009 REV 02. Las Vegas, Nevada: Bechtel SAIC Company. ACC: DOC.20040913.0002.

BSC 2005. Atmospheric Dispersal and Deposition of Tephra from a Potential 174067 Volcanic Eruption at Yucca Mountain, Nevada. MDL-MGR-GS-000002 REV 02. Las Vegas, Nevada: Bechtel SAIC Company. ACC: DOC.20050825.0001; DOC.20050908.0001.

BSC 2005. Biosphere Dose Conversion Factor Importance and Sensitivity 173194 Analysis. ANL-NBS-MD-000014 REV 01. Las Vegas, Nevada: Bechtel SAIC Company. ACC: DOC.20050620.0002.

BSC 2005. Characteristics of the Receptor for the Biosphere Model. ANL-MGR-MD-000005 REV 04. Las Vegas, Nevada: Bechtel SAIC Company. ACC: DOC.20050405.0005. 
BSC 2005. Disruptive Event Biosphere Dose Conversion Factor Analysis.

172812 ANL-MGR-MD-000003 REV 04. Las Vegas, Nevada: Bechtel SAIC Company. ACC: DOC.20050509.0002.

BSC 2005. Nominal Performance Biosphere Dose Conversion Factor Analysis.

172814 ANL-MGR-MD-000009 REV 04. Las Vegas, Nevada: Bechtel SAIC Company. ACC: DOC.20050428.0004.

BSC 2005. Q-List. 000-30R-MGR0-00500-000-003. Las Vegas, Nevada: Bechtel 175539 SAIC Company. ACC: ENG.20050929.0008.

BSC 2006. Technical Work Plan for Biosphere Modeling. TWP-NBS-MD-000004 REV 06. Las Vegas, Nevada: Bechtel SAIC Company.

ACC: DOC.20060515.0001.

Buist, A.S.; Bernstein, R.S.; Johnson, L.R.; and Vollmer, W.M. 1986. "Evaluation of Physical Health Effects Due to Volcanic Hazards: Human Studies." 3 American Journal of Public Health, (Supplement). 76. 66-75. Washington, D.C.: American Public Health Association. TIC: 246676.

Buist, A.S.; Johnson, L.R.; Vollmer, W.M.; Sexton, G.J.; and Kanarek, P.H. 1983. "Acute Effects of Volcanic Ash from Mount Saint Helens on Lung Function in Children." American Review of Respiratory Disease, 127, (6), 714-719. New York, New York: National Tuberculosis Association. TIC: 250153.

Buist, A.S.; Martin, T.R.; Shore, J.H.; Butler, J.; and Lybarger, J.A. 1986. "The Development of a Multidisciplinary Plan for Evaluation of the Long-Term Health Effects of the Mount St. Helens Eruptions." Chapter 4 of Health Effects of Volcanoes: An Approach to Evaluating the Health Effects of an Environmental Hazard. Buist, A.S. and Bernstein, R.S., eds. American Journal of Public Health, Volume 76, Supplement. Washington, D.C.: American Public Health Association. TIC: 246677.

Bureau of the Census 2002. "2000 Summary File 3 (SF 3) Sample Data, Amargosa Valley CCD, Nye County, Nevada." Washington, D.C.: U.S. Department of Commerce, Bureau of the Census. Accessed August 28, 2002. TIC: 253098. URL: http://factfinder.census.gov/servlet/DTTable?_ts $=48597952130$

Chow, J.C.; Watson, J.G.; Green, M.C.; Lowenthal, D.H.; DuBois, D.W.; Kohl, S.D.; Egami, R.T.; Gillies, J.; Rogers, C.F.; Frazier, C.A.; and Cates, W. 1999. "Middle- and Neighborhood-Scale Variations of PM10 Source Contributions in Las Vegas, Nevada." Journal of the Air \& Waste Management Association, 49, 641-654. Pittsburgh, Pennsylvania: Air \& Waste Management Association. TIC: 247013. 
Clausnitzer, H. and Singer, M.J. 1997. "Intensive Land Preparation Emits

Respirable Dust." California Agriculture, 51, (2), 27-30. Berkeley, California:

University of California, California Agricultural Experiment Station. TIC: 252403.

Clayton, C.A.; Perritt, R.L.; Pellizzari, E.D.; Thomas, K.W.; Whitmore, R.W.;

159599

Wallace, L.A.; Ozkaynak, H.; and Spengler, J.D. 1993. "Particle Total Exposure

Assessment Methodology (PTEAM) Study: Distributions of Aerosol and Elemental

Concentrations in Personal, Indoor, and Outdoor Air Samples in a Southern

California Community." Journal of Exposure Analysis and Environmental

Epidemiology, 3, (2), 227-250. Princeton, New Jersey: Princeton Scientific

Publishing. TIC: 250270.

CEMP (Community Environmental Monitoring Program) 2006. "Community

Environmental Monitoring Program, Station Summary, Amargosa Valley Nevada,

Daily Summary for December 15, 2005." Data Collection Program. Las Vegas,

Nevada: Desert Research Institute, Community Environmental Monitoring

Program. Accessed January 31, 2006. ACC: MOL.20060206.0208;

MOL.20060206.0209. URL: http://www.cemp.dri.edu/

CEMP 2006. "Community Environmental Monitoring Program, Station Summary,

176776

Amargosa Valley Nevada, Daily Summary for December 16, 2005.” Data

Collection Program. Las Vegas, Nevada: Desert Research Institute, Community

Environmental Monitoring Program. Accessed January 31, 2006.

ACC: MOL.20060206.0210. URL: http://www.cemp.dri.edu/

CEMP 2006. "Community Environmental Monitoring Program, Station Summary,

Amargosa Valley Nevada, Monthly Summary for December 2005.” Data

Collection Program. Las Vegas, Nevada: Desert Research Institute, Community

Environmental Monitoring Program. Accessed January 31, 2006.

ACC: MOL.20060206.0213. URL: http://www.cemp.dri.edu/

CEMP 2006. "Community Environmental Monitoring Program, Station Summary,

176779

Amargosa Valley Nevada, Monthly Summary for November 2005." Data

Collection Program. Las Vegas, Nevada: Desert Research Institute, Community

Environmental Monitoring Program. Accessed January 31, 2006.

ACC: MOL.20060206.0212. URL: http://www.cemp.dri.edu/

CEMP 2006. "Community Environmental Monitoring Program, Station Summary,

Amargosa Valley Nevada, Monthly Summary for October 2005." Data Collection

Program. Las Vegas, Nevada: Desert Research Institute, Community

Environmental Monitoring Program. Accessed January 31, 2006.

ACC: MOL.20060206.0211. URL: http://www.cemp.dri.edu

Craighead, J.E.; Adler, K.B.; Butler, G.B.; Emerson, R.J.; Mossman, B.T.; and

Woodworth, C.D. 1983. "Biology of Disease, Health Effects of Mount St. Helens

160338

Volcanic Dust." Laboratory Investigation, 48, (1), 5-12. Baltimore, Maryland:

Williams \& Wilkins. TIC: 250154. 
CRWMS (Civilian Radioactive Waste Management System) M\&O (Management and Operating Contractor) 1999. Environmental Baseline File for Meteorology and Air Quality. B00000000-01717-5705-00126 REV 00. Las Vegas, Nevada: CRWMS M\&O. ACC: MOL.19990302.0186.

CRWMS M\&O 1999. Evaluation of Soils in the Northern Amargosa Valley. 107736 B00000000-01717-5705-00084 REV 00. Las Vegas, Nevada: CRWMS M\&O. ACC: MOL.19990224.0268.

Dahneke, B. 1975. "Resuspension of Particles." Journal of Colloid and Interface Science, 50, (1), 194-196. Orlando, Florida: Academic Press. TIC: 224931.

Degrange, J.-P. and Witschger, O. 2005. "Aerosol Sampling for Radiological 176119 Protection: Which Particle Size Aerosol Sampler to Select?” Naturally Occurring Radioactive Materials (NORM IV), Proceedings of an International Conference held in Szczyrk, Poland, 17-21 May 2004. IAEA-TECDOC-1472. 389-407. Vienna, Austria: International Atomic Energy Agency. TIC: 257014.

DOE (U.S. Department of Energy) 1997. The 1997 “Biosphere” Food 100332 Consumption Survey Summary Findings and Technical Documentation. Las Vegas, Nevada: U.S. Department of Energy, Office of Civilian Radioactive Waste Management. ACC: MOL.19981021.0301.

DOE 2005. Site Environmental Report for the Yucca Mountain Project Calendar 176996 Year 2004. PGM-MGR-EC-000006 REV 00. Las Vegas, Nevada: U.S. Department of Energy, Office of Civilian Radioactive Waste Management. ACC: MOL.20051206.0012.

EPA (U.S. Environmental Protection Agency) 2004. Air Quality Criteria for 175978 Particulate Matter. EPA/600/P-99/002. Two volumes. Research Triangle Park, North Carolina: U.S. Environmental Protection Agency.

ACC: MOL.20060105.0151; MOL.20060105.0152.

Evans, G.F.; Highsmith, R.V.; Sheldon, L.S.; Suggs, J.C.; Williams, R.W.; 159679

Zweidinger, R.B.; Creason, J.P.; Walsh, D.; Rodes, C.E.; and Lawless, P.A. 2000. "The 1999 Fresno Particulate Matter Exposure Studies: Comparison of Community, Outdoor, and Residential PM Mass Measurements." Journal of the Air \& Waste Management Association, 50, 1887-1896. Pittsburgh, Pennsylvania: Air \& Waste Management Association. TIC: 250561.

Garger, E.K.; Hoffman, F.O.; and Thiessen, K.M. 1997. "Uncertainty of the LongTerm Resuspension Factor.” Atmospheric Environment, 31, (11), 1647-1656. Oxford, United Kingdom: Elsevier. TIC: 246785. 
Gordian, M.E.; Ozkaynak, H.; Xue, J.; Morris, S.S.; and Spengler, J.D. 1996.

"Particulate Air Pollution and Respiratory Disease in Anchorage, Alaska."

Environmental Health Perspectives, 104, (3), 290-297. Research Park Triangle, North Carolina: National Institute of Environmental Health Sciences, National Institutes of Health. TIC: 250157.

Hewett, P. 1980. Technical Assistance Report, Gales Creek Diabetic Camp, Glenwood, Oregon. MTA 80-116-34M. Morgantown, West Virginia: National Institute for Occupational Safety \& Health, Division of Respiratory Disease Studies. ACC: MOL.20040311.0042.

Hewett, P. 1980. Technical Assistance Report, State of Washington and Region X 168490 Office of the Department of Health and Human Services. M-TA-80-111(b). Morgantown, West Virginia: National Institute for Occupational Safety \& Health, Division of Respiratory Disease Studies. ACC: MOL.20040311.0015.

Hill, B.E. and Connor, C.B. 2000. Technical Basis for Resolution of the Igneous 160103 Activity Key Technical Issue. Washington, D.C.: U.S. Nuclear Regulatory Commission. TIC: 253022.

Howard-Reed, C.; Rea, A.W.; Zufall, M.J.; Burke, J.M.; Williams, R.W.; Suggs, J.C.; Sheldon, L.S.; Walsh, D.; and Kwok, R. 2000. "Use of a Continuous Nephelometer to Measure Personal Exposure to Particles During the U.S. Environmental Protection Agency Baltimore and Fresno Panel Studies." Journal of the Air \& Waste Management Association, 50, 1125-1132. Pittsburgh, Pennsylvania: Air \& Waste Management Association. TIC: 250562.

IAEA (International Atomic Energy Agency) 1982. Generic Models and Parameters for Assessing the Environmental Transfer of Radionuclides from Routine Releases -- Exposures of Critical Group. IAEA SS-57. Vienna, Austria: International Atomic Energy Agency. TIC: 232649.

IAEA 1992. Modelling of Resuspension, Seasonality and Losses During Food Processing. First Report of the VAMP Terrestrial Working Group.

IAEA-TECDOC-647. Vienna, Austria: International Atomic Energy Agency. TIC: 243498.

IAEA 2001. Generic Models for Use in Assessing the Impact of Discharges of Radioactive Substances to the Environment. Safety Reports Series No. 19. Vienna, Austria: International Atomic Energy Agency. TIC: 251295.

ICRP (International Commission on Radiological Protection) 1994. Human Respiratory Tract Model for Radiological Protection. Volume 24, Nos. 1-3 of Annals of the ICRP. Smith, H., ed. ICRP Publication 66. New York, New York: Pergamon. TIC: 249223. 
Janssen, N.A.H.; Hoek, G.; Brunekreef, B.; Harssema, H.; Mensink, I.; and

Zuidhof, A. 1998. "Personal Sampling of Particles in Adults: Relation Among

Personal, Indoor, and Outdoor Air Concentrations." American Journal of Epidemiology, 147, (6), 537-547. Baltimore, Maryland: Johns Hopkins University, School of Hygiene and Public Health. TIC: 250565.

Kullman, G.J.; Thorne, P.S.; and Waldron, P.F. 1998. "Organic Dust Exposures 159586 from Work in Dairy Barns." American Industrial Hygiene Association Journal, 59, (6), 403-413. Fairfax, Virginia: American Industrial Hygiene Association.

TIC: 252362.

LDAS (Land Data Assimilation System) [n.d.]. "LDAS Soil Illustrations and Data 176392 Sets." Land Surface Parameters. Washington, D.C.: National Aeronautics and Space Administration, Land Data Assimilation System. Accessed January 31, 2006. ACC: MOL.20060206.0215; MOL.20060206.0216.

URL: http://ldas.gsfc.nasa.gov/

Leaderer, B.P.; Naeher, L.; Jankun, T.; Balenger, K.; Holford, T.R.; Toth, C.; Sullivan, J.; Wolfson, J.M.; and Koutrakis, P. 1999. "Indoor, Outdoor, and Regional Summer and Winter Concentrations of $\mathrm{PM}_{10}, \mathrm{PM}_{2.5}, \mathrm{SO}_{4}{ }^{2-}, \mathrm{H}^{+}, \mathrm{NH}_{4}{ }^{+}$, $\mathrm{NO}_{3}{ }^{-}, \mathrm{NH}_{3}$, and Nitrous Acid in Homes with and without Kerosene Space Heaters." Environmental Health Perspectives, 107, (3), 223-231. Washington, D.C.: U.S. Department of Health and Human Services, Public Health Service. TIC: 250573.

Linn, W.S.; Gong, H., Jr.; Clark, K.W.; and Anderson, K.R. 1999. "Day-to-Day Particulate Exposures and Health Changes in Los Angeles Area Residents with Severe Lung Disease." Journal of the Air \& Waste Management Association, 49, 108-115. Pittsburgh, Pennsylvania: Air \& Waste Management Association.

TIC: 250575.

Lioy, P.J.; Waldman, J.M.; Buckley, T.; Butler, J.; and Pietarinen, C. 1990. "The 159655 Personal, Indoor and Outdoor Concentrations of PM-10 Measured in an Industrial Community During the Winter." Atmospheric Environment, 24B, (1), 57-66. New York, New York: Pergamon Press. TIC: 251308.

Long, C.M.; Suh, H.H.; and Koutrakis, P. 2000. "Characterization of Indoor 159681 Particle Sources Using Continuous Mass and Size Monitors." Journal of the Air \& Waste Management Association, 50, 1236-1250. Pittsburgh, Pennsylvania: Air \& Waste Management Association. TIC: 250576.

Long, C.M.; Suh, H.H.; Catalano, P.J.; and Koutrakis, P. 2001. "Using Time- and Size-Resolved Particulate Data to Quantify Indoor Penetration and Deposition Behavior." Environmental Science \& Technology, 35, (10), 2089-2099.

Washington, D.C.: American Chemical Society. TIC: 250579. 
McGimsey, R.G.; Neal, C.A.; and Riley, C.M. 2001. Areal Distribution, Thickness, 160386 Mass, Volume, and Grain Size of Tephra-Fall Deposits from the 1992 Eruptions of Crater Peak Vent, Mt. Spurr Volcano, Alaska. Open-File Report 01-370.

Anchorage, Alaska: U.S. Geological Survey. TIC: 253361.

McKague, H.L. 1998. "Transmittal of Administrative Item, Summary of CNWRA 151841 Workshop on the Consequences of Volcanic Activity (AI 20-1402-461-831)." Letter from H.L. McKague (CNWRA) to J. Trapp (NRC), August 17, 1998, NRC-02-97-009, with enclosures. ACC: MOL.19981106.0154; MOL.19981106.0155; MOL.19981106.0156; MOL.19981106.0157.

Merchant, J.A.; Baxter, P.; Bernstein, R.; McCawley, M.; Falk, H.; Stein, G.; Ing, 160102 R.; and Attfield, M. 1982. "Health Implications of the Mount St. Helens' Eruption: Epidemiological Considerations." Annals of Occupational Hygiene, 26, (1-4), 911-919. New York, New York: Pergamon Press. TIC: 253237.

Middleton, N. 2000. "Desert Dust." Arid Zone Geomorphology : Process, Form and Change in Drylands. Thomas, D.S.G., ed. New York, New York: John Wiley \& Sons. TIC: 256178.

Molocznik, A. and Zagorski, J. 1998. "Exposure to Dust Among Agriculture Workers." Annals of Agricultural and Environmental Medicine, 5, (2), 127-130. Lublin, Poland: Institute of Agricultural Medicine. TIC: 248132.

Molocznik, A. and Zagórski, J. 2000. "Exposure of Female Farmers to Dust on Family Farms." Annals of Agricultural and Environmental Medicine, 7, 43-50. Lublin, Poland: Institute of Agricultural Medicine. TIC: 252372.

Monn, Ch.; Fuchs, A.; Högger, D.; Junker, M.; Kogelschatz, D.; Roth, N.; and 150888 Wanner, H.-U. 1997. "Particulate Matter Less Than 10 Microns (PM10) and Fine Particles Less Than 2.5 Microns (PM2.5): Relationships Between Indoor, Outdoor and Personal Concentrations." The Science of the Total Environment, 208, (1-2), 15-21. Amsterdam, The Netherlands: Elsevier. TIC: 248133.

Morandi, M.T.; Stock, T.H.; and Contant, C.F. 1988. "A Comparative Study of Respirable Particulate Microenvironmental Concentrations and Personal Exposures." Environmental Monitoring and Assessment, 10, (2), 105-122. Dordrecht, The Netherlands: Kluwer Academic Publishers. TIC: 251310.

Mozzon, D.; Brown, D.A.; and Smith, J.W. 1987. "Occupational Exposure to 159585 Airborne Dust, Respirable Quartz and Metals Arising from Refuse Handling, Burning and Landfilling." American Industrial Hygiene Association Journal, 48, (2), 111-116. Akron, Ohio: American Industrial Hygiene Association.

TIC: 252363. 
Napier, B.A.; Peloquin, R.A.; Strenge, D.L.; and Ramsdell, J.V. 1988. GENII - The

100953

Hanford Environmental Radiation Dosimetry Software System. Three volumes.

PNL-6584. Richland, Washington: Pacific Northwest Laboratory.

ACC: NNA.19920626.0034; NNA.19920626.0036; NNA.19920626.0041.

NCDC (National Climatic Data Center) 1998. Summary of the Day Observations:

135900

West 1 for Arizona, California, Colorado, Nevada, New Mexico, Utah and

Wyoming. Boulder, Colorado: EarthInfo. TIC: 245534.

NCDC 1998. Summary of the Day Observations: West 2 for Alaska, Hawaii, Idaho,

125325 Kansas, Montana, North Dakota, Nebraska, Oklahoma, Oregon, Pacific Islands, South Dakota, Texas, Washington. Boulder, Colorado: EarthInfo. TIC: 245534.

Nieuwenhuijsen, M.J. and Schenker, M.B. 1998. "Determinants of Personal Dust Exposure During Field Crop Operations in California Agriculture." American Industrial Hygiene Association Journal, 59, 9-13. Fairfax, Virginia: American Industrial Hygiene Association. TIC: 248135.

Nieuwenhuijsen, M.J.; Kruize, H.; and Schenker, M.B. 1998. "Exposure to Dust and Its Particle Size Distribution in California Agriculture." American Industrial Hygiene Association Journal, 59, 34-38. Fairfax, Virginia: American Industrial Hygiene Association. TIC: 248134.

Nieuwenhuijsen, M.J.; Noderer, K.S.; Schenker, M.B.; Vallyathan, V.; and Olenchock, S. 1999. "Personal Exposure to Dust, Endotoxin and Crystalline Silica in California Agriculture." Annals of Occupational Hygiene, 43, (1), 35-42. Oxford, England: Elsevier. TIC: 248271.

NRC (U.S. Nuclear Regulatory Commission) 2003. Yucca Mountain Review Plan, Final Report. NUREG-1804, Rev. 2. Washington, D.C.: U.S. Nuclear Regulatory Commission, Office of Nuclear Material Safety and Safeguards. TIC: 254568.

NRC (U.S. Nuclear Regulatory Commission) 2005. Integrated Issue Resolution Status Report. NUREG-1762, Rev. 1. Two volumes. Washington, D.C.: U.S. Nuclear Regulatory Commission, Office of Nuclear Material Safety and Safeguards. ACC: MOL.20051006.0423; MOL.20051006.0424.

Oregon State University 2006. "Prism Data Explorer." Spatial Climate Analysis Service. Corvallis, Oregon: Oregon State University, Spatial Climate Analysis Service. Accessed January 30, 2006. TIC: 258081. URL: http://www.ocs.orst.edu/prism/?\&mode=print

Pellizzari, E.D.; Clayton, C.A.; Rodes, C.E.; Mason, R.E.; Piper, L.L.; Fort, B.; 159702 Pfeifer, G.; and Lynam, D. 1999. "Particulate Matter and Manganese Exposures in Toronto, Canada." Atmospheric Environment, 33, 721-734. New York, New York: Elsevier. TIC: 250596. 
Pinnick, R.G.; Fernandez, G.; Hinds, B.D.; Bruce, C.W.; Schaefer, R.W.; and

Pendleton, J.D. 1985. "Dust Generated by Vehicular Traffic on Unpaved

Roadways: Sizes and Infrared Extinction Characteristics." Aerosol Science and

Technology, 4, (1), 99-121. New York, New York: Elsevier. TIC: 252364.

Quackenboss, J.J.; Lebowitz, M.D.; and Crutchfield, C.D. 1989. "Indoor-Outdoor

Relationships for Particulate Matter: Exposure Classifications and Health Effects."

159682

Environment International, 15, 353-360. New York, New York: Pergamon Press.

TIC: 251313.

Rasmuson, K.E. 2004. "Summary of 2004 Agricultural Activities, Businesses, and

169506

Community Services and Organizations in Amargosa Valley." Interoffice

memorandum from K.E. Rasmuson (BSC) to K.R. Rautenstrauch, May 20, 2004,

0520041667, with enclosures. ACC: MOL.20040519.0033.

Reamer, C.W. 2004. "Staff Review of the U.S. Department of Energy Response to

176773 Igneous Activity Agreement Items 2.11 and 2.14; Status 2.11 'Need Additional Information,' 2.14 'Complete'. Letter from C.W. Reamer (NRC) to J. Ziegler (DOE/ORD), June 14, 2004, 0618042008, with enclosure.

ACC: MOL.20040712.0106.

Rojas-Bracho, L.; Suh, H.H.; and Koutrakis, P. 2000. "Relationships Among Personal, Indoor, and Outdoor Fine and Coarse Particle Concentrations for Individuals with COPD." Journal of Exposure Analysis and Environmental Epidemiology, 10, (3), 294-306. Princeton, New Jersey: Princeton Scientific Publishing. TIC: 250599.

Sanderson, W.T. 1982. Techncial Assistance Report, Forest Serivce, USDA, Spokane, Washington. TA 80-000-105. Morgantown, West Virginia: National Institute for Occupational Safety and Health, Division of Respiratory Disease Studies. ACC: MOL.20040311.0040.

Sarna-Wojcicki, A.M.; Shipley, S.; Waitt, R.B., Jr.; Dzurisin, D.; and Wood, S.H. 1982. "Areal Distribution, Thickness, Mass, Volume, and Grain Size of Air-Fall Ash from the Six Major Eruptions of 1980." The 1980 Eruptions of Mount St. Helens, Washington. Professional Paper 1250. 577-600. Reston, Virginia: U.S. Department of the Interior, U.S. Geological Survey. TIC: 218260.

Searl, A.; Nicholl, A.; and Baxter, P.J. 2002. "Assessment of the Exposure of 160104 Islanders to Ash from the Soufriere Hills Volcano, Montserrat, British West Indies." Occupational and Environmental Medicine, 59, (8), 523-531. Clifton, New Jersey: BMJ Publishing Group. TIC: 253212.

Tanko, D.J. and Glancy, P.A. 2001. Flooding in the Amargosa River Drainage 159895 Basin, February 23-24, 1998, Southern Nevada and Eastern California, Including the Nevada Test Site. Fact Sheet 036-01. Carson City, Nevada: U.S. Geological Survey. ACC: MOL.20010924.0092. 
Thatcher, T.L. and Layton, D.W. 1995. "Deposition, Resuspension, and

Penetration of Particles within a Residence." Atmospheric Environment, 29, (13), 1487-1497. New York, New York: Elsevier. TIC: 251319.

Till, J.E. and Meyer, H.R. 1983. Radiological Assessment, A Textbook on

101895

Environmental Dose Analysis. NUREG/CR-3332. Washington, D.C.: U.S. Nuclear Regulatory Commission. TIC: 223809.

USDA (U.S. Department of Agriculture) 1993. Soil Survey Manual. Handbook No. 18. Washington, D.C.: U.S. Department of Agriculture. TIC: 240569.

USDA 2004. Soil Survey of Nye County, Nevada, Southwest Part. Two parts. Washington, D.C.: U.S. Department of Agriculture. ACC: MOL.20050614.0146.

Wheeler, A.J.; Williams, I.; Beaumont, R.A.; and Hamilton, R.S. 2000.

"Characterisation of Particulate Matter Sampled During a Study of Children's

Personal Exposure to Airborne Particulate Matter in a UK Urban Environment." Environmental Monitoring and Assessment, 65, (1-2), 69-77. Dordrecht, The Netherlands: Kluwer Academic Publishers. TIC: 250607.

Whicker, J.J.; Breshears, D.D.; Wasiolek, P.T.; Kirchner, T.B.; Tavani, R.A.; Schoep, D.A.; and Rodgers, J.C. 2002. "Temporal and Spatial Variation of Episodic Wind Erosion in Unburned and Burned Semiarid Shrubland." Journal of Environmental Quality, 31, (2), 599-612. Madison, Wisconsin: American Society of Agronomy. TIC: 256309.

Wigzell, E.; Kendall, M.; and Nieuwenhuijsen, M.J. 2000. "The Spatial and Temporal Variation of Particulate Matter within the Home." Journal of Exposure Analysis and Environmental Epidemiology, 10, (3), 307-314. Princeton, New Jersey: Princeton Scientific Publishing. TIC: 252367.

Williams, R.; Suggs, J.; Zweidinger, R.; Evans, G.; Creason, J.; Kwok, R.; Rodes, C.; Lawless, P.; and Sheldon, L. 2000. "The 1998 Baltimore Particulate Matter Epidemiology-Exposure Study: Part 1. Comparison of Ambient, Residential Outdoor, Indoor and Apartment Particulate Matter Monitoring." Journal of Exposure Analysis and Environmental Epidemiology, 10, (6), 518-532. Princeton, New Jersey: Princeton Scientific Publishing. TIC: 250608.

Yakovleva, E.; Hopke, P.K.; and Wallace, L. 1999. "Receptor Modeling Assessment of Particle Total Exposure Assessment Methodology Data." Environmental Science \& Technology, 33, (20), 3645-3652. Washington, D.C.: American Chemical Society. TIC: 250612.

Yano, E.; Yokoyama, Y.; Higashi, H.; Nishii, S.; Maeda, K.; and Koizumi, A. 1990. 160112 "Health Effects of Volcanic Ash: A Repeat Study." Archives of Environmental Health, 45, (6), 367-373. Washington, D.C.: Heldref Publications. TIC: 250162. 
YMP (Yucca Mountain Site Characterization Project) 1999. Yucca Mountain Site

158212 Characterization Project: Summary of Socioeconomic Data Analyses Conducted in Support of the Radiological Monitoring Program, April 1998 to April 1999. North Las Vegas, Nevada: Yucca Mountain Site Characterization Office.

ACC: MOL.19991021.0188.

Yocom, J.E.; Clink, W.L.; and Cote, W.A. 1971. "Indoor/Outdoor Air Quality Relationships." Journal of the Air Pollution Control Association, 21, (5), 251-259. Pittsburgh, Pennsylvania: Air Pollution Control Association. TIC: 253031.

\subsection{CODES, STANDARDS, REGULATIONS, AND PROCEDURES}

10 CFR Part 63. 2005 Energy: Disposal of High-Level Radioactive Wastes in a 173273 Geologic Repository at Yucca Mountain, Nevada. ACC: MOL.20050405.0118.

40 CFR 50. 2004 Protection of Environment: National Primary and Secondary Ambient Air Quality Standards. ACC: MOL.20050523.0014.

LP-2.29Q, Rev. 1. Planning for Science Activities. Washington, D.C.: U.S. Department of Energy, Office of Civilian Radioactive Waste Management. ACC: DOC. 20060518.0005.

LS-PRO-0203, Rev 0. Q-List and Classification of Structures, Systems, and Components. Las Vegas, Nevada: Bechtel SAIC Company.

ACC: DOC.20060301.0003.

LP-SIII.9Q-BSC, Rev. 1. Scientific Analyses. Washington, D.C.: U.S. Department of Energy, Office of Civilian Radioactive Waste Management.

ACC: DOC.20060518.0006.

\subsection{SOURCE DATA, LISTED BY DATA TRACKING NUMBER}

MO0008SPATSP00.013. Total Suspended Particle Concentrations - Washington

151750 1979-1982. Submittal date: 08/02/2000.

MO0210SPATSP01.023. Total Suspended Particulate Matter Concentrations, United States. Submittal date: 10/01/2002.

MO98PSDALOG111.000. Particulate Sampler Data Records and Filter Weight Logs, Oct. - Dec. 97. Submittal date: 01/29/1998.

119501

MO0407SEPFEPLA.000. LA FEP List. Submittal date: 07/20/2004.

170760

MO0508SEPFEPLA.002. LA FEP List and Screening. Submittal date:

175064 08/22/2005. 
MO0603UCCF01JS.001. Total Suspended Particulate Matter (TSP) Concentrations 176759 in Milligrams per Cubic Meter $\left(\mathrm{mg} / \mathrm{m}^{3}\right)$ Measured During Soil Disturbing Activities from 12/15/05 to 12/16/05 in Amargosa Valley. Submittal date: 03/13/2006.

TM000000000001.039. Particulate Matter Air Quality Data - January 1992 through 121386 September 1992. Submittal date: 07/27/1993.

TM000000000001.041. Particulate Air Quality Data Forms, January thru June 1991. Submittal date: 07/27/1993.

TM000000000001.042. Particulate Air Quality Forms, July thru September 1991.

121405

Submittal date: 01/23/1992.

TM000000000001.079. Particulate Sampler Data Records and Filter Weight Logs for 1992 through 1995. Submittal date: 03/11/1996.

TM000000000001.082. Particulate Air Quality Data Forms, April 1989 thru December 1990. Submittal date: 03/12/1996.

121396

TM000000000001.084. Particulate Sampler Data Records and Filter Weight Logs, January - March 1996. Submittal date: 05/07/1996.

TM000000000001.096. Particulate Sampler Data Records and Filter Weight Logs, April - June 1996. Submittal date: 01/18/1997.

TM000000000001.097. Particulate Sampler Data Records and Filter Weight Logs, July - September 1996. Submittal date: 04/18/1997.

TM000000000001.098. Particulate Sampler Data Records and Filter Weight Logs, October - December 1996. Submittal date: 04/18/1997.

TM000000000001.099. Particulate Sampler Data Records and Filter Weight Logs, January - March 1997. Submittal date: 04/18/1997.

TM000000000001.105. Particulate Sampler Data Records and Filter Weight Logs, April - June 1997. Submittal date: 07/21/1997.

121410

121416

121419

121421

121426

121429

121435

TM000000000001.108. Particulate Sampler Data Records and Filter Weight Logs, 121442 July - September 1997. Submittal date: 10/22/1997.

\subsection{OUTPUT DATA, LISTED BY DATA TRACKING NUMBER}

MO0605SPAINEXI.003. Inhalation Exposure Input Parameters for the Biosphere Model. Submittal date: 05/04/2006. 


\section{INTENTIONALLY LEFT BLANK}


APPENDIX A

ATMOSPHERIC MASS LOADING SENSITIVITY ANALYSIS 


\section{INTENTIONALLY LEFT BLANK}




\section{APPENDIX A}

\section{ATMOSPHERIC MASS LOADING SENSITIVITY ANALYSIS}

The analysis described in this appendix was conducted to evaluate the sensitivity of calculations of mass of inhaled particles to changes in the input parameter values. The analysis examined influence of mass loading, exposure time and breathing rate in a given environment on the mass of inhaled particulate matter for the nominal and postvolcanic conditions.

The mass of inhaled particles was calculated in this analysis using the following equation:

$$
M_{i n h}=\sum_{n} t_{n} B R_{n} S_{n}
$$

where:

$$
\begin{aligned}
M_{i n h} & =\text { Total mass of inhaled particles }(\mathrm{mg}) \\
t_{n} & =\text { Exposure time, i.e., time spend in environment } n \text { (hours) } \\
B R_{n} & =\text { Breathing rate in environment } n\left(\mathrm{~m}^{3} /\right. \text { hour) } \\
S_{n} & =\begin{array}{l}
\text { Airborne concentration of particulate matter (mass loading) in } \\
\text { environment } n\left(\mathrm{mg} / \mathrm{m}^{3}\right) .
\end{array}
\end{aligned}
$$

This analysis was conducted by holding all parameters at an expected value except one parameter being examined (Tables A-1 and A-2). The ranges of parameter values used in this analysis were selected only to evaluate sensitivity and are intended to be reasonable estimates of the range of average annual values for the Amargosa Valley population and of average annual conditions in Amargosa Valley. They are not intended to represent the recommended values for calculating BDCFs. Nor is it necessary that the values used in this analysis match those used to calculate BDCFs, because the goal here is only to understand the relative importance of each parameter to the calculation of mass of inhaled particles.

Results - The results of sensitivity analysis are very similar for the nominal and postvolcanic conditions. The mass of inhaled particles is most sensitive to changes in airborne mass loading in the active outdoor environment, primarily because mass loading concentrations are one to two orders of magnitude higher during dust-generating activities outdoors than in other environments (Tables A-1 and A-2). Changes in mass loading in the active indoor environment have the third largest effect, primarily because of the large amount of time spent in that environment. Changes in mass loading in the inactive outdoor and asleep indoor environments have little effect on the mass of inhaled particulates.

Changes in time spent in the outdoor active environment have the second largest effect on the mass of particulates inhaled. This is due primarily to the large concentrations of particulates in that environment, but also to uncertainty in estimates of time spent outdoors. Changes in time spent in other environments have little influence on inhalation, in part because of the narrow range of values. Ranges of time spent in each environment are narrow because they represent 
variation and uncertainty around the average of the living style of the population in the town of Amargosa Valley, as required by 10 CFR 63.312(b) [DIRS 173273].

Breathing rates have little influence on the rate of inhalation of particulates, primarily because variation in those rates is low.

Table A-1. Mass Loading Sensitivity Analysis - Nominal Conditions

\begin{tabular}{|c|c|c|c|c|c|c|c|}
\hline \multirow[b]{2}{*}{$\begin{array}{c}\text { Environment } \\
\text { Parameter }\end{array}$} & \multirow[b]{2}{*}{$\begin{array}{c}\text { Expected } \\
\text { Parameter } \\
\text { Value }\end{array}$} & \multicolumn{3}{|c|}{ Minimum Values } & \multicolumn{3}{|c|}{ Maximum Values } \\
\hline & & $\begin{array}{c}\text { Parameter } \\
\text { Value }\end{array}$ & $\begin{array}{c}\text { Mass } \\
\text { Inhaled } \\
(\mathrm{mg})^{\mathrm{a}}\end{array}$ & $\%$ Change $^{b}$ & $\begin{array}{c}\text { Parameter } \\
\text { Value }\end{array}$ & $\begin{array}{l}\text { Mass } \\
\text { Inhaled } \\
(\mathrm{mg})^{\mathrm{a}}\end{array}$ & $\%$ Change $^{b}$ \\
\hline \multicolumn{8}{|l|}{ Active Outdoors } \\
\hline Time (hours) & 0.5 & 0.3 & 2.87 & $-24.6 \%$ & 0.8 & 5.22 & $36.9 \%$ \\
\hline Breathing Rate $\left(\mathrm{m}^{3} / \mathrm{hr}\right)$ & 1.6 & 1.4 & 3.51 & $-7.9 \%$ & 1.8 & 4.11 & $7.9 \%$ \\
\hline Mass Load $\left(\mathrm{mg} / \mathrm{m}^{3}\right)$ & 3 & 1 & 2.21 & $-42.0 \%$ & 10 & 9.41 & $147.0 \%$ \\
\hline \multicolumn{8}{|l|}{ Inactive Outdoors } \\
\hline Time & 1.5 & 1 & 3.83 & $0.6 \%$ & 2 & 3.79 & $-0.6 \%$ \\
\hline Breathing Rate $\left(\mathrm{m}^{3} / \mathrm{hr}\right)$ & 1.1 & 0.95 & 3.80 & $-0.4 \%$ & 1.25 & 3.82 & $0.4 \%$ \\
\hline Mass Load $\left(\mathrm{mg} / \mathrm{m}^{3}\right)$ & 0.06 & 0.025 & 3.75 & $-1.5 \%$ & 0.1 & 3.87 & $1.7 \%$ \\
\hline \multicolumn{8}{|l|}{ Active Indoors } \\
\hline Time & 11 & 10 & 3.76 & $-1.2 \%$ & 12 & 3.85 & $1.2 \%$ \\
\hline Breathing Rate $\left(\mathrm{m}^{3} / \mathrm{hr}\right)$ & 1.1 & 0.95 & 3.64 & $-4.3 \%$ & 1.25 & 3.97 & $4.3 \%$ \\
\hline Mass Load $\left(\mathrm{mg} / \mathrm{m}^{3}\right)$ & 0.1 & 0.06 & 3.32 & $-12.7 \%$ & 0.175 & 4.72 & $23.8 \%$ \\
\hline \multicolumn{8}{|l|}{ Asleep Indoors } \\
\hline Time & 8.3 & 8.1 & 3.83 & $0.5 \%$ & 8.5 & 3.79 & $-0.5 \%$ \\
\hline Breathing Rate $\left(\mathrm{m}^{3} / \mathrm{hr}\right)$ & 0.4 & 0.35 & 3.80 & $-0.3 \%$ & 0.45 & 3.82 & $0.3 \%$ \\
\hline Mass Load $\left(\mathrm{mg} / \mathrm{m}^{3}\right)$ & 0.03 & 0.01 & 3.74 & $-1.7 \%$ & 0.05 & 3.88 & $1.7 \%$ \\
\hline $\begin{array}{l}\text { Total Expected Mass } \\
\text { Inhaled (mg) }\end{array}$ & $3.81^{c}$ & & & & & & \\
\hline
\end{tabular}

See Excel file Mass loading sensitivity analysis.xls.

a Total dust inhaled with all values held at the expected value except one, calculated using the equation in footnote $c$.

${ }^{b}$ Percent change in total dust inhaled from the expected value $(5.409 \mathrm{mg})$. Time added or subtracted from the active and inactive outdoor and asleep indoor environments was accounted for in the active indoor environment. Time added or subtracted from the active indoor environment was accounted for in the inactive outdoor environment. The total time does not add to 24 hours because an average of 2.7 hours per day spent away from contaminated areas is not shown.

${ }^{\mathrm{c}}$ Calculated as the sum over four environments of the expected values of (time $\times$ breathing rate $\times$ mass load). 
Table A-2. Mass Loading Sensitivity Analysis - Postvolcanic Conditions

\begin{tabular}{|c|c|c|c|c|c|c|c|}
\hline \multirow[b]{2}{*}{$\begin{array}{c}\text { Environment } \\
\text { Parameter }\end{array}$} & \multirow[b]{2}{*}{$\begin{array}{c}\text { Expected } \\
\text { Parameter } \\
\text { Value }\end{array}$} & \multicolumn{3}{|c|}{ Minimum Values } & \multicolumn{3}{|c|}{ Maximum Values } \\
\hline & & $\begin{array}{c}\text { Parameter } \\
\text { Value }\end{array}$ & $\begin{array}{l}\text { Mass } \\
\text { Inhaled } \\
(\mathrm{mg})^{\mathrm{a}}\end{array}$ & $\%$ Change $^{b}$ & \begin{tabular}{|c|} 
Parameter \\
Value
\end{tabular} & $\begin{array}{l}\text { Mass } \\
\text { Inhaled } \\
(\mathrm{mg})^{\mathrm{a}}\end{array}$ & $\%$ Change $^{b}$ \\
\hline \multicolumn{8}{|l|}{ Active Outdoors } \\
\hline Time (hours) & 0.5 & 0.3 & 5.74 & $-24.6 \%$ & 0.8 & 10.43 & $36.9 \%$ \\
\hline Breathing Rate $\left(\mathrm{m}^{3} / \mathrm{hr}\right)$ & 1.6 & 1.4 & 7.02 & $-7.9 \%$ & 1.8 & 8.22 & $7.9 \%$ \\
\hline Mass Load $\left(\mathrm{mg} / \mathrm{m}^{3}\right)$ & 6 & 1 & 3.62 & $-52.5 \%$ & 15 & 14.82 & $94.5 \%$ \\
\hline \multicolumn{8}{|l|}{ Inactive Outdoors } \\
\hline Time & 1.5 & 1 & 7.66 & $0.6 \%$ & 2 & 7.57 & $-0.6 \%$ \\
\hline Breathing Rate $\left(\mathrm{m}^{3} / \mathrm{hr}\right)$ & 1.1 & 0.95 & 7.59 & $-0.4 \%$ & 1.25 & 7.64 & $0.4 \%$ \\
\hline Mass Load $\left(\mathrm{mg} / \mathrm{m}^{3}\right)$ & 0.12 & 0.05 & 7.50 & $-1.5 \%$ & 0.3 & 7.91 & $3.9 \%$ \\
\hline \multicolumn{8}{|l|}{ Active Indoors } \\
\hline Time & 11 & 10 & 7.53 & $-1.2 \%$ & 12 & 7.71 & $1.2 \%$ \\
\hline Breathing Rate $\left(\mathrm{m}^{3} / \mathrm{hr}\right)$ & 1.1 & 0.95 & 7.29 & $-4.3 \%$ & 1.25 & 7.95 & $4.3 \%$ \\
\hline Mass Load $\left(\mathrm{mg} / \mathrm{m}^{3}\right)$ & 0.2 & 0.12 & 6.65 & $-12.7 \%$ & 0.35 & 9.43 & $23.8 \%$ \\
\hline \multicolumn{8}{|l|}{ Asleep Indoors } \\
\hline Time & 8.3 & 8.1 & 7.66 & $0.5 \%$ & 8.5 & 7.58 & $-0.5 \%$ \\
\hline Breathing Rate $\left(\mathrm{m}^{3} / \mathrm{hr}\right)$ & 0.4 & 0.35 & 7.59 & $-0.3 \%$ & 0.45 & 7.64 & $0.3 \%$ \\
\hline Mass Load $\left(\mathrm{mg} / \mathrm{m}^{3}\right)$ & 0.06 & 0.02 & 7.48 & $-1.7 \%$ & 0.1 & 7.75 & $1.7 \%$ \\
\hline $\begin{array}{l}\text { Total Expected Mass } \\
\text { Inhaled (mg) }\end{array}$ & $7.62^{c}$ & & & & & & \\
\hline
\end{tabular}

See Excel file Mass loading sensitivity analysis.xls.

a Total dust inhaled with all values held at the expected value except one, calculated using the equation in footnote $\mathrm{c}$.

${ }^{b}$ Percent change in total dust inhaled from the expected value $(5.409 \mathrm{mg})$. Time added or subtracted from the active and inactive outdoor and asleep indoor environments was accounted for in the active indoor environment. Time added or subtracted from the active indoor environment was accounted for in the inactive outdoor environment. The total time does not add to 24 hours because an average of 2.7 hours per day spent away from contaminated areas is not shown.

${ }^{c}$ Calculated as the sum over four environments of the expected values of (time $\times$ breathing rate $\times$ mass load). 


\section{INTENTIONALLY LEFT BLANK}


APPENDIX B

TOTAL SUSPENDED PARTICULATE CONCENTRATION FOR INACTIVE OUTDOOR ENVIRONMENT AND SOIL TEXTURE DATA 


\section{INTENTIONALLY LEFT BLANK}




\section{APPENDIX B}

\section{TSP CONCENTRATION FOR INACTIVE OUTDOOR ENVIRONMENT AND SOIL TEXTURE DATA}

This appendix summarizes information on the rural agricultural TSP monitoring sites. Table B-1 is a list of all rural agricultural sites in Arizona, California, Idaho, Nevada, New Mexico, Oregon (excluding those sites west of the Cascade Mountains), Utah, and Washington, including descriptive information about each site, average annual precipitation and snowfall from the NCDC (NCDC 1998 [DIRS 135900]; NCDC 1998 [DIRS 125325]), and average annual TSP concentration. Average annual TSP concentrations at the AirData monitoring network sites were obtained from the EPA (DTN: MO0210SPATSP01.023 [DIRS 160426]) and were averaged for the years having TSP measurements. TSP data in Table B-1 represent these averages. Excel file Subset TSP_Rural Agricultural Sites.xls in Appendix C contains annual average TSP measurements for the individual monitoring years. The TSP data shown in Table B-1 were used in this analysis to develop distributions of atmospheric mass loading for the inactive outdoor environment. Note that TSP concentrations are in units of micrograms per cubic meter $\left(\mu \mathrm{g} / \mathrm{m}^{3}\right)$, the unit of measure reported by the EPA. Particulate concentrations in the remainder of this analysis are in units of milligrams per cubic meter $\left(\mathrm{mg} / \mathrm{m}^{3}\right)$.

The average annual precipitation and snowfall data shown in Table B-1 were obtained from the NCDC for the meteorological stations that were closest to the sites that were sources of the TSP data. The AirData monitoring network is separate from the network of the weather stations; however, in most cases, the locations of the meteorological monitoring stations were very close to the locations of the particulate matter monitoring stations. The weather data used in the supplemental analysis of TSP dependence on precipitation (Section 6.1.3.2) encompasses a wider range of precipitation levels and were obtained from the Spatial Climate Analysis Service (Oregon State University 2006 [DIRS 176346]). This source allows extraction of the precipitation data for any geographical coordinates, because the data are modeled based on the meteorological measurements using a climate mapping system (Section 6.1.3.1). To compare the two data sources, precipitation data obtained from the Spatial Climate Analysis Service for the geographical coordinates of the EPA particulate matter monitoring sites (Excel file Precipitation Ag_Rural_Western 1971-2000.xls in Appendix C) were compared with the precipitation data for the corresponding weather stations (see Table B-1 for the IDs of the EPA sites and the weather stations). The data were compiled in the Excel file TSP Data_Ag_Rural_Western States.xls in a worksheet named Summaries and the plot of the data is shown in Figure B-1.

The precipitation data in the two sets are not identical because the weather stations are in the vicinity of but not co-located with the particulate matter monitoring sites and because the data collection periods are not the same. As noted in Section 6.1.3.1, the precipitation data from the Spatial Climate Analysis Service were extracted for the narrower range of years to better coincide with the TSP measurements period of time. In spite of that, the two sets of data shown in Figure B-1 show a very good agreement except for the three stations (four data points in Figure B-1). Additional analysis (Excel file TSP Data_Ag_Rural_Western States.xls, worksheet Summaries) determined that the difference was due to the fact that precipitation at these three weather stations did not correspond well to the precipitation at the EPA particulate matter monitoring sites. The Spatial Climate Analysis Service precipitation data for these three weather stations themselves agree very well with the NCDC data. 
Table B-1. Average Concentration of TSP $\left(\mathrm{mg} / \mathrm{m}^{3}\right)$ at Rural, Agricultural Monitoring Sites in the Western United States

\begin{tabular}{|c|c|c|c|c|c|c|c|c|c|}
\hline \multicolumn{4}{|c|}{ Monitoring Site } & \multicolumn{2}{|c|}{ Precipitation (in.) } & \multirow[b]{2}{*}{$\begin{array}{l}\text { Weather } \\
\text { Station }\end{array}$} & \multirow{2}{*}{$\begin{array}{c}\text { Mean } \\
\text { TSP } \\
\left(\mathrm{mg} / \mathrm{m}^{3}\right)\end{array}$} & \multirow[b]{2}{*}{$\begin{array}{l}\text { Number } \\
\text { of Years }\end{array}$} & \multirow[b]{2}{*}{ Comments } \\
\hline EPA Site ID & State & City & County & $\begin{array}{c}\text { Mean } \\
\text { Snowfall } \\
\end{array}$ & $\begin{array}{c}\text { Mean Total } \\
\text { Precipitation }\end{array}$ & & & & \\
\hline 04-007-0003 & Arizona & Miami & Gila & 2.9 & 19.3 & 25512 & 0.050 & 2 & Duplicate with 04-007-1902 \\
\hline 04-007-1902 & Arizona & Miami & Gila & 2.9 & 19.3 & 25512 & 0.030 & 8 & Selected \\
\hline 04-013-0008 & Arizona & Guadalupe & Maricopa & 0.0 & 8.9 & 28499 & 0.131 & 4 & Has atypical values due to updraft \\
\hline 04-019-0006 & Arizona & Tucson & Pima & 0.0 & 13.9 & 28795 & 0.133 & 1 & Duplicate with 04-019-0010 \\
\hline 04-019-0009 & Arizona & Tucson & Pima & 0.0 & 13.9 & 28795 & 0.081 & 4 & Near power plant substation \\
\hline 04-019-0010 & Arizona & Tucson & Pima & 0.0 & 13.9 & 28795 & 0.089 & 2 & Selected \\
\hline 06-013-1002 & California & Bethel Island & Contra Costa & 0.0 & 12.7 & 45232 & 0.041 & 6 & Selected \\
\hline 06-019-1002 & California & Five Points & Fresno & 0.2 & 6.6 & 43083 & 0.078 & 13 & Selected \\
\hline 06-019-3001 & California & Parlier & Fresno & 0.1 & 10.9 & 43257 & 0.094 & 7 & Duplicate with 06-031-1002 \\
\hline 06-027-0002 & California & Bishop & Inyo & 8.0 & 5.3 & 40822 & 0.025 & 8 & Selected \\
\hline 06-027-0011 & California & Olancha & Inyo & 4.2 & 6.7 & 43710 & 0.023 & 3 & Duplicate with 06-027-0002 \\
\hline 06-031-0002 & California & Corcoran & Kings & 0.1 & 7.2 & 42012 & 0.120 & 4 & Duplicate with 06-031-1002 \\
\hline 06-031-1002 & California & Kettleman City & Kings & 0.1 & 7.2 & 42012 & 0.086 & 9 & Selected \\
\hline 06-033-0002 & California & Kelseyville & Lake & 0.5 & 29.1 & 44701 & 0.034 & 8 & Precipitation > 20 in. \\
\hline 06-033-0003 & California & Upper Lake & Lake & 0.5 & 29.1 & 44701 & 0.019 & 4 & Precipitation > 20 in. \\
\hline 06-049-1001 & California & Cedarville & Modoc & 32.6 & 13.1 & 41614 & 0.017 & 6 & Snowfall $>20$ in. \\
\hline 06-061-0001 & California & Auburn & Placer & 1.2 & 35.3 & 40383 & 0.040 & 5 & Precipitation > 20 in. \\
\hline 06-071-1101 & California & Twentynine Palms & San Bernardino & 1.0 & 4.1 & 49099 & 0.049 & 11 & Selected \\
\hline 06-083-1011 & California & Jalama & Santa Barbara & 0.0 & 14.6 & 45064 & 0.045 & 7 & Selected \\
\hline 06-083-1012 & California & Concepcion & Santa Barbara & 0.0 & 14.6 & 45064 & 0.043 & 7 & Duplicate with 06-083-1011 \\
\hline 06-083-1015 & California & Gaviota & Santa Barbara & 0.0 & 14.6 & 45064 & 0.024 & 6 & Duplicate with 06-083-1011 \\
\hline 06-083-1016 & California & Gaviota & Santa Barbara & 0.0 & 14.6 & 45064 & 0.025 & 6 & Duplicate with 06-083-1011 \\
\hline 06-083-1017 & California & Gaviota & Santa Barbara & 0.0 & 14.6 & 45064 & 0.039 & 7 & Duplicate with 06-083-1011 \\
\hline 06-083-1019 & California & Gaviota & Santa Barbara & 0.0 & 14.6 & 45064 & 0.030 & 7 & Duplicate with 06-083-1011 \\
\hline 06-083-1020 & California & Isla Vista & Santa Barbara & 0.0 & 17.8 & 47902 & 0.043 & 6 & Duplicate with 06-083-1011 \\
\hline 06-083-1030 & California & Concepcion & Santa Barbara & 0.0 & 14.6 & 45064 & 0.038 & 6 & Duplicate with 06-083-1011 \\
\hline
\end{tabular}


Table B-1. Average Concentration of TSP $\left(\mathrm{mg} / \mathrm{m}^{3}\right)$ at Rural, Agricultural Monitoring Sites in the Western United States (Continued)

\begin{tabular}{|c|c|c|c|c|c|c|c|c|c|}
\hline \multicolumn{4}{|c|}{ Monitoring Site } & \multicolumn{2}{|c|}{ Precipitation (in.) } & \multirow[b]{2}{*}{$\begin{array}{l}\text { Weather } \\
\text { Station }\end{array}$} & \multirow{2}{*}{$\begin{array}{c}\text { Mean } \\
\text { TSP } \\
\left(\mathrm{mg} / \mathrm{m}^{3}\right)\end{array}$} & \multirow[b]{2}{*}{$\begin{array}{l}\text { Number } \\
\text { of Years }\end{array}$} & \multirow[b]{2}{*}{ Comments } \\
\hline EPA Site ID & State & City & County & $\begin{array}{c}\text { Mean } \\
\text { Snowfall } \\
\end{array}$ & $\begin{array}{c}\text { Mean Total } \\
\text { Precipitation }\end{array}$ & & & & \\
\hline 06-083-4003 & California & Vandenburg AFB & Santa Barbara & 0.0 & 14.6 & 45064 & 0.031 & 7 & Duplicate with 06-083-1011 \\
\hline 06-083-5001 & California & Vandenburg AFB & Santa Barbara & 0.0 & 12.6 & 47946 & 0.037 & 3 & Duplicate with 06-083-1011 \\
\hline 06-089-1002 & California & Burney & Shasta & 50.6 & 27.5 & 41214 & 0.034 & 2 & Precipitation > 20 in. \\
\hline 06-103-1001 & California & Los Molinos & Tehama & 2.3 & 22.8 & 47292 & 0.047 & 8 & Precipitation > 20 in. \\
\hline 06-111-0004 & California & Piru & Ventura & 0.0 & 17.0 & 46940 & 0.047 & 7 & Duplicate with 06-111-3001 \\
\hline 06-111-0005 & California & Oak View & Ventura & 0.1 & 21.2 & 46399 & 0.038 & 5 & Precipitation > 20 in. \\
\hline $06-111-1101$ & California & Piru & Ventura & 0.0 & 17.0 & 46940 & 0.064 & 2 & Duplicate with $06-111-3001$ \\
\hline 06-111-3001 & California & El Rio & Ventura & 0.1 & 14.4 & 46569 & 0.064 & 13 & Selected \\
\hline 06-113-4001 & California & Dunnigan & Yolo & 0.1 & 18.6 & 49781 & 0.044 & 13 & Selected \\
\hline 06-115-0002 & California & Smartsville & Yuba & 10.2 & 53.2 & 43573 & 0.027 & 2 & Precipitation > 20 in. \\
\hline 16-001-0001 & Idaho & Boise & Ada & 20.9 & 11.9 & 101022 & 0.044 & 20 & Snowfall $>20$ in. \\
\hline $16-005-1003$ & Idaho & Pocatello & Bannock & 41.8 & 11.8 & 107211 & 0.068 & 3 & Snowfall > 20 in. \\
\hline 16-011-0001 & Idaho & Grandview & Bingham & 22.4 & 11.4 & 103297 & 0.049 & 1 & Snowfall > 20 in. \\
\hline $16-029-0001$ & Idaho & Soda Springs & Caribou & 43.8 & 16.1 & 108535 & 0.070 & 1 & Snowfall > 20 in. \\
\hline $16-029-0002$ & Idaho & Conda & Caribou & 95.0 & 22.1 & 104230 & 0.038 & 16 & Precipitation $>20$ in. \\
\hline $16-053-0001$ & Idaho & Jerome & Jerome & 23.2 & 10.3 & 104670 & 0.047 & 7 & Snowfall $>20$ in. \\
\hline $16-055-1002$ & Idaho & Coeur D'Alene & Kootenai & 51.3 & 25.4 & 101956 & 0.052 & 8 & Precipitation $>20$ in. \\
\hline $16-077-0005$ & Idaho & Pocatello & Power & 41.8 & 11.8 & 107211 & 0.118 & 2 & Snowfall > 20 in. \\
\hline 16-083-0003 & Idaho & Twin Falls & Twin Falls & 28.2 & 10.8 & 109303 & 0.047 & 3 & Snowfall > 20 in. \\
\hline 16-083-0004 & Idaho & Hansen & Twin Falls & 28.2 & 10.8 & 109303 & 0.038 & 4 & Snowfall > 20 in. \\
\hline $16-083-1001$ & Idaho & Twin Falls & Twin Falls & 28.2 & 10.8 & 109303 & 0.045 & 3 & Snowfall > 20 in. \\
\hline $32-003-1003$ & Nevada & Moapa & Clark & 0.4 & 4.1 & 265846 & 0.061 & 1 & Selected \\
\hline $32-031-1004$ & Nevada & Sparks & Washoe & 6.9 & 8.1 & 267697 & 0.054 & 12 & Selected \\
\hline $32-031-2003$ & Nevada & Wadsworth & Washoe & 0.3 & 5.7 & 268838 & 0.041 & 3 & Duplicate with 32-031-1004 \\
\hline $35-013-0004$ & New Mexico & Sunland Park & Dona Ana & 4.5 & 9.4 & 298535 & 0.080 & 17 & Selected \\
\hline $35-013-0006$ & New Mexico & Afton & Dona Ana & 4.5 & 9.4 & 298535 & 0.045 & 3 & Duplicate with 35-013-0004 \\
\hline
\end{tabular}


Table B-1. Average Concentration of TSP $\left(\mathrm{mg} / \mathrm{m}^{3}\right)$ at Rural, Agricultural Monitoring Sites in the Western United States (Continued)

\begin{tabular}{|c|c|c|c|c|c|c|c|c|c|}
\hline \multicolumn{4}{|c|}{ Monitoring Site } & \multicolumn{2}{|c|}{ Precipitation (in.) } & \multirow[b]{2}{*}{$\begin{array}{l}\text { Weather } \\
\text { Station }\end{array}$} & \multirow{2}{*}{$\begin{array}{c}\text { Mean } \\
\text { TSP } \\
\left(\mathrm{mg} / \mathrm{m}^{3}\right) \\
\end{array}$} & \multirow[b]{2}{*}{$\begin{array}{l}\text { Number } \\
\text { of Years }\end{array}$} & \multirow[b]{2}{*}{ Comments } \\
\hline EPA Site ID & State & City & County & $\begin{array}{c}\text { Mean } \\
\text { Snowfall }\end{array}$ & $\begin{array}{c}\text { Mean Total } \\
\text { Precipitation }\end{array}$ & & & & \\
\hline $35-013-0016$ & New Mexico & Anthony & Dona Ana & 4.5 & 9.4 & 298535 & 0.137 & 2 & Duplicate with 35-013-0004 \\
\hline $35-017-0002$ & New Mexico & Hurley & Grant & 10.0 & 15.8 & 293265 & 0.085 & 3 & Selected \\
\hline $35-045-0013$ & New Mexico & La Plata & San Juan & 7.8 & 8.8 & 293134 & 0.034 & 3 & Duplicate with 35-045-0014 \\
\hline $35-045-0014$ & New Mexico & Kirtland & San Juan & 11.5 & 8.1 & 293340 & 0.044 & 14 & Selected \\
\hline $35-045-0015$ & New Mexico & Kirtland & San Juan & 16.4 & 10.1 & 290692 & 0.029 & 3 & Duplicate with 35-045-0014 \\
\hline $35-045-0021$ & New Mexico & Kirtland & San Juan & 7.8 & 8.8 & 293134 & 0.036 & 1 & Duplicate with 35-045-0014 \\
\hline \begin{tabular}{|l|}
$35-061-0007$ \\
$35-006-0007$ \\
\end{tabular} & New Mexico & Bluewater & Valencia/Cibola & 14.8 & 10.8 & 293682 & 0.071 & 6 & $\begin{array}{l}\text { Selected. Data from } 2 \text { sites at } \\
\text { same location were combined. }\end{array}$ \\
\hline 41-059-1001 & Oregon & Pendleton & Umatilla & 17.1 & 12.2 & 356546 & 0.040 & 5 & Selected \\
\hline 49-015-0002 & Utah & Huntington & Emery & 17.8 & 7.7 & 421214 & 0.030 & 4 & Selected \\
\hline 49-015-0003 & Utah & Huntington & Emery & 17.8 & 7.7 & 421214 & 0.017 & 4 & Duplicate with 49-015-0002 \\
\hline 49-027-0002 & Utah & Delta & Millard & 25.2 & 7.8 & 422090 & 0.041 & 1 & Snowfall $>20$ in. \\
\hline 53-039-0002 & Washington & Bingen & Klickitat & 19.8 & 13.7 & 451968 & 0.056 & 4 & Selected \\
\hline 53-071-1001 & Washington & Wallula Junction & Walla Walla & 7.7 & 10.1 & 453883 & 0.066 & 9 & Selected \\
\hline $53-075-0002$ & Washington & Pullman & Whitman & 28.3 & 21.5 & 456789 & 0.038 & 3 & Precipitation > 20 in. \\
\hline 53-077-0003 & Washington & Sunnyside & Yakima & 11.5 & 7.0 & 458207 & 0.062 & 10 & Selected \\
\hline
\end{tabular}

Source: DTN: MO0210SPATSP01.023 [DIRS 160426]; NCDC 1998 [DIRS 135900]; NCDC 1998 [DIRS 125325].

$E P A=U . S$. Environmental Protection Agency; ID=identification; $T S P=$ total suspended particle concentrations. 


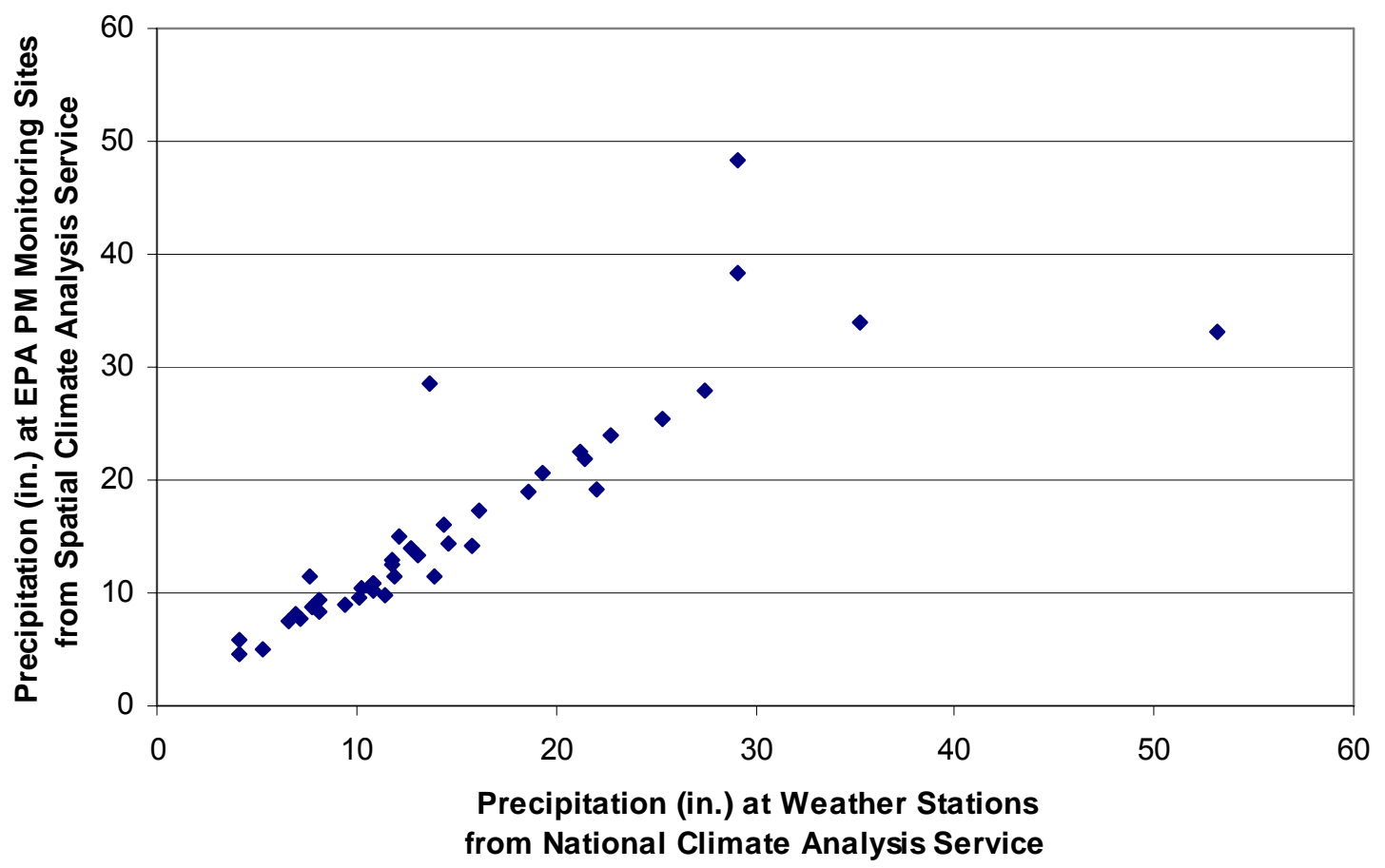

Figure B-1. Comparison of Precipitation at the EPA Particulate Matter Monitoring Sites and at the Corresponding Weather Stations

To evaluate the effect of soil morphology on TSP concentrations, the soil types at the TSP monitoring locations listed in Tables B-1 were examined and a fraction of fine soil separates in the type of soils prevailing in Amargosa Valley was compared to that for the soils typical of the areas where the TSP measurements were taken (Section 6.1.4). The dataset on the predominant soil in the top layer $(0$ to $5 \mathrm{~cm}$ ) included in the LDAS (LDAS [n.d.] [DIRS 176392]) was used to estimate the type of soils in the vicinity of the particulate matter monitoring stations. This data set consists of one soil texture value per 1/8th degree grid box. The LDAS grid consists of $464 \times 2241 / 8$ th degree gridboxes with the centers of gridboxes extending from -124.9375 to -67.0625 degrees longitude and from 25.0625 to 52.9375 degrees latitude. The gridpoint $(1,1)$ in the soil texture data is located at the upper left of the LDAS grid, i.e., at -124.9375 degrees longitude and 52.9375 degrees latitude. The LDAS soil database was used rather than the more detailed NRCS data because of the accessibility of the data from the perspective of this analysis' objectives.

The text file with the LDAS data on the predominant soil class in the top layer (file name LDAS 1st predominant soil class.txt, Appendix C) was parsed using the TextPad utility into two subsets representing the eastern and western states and transferred to the Excel workbook Soil texture.xls, worksheet name: Predominant soil in 1st layer. Parsing of the dataset into two subsets was necessary because the number of columns in the dataset exceeded the available number of columns in Excel. The verification of parsing and the correspondence of the data points to geographical coordinates were done by plotting the outline of the data in a separate worksheet (Check Outline worksheet in the Soil texture.xls workbook). 
The soil texture classes for the EPA monitoring stations are listed in Table B-2.

Table B-2. Soil Texture at Rural, Agricultural Monitoring Sites in the Western United States

\begin{tabular}{|c|c|c|c|c|c|}
\hline KR450_Site ID & State & $\begin{array}{c}\text { Longitude } \\
\text { (decimal degrees) }\end{array}$ & $\begin{array}{c}\text { Latitude } \\
\text { (decimal degrees) }\end{array}$ & $\begin{array}{c}\text { Predominant Soil } \\
\text { Class Code }\end{array}$ & $\begin{array}{l}\text { Predominant Soil } \\
\text { Class Description }\end{array}$ \\
\hline 40071902 & Arizona & -110.86639 & 33.385278 & 3 & sandy loam \\
\hline 40190010 & Arizona & -111.18194 & 32.420556 & 6 & loam \\
\hline 60131002 & California & -121.64139 & 38.010556 & 13 & organic \\
\hline 60191002 & California & -120.10472 & 36.341111 & 9 & clay loam \\
\hline 60270002 & California & -118.35 & 37.366389 & 2 & loamy sand \\
\hline 60310002 & California & -119.55861 & 36.098889 & 12 & clay \\
\hline 60330002 & California & -122.84444 & 39.155833 & 6 & loam \\
\hline 60330003 & California & -122.905 & 39.172222 & 6 & loam \\
\hline 60491001 & California & -120.16667 & 41.55 & 3 & sandy loam \\
\hline 60610001 & California & -121.10833 & 38.937222 & 4 & silt loam \\
\hline 60711101 & California & -116.05833 & 34.141944 & 1 & sand \\
\hline 60831012 & California & -120.45778 & 34.451944 & 3 & sandy loam \\
\hline 60891002 & California & -121.64917 & 40.883889 & 3 & sandy loam \\
\hline 61031001 & California & -122.08333 & 40.033333 & 6 & loam \\
\hline 61110005 & California & -119.41583 & 34.386944 & 6 & loam \\
\hline 61113001 & California & -119.1425 & 34.2525 & 6 & loam \\
\hline 61134001 & California & -121.96639 & 38.896944 & 12 & clay \\
\hline 61150002 & California & -121.27944 & 39.183611 & 4 & silt loam \\
\hline 160010001 & Idaho & -116.31472 & 43.591111 & 4 & silt loam \\
\hline 160051003 & Idaho & -112.46556 & 42.870833 & 4 & silt loam \\
\hline 160110001 & Idaho & -112.83556 & 43.051944 & 6 & loam \\
\hline 160290001 & Idaho & -111.56417 & 42.701389 & 4 & silt loam \\
\hline 160290002 & Idaho & -111.56194 & 42.743611 & 4 & silt loam \\
\hline 160530001 & Idaho & -114.60806 & 42.766111 & 1 & sand \\
\hline 160551002 & Idaho & -116.81056 & 47.776111 & 4 & silt loam \\
\hline 160770005 & Idaho & -112.55083 & 42.906667 & 6 & loam \\
\hline 160830003 & Idaho & -114.35222 & 42.547778 & 4 & silt loam \\
\hline 160830004 & Idaho & -114.30092 & 42.528197 & 4 & silt loam \\
\hline 160831001 & Idaho & -114.35222 & 42.548056 & 4 & silt loam \\
\hline 320031003 & Nevada & -114.58333 & 36.633056 & 3 & sandy loam \\
\hline 320311004 & Nevada & -119.75917 & 39.045 & 1 & sand \\
\hline 350130004 & New Mexico & -106.56 & 31.803889 & 3 & sandy loam \\
\hline 350170002 & New Mexico & -108.10528 & 32.656944 & 6 & loam \\
\hline 350450014 & New Mexico & -108.50028 & 36.708333 & 3 & sandy loam \\
\hline 350610007 & New Mexico & -107.97972 & 35.255556 & 9 & clay loam \\
\hline 410591001 & Oregon & -118.79611 & 45.578056 & 4 & silt loam \\
\hline
\end{tabular}


Table B-2. Soil Texture at Rural, Agricultural Monitoring Sites in the Western United States (Continued)

\begin{tabular}{|c|l|c|c|c|c|}
\hline KR450_Site ID & \multicolumn{1}{|c|}{ State } & $\begin{array}{c}\text { Longitude } \\
\text { (decimal degrees) }\end{array}$ & $\begin{array}{c}\text { Latitude } \\
\text { (decimal degrees) }\end{array}$ & $\begin{array}{c}\text { Predominant Soil } \\
\text { Class Code }\end{array}$ & $\begin{array}{c}\text { Predominant Soil } \\
\text { Class Description }\end{array}$ \\
\hline 490150002 & Utah & -111.04417 & 39.3625 & 6 & loam \\
\hline 490270002 & Utah & -112.61444 & 39.454722 & 3 & sandy loam \\
\hline 530390002 & Washington & -121.46667 & 45.719167 & 6 & loam \\
\hline 530711001 & Washington & -118.90556 & 46.122222 & 4 & silt loam \\
\hline 530750002 & Washington & -117.18472 & 46.757222 & 4 & silt loam \\
\hline 530770003 & Washington & -120.50194 & 46.336389 & 4 & silt loam \\
\hline
\end{tabular}

Source: Based on LDAS [n.d.] [DIRS 176392] data; see Soil texture.xls in Appendix C. 


\section{INTENTIONALLY LEFT BLANK}




\section{APPENDIX C \\ LIST AND DESCRIPTION OF FILES USED IN THIS ANALYSIS}




\section{INTENTIONALLY LEFT BLANK}




\section{APPENDIX C}

\section{LIST AND DESCRIPTION OF FILES USED IN THIS ANALYSIS}

This appendix contains descriptions of the files with data and calculations that were used in this analysis. The files are listed in alphabetical order and can be found on the CD-ROM included as an electronic attachment to this document (Figure C-1).

\begin{tabular}{|c|c|c|c|c|}
\hline \multirow{2}{*}{7 : } & Name $A$ & Size & Type & Modified \\
\hline & 24h TSP Database.mdb & $5,872 \mathrm{~KB}$ & Microsoft Access Application & $5 / 14 / 200610: 55 \mathrm{AM}$ \\
\hline \multirow[b]{2}{*}{ Final check files } & Ash thickness histogram.xls & $29 \mathrm{~KB}$ & Microsoft Excel Worksheet & $5 / 7 / 20065: 52 \mathrm{PM}$ \\
\hline & 㫵 LDAS 1st predominant soil class.txt & $305 \mathrm{~KB}$ & Text Document & $11 / 15 / 200511: 08 \mathrm{AM}$ \\
\hline \multirow{10}{*}{$\begin{array}{l}\text { Select an item to view its description. } \\
\text { See also: } \\
\text { My Documents } \\
\text { My Network Places } \\
\text { My Computer }\end{array}$} & Mass loading Amargosa Valley.xls & $470 \mathrm{~KB}$ & Microsoft Excel Worksheet & $5 / 7 / 20067: 48 \mathrm{PM}$ \\
\hline & Mass loading graphs.xls & $63 \mathrm{~KB}$ & Microsoft Excel Worksheet & $5 / 7 / 20067: 47 \mathrm{PM}$ \\
\hline & (2) Mass loading sensitivity analysis.xls & $24 \mathrm{~KB}$ & Microsoft Excel Worksheet & $5 / 14 / 200611: 32 \mathrm{AM}$ \\
\hline & Precipitation Ag_Rural_Western 1971-2000.xls & $65 \mathrm{~KB}$ & Microsoft Excel Worksheet & 4/13/2006 9:02 AM \\
\hline & Soil texture.xls & $8,531 \mathrm{~KB}$ & Microsoft Excel Worksheet & $2 / 6 / 20065: 49 \mathrm{PM}$ \\
\hline & Subset TSP_Rural Agricultural Sites.xls & $47 \mathrm{~KB}$ & Microsoft Excel Worksheet & $4 / 7 / 20064: 21 \mathrm{PM}$ \\
\hline & TSP Data_Ag_Rural_Western States.xls & $1,104 \mathrm{~KB}$ & Microsoft Excel Worksheet & $5 / 7 / 20067: 48 \mathrm{PM}$ \\
\hline & TSP Mount St Helens_1979-1982.xls & $87 \mathrm{~KB}$ & Microsoft Excel Worksheet & $4 / 11 / 20069: 08 \mathrm{AM}$ \\
\hline & TSP vs Soil Texture.xls & $23 \mathrm{~KB}$ & Microsoft Excel Worksheet & $1 / 26 / 20069: 47 \mathrm{AM}$ \\
\hline & (2)TSP-to-PM10 Ratios_Yucca Mountain.xls & $189 \mathrm{~KB}$ & Microsoft Excel Worksheet & $4 / 11 / 20065: 04 \mathrm{PM}$ \\
\hline
\end{tabular}

Figure C-1. List of Files Used in the Analysis

Ash thickness histogram.xls - This Excel file was used to construct a histogram of the predicted ash thickness at the location of the receptor when wind blows to the south, which appears in Section 6.3. The data for the histogram were copied into the worksheet from Table 6.4 of Atmospheric Dispersal and Deposition of Tephra from a Potential Volcanic Eruption at Yucca Mountain, Nevada (BSC 2005 [DIRS 174067]).

LDAS 1st predominant soil class.txt-This text file contains LDAS data on the predominant soil class in the top soil layer $(0$ to $5 \mathrm{~cm})$ (LDAS [n.d.] [DIRS 176827]). The data are included as an electronic file in LDAS ([n.d.] [DIRS 176827]), and this file is reproduced here for completeness. The data were obtained from the LDAS (LDAS [n.d.] [DIRS 176392]) and were used in Section 6.1.4 and in Appendix B to estimate the type of soils in the vicinity of the particulate matter monitoring stations (Section 6.1.4). The files consist of one soil texture class value per $1 / 8$ th degree grid box. The LDAS grid consists of $464 \times 2241 / 8$ th degree gridboxes with the centers of gridboxes extending from -124.9375 to -67.0625 degrees longitude and from 25.0625 to 52.9375 degrees latitude. The gridpoint $(1,1)$ in the soil texture data is located at the upper left of the LDAS grid, i.e., at -124.9375 degrees longitude and 52.9375 degrees latitude. The text file with the LDAS data on the predominant soil class in the top layer was parsed using the TextPad utility into two subsets representing the eastern and western states and transferred to the Excel workbook Soil texture.xls (see description below).

Mass loading Amargosa Valley.xls - This Excel file contains TSP data collected in Amargosa Valley using the DustScan Scout Model 3020 Aerosol Monitor (DTN: MO0603UCCF01JS.001 [DIRS 176759]). The instrument collected data every 2 seconds. These data are listed in worksheets 4 K0 2005-12-15-06-3 and 4-K0 2005-12-16 10-26-56 for the first and second day of measurements, respectively. The worksheet Field Notes contains descriptions of the activities 
and summaries of the statistics for these activities. A plot of data is also generated in that worksheet. The data are discussed in Section 6.2.1.2 and were used in Section 6.2.1.3 to develop distribution of mass loading for the active outdoor environment.

Mass loading graphs.xls - This Excel file was used to construct mass loading graphs appearing in Section 6.2 and 6.3 (including subsections). The data sources appear in Tables where the graphs are shown is Sections 6.2 and 6.3.

Mass loading sensitivity analysis - This Excel file contains calculations described in Appendix A. The analysis described evaluated the sensitivity of calculations of mass of inhaled particles to changes in the input parameter values. The analysis examined influence of mass loading, exposure time and breathing rate in a given environment on the mass if inhaled particulate matter for the nominal and postvolcanic conditions. The analysis was conducted by holding all parameters at an expected value except one parameter being examined (Tables A-1 and A-2). The mass of particulate matter inhaled is first calculated for individual receptor environments and then combined to calculate total dust inhaled. The influence on total mass inhaled of changing a parameter value is evaluated by calculating percent change in total mass inhaled due to changing a parameter from its expected value to minimum or maximum value.

Precipitation Ag_Rural_Western 1971-2000.xls-This Excel file contains precipitation data for EPA air monitoring sites located in rural agricultural setting in the Western U.S. that were analyzed in spreadsheets. The data encompass a period from 1971 to 2000. The averages for individual stations were then used in Excel file TSP Data_Ag_Rural_Western States.xls (see description below). The precipitation data for the geographical coordinates of the EPA air quality stations, included in the AirData database (DTN: MO0210SPATSP01.023 [DIRS 160426]), were extracted from the SCAS (Oregon State University 2006 [DIRS 176346]) databases at http://www.ocs.orst.edu/prism/ using an on-line OSU Prism Data Explorer tool. The averages for individual stations were then used in Excel file TSP Data_Ag_Rural_Western States.xls.

Soil texture.xls - This Excel file contains soil texture data transferred from the LDAS 1st predominant soil class.txt file described above (LDAS [n.d.] [DIRS 176827]). The data were transferred into the Predominant soil in 1st layer worksheet using the TextPad utility to parse the large text file into two subsets representing Eastern and Western U.S. The transfer was verified by plotting the data in the Check Outline worksheet. In this worksheet, each datapoint representing water was assigned a zero value, while each point representing the land was assigned a value of one. The data were then displayed using a two-dimensional (surface) plotting tool of Excel. The soil texture data were used in Sections 6.1.4 and in Appendix B.

TSP Data_Ag_Rural_Western States.xls_-This Excel file contains TSP data from the EPA AirData database included in DTN: MO0210SPATSP01.023 [DIRS 160426]. The data for rural sites were transferred into the All rural worksheet; the data for rural agricultural and rural desert sites were transferred into the Rural ag and desert worksheet. Some rural agricultural records that appear in the All rural worksheet were not transferred to the Rural ag and desert worksheet because they were lacking geographical coordinates, which are important in the analyses carried out in the latter worksheet. The latter worksheets also contains the following data: 
- Data on annual average precipitation obtained from the NCDC (NCDC 1998 [DIRS 135900]; NCDC 1998 [DIRS 125325]) for the meteorological stations that were closest to the sites that were sources of the TSP data,

- Precipitation data from the Spatial Climate Analysis Service (Oregon State University 2006 [DIRS 176346]) copied from the Precipitation Ag_Rural_Western 1971-2000.xls file and soil texture class data for the grid points corresponding to the EPA air monitoring stations from the Soil texture.xls file.

- Predominant soil class data (LDAS [n.d.] [DIRS 176827]) for the geographical coordinates of the AirData monitoring stations from the file Soil texture.xls.

- County and state data for the AirData monitoring stations (Ambrose 2002 [DIRS 160080], filename - KR380RPT.wpd).

The worksheet Summaries contains a summary of the annual average data for the EPA monitoring stations used in the development of mass loading distributions for the inactive outdoor environment (Section 6.2.2). These are the stations that have "selected" indicated in the comments column of Table B-1 (Appendix B). For these stations two graphs were produced showing to the right of the data (starting in column AD): (1) the comparison of annual average precipitation from the NCDC and the annual average precipitation data from the SCAS (Oregon State University 2006 [DIRS 176346]) and (2) the graph of TSP versus soil texture class.

Three meteorological stations (NCDC data) that were used as representative of the precipitation at the EPA particulate matter monitoring stations have substantially different annual average precipitation than the SCAS values for the same locations. Further analysis (shown in the same spreadsheet, just right of the two figures described above) indicated that the SCAS and the NCDC data for the meteorological stations agree very well. The differences arise from these three NCDC stations not representing very well the precipitation at the EPA monitoring stations. This discrepancy is, however, inconsequential for the analyses presented in this report.

The worksheet Graphs contains the TSP and precipitation data (SCAS) from the Rural ag and desert worksheet (sorted by the site ID and sorted by precipitation) and the graphs used in the analysis of the influence of precipitation on mass loading (Section 6.1.3.1). This spreadsheet contains data for 97 rural agricultural sites and 27 rural desert sites. Several rural agricultural and rural desert sites that appear in the All rural worksheet were not included in the further analysis because of the missing geographical coordinates information for these sites (SCAS precipitation could not be determined without geographical coordinates).

TSP vs Soil Texture.xls - This Excel file contains the list of EPA air monitoring sites in the Western U.S. that were used in the development of mass loading distributions for the inactive outdoor environment, average TSP measurements at these locations and the corresponding soil textural class obtained from the Soil texture.xls file. A plot of TSP versus soil texture class is produced using these data. 
Subset TSP_Rural Agricultural Sites.xls-This Excel file contains TSP concentrations for rural, agricultural sites obtained from the EPA (DTN: MO0210SPATSP01.023 [DIRS 160426]) and used in Section 6.1.3.1 of this analysis to develop distributions of atmospheric mass loading for the inactive outdoor environment. The average annual TSP concentrations are for all rural agricultural sites in Arizona, California, Idaho, Nevada, New Mexico, Oregon (excluding those sites west of the Cascade Mountains), Utah, and Washington (see Section 6.2.2.1 for the description of the site selection).

TSP Mount St Helens_1979-1982.xls - This Excel file contains measurements of 24-hour concentrations of TSP taken at Clarkston, Richland, Longview, Spokane, Vancouver, and Yakima, Washington during 1979 through 1982. The data were obtained from the EPA AirData database (DTN: MO0008SPATSP00.013 [DIRS 151750]). The running average is the average of the measurements for a day and the four previous measurements.

TSP-to-PM10 Ratios_Yucca Mountain.xls-This Excel file contains results of 1,276 measurements of $\mathrm{PM}_{10}$ and TSP concentrations in air taken simultaneously at three sites at Yucca Mountain from 1989 through 1997 (no measurement were taken from October through November 1991) and the TSP-to- $\mathrm{PM}_{10}$ ratio of those measurements. Measurements resulting in 24 ratios of less than or equal to 1.0 are not shown (see Section 6.2.3.1 for justification).

24h TSP Database.mdb - This Access database contains data on average annual concentrations of TSP for the United States and territories for 1970 through 2001. The data were obtained from the AirData database managed by the EPA Office of Air and Radiation (DTN: MO0210SPATSP01.023 [DIRS 160426]). The data transferred to this Access database were from the following two datasets:

1. KR450TSP.TXT, obtained from the EPA on September 6, 2002 (Ambrose 2002 [DIRS 160080]). This dataset contains 76,220 records. Each record includes an annual average concentration of TSP at a monitoring site.

2. KR380.NATION.TXT, obtained from the EPA on September 17, 2002 (Ambrose 2002 [DIRS 160081]). This dataset contains 11,763 records. Each record contains site description information (e.g., address, setting, years active) for TSP monitoring sites.

The data were parsed according to the report manual (AQ1.WPD) provided by the EPA (Ambrose 2002 [DIRS 160080]). The two files were then merged by station number to create a database labeled COMBINEDTSP that contains all the TSP data (from KR450TSP.TXT) for each station as well as the site description data (from KR380.NATION.TXT). All correspondence and data files associated with this set of data are located in the Records Information System and can be accessed via the link on the Automatic Technical Data Information Form for this DTN in the Technical Data Management System. 